\title{
Theodor Zotschew
}

\section{Strukturwandel in Wirtschaft und Gesellschaft Südosteuropas}

Eine sozialökonomische und statistische Analyse anläßlich des 20jährigen Bestehens der Südosteuropa-Gesellschaft

Verlag Otto Sagner München · Berlin · Washington D.C.

Digitalisiert im Rahmen der Kooperation mit dem DFG-Projekt „Digi20“

der Bayerischen Staatsbibliothek, München. OCR-Bearbeitung und Erstellung des eBooks durch den Verlag Otto Sagner:

http://verlag.kubon-sagner.de

() bei Verlag Otto Sagner. Eine Verwertung oder Weitergabe der Texte und Abbildungen, insbesondere durch Vervielfältigung, ist ohne vorherige schriftliche Genehmigung des Verlages unzulässig. 
$t 61.42 / 20$

\section{SÜDOSTEUROPA - STUDIEN}

im Namen der Südosteuropa-Gesellschaft herausgegeben von WALTER ALTHAMMER

20

Theodor D. Zotschew

\section{STRUKTURWANDEL IN WIRTSCHAFT UND GESELLSCHAFT SODOSTEUROPAS}

Eine sozial-ökonomische und statistische Analyse anläBlich des 20jährigen Bestehens der Südosteuropa-Gesellschaft 


\title{
SÜDOSTEUROPA-GESELLSCHAFT
}

8 München 22, Widenmayerstr. 49 - Tel. 294402

\author{
PRÄSIDIUM \\ Präsident: \\ Dr. Walter Althammer, MdB \\ Vizepräsidenten: \\ Prof. Dr. Hermann Gross \\ Dipl. - Kfm. Alfred Hönig \\ Dr. Günther Müller, MdB \\ Schatzmeister: \\ Bankdirektor Dr. Hamilkar Hofmann \\ Beisitzer: \\ Prof. Dr. Mathias Bernath \\ Redakteur Hans Hartl \\ Prof. Dr. Hans-Joachim Kissling \\ Landeshauptmann Dr. Ing. Hans Lechner \\ Bankdirektor i. R. Ernst Lederer \\ Dipl. - Kfm. Burkhard Schuchmann \\ Prof. Dr. Emanuel Turczynski

\section{KURATORIUM} \\ Vorsitz: \\ Staatssekretär a. D. Dr. Rudolf Vogel \\ WISSENSCHAFTLICHER BEIRAT \\ Vorsitzender: Prof. Dr. Erwin Koschmieder \\ Stellv. Vorsitzender: Prof. Dr. Karl Ruppert \\ Sekretariat: \\ Prof. Dr. Klaus-Detlev Grothusen
}

KULTURBEIRAT

Vorsitzender: $\quad$ Prof. Dr. Maximilian Braun

Stellv. Vorsitzender: Ministerialdirigent Prof. Dr. Dr. Walter Keim Sekretariat: Dipl. -Kfm. Burkhard Schuchmanı

GESCHÄFTSFÜHRUNG

Dr. Eberhard Reichert 


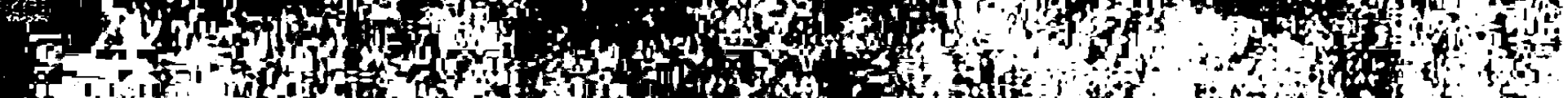

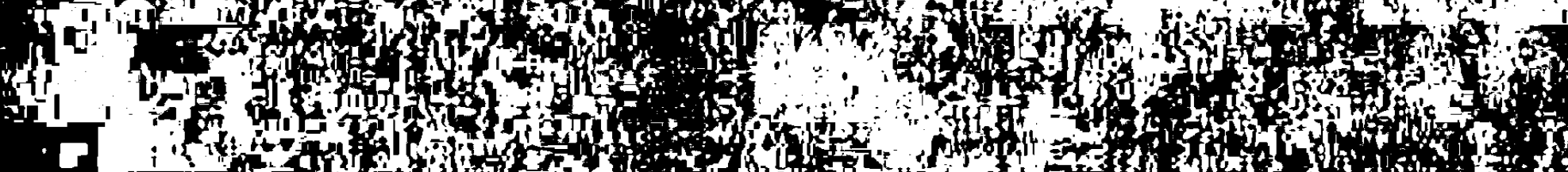

-

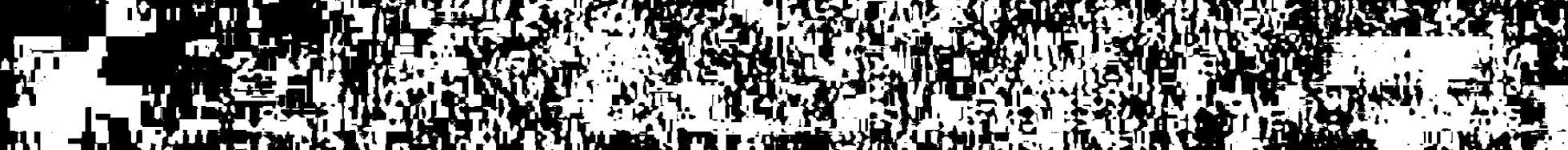

14 If 3 in

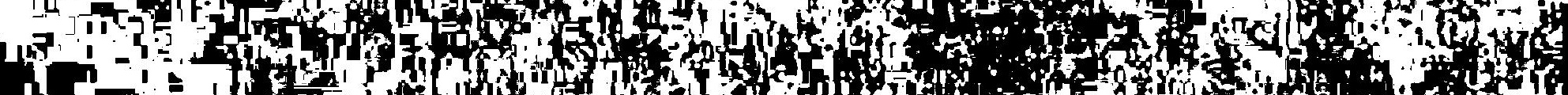

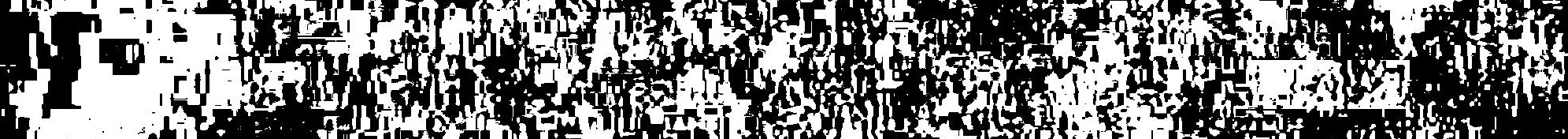

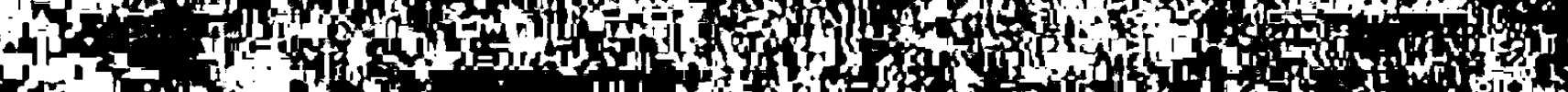

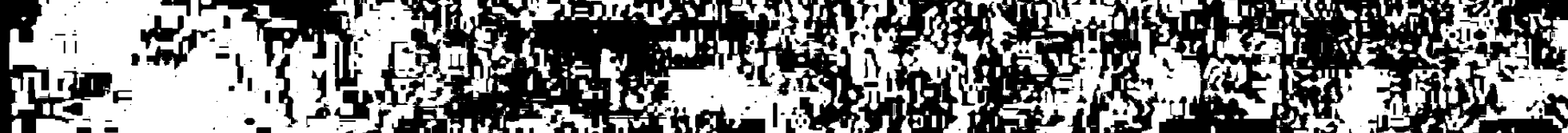

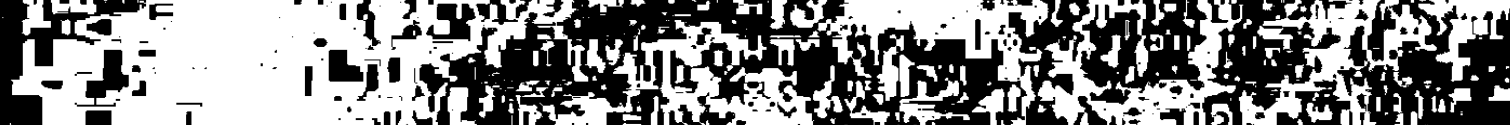

I. I

an

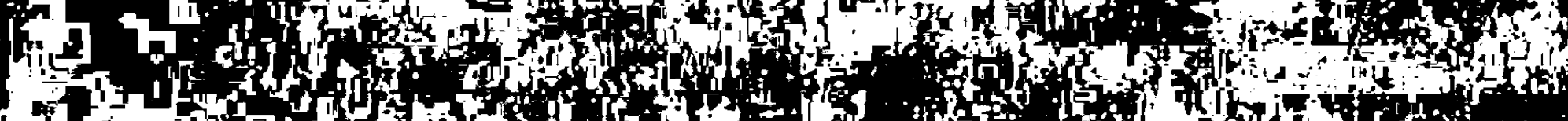

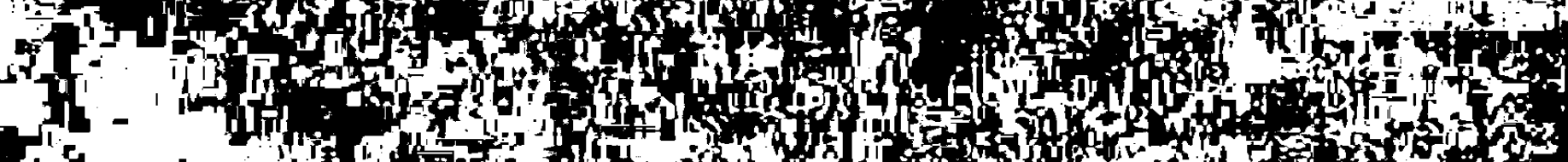
n

I. I. i [1,

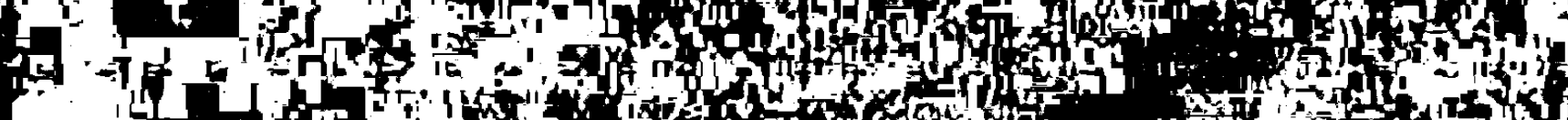

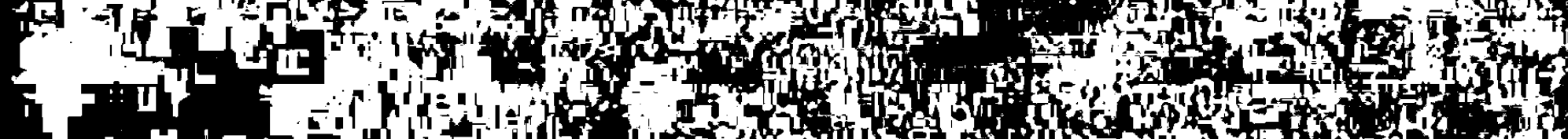

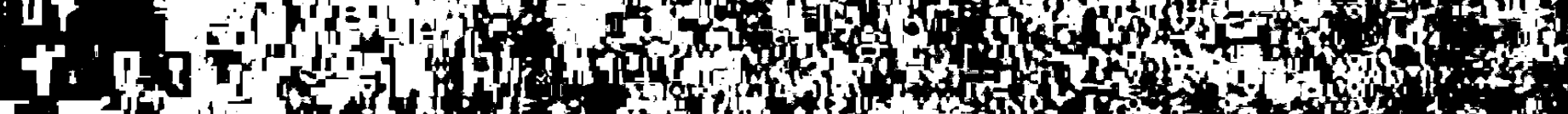

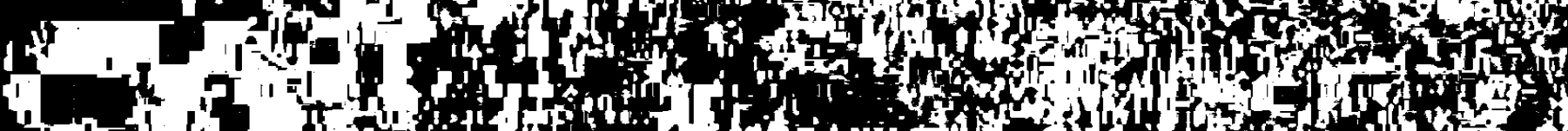

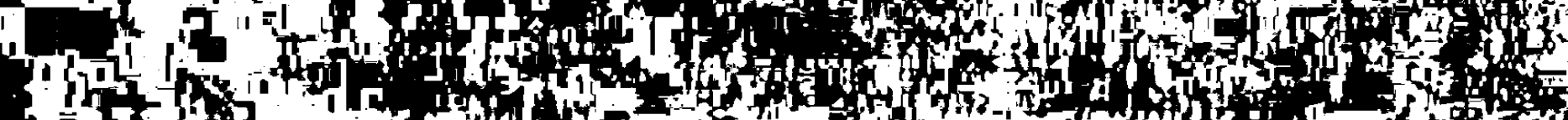
$=40$ a

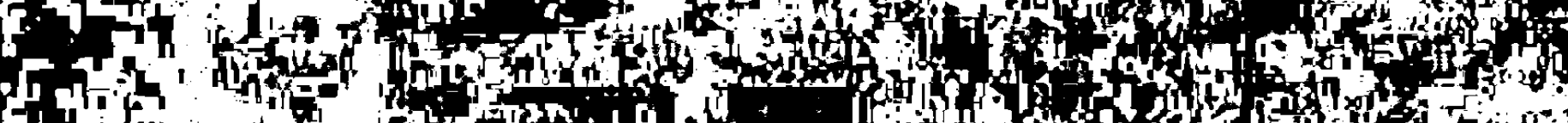

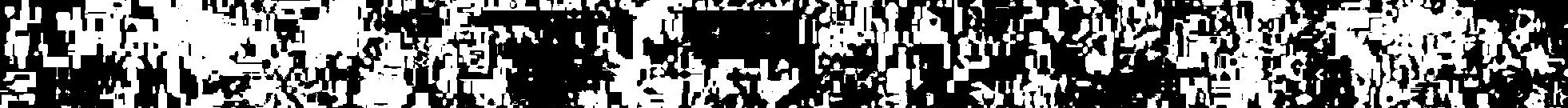
if

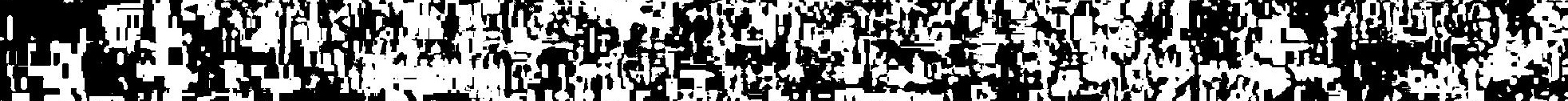

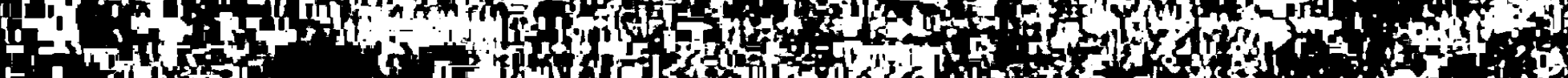

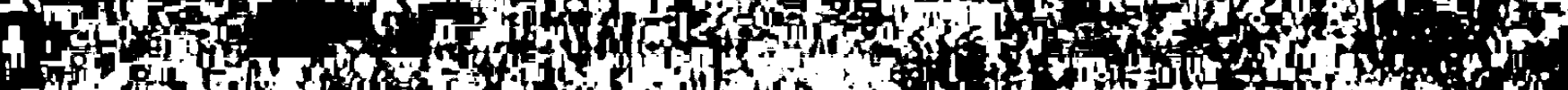
1 -

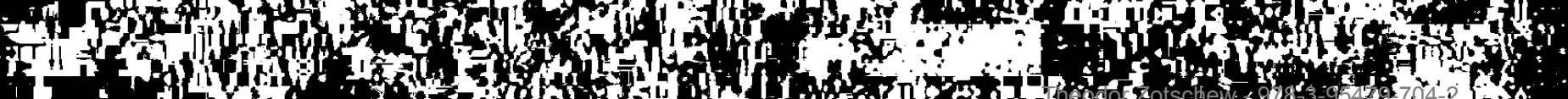

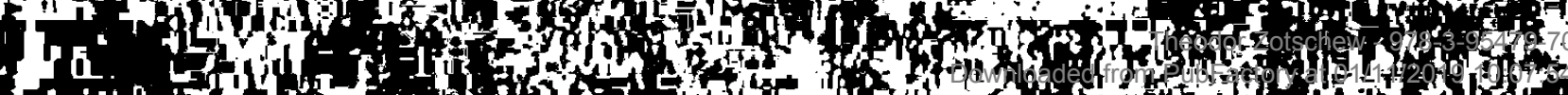




\section{pro}

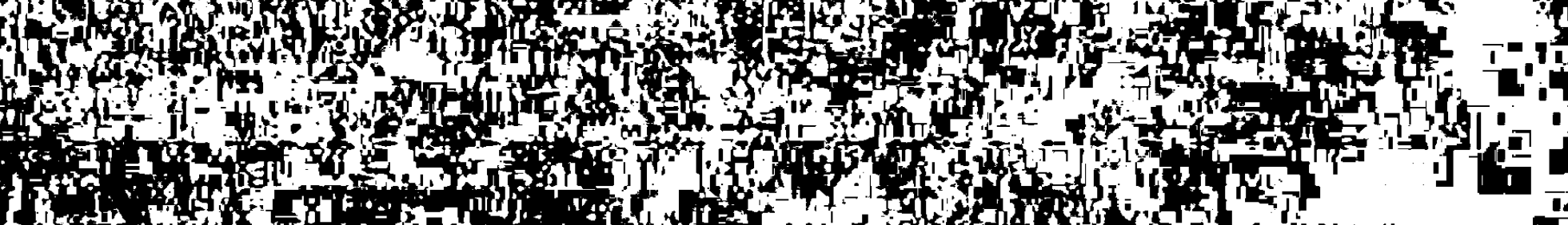

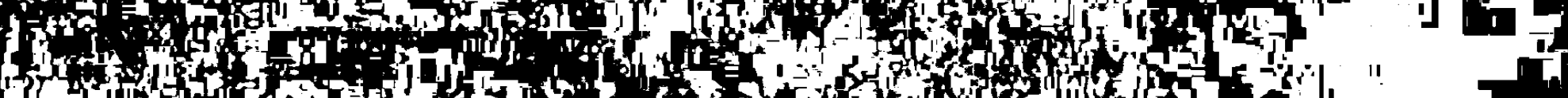

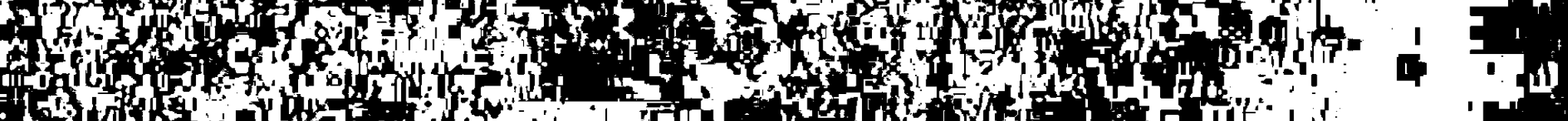

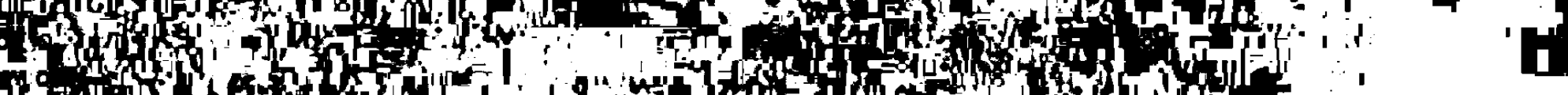
4.

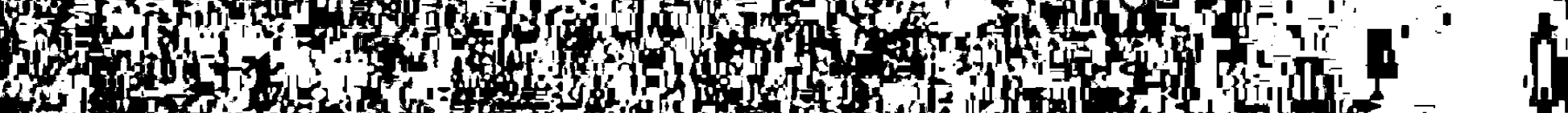

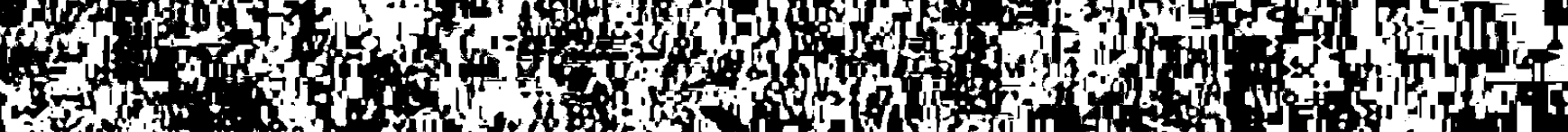

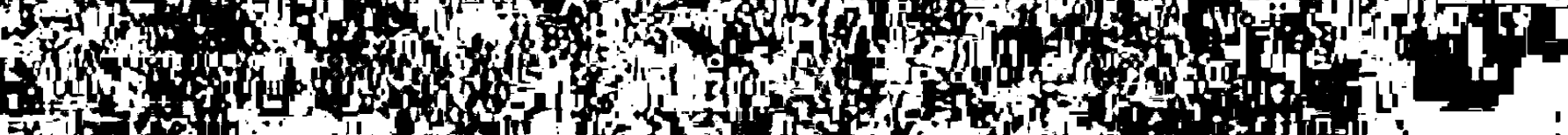

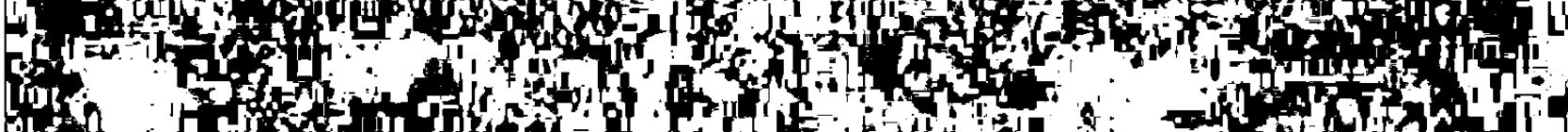

teth

i.

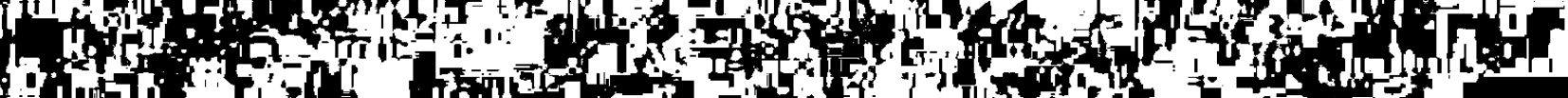

for

(t)

1)

إن

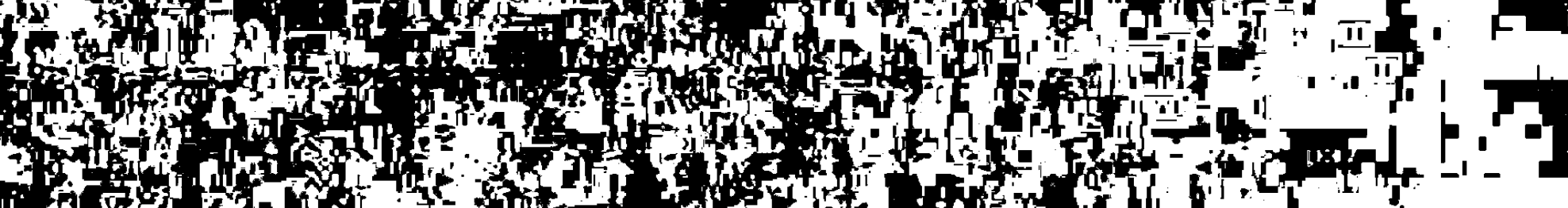

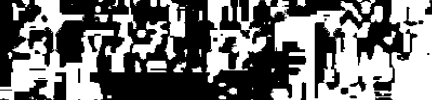

Strats

1)

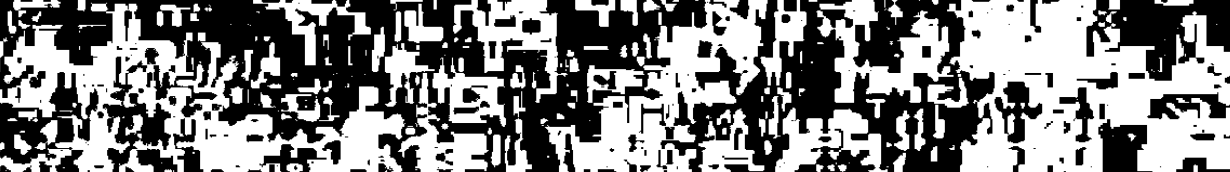

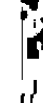

HDi

int

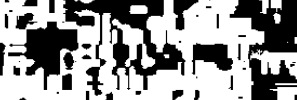

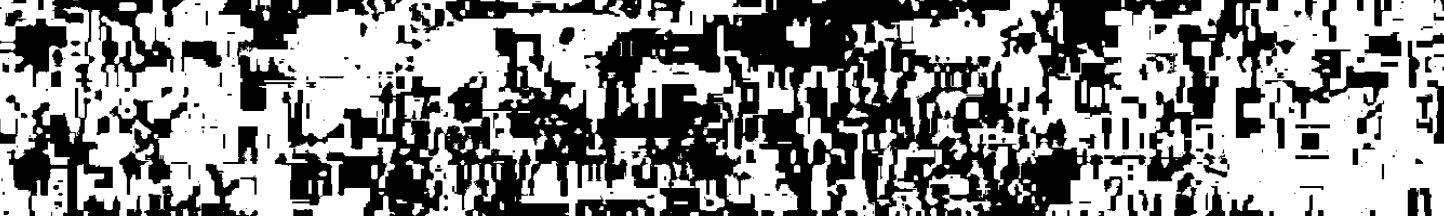

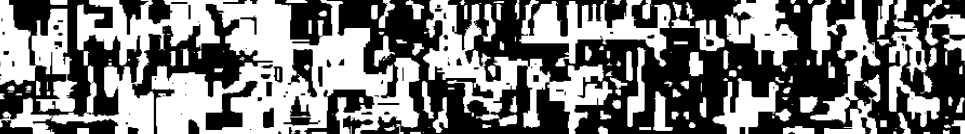

S1, $\therefore$ ind in

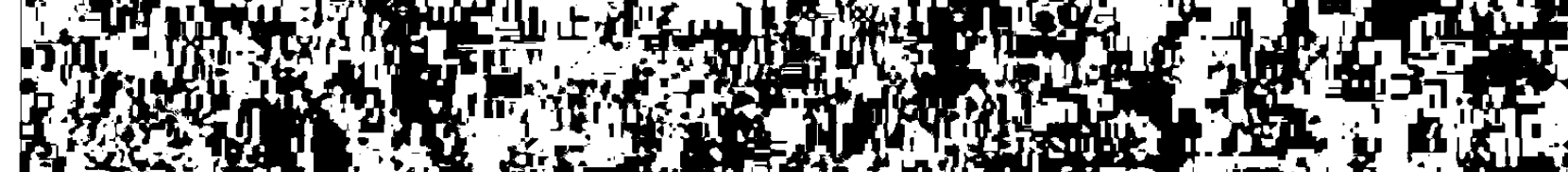

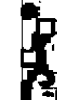

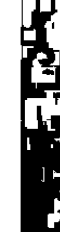

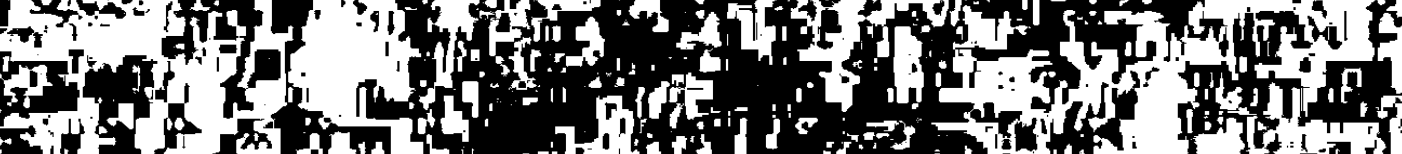

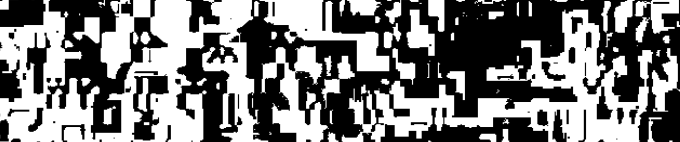

is

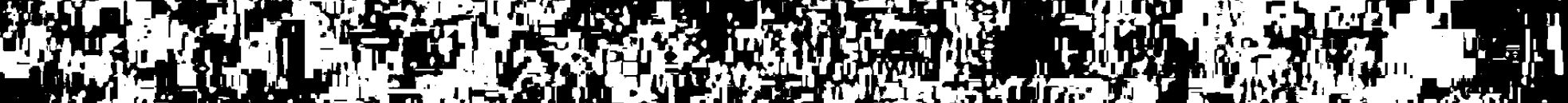

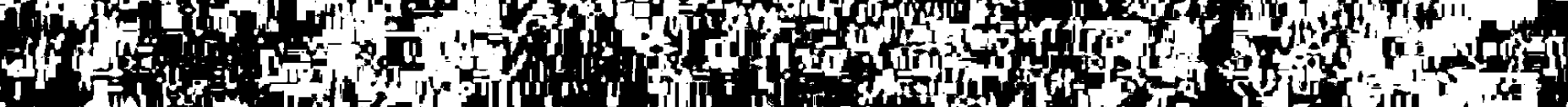

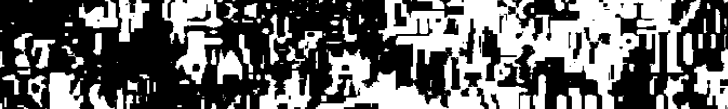
ind a 34 a 


\section{S Ü D O S T E U R O PA - S T U D IEN}

im Namen der Südosteuropa-Gesellschaft herausgegeben von

WALTER ALTHAMMER

Theodor D. Zotschew

\section{STRUKTURWANDEL IN WIRTSCHAFT UND GESELLSCHAFT SODOSTEUROPAS}

Eine sozial-ökonomische und statistische Analyse anläßlich des 20 jährigen Bestehens der Südosteuropa-Gesellschaft 
$z \cdot 61 \cdot 42(20$

\section{Bayentento \\ Staotebibllothn \\ Minchen}

Redaktion: Dr. Hanna Gülich-Bielenberg. Krel

Gleichzeitig erschienen als Kieler Sonderdruck 3

des Instituts für Weltwirtschaft an der Universität Kiel 


\section{Geleitwort}

Seit der Gründung der Südosteuropa-Gesellschaft e.V. im Jahre 1952 in München sind 20 Jahre vergangen. Dies ist der äußere Anlaß für die Herausgabe dieser Studie.

$\mathrm{Zu}$ den vielfältigen Aufgaben der Gesellschaft gehört u.a. die Veröffentlichung von statistischen Arbeiten aus dem wirtschaftlichen und gesellschaftlichen Leben der südosteuropäischen Länder. Zusammen mit den Statistiken in den Beiträgen der einzelnen Autoren in den Publikationsreihen der Südosteuropa-Gesellschaft wird auf diese Weise jedem an Südosteuropa Interessierten eine Fülle von statistischem Material gëboten.

Dem statistischen Teil der vorliegenden Studie hat der Autor eine kurze sozial-ökonomische Analyse vorangestellt, in der er auf die Entwicklungsmodelle, die Entwicklungsprobleme, den sozial-ökonomischen Wandel und die weltwirtschaftliche Orientierung der südosteuropäischen Staaten sowie ihre Wirtschaftsbeziehungen mit der Bundesrepublik Deutschland hinweist.

Die Studie entstand dank der vorzüglichen Forschungsmöglichkeiten im Institut für Weltwirtschaft an der Universität Kiel.

München, im Juni 1972

Dr. Walter Althammer

Präsident der Südosteuropa-Gesellschaft 
7 to

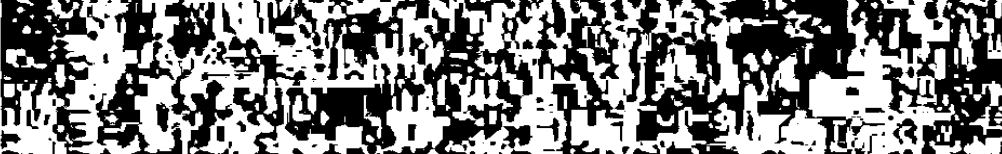

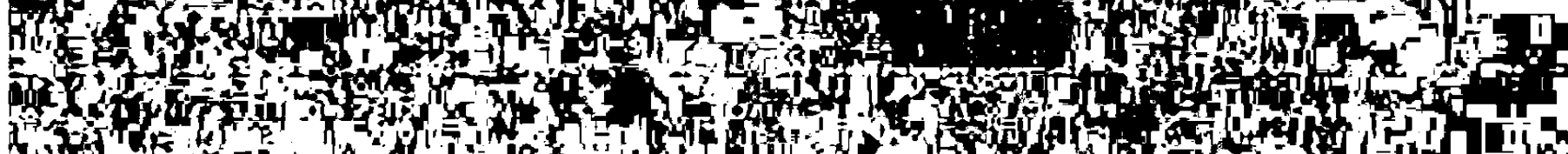

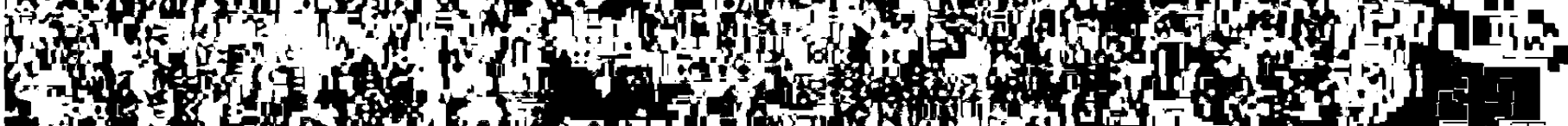

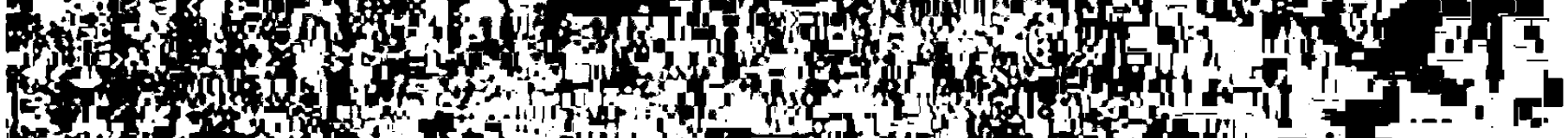

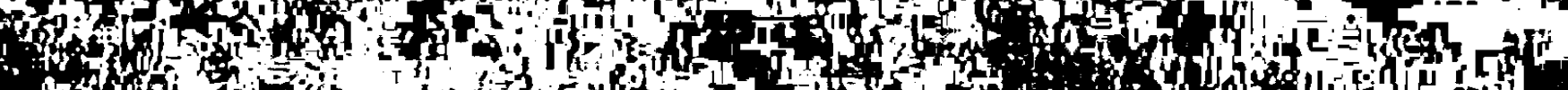

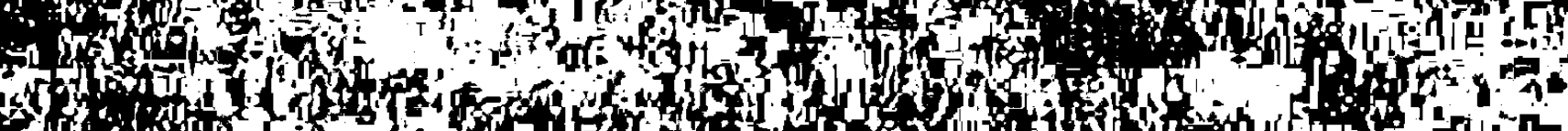

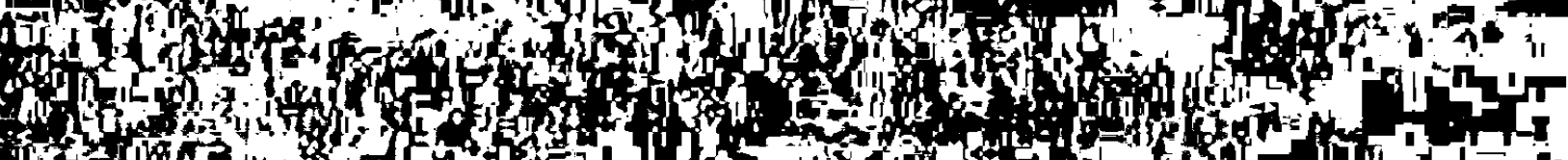

204 (2) 1 ind of

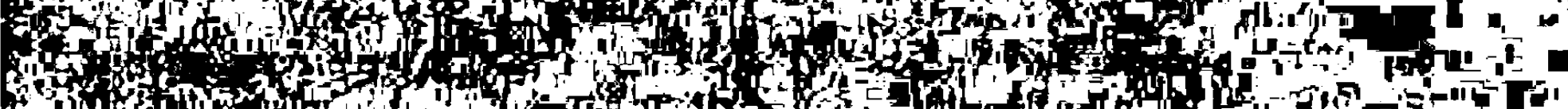
Fon ond

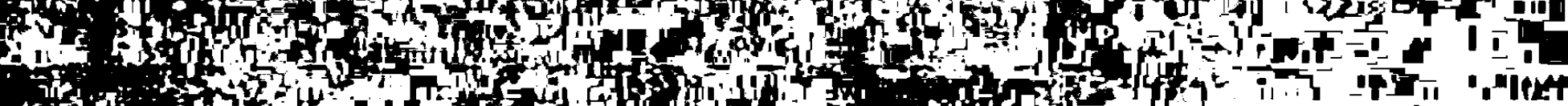
nt of

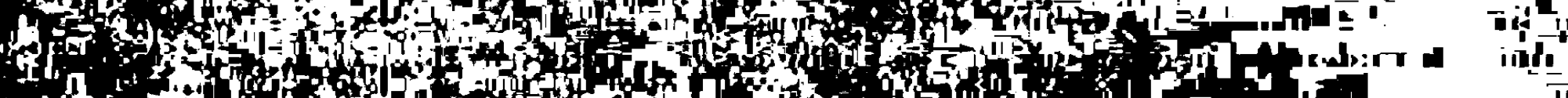
of Q

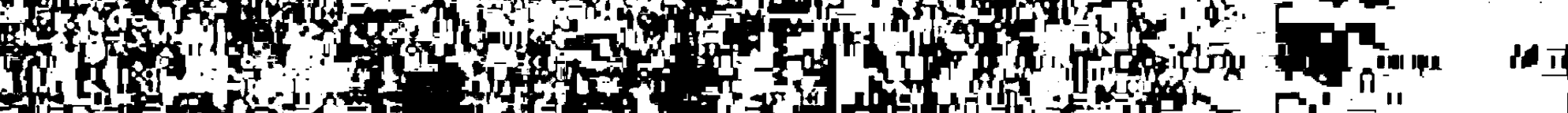
of Noth

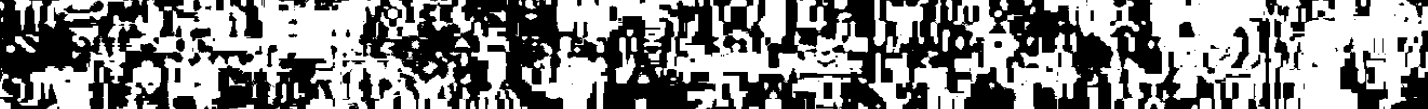
oy in

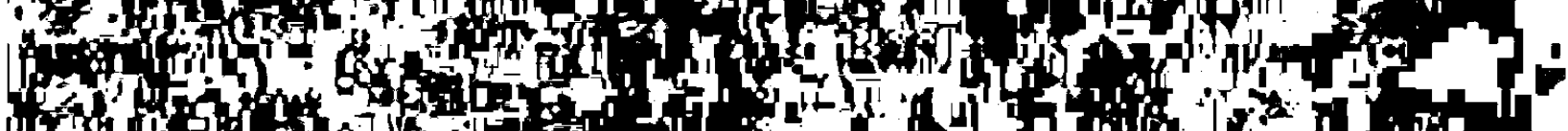
und

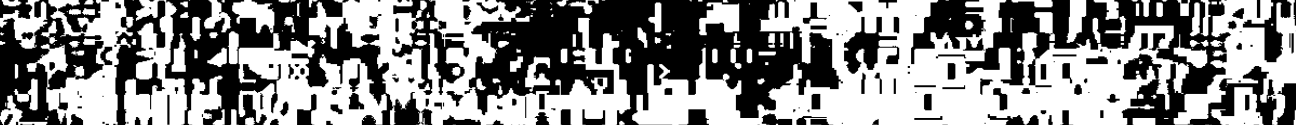

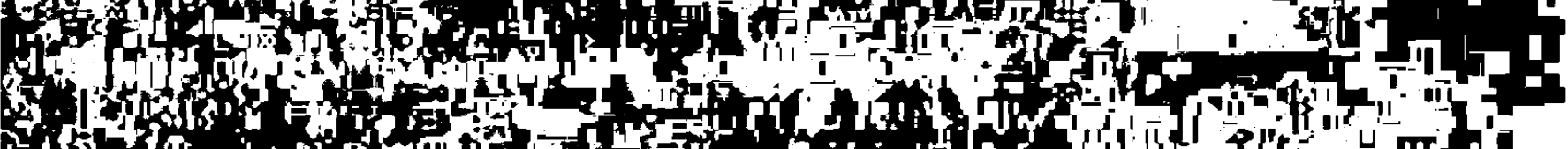
(4) 14 is

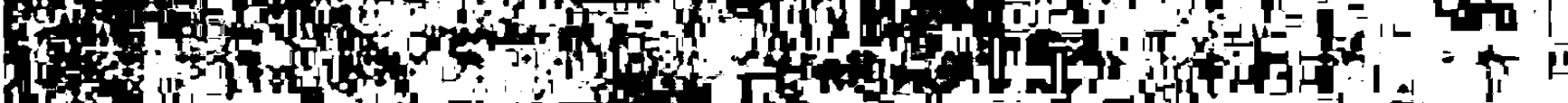

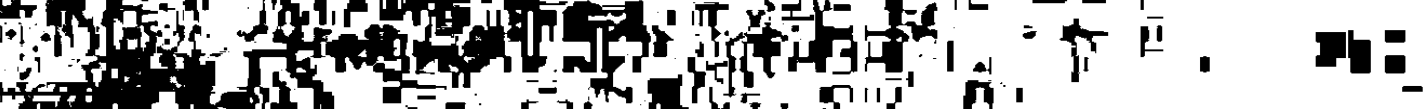

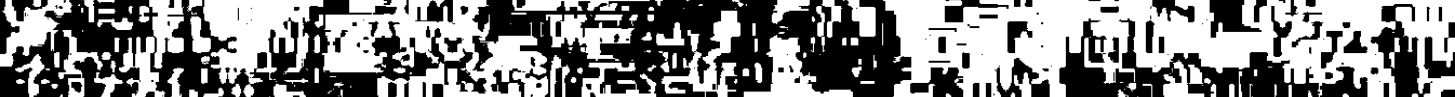

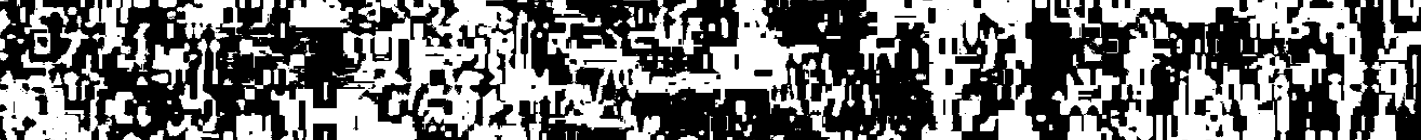

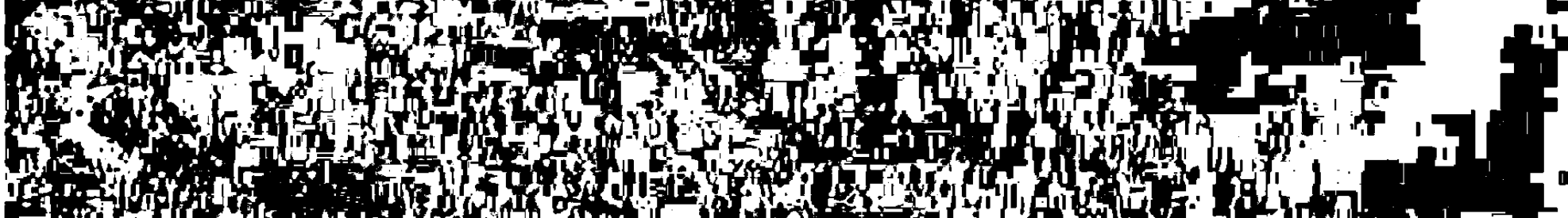

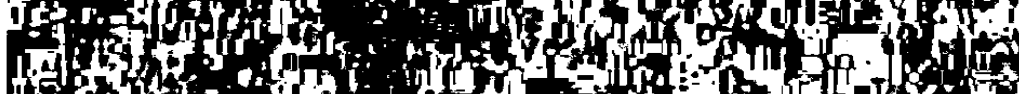

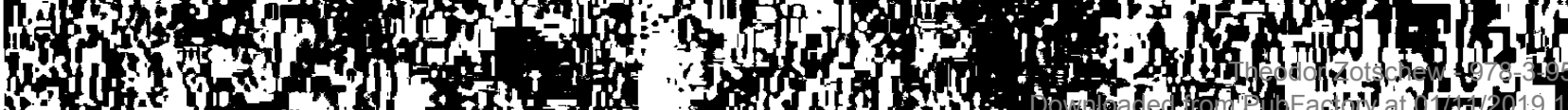




\section{Inhaltsverzeichnis}

Seite

Geleitwort von W. Althammer 3

$\begin{array}{ll}\text { I. Sozial-ökonomische Analyse } & 7\end{array}$

1. Entwicklungsprobleme Südosteuropas 9

2. Entwicklungsmodelle in Südosteuropa 14

3. Wandel von der Agrar-zur Industriegesellschaft 20

a. Entwicklung der Bevölkerung $\quad 20$

b. Sozialstruktur und Arbeitskräftepotential 23

4. Südosteuropa in der Weltwirtschaft 30

II. Statistische Analyse $\quad 43$

Vorbemerkung und Literaturhinweise $\quad 44$

Verzeichnis der Übersichten und Tabellen $\quad 47$

A. Allgemeine Daten $\quad 53$

$\begin{array}{ll}\text { B. Bevölkerung } & 57\end{array}$

C. Beschäftigung $\quad 64$

D. Schulwesen; Gesundheit; Kulturelles Leben 69

E. Wirtschaftswachstum; Nationaleinkommen $\quad 73$

F. Landwirtschaft; Forstwirtschaft; Fischerei $\quad 75$

G. Industrieproduktion; Bergbau; Wohnungsbau 85

H. Verkehr; Nachrichtenwesen $\quad 94$

$\begin{array}{ll}\text { I. Außenhandel, Tourismus } & 101\end{array}$

Anhang: Verzeichnis der Veröffentlichungen der SüdosteuropaGesellschaft 1952-1972 
ing

7.thy

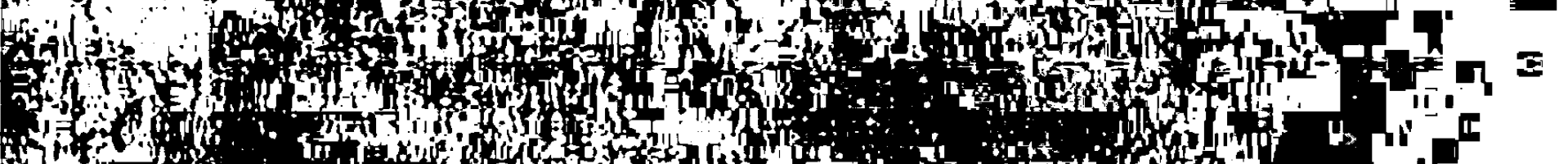

iile

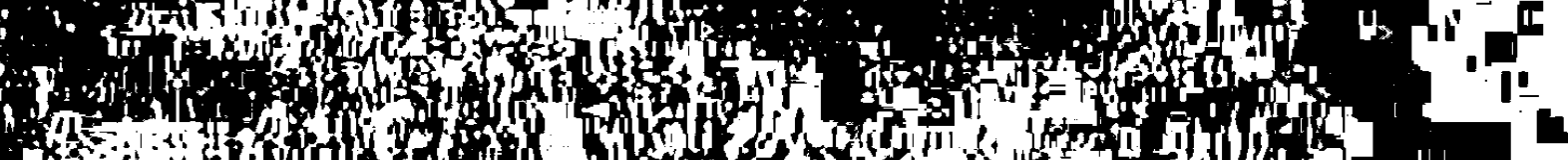

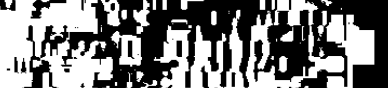

Fof

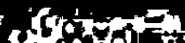

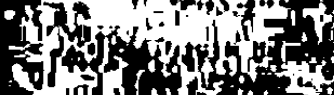

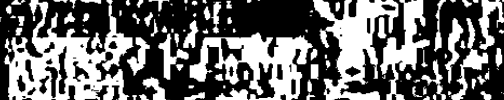

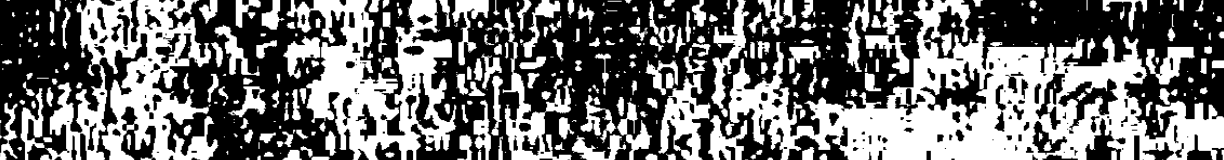

Alish

Hor

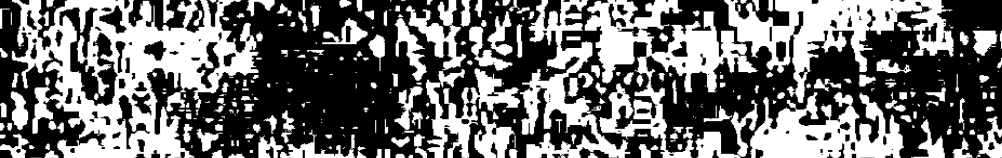

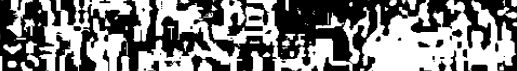

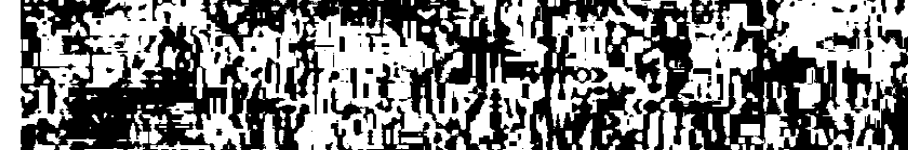

(a)

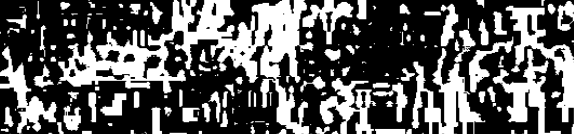

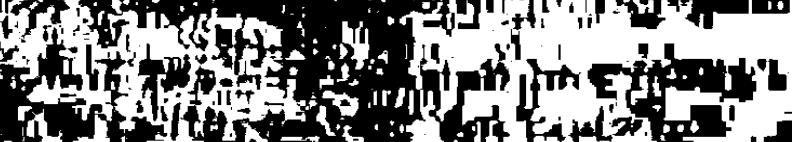

10 III

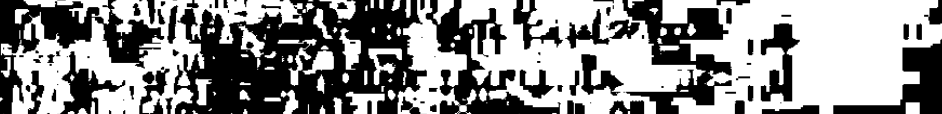

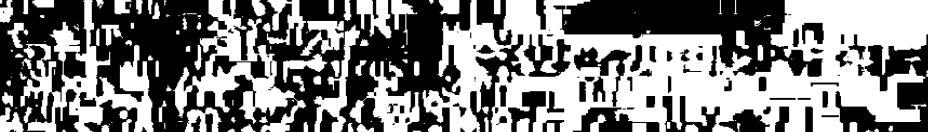

Lys

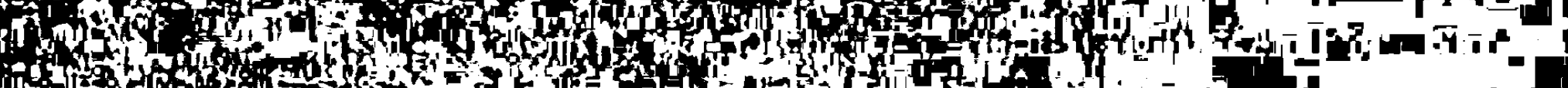

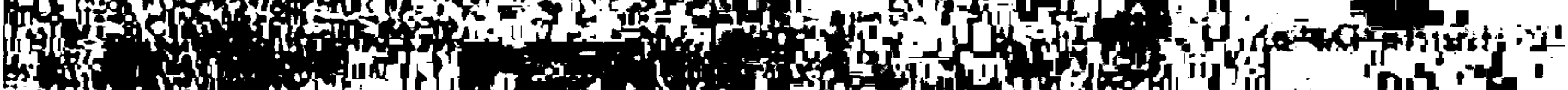

\section{tis.

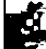
tind

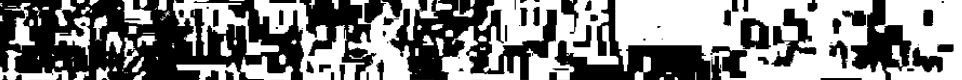

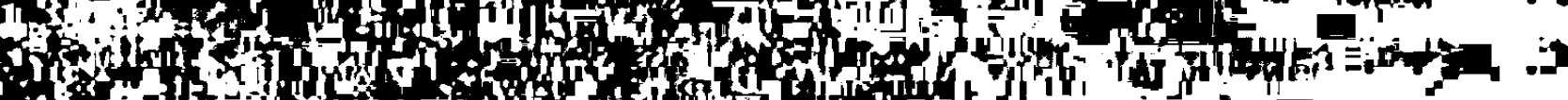

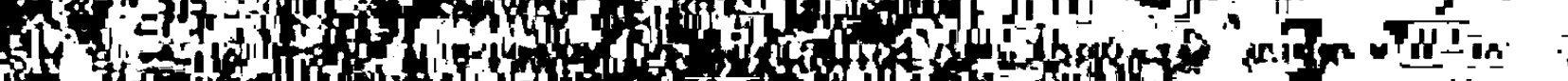
(1)

$\overline{1}$

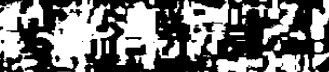
fint

Gidnting

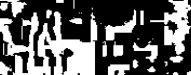

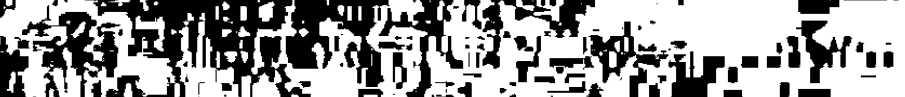

4 ing

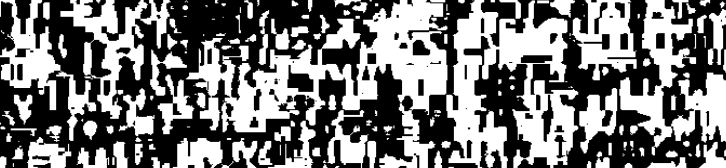

ititus

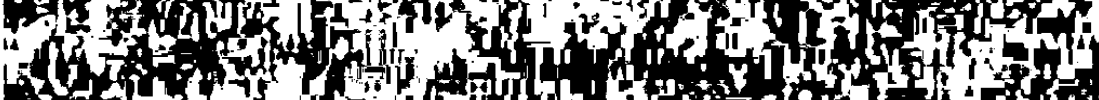

If ,

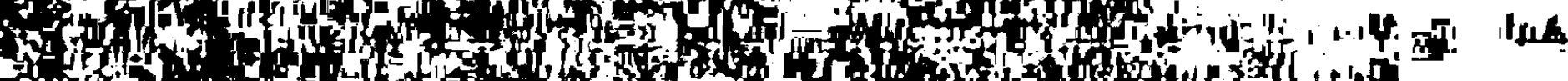
(1)

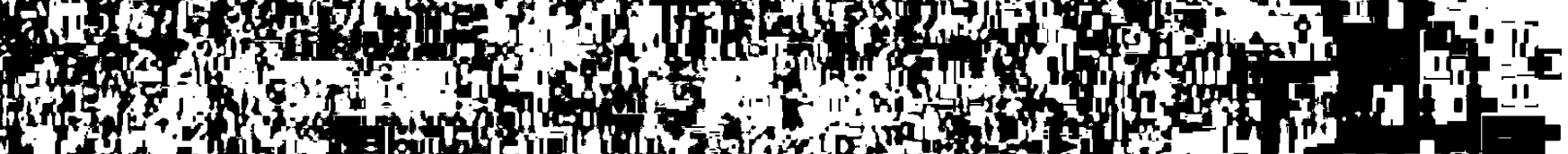
of

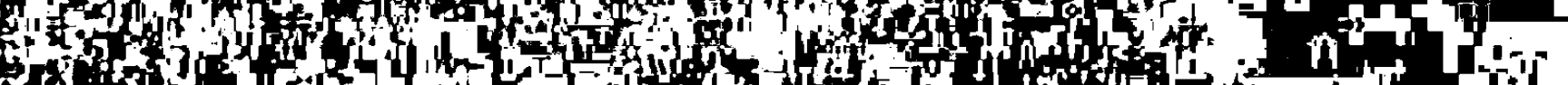
1.

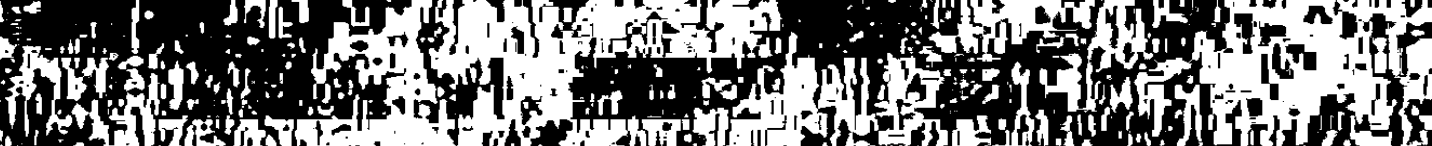

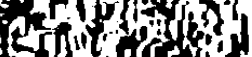

afting

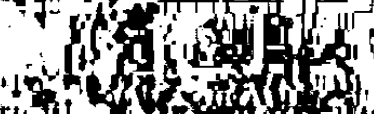

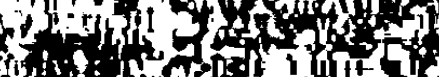
the

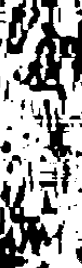

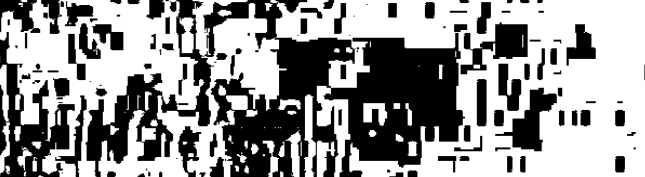

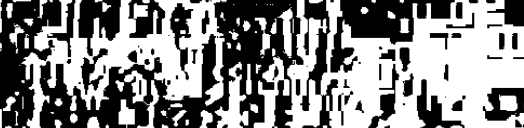

fof

yosing 
I. Sozial-ökonomische Analyse 
a

(1)

Livath

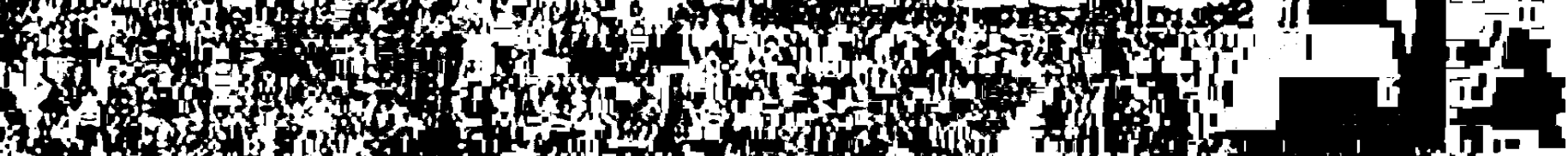

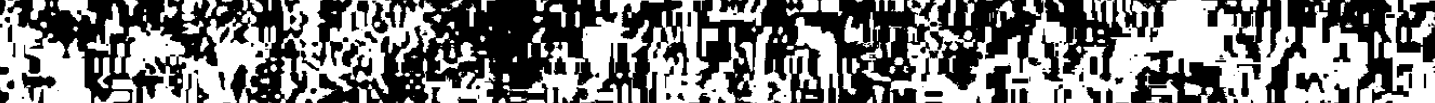

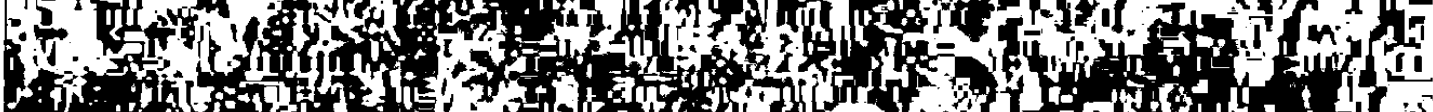

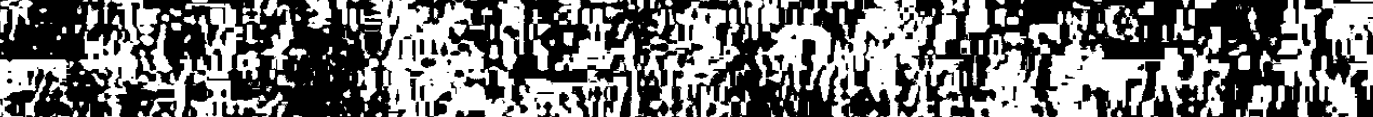

(1) (5)

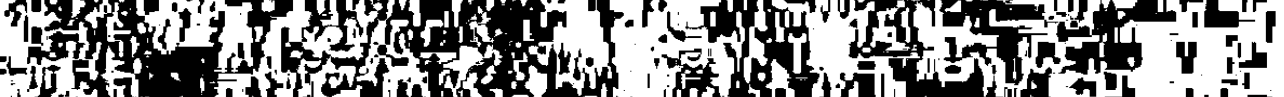

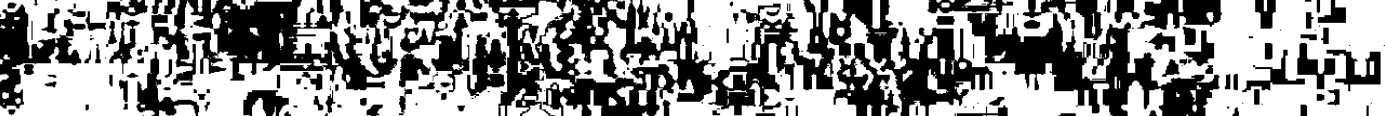

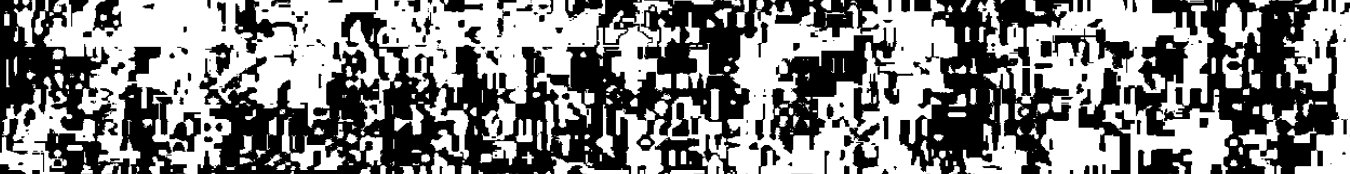

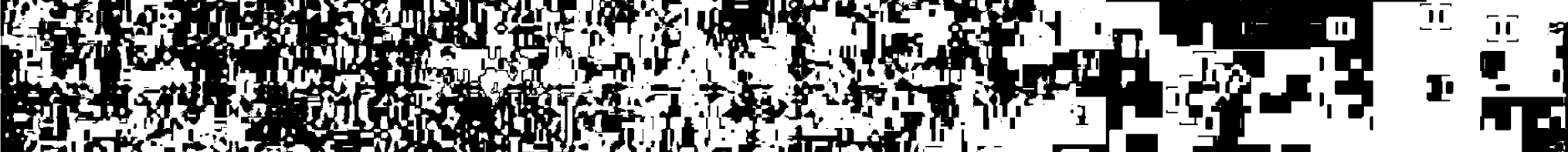

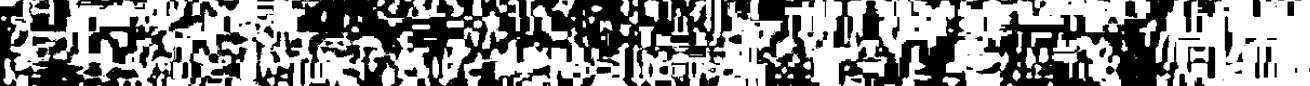

40 tis

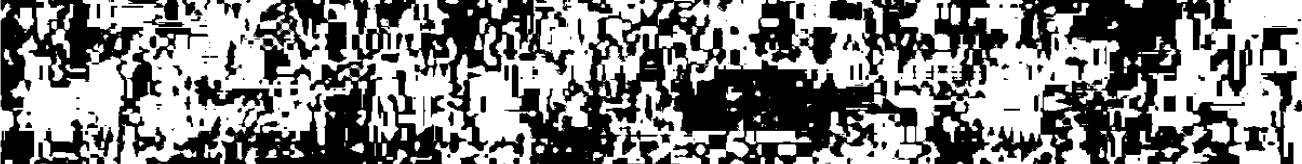

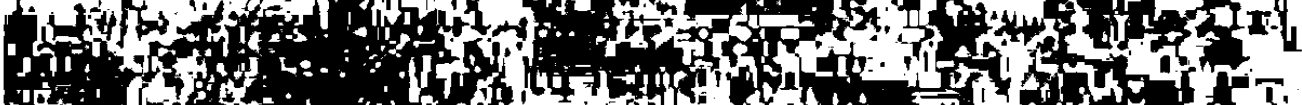

Go 1 if

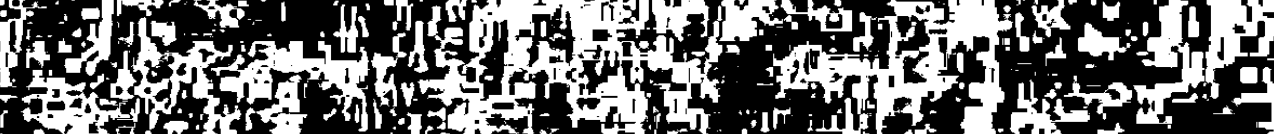

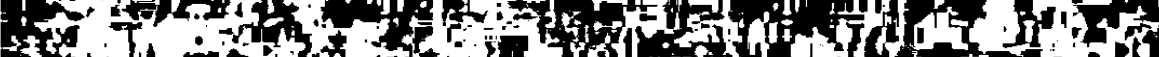
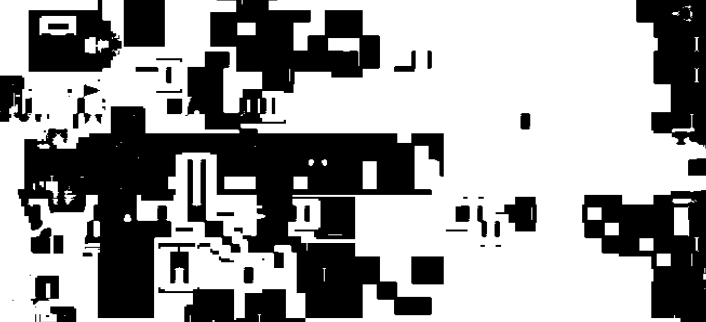

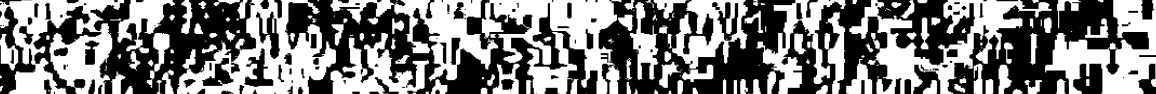

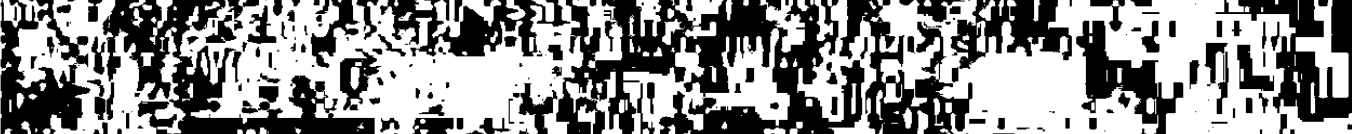
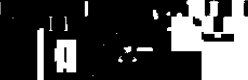

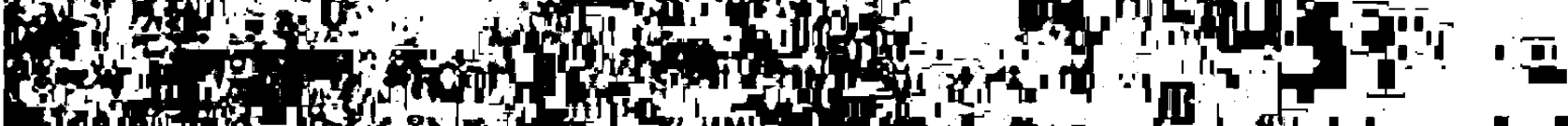

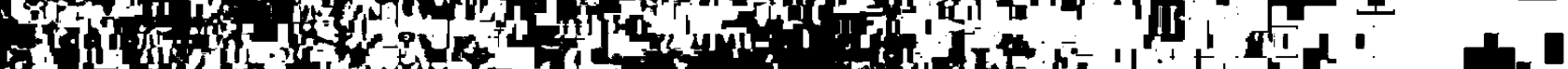

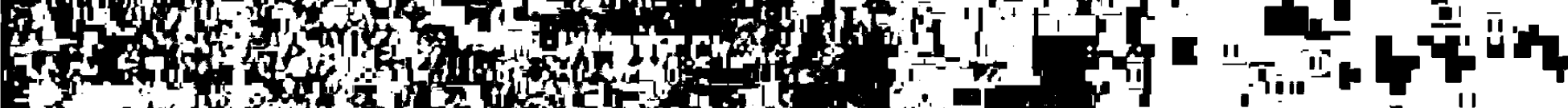

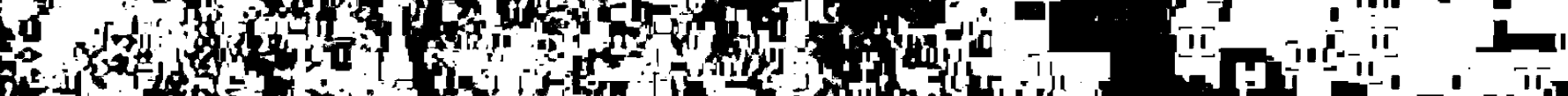

of

(3)

18 te

If

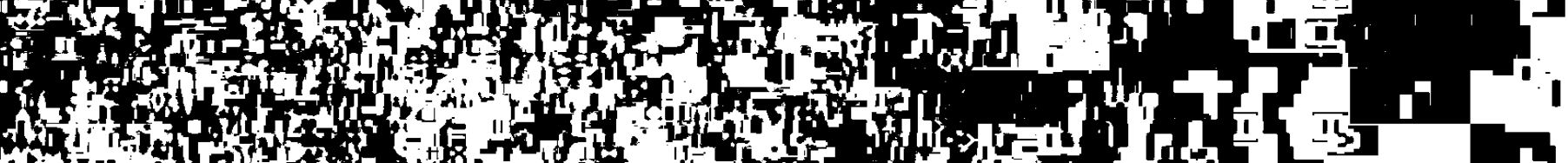

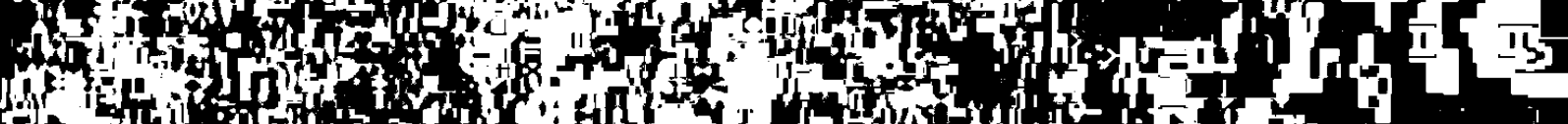

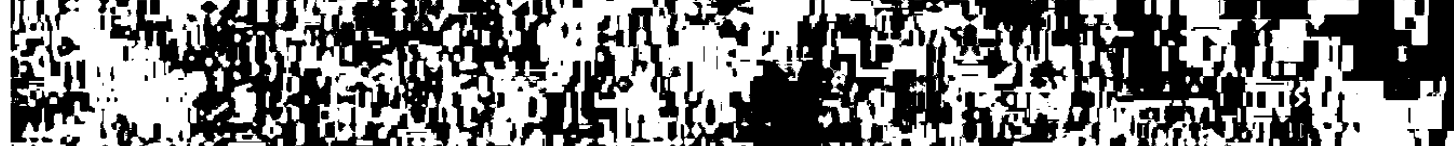

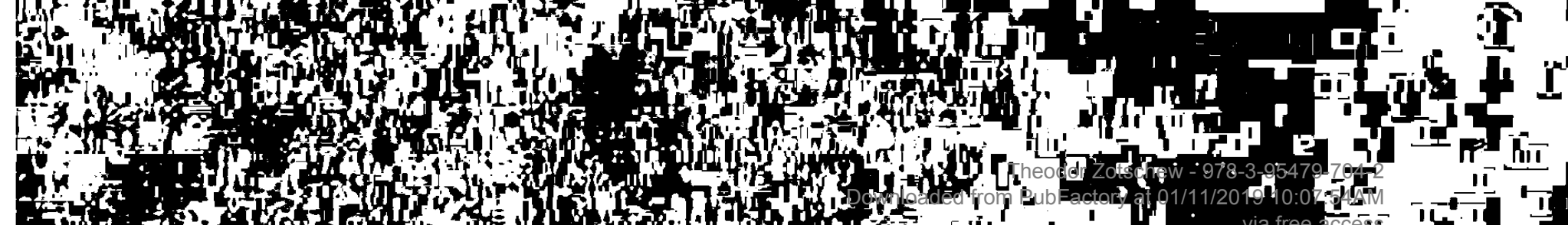
Int: 


\section{ENTWICKLUNGSPROBLEME SÜDOSTEUROPAS}

Gegenstand der sich seit den zwanziger Jahren formierenden Südost e u ropa-Forschung ist die Gesamtheit der sieben Staaten: Ungarn, Rumänien, Jugoslawien, Bulgarien, Albanien, Griechenland und die Türkei; neuerdings ist auch Zypern hinzugetreten. Schon bei dieser Aufzählung sind bereits zwei grundsätzliche Besonderheiten des Forschungsgebiets angesprochen worden, nämlich:

Erstens hat man es hier mit einem jüngeren Zweig der wissenschaftlichen Forschung zu tun und

Zweitens erstrecken sich die genannten Staaten über mehrere geographische und kulturmorphologische Regionen, deren Kulturen eine erstaunliche Vierfalt und Heterogenität der Elemente aufweisen ${ }^{1}$.

Zur ersten Besonderheit seien hier einige Bemerkungen gemacht: Während bei den meisten anderen Zweigen der interdisziplinären Auslandsforschung (wie z. B. Rußland-Forschung, Iberoamerika-Forschung, Skandinavien-Forschung u.dgl. ) im allgemeinen lediglich Aufbau, Methode und Zielsetzung der einzelnen Visziplinen thematisch aufeinander abgestimmt und miteinander verbunden $z u$ werden brauchen, bedarf es bei der Südosteuropa-Forschung zunächst der Übereinkunft der einzelnen Wissenschaften und Fachrichtungen, was man unter Südosteuropa zusammenfassen und verstehen will. Zu den wichtigsten daran beteiligten Wissenschaften zählen: Byzantinistik, Slawistik, Romanistik, Finno-Ugristik, Geschichtswissenschaft, Geo- und Ethnographie, Volkskunde, Religionswissenschaft, Geographie, Naturwissenschaften, Gesellschafts- und Wirtschaftswissenschaften, Politologie. D. h. die Südosteuropa-Forschung ist erst aus der Konkretisierung und aus der Integration des Verhältnisses und der Einstellung der Forscher und der Öfentlichkeit in Mittel- und Westeuropa und insbesondere in Deutschland und Ósterreich in der Zeit zwischen den beiden Weltkriegen zu dem südosteuropäischen und kleinasiatischen Raum und den dortigen Staaten, Völkern und Gesellschaften hervorgegangen. Mit anderen Worten: Der Begriff Südosteuropa ist zugleich Ergebnis wie Voraussetzung der Sủdosteuropa-Forschung selbst ${ }^{2}$.

Zur zweiten Besonderheit - Heterogenität und zugleich Einheit $S$ üdoste uropas als Objekt der Forschung - sei hier nur das Wesentliche herausgegriffen.

1 Hermann GROSS, Südosteuropa. Bau und Entwicklung der Wirtschaft.

Leipzig 1937. = Leipziger Vierteljahresschrift f. Südosteuropa. Beihefte 1.

2 Franz RONNEBERGER, Wandlungen im Verständnis Südosteuropas. In: Wirtschaftswissenschaftliche Südosteuropa-Forschung. Ausgewählt und redigiert von Theodor Zotschew, Südosteuropa-Schriften, Band 4, München 1963, S. 16 . 
Bei Südosteuropa in der oben abgegrenzten :äumlichen Ausdehnung handelt es sich um Nachfolgestaaten der einstigen Österreichisch-Ungarischen Doppelmonarchie auf der einen Seite, und des Osmanischen Reiches auf der anderen Seite, wobei sich die frühere balkanisch-donauländische Kulturgrenze in unterschiedlichen Entwicklungsstufen auch heute noch deutlich zeigt ${ }^{1}$. Südosteuropa ist zudem der Schnittpunkt der Begegnung von Völkern, Kulturen, Interessen und Ideologien an der Nahtstelle $z$ wichen dem Orient und dem Okzident. Nachfahren von Illyrern und Thrakern, slawischen Völkern, Magyaren, Albanern, Griechen, romanisierten Volksgruppen, Türken, Juden, versprengten Levantinern und einer geradezu unübersehbaren Vielzahl von geschlossenen Volksgruppen und von verstreuten Minderheiten, darunter auch Deutschen, sind hier seit Jahrhunderten und Jahrtausenden ansässig und kulturell verwurzelt. Byzanz und Rom, Griechentum und Lateinität, Christentum und Islam, östliche Orthodoxie, westlicher Katholizismus und Protestantismus, orientalische, levantinischmediterrane und habsburgische Lebensart, Volkskulturen und Sprachen, Schicksalsergebenheit und rationelles Denken wirkten hier ebenso mit wie die Überschneidung der außenpolitischen Interessen und Ambitionen fremder Mächte, insbesondere seit dem ausgehenden neunzehnten Jahrhundert: Hierzu rechnen insbesondere das Habsburger Reich, das zaristische Russland, das Deutsche Reich, Großbritannien und Frankreich. Unübersehbar ist schließlich die Folge des Aufeinanderprallens der Ideologien und Hegemonialbestrebungen der Weltmächte und Machtgruppierungen in der jüngsten Zeit. Verwiesen sei in diesem Zusammenhang lediglich auf die NATOPräsenz in Griechenland und in der Türkei, die Zugehörigkeit zur EWG, auf die Vormachtstellung der UdSSR im Rat für Gegenseitige Wirtschaftshilfe und im Warschauer Pakt, auf den Einfluß Chinas in Albanien. Nicht vergessen darf man schließlich Jugoslawien, das als Vorreiter der blockfreien Staaten wirkt und als 'vierte Kraft der Ideologien' von heute gilt.

Des weiteren wäre noch festzuhalten, daß es keinen Staat in Südosteuropa gab und gibt, der an Bevölkerungszahl, an Wirtschaftskraft und Entwicklungsstand sich gegenüber den anderen hätte als überlegen erweisen und entsprechend als integrierend wirken und damit zumindest in Ansätzen zu einer gewissen - sei es politisch oder wirtschaftlich - Verselbständigung des Gesamtraums führen können. Bis auf die Türkei haben nämlich alle anderen Südoststaaten ihre politische Selbständigkeit im Verlauf der letzten 100 Jahre erlangt, genau genommen: Griechenland im Jahre 1829; Bulgarien, Rumänien, Serbien und Montenegro nach dem russischtürkischen Krieg von 1877/78; Albanien im Jahre 1913; Ungarn und Jugoslawien nach dem Ersten Weltkrieg. Zu den letztgenannten zwei Staaten wäre noch zu sagen, daß Ungarn innerhalb der Österreichisch-Ungarischen Monarchie schon seit 1863 eine autonome Wirtschaftspolitik betreiben

- Franz RONNEBERGER, Südosteuropa auf dem Weg zur Industriegesellschaft. Beitrag I, S. 4, in: Von der Agrar-zur Industriegesellschaft. Sozialer Wandel auf dem Lande. Herausgeber Franz Ronneberger und Gerhard Teich, Darmstadt 1970. 
konnte. Jugoslawien ging 1918 hervor als ein Vielvölkerstaat aus Serbien und Montenegro, die bereits 50 Jahre zuvor ihre Selbständigkeit erlangten, ferner aus Kroatien mit der dazu gehörenden dalmatinischen Küste sowie Bosnien und Herzegowina und aus Slowenien (Provinzen, die bis dahin zu Österreich-Ungarn gehörten) und schließlich aus einem Teilgebiet Mazedoniens, das bis 1913 noch unter türkischer Herrschaft stand. Die Modernisierung und "Europäisierung" der Türkei wurde auch erst in den zwanziger Jahren unter Kemal Atatürk eingeleitet.

Über den Rückstand in der ökonomischen, technischen, gesellschaftspolitischen und zivilisatorischen Entwicklung war man sich insbesondere in der Zwischenkriegszeit überall in Südosteuropa einig. Wie allerdings die Länder aus der Umzingelung und aus dem permanenten Kreis der Armut hätten befreit werden können, hierüber gab es keine konkreten Vorstellungen und praktikablen Vorschläge. In wissenschaftlichen Arbeiten begnügte man sich hier wie auch sonst in der Hauptsache damit, Mißstände und Probleme auf ökonomischem und sozialem Gebiet aufzudecken, wie aber an ihre Stelle eine moderne Entwicklung einzuleiten wäre, hierüber gingen die Auffassungen auseinander. Weil die eigenen Kräfte und Möglichkeiten für die Bekämpfung der wirtschaftlichen, technischen und zivilisatorischen Rückständigkeit nicht ausreichten und es auch an den nötigen internationalen Programmen, Konstellationen und Solidaritäten fehlte, kam es zu schweren Staats - und Verfassungskrisen. Die parlamentarischen Regierungen aller Südoststaaten waren in der Zwischenkriegszeit ständigen Umstürzen und Umbildungen ausgesetzt.

Dutzende von größeren und kleineren Parteien und Splittergruppen von Parteien, aber auch einzelne Politiker, Potentaten und ihre Anhänger brachten es zu allen möglichen Koalitionen und Machtkombinationen bei Regierungsneubildungen, die sich dann oft nur Monate oder gar nur Wochen halten konnten. Zu den sozialen und wirtschaftlichen Schwierigkeiten gesellte sich auf diese Weise eine permanente innenpolitische Instabilität. Hinzu kamen die für alle Agrarländer besonders schweren Folgen der Weltwirtschaftskrise der dreißiger Jahre, so daß der Nährboden in Südosteuropa für radikale Ideen von rechts und von links nicht weniger günstig war als in Deutschland in jener Zeit. Man war infolgedessen auch leicht geneigt, mit jedem stärkeren ausländischen Partner zu kollaborieren, wenn er nur, sei es politisch-verbale, sei es materielle Hilfe in irgendeiner Form versprach. Ein solcher Partner war bekanntlich Deutschland, das im Zuge der von allen Staaten eingeleiteten Politik zur Überwindung der Weltwirtschaftskrise und $z$ um Aufbau der nationalen Wirtschaften eine besonders starke Position im Außenhandel und darüber hinaus im gesamten wirtschaftlichen Leben der meisten südosteuropäischen Länder erlangte. Aus welchen Gründen auch immer, aber unbestritten auch zum Vorteil des Südostens selbst, entwickelte sich Deutschland binnen eines Jahrzehnts nicht nur zum weitaus wichtigsten Lieferanten von Industrieerzeugnissen und Abnehmer der agrarischen und 
bergbaulichen Exporterzeugnisse der Südoststaaten ${ }^{1}$, sondern in jenen Jahren wurden auch die Grundsteine für eine umfassende deutsche Entwicklungspolitik gegenüber dem Südosten gelegt ${ }^{2}$.

Der Ausgang des Zweiten Weltkriegs brachte eine geschichtliche W e nde in der gesamten Entwicklung Südosteuropas mit sich. Die Übertragung und die UUbernahme des sowjetsozialistischen Wirtschaftssystems in den dem sowjetischen Einflußbereich anheimgefallenen Staaten Rumänien, Bulgarien, Albanien, Jugoslawien und Ungarn und die dadurch geschaffenen Möglichkeiten für einen Neubeginn ihrer Wirtschaftspolitik, diesmal nach sowjetischem Vorbild und in Anlehnung an die Sowjetunion. Griechenland und die Türkei behielten zwar ihre traditionellen Staatsformen und sozioökonomischen Strukturen bei, doch auch für ihre wirtschaftliche Entwicklung änderte sich die Situation im Vergleich zur Vorkriegszeit grundlegend, und zwar zunächst durch die Marshallplanhilfe und dann durch ihren Einbezug in die wirtschaftlichen Integrationsbestrebungen in Europa und in die Hilfsprogramme sowie Militärbündnisse des Westens. Die politische und ideologische Trennungslinie der Welt in sozialistische staatsund planwirtschaftliche und in privatkapitalistisch-marktwirtschaftliche Länder, in industriell aufstrebende und noch in Tradition verharrende Gesellschaften, in blockgebundene und in blockfreie Staaten vollzieht sich somit auch quer durch Südosteuropa und bereichert die schon immer gegebene Vielfalt des Raumes noch um die Ideologien und politischen Systeme und Systemkombinationen von heute. Seinen Charakter als "weltpolitisches Erdbebenzentrum" à la Wagemann ${ }^{3}$ hat Südosteuropa inzwischen zwar verloren, daß es aber nach wie vor ein Zentrum der Weltpolitik und des Weltinteresses geblieben ist, wird von niemandem bestritten. Erwähnt sei in diesem Zusammenhang noch die unmittelbare Nachbarschaft der Südoststaaten und namentlich Griechenlands und der Türkei zu den Krisenherden im östlichen Mittelmeerraum und am Suez.

1 Siehe hierüber: Anteile Deutschlands am Außenhandel der südosteuropäischen Länder 1928-1970 auf S. 42

2 Hingewiesen sei in diesem Zusammenhang insbesondere auf die vielseitige Tätigkeit des Mitteleuropäischen Wirtschaftstags (MWT). Siehe hierüber u.a.: Tilo Frhr. von WILMOWKI, Rückblickend möchte ich sagen... Hamburg 1961 Veiteres Schrifttum über die deutsch-südosteuropäischen Wirtschaftsbeziehungen siehe bei: Hermann GROSS, Elemente der Agrarstruktur und Tendenzen der Agrarpolitik in Südosteuropa. Beitrag III, S. $28 \mathrm{ff}$., in: Von der Agrar-zur Industriegesellschaft Sozialer Wandel auf dem Lande in Südosteuropa. Herausgeber Franz Ronneberger und Gerhard Teich, Darmstadt 1970. Todor ZOTSCHEW, Wechselbeziehungen von Sozialstruktur und Außenhandel in den südosteuropäischen Ländern. Beitrag IV, S. 29 ff. , a. a. O. , Darmstadt 1969. - Gerhard TEICH, Schrifttum zur Agrarsoziologie Südosteuropas. Beitrag XX, a.a.O., Darmstadt 1972 .

3 Ernst WAGEMANN, Der neue Balkan. Altes Land - junge Wirtschaft. Hamburg 1939 , S. 14 . 
Nach dem jüngsten Stand der Auslandswissenschaften präsentiert sich Südosteuropa somit als ein selbständiges Studien- und Forschungsobjekt, zugleich aber auch als Experimentierfeld für die Überprüfung und Bereicherung gerade der Entwicklungsländerforschung. Was man nämlich in Südosteuropa sozusagen im Kleinen und Uberschaubaren beobachtet und an Erkenntnissen gewinnt, kann als Modell für die sich anbahnenden wirtschaftlichen und gesellschaftspolitischen Umwälzungen in der afro-asiatischen und lateinamerikanischen Welt ausgewertet werden. Dies ist damit zu begründen, daß in Südosteuropa eine ähnliche Buntheit von Strukturen, Entwicklungsstadien und Formen in Wirtschaft und Gesellschaft vorhanden ist, wie sie für die Entwicklungsländer typisch ist, nämlich von der geschlossenen Hauswirtschaft und von Regionen mit hohem naturalem Selbstversorgungsgrad bis hin zum computergesteuerten Industriewerk, von der stationären Gesellschaft in verkehrsentlegenen Dorfgemeinden mit hohem Selbstversorgungsgrad bis hin zur mobilen Industriegesellschaft modernster Art. Dasselbe gilt auch für die Vielfalt der vorhandenen und sich stets neu formierenden und weiter entwickelnden Strukturen in Staat. Wirtschaft und Gesellschaft. Ob es sich um demographische, um schulpolitische oder um Probleme der Berufsausbildung, der Beschäftigung, der Investitionen, der Industrialisierung, um Probleme der Landwirtschaft, des Außenhandels u.dgl. handelt, in allen diesen Fällen kann die Entwicklungsländerforschung brauchbare Ansätze und lehrreiche Ergebnisse bei der Südosteuropaforschung finden.

Den Aufschwung der Südosteuropa-Forschung nach dem Zweiten Weltkrieg in Europa wie in Nordamerika ist nicht zuletzt den IVirtschafts- und Gesellschaftswissenschaften $z u$ verdanken. Außerdem gehen wesentliche theoretische und methodische Impulse von der verhältnismäßig noch sehr jungen Entwicklungsländer-Forschung aus ${ }^{1}$. Hier bahnt sich zweifelsohne eine gegenseitige Befruchtung an, kann doch gerade die EntwicklungsländerForschung viele vor allem empirisch gewonnene Erkenntnisse der schon älteren Südosteuropa-Forschung für sich nützlich machen. Die südosteuropäischen Staaten und Gesellschaften haben schließlich einen Weg der politischen, wirtschaftlichen und sozialen Entwicklung zurückgelegt, der den meisten Entwicklungsländern noch bevorsteht, nämlich den Weg von der Agrar-zur Industriegesells chaft. Während sich dieser Wandel im Rahmen der Weltwirtschaft, wie diese bis zum Zweiten Weltkrieg beschaffen war, allerdings nur langsam vollzog, ist seither eine merkliche Beschleunigung eingetreten.

1 Franz RONNEBERGER, Südosteuropa auf dem Weg zur Industriegesellschaft. Beitrag 1, a.a. O., S. 2. 


\section{ENTWICKLUNGSMODELLE IN SÜDOSTEUROPA}

Im Vorwort zum ersten Band seines Werkes "Das Kapital" schreibt Karl Marx im Juli 1867, also vor mehr als 100 Jahren, folgenden bemerkenswerten Satz: "Das industriell entwickelte Land zeigt dem minder entwickelten nur das Bild der eigenen Zukunft" ${ }^{2}$ ". Für die Industrialisierung der nach 1944/45 kommunistisch gewordenen Staaten Südosteuropas sollte jedenfalls zunächst die Sowjetunion als Vorbild dienen. Obwohl es in der geschichtlichen Entwicklung, geographischen Größe, natürlichen Ausstattung, ferner in den klimatischen, verkehrsmäßigen, arbeitsmäßigen, gesellschaftsstrukturellen und sonstigen Bedingungen überhaupt keine Ähnlichkeit und Vergleichbarkeit $z w i s c h e n$ der Sowjetunion und den als sozialistisch deklarierten Staaten Südosteuropas gab und gibt, konnte die Sowjetunion zumindest in einer Hinsicht als Vorbild gelten, nämlich: Auch das Sowjetregime hat eine soziale Pyramide vorgefunden, die aus einer breiten Unterschicht von rückständigen Bauernmassen, aus einem bedeutungslosen Mittelstand, aus einer dünnen Oberschicht und aus einer agilen Intelligenz - und Revolutionsschicht bestand. Dabei gehörten der gesellschaftlichen Führungsschicht in den Südoststaaten - im Gegensatz zu Rußland - außer Grundbesitzer zumeist wenig bemittelte, d. h. besitzlose und keineswegs reiche Beamte, Offiziere, Professoren, Rechtsanwälte, Zeitungsredakteure, Schriftsteller u.a. an.

Hier ergibt sich nun die Frage: Hat es vor Kriegsende in Südosteuropa innere Bereitschaft und Voraussetzungen für das sowjetsozialistische Wirtschafts- und Gesellschaftssystem gegeben, und wenn ja, worin fanden diese ihren Ausdruck? Als Agrarländer mit vorwiegend individualistisch eingestelltem Kleinbauerntum, mit nur schwachen Ansätzen von Industrie und organisierter A rbeiterschaft spielte in allen Südoststaaten die Kommunistische Partei zahlenmäßig kaum eine Rolle. Trotzdem war die KP überall verboten und als mit der monarchistischen und demokratischen Staatsform unvereinbar und für illegal erklärt. Dies zwang die KP, in den Untergrund $z u$ gehen. Ihre Aktivität nahm im Verlauf des Krieges und ganz besonders in seinen letzten Phasen bedeutend zu. Auf alle Fälle stand diese Aktivität in umgekehrtem Verhältnis zur Mitgliederzahl. Die Erklärung da für liegt darin, daß die Parteianhänger sich hauptsächlich aus stellungslosen oder schlecht bezahlten Intelligenzlern, aus der Beamtenschaft und aus dem Offizierscorps rekrutierten.

Der nächste Faktor, der die Übertragung des sowjetischen sozialistischen Systems begünstigte, war die Sozialstruktur der Bevölkerung. Abgesehen von gewissen Ausnahmen der sehr dünnen Oberschicht von Industriellen und Großgrundbesitzern in Rumänien und Ungarn, von Kaufleuten und Reedereibesitzern in Griechenland und von traditionell privilegierten

1 Karl MARX, Das Kapital. Berlin (Ost) 1960, Bd. I (9. Aufl.), S. 6 (Vorwort vom 25. Juli 1867 zur 1. Aufl.). 
hohen Beamten und Großgrundbesitzern in der Türkei stellten in allen Südoststaaten das Bauerntum und das mittlere und untere Beamtentum die breite Basis der dortigen Gesellschaften. Es waren also Gesellschaften ohne Mittelklasse oder Mittelstand, wie man ihn im Westen kennt. Nach ihrer politischen Verselbständigung wandten alle Südoststaaten ihre Aufmerksamkeit dem Schulsystem zu. Der Drang der Menschen nach Bildung und Studium an den Universitäten im In- und Ausland führte nach wenigen Jahrzehnten dazu, daß überall aus dem Bauerntum, dem Kleinbürgertum und dem sog. Agrarbürgertum ein akademisches Proletariat heranwuchs. Weil die schwach entwickelte Industrie und die bäuerlich betonte Wirtschaftsstruktur nur wenige Arbeitsplätze für Akademiker bieten konnten, blieb im wesentlichen der Staat als der größte Arbeitgeber für akademische Berufe. Das hatte zur Folge, daß sich mit der Zeit Arbeitslosigkeit, schlechte Bezahlung, Resignation und infolgedessen Abneigung gegenüber dem Staat unter den Menschen mit Hochschul- und Gymnasialbildung ausbreiteten. Die besondere und schwerwiegende Bedeutung dieser Erscheinung liegt aber darin, daß die akademischen Kreise und die Kreise der Intelligenzberufe in Südosteuropa viel mehr zur Bildung der Führungsschicht in Staat und Gesellschaft beitragen als etwa in Mittelund Westeuropa, wo bekanntlich Unternehmertum, Kapitalbesitz und Wirtschaftskreise im breitesten Sinne des Wortes eine wichtige Rolle spielen. So ergab sich eine Ahnlichkeit, wenn auch auf unterschiedlichen Ebenen, zwischen der Lage und den Interessen des Beamtentums und der Intelligenzler auf der einen Seite und des Kleinbauerntums auf der anderen Seite, nämlich Landhunger bei den Bauern und Amtshunger bei der Intelligenz! Das weitgehende Fehlen des Mittelstandes und die sehr dünne Oberschicht boten jedenfalls nur geringe Möglichkeiten für einen sozialen Aufstieg. Die Gesellschaften aller Südoststaaten verbarrten daher in einer bemerkenswerten, mehr oder weniger explosivgeladenen I m mob il it ä $t$.

Die straffen berufsständischen Organisationen, das sich schnell ausbreitende Genossenschaftswesen unter Bauern, Handwerkern und Gewerbetreibenden, im Kleinhandel, in Dienstleistungsbetrieben u.dgl. und die Erinnerung vor allem unter den slawischen Völkern an den alten Familienverband "Zadruga" können - wenn auch mit großem Vorbehalt - als eine gewisse Prädisposition für die Verbreitung des Gedankengutes der sozialen Bewegungen angesehen werden. Hinzu kommt noch der Umstand, daß der Sta $\mathrm{t}$ in Südosteuropa von Anbeginn eine viel größere Rolle im Wirtschaftsleben als etwa in Westeuropa gespielt hat und heute erst recht spielt: Er war und ist nicht nur Träger der allgemeinen Wirtschaftspolitik, sondern zugleich selbst ein wichtiger Unternehmer in: Bergbau, Energieversorgung, Industrie, Bauwesen (Straßen, Eisenbahnen, Versorgungsbetriebe), Bank- und Versicherungswesen, Außenhandel u.a.m.; der Staat galt und gilt ferner als einer der größten $\mathrm{Kr}$ editgeber und ebenso als wichtigster $A$ u f $r$ aggeber für Industrie, Verkehr, Handel und Gewerbe. 
Industrialisieren heißt Investieren. Wenn die Finanzmittel für die Investitionen nicht vom Ausland in Form von Krediten oder Schenkungen zufliessen, dann muß man sie selbst aufbringen, indem man spart, d. h. auf Konsum verzichtet. Es sind zwei Formen des Sparens und Investierens bekannt, nämlich: Zuerst sparen und dann investieren oder aber auch umgekehrt: zuerst investieren und dann sparen. Im ersten Fall werden Fabriken gebaut und mit den Ersparnissen der Väter und Großväter sowie ausländischem Kapital finanziert, im zweiten Fall dagegen erfolgt die Finanzierung mit Mitteln, die durch eigenen Konsumverzicht und durch künftigen Konsumverzicht der Kinder und Enkelkinder aufgebracht werden. Mit anderen Worten: Es wird die Gegenwart für die Zukunft geopfert ${ }^{2}$. Und das war und ist im wesentlichen die Finanzierungsmethode des forcierten industriellen Aufbaus in der Sowjetunion und in allen anderen sozialistischen Staaten, die ihre Wirtschaft nach dem sowjetischen Vorbild aufbauen.

Wie vor dem Kriege, so auch nach dem Kriege und erst recht unter den Vorzeichen des Sozialismus wurde die Landwirtschaft als entscheidender Träger der nationalen Kapitalakkumulation und als Finanzierungsquelle für den Aufbau der Industrie herangezogen. Der angewandte Mechanismus sah folgendermaßen aus: Den landwirtschaftlichen Betrieben wurden Produktions- und Ablieferungspflichten auferlegt. Für die abgelieferten Erzeugnisse erhielten die Bauern ein minimales, oft nur symbolisches Entgelt. Auf diese Weise hatte man zwei wichtige Ziele erreicht. Erstens: Das Geldeinkommen und die Kaufkraft der Landbevölkerung wurden niedrig gehalten und damit bei der herrschenden Güterknappheit den inflationistischen Tendenzen entgegengewirkt. Zweitens: Der Stadtbevölkerung konnten Nahrungsmittel und der Industrie agrarische Rohstoffe $z u$ niedrigen Preisen zur Verfügung gestellt werden. Für den Staat war es somit leicht, durch Gewährung höherer Löhne und einer besseren Versorgung in den Städten und den urbanen Siedlungen die nötigen Arbeitskräfte für ErschlieBungs- und Aufbauarbeiten im Bergbau, in der Industrie, Infrastruktur u. dgl. aus dem Agrarsektor zu rekrutieren. Die Landwirtschaft lieferte damit ebenso billige Nahrungsmittel und Rohstoffe, wie sie auch billige Arbeitskräfte für die forcierte Industrialisierung abgab. Der sozialistische Staat und seine Planungsinstanzen erfüllten ihre Aufgaben dabei in erster Linie mit Hilfe der Lohn- und Einkommenspolitik auf der einen Seite und der Preispolitik für Nahrungsmittel, Verbrauchsgüter, Wohnungsmieten, Dienstleistungen u.dgl. auf der anderen Seite.

Aus der Überlegung heraus, daß die Überführung der privaten bäuerlichen Betriebe in Kollektivwirtschaften zumindest vorübergehend Produktionsausfälle mit sich bringen würde, haben die mittel- und südosteuropäischen Staaten davon abgesehen, die Sozialisierung der Landwirtschaft gleichzeitig mit der Sozialisierung der übrigen Bereiche der Volkswirtschaft voranzutreiben. Als der Industrielle Aufbau bereits angelaufen war, der

1 Michail MANOILESCO, Probleme des Industrialisierungsprozesses in Südosteuropa. In: "Weltwirtschaftliches Archiv", Bd. 61 (1945), H. 1, S. 6. 
Außenhandel intensiviert und die allgemeine Versorgungslage verbessert wurden und für die weitere Industrialisierung neue A rbeitskraftreserven erschlossen werden mußten, wurde auch die Sozialisierung der Landwirtschaft in den meisten Staaten in den fünfziger Jahren eingeleitet und durchgeführt. (Wichtige Ausnahme Jugoslawien, das in dieser Zeit bereits die Kollektivierung rückgängig machte). Die damals eingetretenen Produktionsausfälle und Versorgungsschwierigkeiten beeinträchtigten die gesamte wirtschaftliche Entwicklung und waren mit die Ursache für die Unruhen in der DDR im Juni 1953 und in Polen und Ungarn im Herbst 1956. Hierauf wurde die Kollektivierung in Polen eingestellt und die meisten Kollektivbetriebe aufgelöst.

Dem sowjetischen Beispiel nachahmend, gingen alle sozialistischen Staaten nach dem Kriege zunächst daran, eine eigene Basis für den Aufbau von bodenständigen Industrien zu schaffen. Diese Basis bildeten die Grundstoff- und energetische Industrie sowie die metallschaffende und metallverarbeitende Industrie. Gerade für die Erschließung der Bodenschätze, für den Bau von Staudämmen für Elektrizitätswerke und für Bewässerungszwecke, dann im Straßenbau und für A rbeiten im infrastrukturellen Bereich schlechthin als Grundvoraussetzung für jede Industrialisierung konnten in allen sozialistischen Staaten in kurzer Zeit nach dem Kriege Hunderttausende von Arbeitskräften den ländlichen Gebieten entzogen und an neuen Arbeitsplätzen eingesetzt werden. Dies gilt als Beginn des sich seither vollziehenden Wandels in Wirtschaft und Gesellschaft in den sozialistischen Staaten Ost- und Südosteuropas. Die Vielfalt der vorhandenen und neu geschaffenen Produktionsstrukturen, angefangen bei den stark industrialisierten Volkswirtschaften der DDR und CSSR bis hin zu den ausgesprochenen Agrar- und Rohstoffländern wie Rumänien und Bulgarien und bis zur sowjetischen Großraumwirtschaft mit ihrem Importbedarf an Industriegütern und mit ihrem Exportpotential an Rohstoffen und Primärerzeugnissen, machte es schließlich möglich, daß alle sozialistischen Staaten im Verlauf von zwei Jahrzehnten eine differenzierte Industrie aufbauen und ebenso ihre gegenseitigen wirtschaftlichen Beziehungen intensivieren konnten.

Die wichtigsten Tatbestände und Startbedingungen der Vor- und Nachkriegsentwicklung von Wirtschaft und Gesellschaft in den südosteuropäischen Ländern lassen sich folgendermaßen charakterisieren:

1. Von der Wissenschaft war bereits hinreichend nachgewiesen worden (so u.a. in den entsprechenden Veröffentlichungen von Manoilesco) ${ }^{1}$, in welchem Ausmaß die Produktivität der Arbeit in der traditionellen Landwirtschaft gegenüber der Arbeit in der Industrie - und erst recht

1 Michail MANOILESCO, Die nationalen Produktivkräfte und der Außenhandel. Berlin 1937. - Derselbe, Die sozialökonomische Struktur Südosteuropas. In: "Weltwirtschaftliches A rchiv", Bd. 60 (1944), H. 1/2, S. 1-22. - Derselbe, Probleme des Industrialisierungsprozesses in Südosteuropa, a. a. O. , S. 1-12. 
der Arbeit in der Industrie der entwickelten Länder - unterlegen ist. Diese Unterlegenheit untermauert die These, daß bei den gegebenen Bedingungen der Unterbeschäftigung in der Landwirtschaft und der niedrigen Produktionsleistung je Arbeitskraft dort jeder Entzug von Arbeitskräften aus dem Agrarsektor und ihre Überführung in andere Beschäftigungsbereiche (Industrie, Handel, Verkehr usw.) von volkswirtschaftlichem Nutzen sein kann. In Anbetracht der unzureichenden allgemeinen Organisation und der mangelhaften fachlichen Vorbereitung der von der Landwirtschaft in die Industrie übergeführten Arbeitskräfte kann im ersten Stadium der Industrialisierung freilich keine allzu hohe Arbeitsproduktivität in der Industrie erbracht werden. Solange die Produktivität in den anderen Bereichen der eigenen Volkswirtschaft jedoch höher ist als im Agrarsektor, ebensolange erscheint die besagte Utberführung von A rbeitskräften volkswirtschaftlich und gesamtgesellschaftlich als gerechtfertigt. Es ist eine andere Frage, ob diese Entwicklung beschleunigt, d. h. mit Druckmitteln irgendwelcher Art und ohne Rücksicht auf das psychische und physische Leben der davon betroffenen Menschen und Bevölkerungsgruppen vorangetrieben wird oder ob man sich für einen organischeren Entwicklungsprozess mehr Zeit läßt.

2. Wenn bürgerlich-demokratische Regierungen und liberale marktwirtschaftliche Ordnungsprinzipien versagen, mit den sozialen und ökonomischen Problemen eines Landes fertig $\mathrm{zu}$ werden, dann können an ihre Stelle radikale und revolutionäre Lösungsversuche treten. Diese Wendung kann aus der inneren Dynamik der gesellschaftlichen und politischen Kräfte des betreffenden Landes selbst erwachsen und getragen werden, wie z. B. in der Sow jetunion nach 1917, sie kann aber auch mit fremder Hilfe herbeigeführt werden, wie dies in den kommunistisch gewordenen Staaten Mittel- und Südosteuropas nach dem Zweiten Weltkrieg geschehen ist.

3. Der Drang zur Industrialisierung, zur Befreiung der Menschen aus materieller Not, zur sozialen Gerechtigkeit und zur freien geistigen Entfaltung ist universell und unaufhaltsam. Nur jene Gesellschaftsund Wirtschaftssysteme haben auf die Dauer Chancen auf Erfolg und auf Überleben, wenn sie sich als fähig und als flexibel erweisen, diese Bedürfnisse zu befriedigen. Die Erfahrungen aus der Entwicklung in Wirtschaft und Gesellschaft der südosteuropäischen Länder bis zum Zweiten Weltkrieg, dann aber erst recht nach 1945 lehren dabei hinreichend, daß auf $E$ ing $r$ iffe des $S t a a t e s$, im Sinne einer zielbewußten Konzentration und des Einsatzes der knappen Mittel in Bereichen der Wirtschaft, die eine multiple Wirkung initiieren, nicht verzichtet werden kann. Dies gilt gleichermaßen für die sozialistischen wie für die nichtsozialistischen Staaten.

4. Schablonenhafte und pauschale Übertragung von Maßnahmen, die unter anderen Bedingungen entwickelt worden sind, birgt die Gefahr in sich, 
daß die davon betroffenen Länder und Gesellschaften Rückschläge erleiden, die erhofften Fortschritte nicht erzielen und im internationalen Wettbewerb zurückbleiben. Wie der Fall Südosteuropas zeigt, gingen die Staaten früher (so z. B. Jugoslawien schon Anfang der fünfziger Jahre) oder später (hier z. B. Ungarn seit dem Ende der sechziger Jahre) dazu über, die von außen übernommenen Prinzipien und Methoden zu modulieren und zu reformieren, kurzum, sie den eigenen bodenständigen, kulturellen, sozialen und wirtschaftlichen Gegebenheiten und Möglichkeiten anzupassen, um dadurch eine höhere Effizienz ihrer ökonomischen Leistung zu erlangen und schneller in ihrer gesamtgesellschaftlichen Entwicklung voranzuschreiten.

5. Die weitere unbestrittene Erkenntnis lautet: Die kleinbäuerlich betonten, finanzschwachen, potential- und marktmäßig kleinen Volkswirtschaften können eine eigene Industrie, eine Industrie also, die geeignet ist, das Bevölkerungs- und Beschäftigungsproblem auf die Dauer zu lösen, nur dann schaffen, wenn die Industrialisierung in einem entsprechend erweiterten internationalen Rahmen - und wenn nicht im Rahmen der Weltwirtschaft, dann zumindest in Anlehnung an eine entwicklungsfähige und sich formierende und verfestigende internationale Integrationsgemeinschaft - vorangetrieben wird. Die Bedeutung des Marktes von Österreich-Ungarn vor dem Ersten Weltkrieg und des deutschen Marktes zwischen den Kriegen, aber auch die Erfahrungen mit der WVeltwirtschaftskrise der dreißiger Jahre haben die Südost staaten gelehrt, daß sie vor allem dann Aussicht auf wirtschaftliche Prosperität haben, wenn ihre Volkswirtschaften in eine entsprechende internationale Zusammenarbeit und in einen international großräumigen Markt einbezogen und gegenüber der Einwirkung der spontanen Kräfte der Weltwirtschaft weitgehend geschützt werden. Ohne die Einbettung in größere, übernationale Integrationsgemeinschaften und - räume und ohne die Intensivierung des Außenhandels und überhaupt des gesamten Wirtschaftsverkehrs mit dem Ausland und mit der Weltwirtschaft ist heute kein Land in der Lage, seine sozialökonomischen Probleme im Alleingang zu lösen, nicht einmal das bevölkerungsreichste Land der Welt, China. Ohne materielle, finanzielle, wissenschaftliche und technische Hilfe des A uslands und ohne eine allgemein zielgerichtete Orientierung der politisch und wirtschaftlich führenden Staaten sind infolgedessen die kleinen Länder nicht im Stande, ihre Wirtschaft kontinuierlich aufzubauen und $z u$ entwickeln. Der Wandel von der Agrar-zur Industriegesellschaft in den südosteuropäischen Ländern vollzieht sich auch entsprechend in den zwei heute in Europa vorherrschenden Integrationsgemeinschaften: im Rat für Gegenseitige Wirtschaftshilfe (RGW) und in der Europäischen Wirtschafts-Gemeinschaft (EWG). Dabei spielt - abgesehen vom Sonderfall Jugoslawien - der Ausbau der Handels - und Wirtschaftsbeziehungen unter den Ländern mit unterschiedlichen Wirtschafts- und Gesellschaftssystemen eine immer größere Rolle, wie unten noch gezeigt wird. 
6. Die inneren und äußeren Bedingungen, unter denen sich die wirtschaftliche Entwicklung in den sozialistischen und in den marktwirtschaftlichen Ländern Südosteuropas vollzieht, sind zwar grundverschieden, doch die Ausdrucksform des damit einhergehenden sozialökonomischen Wandels sind hier wie dort mehr oder weniger dieselben, und diese heißen: Industrialisierung, Urbanisierung, Abschütteln der traditionell überlieferten und Übergang zu neuen Lebensformen mit allen ihren gesellschaftspolitischen Begleiterscheinungen und Artikulationen. Agilität und Mobilität der Jugend, Verlangen nach Schule und sozialem Aufstieg, nach persönlicher Freiheit, nach materiellem Wohlstand, nach sozialer Sicherheit und überhaupt nach Teilnahme an den zivilisatorischen Errungenschaften der industriell entwickelten Länder sind Erscheinungen, die gleichermaßen für Ungarn wie für die Türkei zutreffen.

\section{WANDEL VON DER AGRAR- ZUR INDUSTRIEGESELLSCHAFT}

\section{a. Entwicklung der Bevölkerung}

Industrialisierung, Urbanisierung und sozialer Wandel bedingen einander gegenseitig und gehen auch in Südosteuropa wie überall in der Welt Hand in Hand miteinander. Die genannten Wechselbeziehungen sind dabei in der Nachkriegsentwicklung der sozialistischen wie der nichtsozialistischen Staaten Südosteuropas besonders deutlich in Erscheinung getreten. Als Ursachen dafür können $u$. a. genannt werden: Die dortigen Gesellschaften verharrten bis dahin mehr oder weniger in statischen Strukturen und zeichneten sich durch eine explosivgeladene Immobilität aus; die forcierte Industrialisierung insbesondere in den kommunistisch gewordenen sowjetorientierten Staaten, aber auch der weniger radikale Industrialisierungsprozess in Griechenland und der Türkei öffneten dann sozusagen die gestauten Dämme, so daß der seither eingetretene gesamtgesellschaftliche und ökonomische Wandel ebenso hektisch wie tiefgreifend vor sich gegangen ist und diese Entwicklung weiterhin anhält. Es versteht sich, daß von einem derartigen Umbruch alle Bereiche des Lebens der Menschen und ihrer gesellschaftlichen Formationen betroffen werden.

Wie die meisten kleinbäuerlichen Agrarländer mit traditionellen Anbauund Produktionsmethoden, mit schwach entwickelter Technik und mit niedrigem Pro-Kopf-Einkommen, so zeichneten sich auch die Südostländer in den vergangenen Jahrzehnten durch hohe Geburtenquoten der Bevölkerung aus. Der noch niedrige allgemeine zivilisatorische Stand, gepaart mit Armut und Unwissen unter den breiten Bevölkerungsmassen, unzureichende Gesundheitsfürsorge $u$. dgl. mehr hatten zumindest bis in die ersten Nachkriegsjahre hinein auch eine relativ hohe Sterblichkeitsquote zur Folge. Dies gilt insbesondere für die Sterblichkeit 
unter den Neugeborenen und unter den Kindern im ersten Lebensjahr, also für die sog. Säuglingssterblichkeit. Auf diese Weise hielt sich die natürliche Vermehrungsquote noch in Grenzen. Inzwischen ist bis af die Türkei und Albảnien überall die Geburtenzahl erheblich zurückgegangen. Durch die erfolgreiche Bekämpfung gerade der Säuglingssterblichkeit nach dem Zweiten Weltkrieg konnte die zurückgehende Geburtenhäufigkeit jedoch aufgefangen und dadurch weiterhin eine normale Vermehrungsquote aufrechterhalten werden (siehe Tab. 7). Mit Ausnahme der Türkei, deren Wachstumsrate auch in den achtziger Jahren kaum unter 2, $5 \mathrm{vH}$ sinken dürfte, und Albanien für das sogar eine Wachstumsrate von 2, $8 \mathrm{vH}$ geschätzt wird (1980/85), liegen die anderen Länder auf dem allgemeinen europäischen Niveau: Jugoslawien $(0,9 \mathrm{vH})$, Rumänien $(0,8 \mathrm{vH})$, Bulgarien $(0,5 \mathrm{vH})$, Griechenland $(0,5 \mathrm{vH})$ und Ungarn $(0,4 \mathrm{vH})$ (Tab. 7). Im Vergleich dazu: Die Wachstumsrate für 1980/85 wird für die Bundesrepublik Deutschland auf $0,4 \mathrm{vH}$, für Frankreich auf $0,8 \mathrm{vH}$, für Großbritannien auf $0,8 \mathrm{vH}$, für die UdSSR auf $1,2 \mathrm{vH}$ und für die USA auf $1,4 \mathrm{vH}$ geschätzt.

Untersucht man die Entwicklung der Bevölkerung in den südosteuropäischen Ländern im Zeitraum von 1938 bis 1985 , dann zeigt sich folgendes Bild (siehe auch Tab. 3, 4, 5 und 6 in der statistischen Analyse):

Zuwachs der Eevölkerung in den südcsteuropäischen Ländern 1938 - 1985 (in 1000 Personen im Jahresdurchschnitt)

\begin{tabular}{|l|c|c|c|}
\hline & Südosteuropa ohne Türkei & \multicolumn{1}{c|}{ Türkei } & \multicolumn{1}{c|}{ Südosteuropa insges. } \\
\cline { 2 - 4 } $1938 / 1950$ & 287,3 & 327,6 & 614,9 \\
$1950 / 1960$ & 660,8 & 656,2 & 1317,0 \\
$1960 / 1970$ & 588,6 & 805,4 & 1394,0 \\
$1970 / 1980^{2}$ & 702,4 & 1096,4 & 1798,8 \\
$1980 / 1985^{\mathrm{a}}$ & 613,6 & 1264,6 & 1878,2 \\
a Schätzung & & & \\
\hline
\end{tabular}

Wie ersichtlich, ist bis 1985 eher mit einem zunehmenden als mit einem abnehmenden absoluten jährlichen Wachstum der Bevölkerung Südosteuropas als Ganzes zu rechnen. Allerdings wird dieses Ergebnis in besonderem Maße von der zu erwartenden Entwicklung der Bevölkerung in der Türkei mitbestimmt, wo Geburtenhäufigkeit, Sterblichkeit und Vermehrungsquote am höchsten sind (Tab. 4 und 7). Betrachtet man die übrigen (kontinentalen) südosteuropäischen Länder und die Türkei getrennt, dann ergeben sich für die Entwicklung der Bevölkerung bis 1985 nach den Schätzungen der UN folgende Zahlen. 
Zunahme der Bevölkerung in den südosteuropäischen Ländern 1938 - 1985 (in 1000 Personen)

\begin{tabular}{|c|c|c|c|}
\hline & $\begin{array}{l}\text { Südosteuropa } \\
\text { ohne Türkei }\end{array}$ & Türkei & $\begin{array}{c}\text { Südosteuropa } \\
\text { insges. }\end{array}$ \\
\hline Zeitraum 1938-1950 & +3448 & +3931 & +7379 \\
\hline Zeitraum 1950-1970 & +12742 & +14616 & +27358 \\
\hline Zeitraum 1970-1980 & +9844 & +17287 & +27131 \\
\hline $\begin{array}{l}\text { Zeitraum 1950-1985 } \\
{ }^{a} \text { Schätzung }\end{array}$ & +22586 & +31903 & +54489 \\
\hline
\end{tabular}

Von der biologischen Seite her gesehen, wird also in dem nächsten Jahrzehnt, und zwar bis 1985 in den kontinentalen südosteuropäischen Ländern mit einem etwas geringeren, in der Türkei jedoch mit einem größeren natürlichen Zuwachs der Bevölkerung als bisher gerechnet. Dadurch jedoch, daß in den siebziger und in den achtziger Jahren die geburtenstarken Jahrgänge der fünfziger und der sechziger Jahre in das berufsfähige Alter eintreten, dürfte die Zahl der Arbeitskräfte in den meisten Ländern entweder noch stärker als bisher oder zumindest nicht schwächer als bisher ansteigen.

Was die Altersstruktur der Bevölkerung anbetriff,, so erfreuen sich nämlich bis auf Ungarn alle Südoststaaten eines verhältnismäßig hohen Anteils der jungen Generation (unter 20 Jahren) und eines niedrigen Anteils der alten Generation (über 65 Jahre) an der Gesamtbevölkerung. Hier steht wiederum (Zahlen für 1965-1968) die Tü rkei an der Spitze mit einem Anteil der Altersgruppe 19 Jahre und darunter von 51 vH (und der Altersgruppe 65 Jahre und darüber von 4,1 vH), gefolgt von: Jugoslawien mit 38,2 vH (bzw. 7,2 vH); Rumänien mit 34,9 vH (bzw. 8, 3 vH); Griechenland mit 33,1 vH (bzw. 9,6 vH) und Bulgarien mit $31,5 \mathrm{vH}$ (bzw. $9,1 \mathrm{vH})$; Ungarn weist hingegen mit 30,4 vH (bzw. 11,1 vH) eine Altersstruktur auf, die sich nur unwesentlich von der Altersstruktur z. B. der Bundesrepublik Deutschland mit 30,3 vH (bzw. 12,5 vH) unterscheidet (Siehe Tab. 3 der Statistischen Analyse). Auf alle Fälle versprechen die heutigen Arbeitskraftüberschußländer Südosteuropas: Türkei, Griechenland, Jugoslawien und Rumänien, auch künftig ein wichtiges Arbeits k räftereservoir zubleiben. Weil in den nächsten Jahrzehnten mit einer schärferen Verknappung der Arbeitskräfte in Westeuropa gerechnet werden muß - nicht zuletzt als Folge des teilweise sinkenden Zustroms von Arbeitskräften aus den eigenen jungen Jahrgängen -, können die Arbeitskraftreserven in Südosteuropa um so mehr an Bedeutung für Gesamteuropa gewinnen. 


\section{b. Sozialstruktur und Arbeitskräftepotential}

Außer durch die natürliche Vermehrung der Bevölkerung wächst das Arbeitskräftevolumen der südosteuropäischen Volkswirtschaften noch durch die Freisetzung von Arbeitskräften aus der Landwirtschaft und deren Überführung in die Industrie und in andere Beschäftigungsbereiche sowie durch die Mobilisierung der Frauenarbeit. Damit ist die mit der Industrialisierung einhergehende sog. 'Entagrarisierung' des wirtschaftlichen und des gesamtgesellschaftlichen Lebens und überhaupt der all $\mathbf{g e m e i n e}$ zivilisatorische Prozeß der Urbanisierung und der Vollbeschäftigung der männlichen und weiblichen Arbeits$k r$ äf e angesprochen worden.

Der Drang insbesondere unter den jungen Menschen, vom Dorf in die Stadt zu ziehen und damit der Enge und den verfestigt en Strukturen des Dorflebens zu entkommen, ist gerade in Südosteuropa schon immer sehr stark gewesen. Der Ruf der früheren Jahrhunderte "Stadtluft macht frei" galt für Südosteuropa bis in die jüngste Zeit hinein, und er gilt auch heute noch, einerlei, ob es sich um Länder mit kollektivierter Landwirtschaft (Ungarn, Rumänien, Bulgarien, Albanien) oder mit privater bäuerlicher Landwirtschaft (Jugoslawien, Griechenland, Türkei) handelt. Der Mangel an Beschäftigungsmöglichkeiten außerhalb der kleinbäuerlichen, mit Menschen überfüllten Betriebe hat eine Massenabwanderung vom flachen Land in die Städte bis zum Ausgang des Zweiten Weltkriegs verhindert. Die traditionellen Strukturen in Wirtschaft und Gesellschaft konnten sich auf diese Weise über lange Zeit halten. Mit der Verkündung der ersten Industrialisierungspläne in den kommunistischen Staaten und erst recht mit der Kollektivierung der Landwirtschaft trat dann aber um so stürmischer die Urbanisierungswelle ein, die auch heute noch anhält und mit deren $A b-$ flauen erst nach den achtziger Jahren zu rechnen ist. Um welche Größenordnungen es sich handelt, veranschaulichen folgende Zahlen:

Veränderung (+ = Zunahme; - = Abnahme) der Stadt- und Landbevölkerung in Südosteuropa 1950-1985'

\begin{tabular}{|l|c|c|c|r|}
\hline \multirow{2}{*}{ Zeitraum } & \multicolumn{2}{|c|}{$\begin{array}{c}\text { Südosteuropa } \\
\text { (ohne Türkei) }\end{array}$} & \multicolumn{2}{c|}{ Türkei } \\
\hline & Stadt & Land & Stadt & Land \\
\cline { 2 - 5 } $1950-1960$ & $+3,37$ & $+3,25$ & $+4,7$ & $+1,9$ \\
$1960-1970$ & $+8,0$ & $-1,86$ & $+4,4$ & $+3,7$ \\
$1970-1980^{\mathrm{a}}$ & $+9,43$ & $-2,65$ & $+6,6$ & $+4,3$ \\
$1980-1985^{\mathrm{a}}$ & $+5,0$ & $-1,95$ & $+4,2$ & $+2,1$ \\
$1950-1985^{\mathrm{a}}$ & $+25,80$ & $-3,21$ & $+19,9$ & $+12,0$ \\
${ }^{2}$ Geschätzt & & & & \\
\hline
\end{tabular}

1 Quelle: Siehe Tabellen 4 bis 7 der Statistischen Analyse. 
Demnach steht die höchste Intensität der Urbanisierungswelle in Südosteuropa noch bevor: Im Zeitraum 1970 - 1985 wird in den kontinentalen Ländern mit einer jährlichen Zunahme der städtischen Bevölkerung um rd. 1 Mill. Menschen (oder insgesamt um 14,43 Mill.) und in der Türkei um 0,7 Mill. (oder um 10,8 Mill) gerechnet. Der Anteil der Stadtbevölkerung an der Gesamtbevölkerung wird sich bis 1985 auf diese Weise bei den kontinentalen Südoststaaten auf über $50 \mathrm{vH}$ (bei Bulgarien sogar auf $67,5 \mathrm{vH}$ ) erhöhen, gegenüber 30 bis $40 \mathrm{vH}$ im Jahre 1960 und von 20 bis $30 \mathrm{vH}$ vor dem Zweiten Weltkrieg (siehe Tabellen 5 und 9 der Statistischen Analyse). Damit erhielten die Südoststaaten im Verlauf von wenigen Jahrzehnten eine teilweise stark prononcierte urbane Struktur. Als komplementäre Hauptursachen dafür können u. a. genannt werden: die hohe Geburten- und Vermehrungsquote der Stadtbevölkerung selbst, der starke Zustrom vor allem von jungen Menschen vom flachen Land und sodann die von allen Staaten betriebene Industrialisierungspolitik.

Die im Zuge der Industrialisierung eingetretene Wanderbewegung insbesondere junger Menschen vom flachen Land in die Städte und in die Industriezentren brachte eine Verjüngung der Stadtbevölkerung und die Überalterung der Dorfbevölkerung mit sich. Dies führte zum paradoxen Zustand, daß die Vermehrungsquote der Stadtbevölkerung oft höher liegt als jene der Dorfbevölkerung. Bessere gesundheitliche Fürsorge in den Städten und die niedrigere Kindersterblichkeit dort haben freilich wesentlich zur erwähnten Erscheinung beigetragen. Die geburtenstarken Jahrgänge der ersten anderthalb Dezennien nach dem Kriege werden in den achtziger Jahren, wenn die Jahrgänge in das heiratsfähige Alter eintreten, zu einem erneuten starken Bevölkerungszuwachs führen. Mit zunehmender Verstädterung wird die natürliche Vermehrungsquote auf lange Sicht in ganz Südosteuropa abnehmen.

Wie sehr übrigens die biologische Entwicklung der Bevölkerung und damit der Nachwuchs von Arbeitskräften von der ökonomisch-sozialen Lebensweise abhängen, veranschaulichen einige Zahlen für Bulgarien, als ein typisch sozialistisches Land mit forcierter Industrialisierung und mit gänzlich kollektivierter Landwirtschaft: 
Biologisch-soziale Entwicklung der Stadt- und Dorfbevölkerung in Bulgarien ${ }^{1}$

a) Anteil der Stadtbevölkerung an der Gesamtbevölkerung (in vH)

$\begin{array}{llllll}1910 & 1940 & 1945 & 1955^{\mathrm{a}} & 1970 & 1985 \\ 19,1 & 23,0 & 24,4 & 32,1 & 53,0 & 67,5\end{array}$

b) Kindersterblichkeit (gestorbene Kinder im Alter unter 1 Jahr auf 1000 Geburten)

$\begin{array}{lrrr} & 1940 & 1955^{2} & 1970 \\ \text { In den Städten } & 112 & 61 & 19 \\ \text { In den Dörfern } & 141 & 91 & 28 \\ \text { Bulgarien insgesamt } & 136 & 82 & 23\end{array}$

c) Natürliche Vermehrung (mehr Lebendgeburten als Sterbefälle auf 1000 Einwohner)

$\begin{array}{lrrr} & 1940 & 1955^{\mathrm{a}} & 1970 \\ \text { In den Städten } & 4,1 & 11,5 & 11,0 \\ \text { In den Dörfern } & 10,1 & 10,9 & 3,2 \\ \text { Bulgarien insgesamt } & 8,8 & 11,1 & 7,2\end{array}$

d) Von den geborenen Kindern sind drittes Kind und mehr (in vH)

$\begin{array}{lccc} & 1906 / 10 & 1936 / 40 & 1970 \\ \text { In den Städten } & 56,1 & 33,7 & 10,8 \\ \text { In den Dörfern } & 61,5 & 47,4 & 27,6 \\ \text { Bulgarien insgesamt } & 60,8 & 45,1 & 17,8\end{array}$

${ }^{a}$ Nach 1955 erfolgte die Kollektivierung der Landwirtschaft.

\footnotetext{
1 Quelle: Statističeski godišnik na Carstvo Bălgaria 1941, S. 86 ff. Statističeski godišnik náx NR Bălgaria 1971, S. 16 ff.
} 
A usschlaggebend für den Zustrom von Menschen vom flachen Land in die Städte ist letztlich die betriebene Politik zur Industrialisierung und zur Schaffung von Arbeitsplätzen außerhalb des Agrarsektors. Bei den sozialistischen Staaten spielte und spielt in diesem Zusammenhang die ungeheuere Aufblähung des bürokratischen und parteipolitischen Apparates eine wesentliche Rolle. Hierin spiegelt sich der allgemeine Wandel von der Agrar- zur Industriegesellschaft am deutlichsten wider. In den zwanziger Jahren von 1950 bis 1970 hat sich die Zahl der Beschäftigten in Südosteuropa folgendermaßen erhöht:

Zahl der Beschäftigten (ohne Agrarsektor) in Südosteuropa 1950 und $1970^{1}$ (in Mill.)

\begin{tabular}{|l|c|c|c|c|}
\hline & 1950 & 1970 & Zunahme & $\begin{array}{c}\text { Index 1970 } \\
(1950=100)\end{array}$ \\
\cline { 2 - 5 } $\begin{array}{l}\text { Bergbau, Industrie, } \\
\text { Bauwirtschaft }\end{array}$ & 4,74 & 10,58 & 5,84 & 223 \\
Andere Bereiche & 4,50 & 9,93 & 5,43 & 221 \\
Beschäftigte insges. & 9,24 & 20,51 & 11,27 & 222 \\
\hline
\end{tabular}

Mit anderen Worten: die Schaffung eines neuen Arbeitsplatzes in der unmittelbaren materiellen Güterproduktion, also im Bergbau, in der Industrie und in der Bauwirtschaft, zog mit sich die Schaffung eines weiteren A rbeitsplatzes in allen übrigen Beschäftigungsbereichen, sei es, daß sie unmittelbar zur materiellen Güterproduktion gerechnet werden können, wie z. B. Handel und Verkehr, oder daß sie zum öffentlichen, kulturellen und allgemeinen Dienstleistungs- und Betreuungsbereich im weitesten Sinne des Wortes zählen. Auf alle Fälle, die Neueinstellung von 11,27 Mill. A rbeitskräften und damit mehr als der Verdoppelung der Zahl der nichtagrarisch Beschäftigten in Südosteuropa im Verlauf von zwanzig Jahren, markieren wohl den bisher größten sozial-ökonomischen Wandlungsprozess in der Wirtschaftsgeschichte dieser Staaten.

Bis auf Griechenland kann bei allen anderen Südoststaaten von einem stellenweise hektischen industriellen Umbruch gesprochen werden. Dies veranschaulichen folgende Übersichten:

1 Quelle: Siehe Tabelle 11 der Statistischen Analyse. 
Neugeschaffene Arbeitsplätze außerhalb des Agrarsektors in den südosteuropäischen Ländern im Zeitraum von 1950 bis $1970^{1}$

\begin{tabular}{|c|c|c|c|c|}
\hline \multirow[t]{2}{*}{ Land } & \multicolumn{2}{|c|}{$\begin{array}{l}\text { Neugeschaffene } \\
\text { Arbeitsplätze } \\
(\text { in } 1000)\end{array}$} & \multicolumn{2}{|c|}{$\begin{array}{r}\text { Index } 1970 \\
(1950=100)\end{array}$} \\
\hline & Insgesamt & $\begin{array}{c}\text { davon } \\
\text { Industrie }\end{array}$ & Insgesamt & $\begin{array}{c}\text { davon } \\
\text { Industrie }\end{array}$ \\
\hline 1. Albanien ${ }^{a}$ & 0,23 & 0,11 & 388 & 375 \\
\hline 2. Bulgarien & 1,71 & 1,04 & 325 & 350 \\
\hline 3. Rumänien & 2,77 & 1,76 & 246 & 278 \\
\hline 4. Ungarn & 1,88 & 1,19 & 232 & 244 \\
\hline 5. Jugoslawien & 1,73 & $0,74^{b}$ & 195 & 170 \\
\hline 1-5 insgesamt & 8,32 & 4,84 & 239 & 242 \\
\hline 6. Griechenland & 0,45 & 0,3 & 130 & 160 \\
\hline 7. Türkei & 2,50 & 0,7 & 238 & 178 \\
\hline $1-7$ insgesamt & 11,27 & 5,84 & 222 & 223 \\
\hline
\end{tabular}

Struktur der Erwerbsbevölkerung der südosteuropäischen Länder 1950 und 1970 (in $\mathrm{vH})^{2}$

\begin{tabular}{|c|c|c|c|c|}
\hline \multirow[b]{3}{*}{ Albanien } & \multicolumn{2}{|c|}{$\begin{array}{l}\text { Landwirtschaft, } \\
\text { Forstwirtschaft }\end{array}$} & \multicolumn{2}{|c|}{$\begin{array}{l}\text { Gewerbliche Wirtschaft } \\
\text { und andere Bereiche }\end{array}$} \\
\hline & 1950 & 1970 & 1950 & 1970 \\
\hline & 85,0 & $66,5^{a}$ & 15,0 & $33,5^{a}$ \\
\hline Bulgarien & 79,5 & 35,8 & 20,5 & 64,2 \\
\hline Rumänien & 74,3 & 49,3 & 25,7 & 50,7 \\
\hline Ungarn & 50,6 & 26,2 & 49,4 & 73,8 \\
\hline Jugoslawien & $66,8^{b}$ & $53,0^{c}$ & $33,2^{b}$ & $47,0^{c}$ \\
\hline Griechenland & $48,2^{d}$ & $52,0^{c}$ & $51,8^{d}$ & $48,0^{c}$ \\
\hline Türkei & 85,7 & $71,8^{c}$ & 14,3 & $28,2^{c}$ \\
\hline
\end{tabular}

1 Quelle: Siehe Tabelle 11 der Statistischen Analyse.

2 Quelle: Siehe Tabelle 9 der Statistischen Analyse. 
Die Länder Ungarn und Bulgarien befinden sich somit auf dem Wege, bereits Indust $r$ i $-A g r a r-S t a a t e n z u$ werden, gefolgt mit Abstand von Rumänien. In Jugoslawien und in Griechenland lebt nach wie vor über die Hälfte der Bevölkerung von der Landwirtschaft, doch durch den Ausbau des Tourismus und durch die Beschäftigung von A rbeitskräften im Ausland wandelt sich auch in diesen Ländern die sozial-ökonomische Struktur zusehends. In Griechenland spielt zudem die Beschäftigung in Schiffahrt, Hafendienste, Kleinhandel und Kleingewerbe traditionsgemäß eine wichtige Rolle. Nur Albanien und die Türkei gelten noch als agrarisch stark betonte Volkswirtschaften. Es muß jedoch als eine beachtliche Leistung registriert werden, daß in der Türkei von 1950 bis $1970 \mathrm{immerhin} \mathrm{2,5}$ Mill. Arbeitsplätze außerhalb des Agrarsektors geschaffen worden sind. In Anbetracht der Vermehrung der Bevölkerung in dieser Zeit um 14,6 Mill. Menschen bedeutet dies allerdings noch nicht einmal den berühmten Tropfen auf dem heißen Stein. Dafür kann die Türkei auf der anderen Seite als ein potentielles A rbeitskräftereservoir von gesamteuropäischem Interesse angesehen werden, ist doch damit zu rechnen, daß in den folgenden fünfzehn Jahren von 1970 bis 1985 die Einwohnerzahl um weitere 17, 2 Mill. Menschen (von 35,6 Mill. auf 52,8 Mill.) anwachsen wird, und weist doch die türkische Bevölkerung heute mit einem Anteil der Altersgruppe bis zu 20 Jahren von $51 \mathrm{vH}$ (siehe Tabelle 3 der Statistischen Analyse) die jüngste Altersstruktur in Europa auf.

Bei dem, wie oben gezeigt, verhältnismäßig noch hohen Anteil der Erwerbstätigen in der Landwirtschaft an der Gesamtzahl der Erwerbstätigen und in Anbetracht der vielerorts vorhandenen Überbelegung der gewerblichen Betriebe und des Verwaltungs- und Parteiapparates mit A rbeitskräften, ferner bei Berücksichtigung der Arbeitslosigkeit und der Teilbeschäftigung unter der ländlichen wie unter der städtischen Bevölkerung, stecken jedoch nicht nur in der Türkei, sondern in ganz Südosteuropa noch beachtlich e erschließbare Arbeitskraftreserven. Wurde man auch fur Südosteuropa einen Anteil der Agrarbeschäftigung von 20 bis 30 vH und für die Türkei von $50 \mathrm{vH}$ ansetzen, dann könnte die südosteuropäische Landwirtschaft im Verlauf der nächsten Jahrzehnte und mit dem Ablösen der Generationen 7 bis $10 \mathrm{Mill}$. Arbeitskräfte abgeben, davon 4 bis $6 \mathrm{Mill}$. in den kontinentalen Ländern und 3 bis $4 \mathrm{Mill}$. in der Türkei. Rechnet man hinzu noch die zu erwartende Vermehrung der Bevölkerung bzw. Erhöhung der Zahl der Arbeitskräfte um

rd. $10 \mathrm{Mill}$. bzw. $5 \mathrm{Mill}$. und

rd. 17 Mill. bzw. 7 - 8 Mill. in der Türkei,

dann lassen in den nächsten 15 bis 20 Jahren

7 bis 10 Mill. Arbeitskräfte in den kontinentalen Ländern

und 5 bis 7 Mill. Arbeitskräfte in der Türkei ihren Einsatz und ihre Überführung in Beschäftigungsbereichen außerhalb des Agrarsektors erwarten. 
Die Lösung dieser gewaltigen Aufgabe können die Südoststaaten weiterhin wie in den letzten Jahren auf zwei Wegen gleichzeitig anstreben, nämlich: durch Aufbau von Industrien, d. h. durch Schaffung von neuen Arbeitsplätzen in den jeweiligen Volkswirtschaften und $\mathrm{durch} B$ eschäftigung von A rbeitskräften im A usland.

Was die Beschäftigung von Arbeitskräften aus Südosteuropa im Ausland anbetrift, so gilt die Bundesrepublik Deutschland als der bei weitem wichtigste westliche Arbeitgeber. Von den 930000 in Westeuropa beschäftigten Gastarbeitern aus Jugoslawien, der Türkei und Griechenland im Jahre 1969 entfielen 700000 oder 75 vH auf die Bundesrepublik Deutschland1. Bei einem Anstieg der Gastarbeiter in der Bundesrepublik von 1967 bis 1971 :

aus Südosteuropa von aus anderen Ländern von

aus allen Ländern von
367000 auf 1200 000; Zunahme um $227 \mathrm{vH}$ 624000 auf 1041000 ; Zunahme um $67 \mathrm{vH}$

ist auch der Anteil Südosteuropas an der Gesamtzahl der Gastarbeiter von $37 \mathrm{vH}(1967)$ auf 53,6 vH (1971) gestiegen (siehe Tabelle 16 der Statistischen Analyse). In Anbetracht der Verbesserung der Beschäftigungslage und der Verknappung des Arbeitskräfteüberschusses in Italien, Spanien und Portugal und bei einem Anhalten der Konjunktur in den westeuropäischen Industrieländern dürfte der weitere Zustrom von Gastarbeitern aus Jugoslawien, der Türkei und Griechenland, und neuerdings, wenn auch unter anderen Vorzeichen und in beschränktem Umfang, auch aus Rumänien (Ủbernahme von Bauaufträgen in der Bundesrepublik), an Bedeutung zunehmen.

Unbesehen der politischen Verhältnisse kommen die anderen drei Südoststaaten Ungarn, Bulgarien und Albanien dagegen als Gastarbeiter-Ursprungsländer für Westeuropa kaum in nennenswertem Umfang in Betracht. Es ist zwar damit zu rechnen, da $\beta$ aus dem Agrarsektor aller drei Länder weiterhin, allerdings schwächer als bisher, Arbeitskräfte freigesetzt werden; auch der Zustrom von Arbeitskräften aus der natürlichen Vermehrung der Bevölkerung dürfte wohl unverändert und wie bisher bleiben. Doch macht sich bereits heute insbesondere in Ungarn, aber auch in Bulgarien, die Knappheit an Arbeitskräften, zumindest in einigen Beschäftigungsbereichen, bemerkbar. Dies gilt zuallererst für die Bauwirtschaft. Zudem werden Gastarbeiter aus Ungarn vor allem in der DDR (Anfang 1972: rd. 10 000) und aus Bulgarien in der Sowjetunion und $z$. $T$. in der Tschechoslowakei beschäftigt. Nach einem Abkommen vom Februar 1972 sollen in Bulgarien sogar 10000 ägyptische Bauarbeiter eingesetzt werden; die bulgarische Gegenleistung besteht aus einem langfristigen Kredit von $40 \mathrm{Mill}$. Dollar für den Bau einer Anzahl von Industrieprojekten u. a. auch mit Hilfe von bulgarischen Technikern. Damit macht sich zum ersten Mal auch für die sozialistischen Staaten das Nord-Süd-Gefälle in der wirt-

1 Council for Europe. Report on the demographic and social pattern of migrants in Europe. Strasbourg 1971 (CDE 71, T. IV), S. 7. 
schaftlichen Entwicklung und das Süd-Nord-Gefälle in der Wanderbewegung von Arbeitskräften bemerkbar.

Im Gegensatz zu den Überlegungen, die zu Beginn des Zweiten Weltkrieges in Deutschland bestanden, Gastarbeiter aus Südosteuropa in erster Linie im Tiefbau (dazu hat man wohl auch Straßenbau und Bergbau gerechnet) und im begrenzten Umfang auch in der Landwirtschaft einzusetzen, weist die Branchenstruktur der heute in der Bundesrepublik beschäftigten Gastarbeiter aus Südosteuropa folgendes Bild auf:

Gastarbeiter aus Südosteuropa in der Bundesrepublik Deutschland nach Beschäftigungsbereichen Stand: 30. September $1971^{1}$

\begin{tabular}{|l|rc|}
\hline & \multicolumn{1}{|c|}{ Personen } & vH \\
\cline { 2 - 3 } 1. Landwirtschaft, Gartenbau, & & \\
Forstwirtschaft, Fischerei & 9122 & 0,8 \\
2. Bergbau, Baugewerbe & 283500 & 23,6 \\
3. Industrie & 754385 & 62,9 \\
4. Dienstleistungen & 153112 & 12,7 \\
1-4 Alle Bereiche insgesamt & 1200119 & 100,0 \\
\hline
\end{tabular}

Gerade durch den hohen Anteil und die Schulung der beschäftigten Gastarbeiter in der Industrie der Bundesrepublik, dann aber auch durch den Geldtransfer in die Heimatländer erfahren die Industrialisierungsbestrebungen in den entsprechenden Südoststaaten wichtige Impulse: Es werden qualifiziertere Arbeitskräfte für die eigene Industrie herangebildet; der Geldtransfer ermöglicht den Heimatländern zusätzliche Importe aus dem Westen, nicht zuletzt auch an Ausrüstungen für Ausbau und Modernisierung der Industrie in Südosteuropa ${ }^{2}$.

\section{SÜDOSTEUROPA IN DER WELTWIRTSCHAFT}

Seit ihrer politischen Verselbständigung sind die südosteuropäischen Staaten an allseitiger $Z$ usa $m$ menarbit $m i t$ de $m$ A usland interessiert und darauf angewiesen gewesen. Gerade für den Aufbau von bodenständigen Industrien, für die Ausstattung der Volkswirtschaften mit technischen Einrichtungen aller Art, darunter vor allem mit Nachrichten- und Verkehrsmitteln, dann für die Belieferung der Bevölkerung mit industriel-

1 Quelle: Siehe Tabelle 16 der Statistischen Analyse.

2 Über "Die jugoslawischen Gastarbeiter" siehe den gleichnamigen Beitrag in: Wissenschaftlicher Dienst Südosteuropa, München 1972, H. 4, S. 49-55. 
len Verbrauchsgütern, für die Versorgung der neuentstandenen Industrien mit Rohstoffen und Hilfsmaterialien, und nicht zuletzt für die Deckung des militärischen Rüstungsbedarfs, mußten die Südoststaaten ausländische Partner suchen, die in Zahlung dafür entweder agrarische und bergbauliche Güter abnahmen, oder die Lieferungen durch Kredite ermöglichten. Bedingt durch ihre kleinbäuerliche Agrarstruktur, durch die niedrige Produktionsleistung der Landwirtschaft, durch den zunehmenden eigenen Nahrungsmittelbedarf als Folge der wachsenden Bevölkerung, dann durch die Konkurrenz agrarischer Angebote aus Übersee und nicht zuletzt durch den Verfall der Preise für Nahrungsmittel und für Rohstoffe Ende der zwanziger Jahre, gerieten alle Südoststaaten in der Zeit der Weltwirtschaftskrise der Dreißiger Jahre in eine hoffnungslose a ußenwirtschaftliche wie innerwirtschaftliche Situation. Der Ruf in jener Zeit nach dirigistischen Eingriffen des Staates in das wirtschaftliche Geschehen auf der einen Seite und nach Partnerschaft mit dem Ausland auf bilateraler Basis bei garantierten Kontingenten und Preisen für die Exporterzeugnisse der Südoststaaten, wird um so verständlicher, wenn berücksichtigt wird, daß sich in der volkswirtschaftlichen Leistung, in der sozial-ökonomischen Struktur und im Lebensstandard der breiten Massen der Bevölkerung in Südosteuropa in der Zwischenkriegszeit und zumindest bis zur Ubberwindung der Krise Anfang der dreißiger Jahre wenig verbessert hat. Mitte der dreißiger Jahre trat für die südosteuropäische Landwirtschaft und Rohstoffgewinnung und für deren nachgeordnete Industrien, insbesondere dank der Belebung des deutschen Marktes und dank der vom Dritten Reich nicht zuletzt aus wehrwirtschaftlichen Gründen betriebenen Politik, ein gewisser Aufschwung ein. Dies wurde zwar auch in Südosteuropa als ein großer Fortschritt gewertet, aber dennoch verfestigten sich und stagnierten die Sozialstrukturen immer mehr, standen doch den jährlichen Wachstumsraten in der Wirtschaft von 2 bis $5 \%$ letztlich Vermehrungsquoten der Bevölkerung von 1,5 bis $3 \%$ gegenüber. Oder anders ausgedrückt: Die Kinder zehrten den vermeintlichen Fortschritt in der Wirtschaft zum größten Teil auf, so daß die Ersparnisquote und damit die Investitionen nur gering sein konnten, was wiederum retardierende Wirkung auf Investitionen, Leistung und Produktivität der Volkswirtschaften und auf die Verbesserung der Strukturen haben mußte. Damit blieb aber das zur siedenden Virulenz kumulierte sozial-ökonomische Problem $\mathrm{Nr} .1$ ungelöst, und dieses Problem hieß: Ubberbesetzung der kleinbäuerlichen, parzellierten und oft atomisierten, unproduktiven Kleinstbetriebe mit Menschen und mit Arbeitskräften, deren Produktionsleistung nicht einmal für eine kärgliche Selbstversorgung ausreichte ${ }^{1}$.

Mit einem durchschnittlichen jährlichen Einkommen von weniger als 100 Dollar und mit Exportleistungen von 7 bis 17 Dollar je Kopf der Bevölkerung standen die Südoststaaten jedenfalls auch am Vorabend des Zweiten

1 Siehe hierüber insbesondere Hermann GROSS, Elemente der Agrarstruktur und Tendenzen der Agrarpolitik in Südosteuropa. Beitrag III in: Von der Agrar-zur Industriegesellschaft, a. a. O. 
Weltkrieges an letzter Stelle der Wohlstandsskala ir Europa'. Hier muß dabei mit Nachdruck darauf hingewiesen werden, daß in der Zwischenkriegszeit kaum nennenswerte Verbesserungen speziell in der Struktur des Exports der südosteuropäischen Volkswirtschaften eingetreten sind, wenn man von dem Export an arbeitsintensiven Erzeugnissen des Gartenbaus und vereinzelt der tierischen Veredelungswirtschaft einiger Länder absieht.

Die eigentliche $Z$ äs ur trat hier im Verlauf der Entwicklung nach dem Zweiten Weltkrieg ein, und zwar für die sozialistischen Staaten als Folge und Ergebnis ihrer neuen Wirtschafts - d. h. Industrialisierungs - politik und ihrer Zusammenarbeit insbesondere mit der Sowjetunion, für die Türkei und Griechenland vor allem dank der Erschließung der Bodenschätze und der Förderung der Wirtschaft mit Hilfe und in Zusammenarbeit mit westlichen Partnern.

Im Kräftespiel der Weltwirtschaft von heute nehmen die Südoststaaten jedenfalls eine neue Position ein. Produktionsleistung der Volkswirtschaften, Exportpotential und Exportstruktur, Importbedarf und Importstruktur sowie regionale außenwirtschaftliche Orientierung zeigen ebenso ein neuen Gesicht wie auch eine neue Dynamik. Dies veranschaulichen folgende Übersichten:

Nationaleinkommen und Außenhandel der südosteuropäischen Länder je Kopf der Bevölkerung (Index 1970: 1950 = 100)

\begin{tabular}{|l|c|c|c|}
\hline \multicolumn{1}{|c|}{ Land } & $\begin{array}{c}\text { National- } \\
\text { einkommen }\end{array}$ & Import & Export \\
\hline Albanien & - & $230^{\mathrm{a}}$ & $460^{\mathrm{a}}$ \\
Bulgarien & 506 & 163 & 145 \\
Rumänien & 484 & 647 & 708 \\
Ungarn & 278 & 700 & 640 \\
Jugoslawien & 287 & 305 & 845 \\
Griechenland & $289 \mathrm{~b}$ & 600 \\
Tükei & $160^{b}$ & 180 & 140 \\
a $1955=100 . \quad-{ }^{\prime}$ Index 1968-70: $1953-57=100$. & & \\
\hline
\end{tabular}

Quelle: Siehe Tabellen 22, 61 und 62 der Statistischen Analyse. UN/ECE, Economic Bulletin for Europe. Vol. 23 (1972), No. 2, S. 47 .

1 Theodor D. ZOTSCHEW, Der Außenhandel als Faktor des wirtschaftlichen Wachstums der sozialistischen Staaten Sudosteuropas. SüdosteuropaStudien 16. München 1971, S. 12. 
Das erste aufällige Merkmal der bisherigen Entwicklung der südosteuropäischen Volkswirtschaften ist, daß der wirtschaftliche Aufbau in besonders starkem Maße vom Außenhandel abhängt; dies kommt darin zum Ausdruck, daß der Außenhandel weitaus stärker - bis zum zwei- und dreifachen gestiegen ist als das Nationaleinkommen. Die gegenseitige Abhängigkeit zw ischen wirtschaftlichem Wachstum und a ußenwirtschaftlicher Integration kommt in diesen Relationszahlen deutlich zum Ausdruck. Soweit Pläne für die nächsten Jahre vorliegen, soll sich diese Entwicklung folgendermaßen fortsetzen:

Durchschnittliche Jahreszuwachsraten des Nationaleinkommens (NE) und des Außenhandels (AH) 1960-1975 (in vH)

\begin{tabular}{|l|c|c|c|c|c|c|}
\hline \multirow{2}{*}{} & \multicolumn{2}{|c|}{ Bulgarien } & \multicolumn{2}{c|}{ Rumänien } & \multicolumn{2}{c|}{ Ungarn } \\
\cline { 2 - 7 } & NE & AH & NE & A H & NE & AH \\
\hline $1960 / 65$ & 6,7 & 14,3 & 9,1 & 9,9 & 4,7 & 10,4 \\
$1966 / 70$ & 8,6 & 10,3 & 7,7 & 11,8 & 6,8 & 9,7 \\
$1971 / 75$ & 8,5 & 10,5 & 12,2 & 11,5 & 6,6 & 8,4 \\
\hline
\end{tabular}

Quelle: UN/ECE, Economic Bulletin for Europe, Vol. 23 (1972), No. 2, S. 27. - Siehe auch. A. SOKOLOV, V. TERECHOV, Ekonomika stran SEV: Itogi i perspektivy. In: "Voprossy ekonomiki". Moskva 1971, Nr. 9, S. $78 \mathrm{ff}$.

Das zweite Charakteristikum ist, daß alle Südoststaaten, zwar unterschiedlich, aber durchweg bereits als aufstrebende Industriewarenexport e ure anzusehen sind, und der Export von Nahrungsmitteln und Rohstoffen mitunter stark zurücktritt, wie z. B. bei Rumänien, Ungarn und Jugoslawien, und wenn Nahrungsmittel exportiert werden, dann dominiert auch hier wie bei Bulgarien der Export von verarbeiteten und veredelten Nahrungsmitteln. Dies gilt für Früchte, Gemüse, Konserven, technische Kulturen u. a., wohingegen der Export z. B. von Getreide kaum eine Rolle spielt. Bei Bulgarien, Rumänien, Ungarn und Jugoslawien macht der Export von Maschinen, Ausrüstungen und industriellen Verbrauchsgütern u. dgl. zwischen 50 und $70 \mathrm{vH}$ des Gesamtexport aus, worin sich der in$z w i s c h e n$ eingetretene Wandel in der Volkswirtschaft der genannten Staaten und deren Stellung im internationalen Handel sehr deutlich dokumentiert.

Schließlich entspricht die regionale A usrichtung der Handelsbeziehungen der einzelnen Südoststaaten: erstens der vom System her resultierenden außenpolitischen Bindung und zweitens der Produktionsleistung und der Produktionsstruktur der jeweiligen Volkswirtschaft. Grie chenland und die Türkei sind am stärksten "westorientiert". Bei dem steigenden Lebensstandard und ebenso Rohstoffbedar $f$ in der Sowjetunion und in den anderen sozialistischen Staaten dürften sich die Absatzchancen 
Struktur des Außenhandels der südosteuropäischen Länder nach Warengruppen 1970 (in $\mathrm{vH}$ )

\begin{tabular}{|c|c|c|c|c|c|c|}
\hline \multirow[t]{2}{*}{ Land } & \multicolumn{2}{|c|}{$\begin{array}{l}\text { Maschinen, } \\
\text { Ausrüstungen, } \\
\text { Industrie- } \\
\text { erzeugnisse }\end{array}$} & \multicolumn{2}{|c|}{$\begin{array}{l}\text { Brennstoffe, } \\
\text { mineralische } \\
\text { Rohstoffe, } \\
\text { Metalle }\end{array}$} & \multicolumn{2}{|c|}{$\begin{array}{c}\text { Landwirtschaft- } \\
\text { liche Rohsioffe, } \\
\text { Nahrungs- } \\
\text { mittel }\end{array}$} \\
\hline & Import & Export & Import & Export & Import & Export \\
\hline Bulgarien & 54,8 & 48,4 & 29,1 & 8,2 & 16,1 & 43,4 \\
\hline Rumänien & 53,3 & 50,3 & 31,1 & 22,9 & 15,6 & 26,8 \\
\hline Ungarn & 52,4 & 58,4 & 23,2 & 14,9 & 24,4 & 26,7 \\
\hline Jugoslawien & 75,5 & 69,6 & 17,6 & 10,8 & 6,9 & 19,6 \\
\hline Griechenland $^{a}$ & 56,0 & 18,5 & 30,6 & 24,3 & 13,4 & 57,2 \\
\hline Türkeia & 82,9 & 7,3 & 14,2 & 35,5 & 2,9 & 57,2 \\
\hline
\end{tabular}

Ouelle: Siehe Tabelle 67 der Statistischen Analyse.

für die mediterranen Erzeugnisse beider Länder und bei der Türkei auch für bergbauliche Rohstoffe verbessern.

Jugoslawien, als blockfreies Land, ist bemüht, seine wirtschaftlichen Beziehungen sowohl mit den marktwirtschaftlichen als auch mit den sozialistischen Staaten auszubauen. Dies hängt freilich von der weiteren innerwirtschaftlichen Entwicklung des Landes ab, die allerdings gerade im Jahre 1971 durch eine "alpine" Preissteigerung, durch Liquiditätsschwierigkeiten bei einem großen Teil der Betriebe, durch überhitzte Investitionsnachfrage und durch hohe Verschuldung der Betriebe im Inland und der Volkswirtschaft im Ausland gekennzeichnet ist. Die Deviseneinnahmen aus dem Fremdenverkehr (bis zu 360 Mill. Dollar jährlich) und durch Gastarbeiter im Ausland (bis zu $400 \mathrm{Mill}$. Dollar jährlich) bringen die eigentliche Entlastung der stets angespannten Lage in der jugoslawischen Zahlungsbilanz, weist doch die Handelsbilanz jährliche Defizite zwischen 0,5 und 1 Mrd. Dollar a uf ${ }^{1}$.

Ungarn, das industriell am weitesten fortgeschrittene Land Südosteuropas, erfreut sich bereits eines von Jahr zu Jahr steigenden Absatzes an Industrieerzeugnissen in Westeuropa. Die Lieferverpflichtungen gegenüber den anderen sozialistischen Staaten und insbesondere gegenüber der Sowjetunion und überhaupt die Verfestigung der Integration innerhalb des Rats für Gegenseitige Wirtschaftshilfe dürften kaum große Veränderungen in der regionalen Ausrichtung des Exports und analog des Imports ebenso

1 Siehe Fußnote 2 auf Seite 33. 
Ungarns wie auch Bulgariens und Rumäniens zulassen. Bulgarien ist dabei besonders stark auf die Zusammenarbeit mit der Sowjetunion angewiesen, besteht doch nirgendwo in Europa ein so großer Absatzmarkt gerade für die Exporterzeugnisse des bulgarischen Gartenbaus, der Landwirtschaft, der Viehwirtschaft und nachgeordneten Industrien. Auch durch die Verschuldung gegenüber der Sowjetunion ist der bulgarische Export langfristig zu 50 bis $60 \mathrm{vH}$ auf die Sowjetunion fixiert. R u mänien gilt als das RGW-Land mit dem stärksten Westhandel. Dies ist darauf zurückzuführen, daß das Land einige in Westeuropa und in Übersee nachgefragten Güter zu exportieren in der Lage ist, wozu an erster Stelle Erdöl, Erdölderivate, chemische Vorprodukte, Zement, Bohrausrüstungen und neuerdings in zunehmendem Maße auch andere Industrieerzeugnisse zählen. Auch mit Hilfe von westlichen Krediten konnte Rumänien bisher zusätzliche Importe aus Westeuropa finanzieren.

Außenhandel der südosteuropäischen Länder nach Regionen 1970 (in $\mathrm{vH}$ )

\begin{tabular}{|l|r|r|r|r|r|r|}
\hline \multirow{2}{*}{ Land } & \multicolumn{3}{|c|}{ Import } & \multicolumn{3}{c|}{ Export } \\
\cline { 2 - 7 } & $\begin{array}{c}\text { Sozial. } \\
\text { Länder }\end{array}$ & $\begin{array}{c}\text { Industrie- } \\
\text { Länder }\end{array}$ & $\begin{array}{c}\text { Entw. - } \\
\text { Länder }\end{array}$ & $\begin{array}{c}\text { Sozial. } \\
\text { Länder }\end{array}$ & $\begin{array}{c}\text { Industrie- } \\
\text { Länder }\end{array}$ & $\begin{array}{c}\text { Entw. - } \\
\text { Länder }\end{array}$ \\
\hline Albanien (1969) & 82,6 & 16,7 & 0,7 & 86,7 & 12,2 & 1,1 \\
Bulgarien & 76,2 & 19,1 & 4,7 & 79,3 & 14,2 & 6,5 \\
Rumänien & 53,9 & 39,5 & 6,6 & 58,1 & 31,9 & 10,0 \\
Ungarn & 65,0 & 28,8 & 6,2 & 65,6 & 28,0 & 6,4 \\
Jugoslawien & 20,7 & 68,9 & 10,4 & 32,5 & 56,8 & 10,7 \\
Griechenland & 5,2 & 83,6 & 11,2 & 16,5 & 75,2 & 8,3 \\
Türkei & 13,0 & 78,8 & 8,2 & 14,4 & 74,5 & 11,1 \\
\hline
\end{tabular}

Quelle: Siehe Tab. 70 in der Statistischen Analyse. - Statističeskij ezegodnik stran-členov SËV 1971 (Moskva), S. 342.

Was die Möglichkeiten zur Intensivierung der Ost-West-Wirtschaftsbeziehungen aufgrund westlicher $\mathrm{Kredite}$ anbetriff, wäre folgendes zu sagen: Durch das hohe Zinsniveau auf dem westlichen Kapitalmarkt ist die Bereitschaft der Oststaaten, teure Kredite aufzunehmen, gedämpft. Verbilligte Kredite wären im Prinzip bei Zinssubventionen seitens der westlichen Staaten möglich. Es erscheint aber fraglich, ob sich eine westliche Regierung bereit finden kann, solche Zinssubventionen den eigenen Steuerzahlern aufzubürden. In Anbetracht der gerade heute im Westen offenkundig gewordenen Geldentwertung stellen sich der Gewährung von langfristigen Krediten an östliche Partner zusätzliche Schwierigkeiten in den Weg. In Einzelfällen werden aber sicherlich weiterhin und wie bisher Kredite gewährt, sei es, daß der Umfang des Geschäfts und die günstigen Preise für die westlichen Lieferungen entsprechende Zinsnachlässe ermög- 
lichen (Beispiel: das Erdgas-Röhren- und 1,2 Mrd. DM-Kredit-Geschäft vom Febr. $1970 \mathrm{zwischen} \mathrm{westdeutschen} \mathrm{Stahlfirmen} \mathrm{und} \mathrm{Banken} \mathrm{einerseits}$ und der Sowjetunion andererseits), sei es, daß aus Gründen der Konjunkturbelebung oder der Sicherung von Marktpositionen Lieferungen auf Kredit an die sozialistischen Staaten für notwendig und richtig gehalten werden. Durch die Gründung der Ost-West-Handelsbank in Frankfurt a. M. will speziell die Sowjetunion nähere Kontakte mit dem westdeutschen wie westeuropäischen Kapitalmarkt aufnehmen.

Im Prinzip und abgesehen von gelegentlichen Erleichterungen durch westliche Kredite, hängt der Handels-, Dienstleistungs- und Zahlungsverkehr $z w i s c h e n$ den sozialist ischen Staaten und dem Westen letztlich davon ab, inwiefern die Industrie der ost-und südosteuropäischen State $n$ in der Lage sein wird, durch marktkonforme und in Preis, Qualität, Sortiment und Service konkurrenzfähige Angebote ihre Westexporte auszubauen. Nach Schätzungen der ECE dürfte sich der Export der RGW-Staaten nach Westeuropa immer mehr auf Industrieerzeugnisse verlagern und bis 1980 folgenden Umfang erreichen:

Export der RGW-Staaten nach Westeuropa 1966/68 - 1980

\begin{tabular}{|c|c|c|c|c|c|}
\hline \multirow[b]{2}{*}{ Güter } & \multicolumn{2}{|c|}{ in Mrd. US-Dollar } & \multirow{2}{*}{$\begin{array}{c}\text { Zunahme } \\
1966 / 68 \\
-1980 \\
\end{array}$} & \multicolumn{2}{|c|}{ in $\mathrm{vH}$} \\
\hline & $1966 / 68$ & $1980^{a}$ & & $1966 / 68$ & $1980^{a}$ \\
\hline Industrieerzeugnisse & 1,1 & 8,7 & $7,7 \mathrm{fach}$ & 25 & $54(45)$ \\
\hline Metalle; Holz & 0,9 & 3,3 & $3,8 \mathrm{fach}$ & 20 & $21(18)$ \\
\hline Andere & 2,5 & 3,9 & $1,6 \mathrm{fach}$ & 55 & $25(37)$ \\
\hline & & 7,0 & $(2,8 \mathrm{fach})$ & & \\
\hline Insgesamt & 4,5 & $\begin{array}{c}15,9 \\
(19,0)\end{array}$ & $\begin{array}{c}3,5 \mathrm{fach} \\
(4,2 \mathrm{fach})\end{array}$ & 100 & 100 \\
\hline
\end{tabular}

@uelle: UN/ECE, Economic Bulletin for Europe, Vol. 22 (1971), No. 1, S. 46 .

Bedingt durch die geschichtliche Entwicklung, durch die geographische Lage, durch die Struktur der Wirtschaft und durch die Größe des Marktes ist Deutschland stets der wichtigste Wirtschafts- und Handelspartner für die südosteuropäischen Länder gewesen. Auch unter den veränderten weltpolitischen und weltwirtschaftlichen Verhältnissen nach dem Zweiten Weltkrieg ist diesmal die Bundesrepublik Deutschland zumindest der wichtigste westliche Handelspartner für die nach 1945 sozialistisch gewordenen Südoststaaten geblieben. Bei den mit der EWG assoziierten 


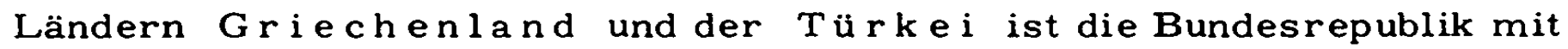
rd. je einem Fünftel am Export und am Import beider Länder beteiligt. Dank der Einnahmen aus dem Touristenverkehr vor allem aber aus dem Geldtransfer der in der Bundesrepublik Deutschland beschäftigten Gastarbeiter, importieren Griechenland und die Türkei bis zu zweimal soviel Güter aus der BRD wie sie dorthin exportieren. Durch deutsche und andere westliche Kredite, durch EWG-Zollpräferenzen und durch höhere Arbeitsund Dienstleistungen der Gegenseite dürften bei zunehmender Integrierung in die EWG die deutsch-türkischen wie die deutsch-griechischen Wirtschaftsbeziehungen neue Impulse bekommen.

Dasselbe gilt im großen und ganzen auch für die Wirtschaftsbeziehungen mit Jugoslawien. Im Lohnveredelungsverfahren, aber auch auf dem Wege des normalen Exports konnte die jugoslawische Industrie ihren Absatz auf dem westdeutschen Markt bisher wesentlich ausweiten und festigen; lange Lieferzeiten und hohe Preise in der Bundesrepublik erleichterten diese Entwicklung; fast vier Fünftel (1970:78,4 vH) des deutschen Imports aus Jugoslawien bestehen bereits aus industriellen Halbwaren und Enderzeugnissen (siehe Tabelle 71 der Statistischen Analyse).

Handelsbilanz der Bundesrepublik Deutschland mit Jugoslawien, Griechenland und der Türkei 1971 (in Mill. DM)

\begin{tabular}{|l|r|r|rr|}
\hline & Import & Export & \multicolumn{2}{|c|}{+ Exportüberschuß (1970) } \\
\hline 1. Jugoslawien & 1138,3 & 2527,3 & $+1389,0 \quad(+1345,9)$ \\
2. Griechenland & 684,8 & 1639,5 & $+954,7 \quad(+\quad 657,5)$ \\
3. Türkei & 481,6 & 775,0 & $+293,4 \quad(+252,0)$ \\
\cline { 2 - 5 } $1-3$ insgesamt & 2304,7 & 4941,8 & $+2637,1$ & $(+2255,4)$ \\
\hline
\end{tabular}

Ouelle: Statistisches Bundesamt Wiesbaden, Außenhandel. Zusammenfassende Übersichten. Dezember 1971, S. 26.

Die Außenhandelsumsätze der Bundesrepublik mit den südosteuropäischen $\mathrm{Sta}$ a $\mathrm{s}$ handel $\mathrm{s} l$ ändern nehmen im allgemeinen $\mathrm{z} u$, wenn man von gelegentlichen Ausnahmen absieht. Im Prinzip hängt der weitere Ausbau des gegenseitigen Warenaustausches von der Exportfähigkeit der Südoststaaten ab. Diesbezüglich hat bisher Ungarn die größten Erfolge erzielt. Die ungarischen Reformen und im Konkreten die teilweise Dezentralisie-ing der Entscheidungen auch im Außenhandel, die zielstrebige Marketingpolitik Ungarns, die Intensivierung der Kooperationsgeschäfte mit westdeutschen Firmen, die Aufnahme eines 25 Mill. - Dollar-Kredits zuf dem Eurs-Dollar-Markt, die merkliche Anhebung der Exportleistung der ungarischen Industrie und nicht zuletzt der im Oktober 1970 geschlossene Vertrag für Zusammenarbeit auf wirtschaftlichem, industriellem und technologischem Gebiet für 1971-1975 mit der darin vorgesehenen weitgehenden 
Liberalisierung des ungarischen Exports in die Bundesrepublik, markieren diese Erfolge. Alle Anzeichen sprechen dafür, daß diese Entwicklung anhalten und die Bundesrepublik weiterhin der größte westliche Handelspartner für Ungarn bleiben wird ${ }^{1}$.

Ähnlich gestalten sich die Wirtschaftsbeziehungen zwischen der Bundesrepublik und Rumänien, wobei die Handelsumsätze hier je nach dem Stand der rumänischen Verschuldung ständigen Schwankungen unterworfen sind. Die Normalisierung der diplomatischen Beziehungen zwischen den beiden Staaten, der rege gegenseitige Besuch von Politikern, Wirtschaftlern. Wissenschaftlern usw., die Vergabe von Bauaufträgen an rumänische Firmen, der noch ausbaufähige Touristenverkehr, dann die weiteren Industrialisierungspläne Rumäniens u.a.m., versprechen jedenfalls, den deutsch-rumänischen Wirtschaftsbeziehungen weitere Impulse zu geben. Die Plattform dazu ist durch das Abkommen zwischen den Regierungen der BRD und Rumäniens vom Dezember 1969 über den Warenverkehr und die Erweiterung der wirtschaftlichen Zusammenarbeit (Geltungsdauer bis 31.12.1974) geschaffen worden.

Bulgarien bemüht sich neuerdings, auf den westdeutschen Märkten in zunehmendem Maße auch Industrieerzeugnisse, insbesondere Flurtransportmittel, Fördereinrichtungen, Werkzeugmaschinen, Elektroausrüstung, elektronisches Zubehör und eine Vielzahl anderer Industrieerzeugnisse, anzubieten. Nach wie vor spielen jedoch die bulgarischen Exporte an Früchten, Obst, Gemüse, Konserven u.a. verarbeitenden und veredelten landwirtschaftlichen Erzeugnissen eine wichtige Rolle. Der im Rahmen des langfristigen Abkommens vom Februar 1971 über den Warenverkehr und die Zusammenarbeit auf wirtschaftlichem und technischem Gebiet zu erwartende Abbau der noch bestehenden Importbeschränkungen in der Bundesrepublik für bulgarische Agrarprodukte, die Gewährung von Meistbegünstigung in Zoll- und Zollformalitätsfragen, die Ende 1971 bei der bulgarischen Handelskammer errichtete deutsche Sektion, der neugegründete Bulgarien-Kreis beim Ostausschuß der deutschen Wirtschaft und viele andere beiderseitige Aktivitäten werden dazu beitragen, daß der seit 1966 eher stagnierende als florierende Handel $z w$ ischen der Bundesrepublik und Bulgarien neuen Auftrieb bekommt. Dasselbe gilt a uch für den Fremdenverkehr, verbrachten doch 1968:83 184, 1969:124874 und 1970: 141914 westdeutsche Touristen ihren Urlaub in Bulgarien.

1 Vgl. hierzu insbes. : Walter ALTHAMMER, Die wirtschaftlichen Beziehungen der Bundesrepublik Deutschland und der VR Ungarn. In: "Mitteilungen der Südosteuropa-Gesellschaft", München, 11. Jg. (1971), Nr. 1/2, S. 21 ff. 
Außenhandel der Bundesrepublik Deutschland mit Albanien, Bulgarien, Rumänien und Ungarn 1969 - 1971

(in Mill. DM)

\begin{tabular}{|l|r|r|r|r|r|r|}
\hline \multirow{2}{*}{ Land } & \multicolumn{3}{|c|}{ Import } & \multicolumn{3}{c|}{ Export } \\
\cline { 2 - 7 } & \multicolumn{1}{|c|}{1969} & 1970 & 1971 & 1969 & 1970 & 1971 \\
\hline 1. Albanien & 2,6 & 4,5 & 3,9 & 7,3 & 12,1 & 11,7 \\
2. Bulgarien & 206,6 & 236,8 & 226,3 & 246,8 & 240,4 & 256,4 \\
3. Rumänien & 464,0 & 580,2 & 747,3 & 729,4 & 722,1 & 678,7 \\
4. Ungarn & 402,8 & 490,0 & 520,3 & 353,4 & 522,4 & 709,5 \\
\cline { 2 - 7 } & 1076,0 & 1311,5 & 1497,8 & 1337,3 & 1496,9 & 1656,3 \\
\hline
\end{tabular}

Quelle: Statistisches Bundesamt Wiesbaden. Außenhandel. Zusammenfassende Übersichten. Dezember 1970, S. 26. - Dezember 1971, S. 26 .

Anteile Deutschlands am Außenhandel der südosteuropäischen Länder 1928, 1938 und 1970 (in $\mathrm{vH}$ )

\begin{tabular}{|l|r|r|r|r|r|r|r|r|}
\hline \multirow{2}{*}{ Land } & \multicolumn{4}{|c|}{ Import } & \multicolumn{4}{c|}{ Export } \\
\cline { 2 - 9 } & 1928 & 1938 & \multicolumn{2}{|c|}{1970} & 1928 & 1938 & \multicolumn{2}{c|}{1970} \\
\cline { 2 - 9 } & & & BRD & DDR & & & BRD & DDR \\
\hline Bulgarien & 20,9 & 46,7 & 2,7 & 8,6 & 27,6 & 51,5 & 2,6 & 8,7 \\
Rumänien & 23,6 & 31,4 & 8,1 & 5,9 & 24,9 & 19,5 & 9,0 & 5,7 \\
Ungarn & 19,6 & 30,3 & 5,1 & 10,4 & 11,9 & 28,4 & 6,8 & 9,4 \\
Jugoslawien & 13,7 & 33,3 & 19,7 & 2,6 & 12,0 & 35,9 & 11,8 & 3,0 \\
Griechenland & 8,4 & 29,0 & 18,6 & 0,3 & 27,3 & 38,9 & 20,2 & 2,0 \\
Türkei & 14,5 & 47,2 & 18,5 & 1,3 & 12,7 & 43,4 & 20,0 & 1,7 \\
\hline
\end{tabular}

Quelle: Theodor ZOTSCHEW, Wirtschaftliche Entwicklung und gegenseitige Handelsbeziehungen der südosteuropäischen Staaten. In: Südosteuropa-Schriften, 4., München 1963, S. $63 \mathrm{ff}$. IMF, Direction of Trade, Annuel 1966-70, S. 151 ff. - Nationale Statistiken. 
Zusammenfassend läßt sich über die Stellung der südosteuropäischen Länder in der Weltwirtschaft von heute und morgen folgendes sagen:

1. Der Trend zur Industrialisierung und der Wandel von der Agrar-zur Industriegesellschaft ist in ganz Südosteuropa, besonders in den sozialistischen Staaten, unaufhaltsam. Die betreffenden Volkswirtschaften wachsen immer stärker in höhere und differenzierte Stufen der Industrieproduktion hinein, was ebenso zur Folge wie auch zur Voraussetzung eine stets intensiver werdende industrielle Integration und Kooperation in internationalem Maßstab hat ${ }^{1}$.

2. Außer Wachstum für die Wirtschaft der südosteuropäischen Länder selbst bringt diese Entwicklung zweifelsohne auch für die westlichen und namentlich für die westeuropäischen Partner wesentliche wirtschaftliche Vorteile, darunter z. B. : verbesserte Absatzchancen für die westeuropäische Industrie; Verlagerung von Industrien und von urbanen Verkehrsströmen auch auf andere Regionen in Europa und damit Entlastung der Infrastruktur und der umweltbezogenen Bedingungen in Westeuropa; Rückgriff auf die Arbeitskraftreserven in Südosteuropa und damit Begegnung des immer spürbarer werdenden Mangels an Arbeitskräften niedrigeren Produktivitätsgrades, hier u.a. auch für schwere körperliche sowie der Witterung ausgesetzte Arbeiten ${ }^{2}$.

3. Im Rahmen des erweiterten gemeinsamen Marktes unter den zehn Volkswirtschaften in Westeuropa (EWG) und ebenso im Rahmen der Entwicklungspläne der sozialistischen Stazten und deren Gemeinschaft (RGW) erwachsen jedenfalls auch für die Industrien und für die Volkswirtschaften aller südosteuropäischen Länder neue Absatz-, Kooperationsund Integrationsmöglichkeiten. Die Nutzung dieser Möglichkeiten kann um so effektiver werden, wenn alle europäischen Staaten und Gemeinschaften den Weg zu einer umfassenden politischen, wirtschaftlichen und gesamtgesellschaftlichen Zusammenarbeit untereinander beschrei-

1 Vgl. auch: Todor D. ZOTSCHEW, Wechselbeziehungen von Sozialstruktur und Außenhandel in den südosteuropäischen Ländern. Beitrag IV in: Von der Agrar-zur Industriegesellschaft, a.a. O.

2 Die Erhebungen vom März 1971 in Jugoslawien ergeben z. B., daß von den 682000 im Ausland beschäftigten jugoslawischen Gastarbeitern (davon: 411500 in der Bundesrepublik, 83000 in Österreich, 37000 in Frankreich und 40000 in Australien) nur 1,5\% eine Hochschulbildung oder sonstige höhere Qualifikation besaßen, während der Anteil derer mit Grundschulabschluß oder ohne jede Qualifikation bei $70 \%$ liegt. Quelle : Mitteilungen der BfA, Köln, 22. Jg. (1972), Nr. 38, S. 3. - Über "Die jugoslawischen Gastarbeiter" siehe den gleichnamigen Beitrag in: Wissenschaftlicher Dienst Südosteuropa, München, 21. Jg. (1972), H. 4, S. 49-55. 
ten würden'. Daß bei einer solchen Entwicklung die sozialistischen Staaten ihre wirtschaftlichen Leistungen immer stärker nach den Erfordernissen der ökonomischen Rationalität und der freien Märkte ausrichten müssen, versteht sich von selbst.

4. Für die theoretischen wie für die empirischen Wirtschafts- und Sozialwissenschaften stellt Südosteuropa in seiner Vielfalt und in seiner darin zugleich mitbegründeten Gemeinsamkeit ein ebenso interessantes wie lehrreiches Studienobjekt. Daß die jüngere Entwicklungsländerforschung auf brauchbare und nützliche Ansätze, Ergebnisse und Erkenntnisse bei der viel älteren Südosteuropaforschung zurückgreifen kann, unterstreicht die Bedeutung Südosteuropas auch auf diesem Gebiet.

5. Wissenschaft, Wirtschaft und Politik in Ost und West sind damit gleichermaßen an der Erforschung und an der Integration der südosteuropäischen Volkswirtschaften und Gesellschaften in die gesamteuropäische Entwicklung interessiert.

1 Dazu gehören u. a. auch der internationale Verkehr und Tourismus. Siehe hierüber daher insbesondere: Die Donau als Verkehrsweg Südosteuropas und die Großschiffahrtsstraße Rhein-Main-Donau. Südosteuropa-Studien 14. München 1969. - Der Tourismus und seine Perspektiven für Südosteuropa. Beiträge zusammengestellt von Karl Ruppert und Jörg Maier. SüdosteuropaStudien 17. München 1971. 


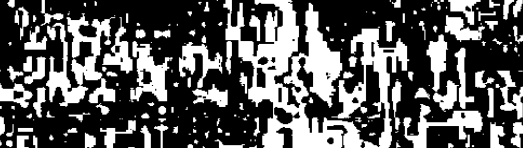




\section{Statistische Analyse}




\section{Vorbemerkung und Literaturhinweise}

1. In der vorliegenden Statistischen Analyse sind Zahlen und Daten ge. bracht, die meistens aus zusammengefaßten internationalen Statistiken entnommen worden sind. Damit sollte die Vergleichbarkeit des wiedergegebenen Materials in methodologischer Hinsicht gewahrt bleiben. Wo es sich als notwendig und möglich erwies, sind auch die nationalen Statistiken, meistens die statistischen Jahrbücher, der jeweiligen Staaten herangezogen worden.

2. In erster Linie wurden statistische und sonstige Veröffentlichungen folgender internationaler Organisationen berücksichtigt:

Unites Nations (UN), New York.

UN, Economic Commission for Europe (ECE), Genf.

UN, Educational, Scientific and Cultural Organisation (UNESCO), Paris.

UN, Food and Agricultural Organisation (FAO), Rom.

International Monetary Fund (IMF), Washington.

GATT, General Agreement on Tariffs and Trade, Geneva.

Organisation for Economic Co-operation and Development (OECD), Paris.

Commission du Danube, Budapest.

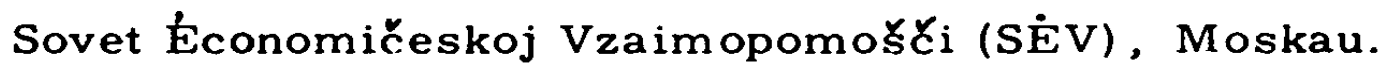

3. Auch im internationalen Teil der statistischen Jahrbücher einzelner Länder sind nach einheitlichen Gesichtspunkten aufbereitete Zahlen für sozialistische und nichtsozialistische Länder enthalten. Dies gilt besonders für die statistischen Jahrbücher von:

Polen, Rocznik Statystyczny.

DDR, Statistisches Jahrbuch der Deutschen Demokratischen Republik.

BRD, Statistisches Jahrbuch für die Bundesrepublik Deutschland.

4. Verwiesen sei auf einige Veröffentlichungen, in denen sich statistisches Material für alle, für einige oder nur für einzelne südosteuropäische Länder befindet: 
Congress of the Unites States, Joint Economic Committee, Economic Developments in Countries of Eastern Europe.

A Comparison of Papers. Washington 1970.

UN/ECE, Analytical Report on the State of Intra-European Trade. New York 1970.

EWG, Statistisches Amt der Europäischen Gemeinschaften, Brüssel. Ostblock. Außenhandel der europäischen Ostblockländer (laufende Veröffentlichung).

OECD, Economic Surveys. Turkey, Dec. 1970. - Greece, Febr. 1971 .

Statistisches Bundesamt (Wiesbaden), Allgemeine Statistik des Auslandes

Länderberichte: Länder im Rat für Gegenseitige Wirtschaftshilfe 1970. - Rumänien 1967.

Länderkurzberichte: Albanien 1967. - Bulgarien 1967 und 1969. - Rumänien 1967, 1968 und 1969. - Ungarn 1967, 1969 und 1970. - Jugoslawien 1967, 1968 und 1969. Griechenland 1970. - Türkei 1968 und 1969. - Zypern 1968.

Fachserie G. Außenhandel. Reihe 8. Außenhandel des Auslandes: Bulgarien 1967. - Ungarn 1966. - Jugoslawien 1966. Griechenland 1966. - Türkei 1966.

Jahrbuch der Wirtschaft Osteuropas. Veröffentlichung des Osteuropa-Instituts München. Bd. 1/1970. - Bd. 2/1972. Bd. 3/1972.

5. Außer in den Beiträgen vieler Autoren in den Veröffentlichungsreihen der SOG sind Statistiken in einer Anzahl von Beiträgen im Sammelwerk: Von der Agrar-zur Industriegesellschaft. Sozialer Wandel auf dem Lande in Südosteuropa. Herausgeber Franz Ronneberger und Gerhard Teich. München und Darmstadt. XX Lieferungen 1968 bis 1972 , enthalten.

6. Mit der vorliegenden Statistischen Analyse werden die von Theodor Zots chew bisher gebrachten statistischen Zusammenstellungen in:

Südosteuropa-Jahrbuch 6. Anhang: Statistische Übersichten. München 1962.

Südosteuropa-Jahrbuch 7. Anhang: Statistische Übersichten. München 1966 .

Mitteilungen der SOG 1968, No. 3/4, S. 19-30.

fortgeführt und ergänzt. 
- $($ Strich $)=$ Statistischer Fall nicht gegeben.

- $($ Punkt $)=$ Statistischer Fall vorhanden, aber ohne Zahlenangabe

$0 \quad($ Null $)=$ Statistisches Ergebnis liegt unter der Hälfte der niedrig sten Einheit. 


\section{Verzeichnis der Übersichten und Tabellen}

Seite

A. Allgemeine Daten 53

Albanien 53

Bulgarien 53

Rumänien 54

Ungarn

Jugoslawien 55

Griechenland 55

Türkei 56

Zypern

B. Bevölkerung

Tabelle 1: Fläche, Bevölkerung und Hauptstädte der südosteuropäischen Länder

Tabelle 2: Größere Städte in den südosteuropäischen Ländern (in 1000 Einwohnern)

Tabelle 3: Bevölkerung der südosteuropäischen Länder nach Altersgruppen 1969

Tabelle 4: Entwicklung der Bevölkerung der südosteuropäischen Länder 1938-1985

Tabelle 5: Entwicklung der Stadt- und Landbevölkerung in den südosteuropäischen Ländern 1960-1985

Tabelle 6: Zunahme (+) bzw. Abnahme (-) der Stadt- und Landbevölkerung der südosteuropäischen Länder 1960-1985

Tabelle 7: Zunahmequoten (+) bzw. Abnahmequoten (-) der Stadt - und Landbevölkerung in den südosteuropäischen Ländern 1960-1985 (Jahresdurchschnittszahlen in $\mathrm{vH}$ )

Tabelle 8: Bevölkerungsbewegung in den südosteuropäischen Ländern 1935/39 und 1950-1970 (a uf 1000 Einwohner) 


\section{Seite}

C. Beschäftigung

Tabelle 9: Beschäftigung in den südosteuropäischen Ländern:

Struktur nach Wirtschaftszweigen vor und nach dem Zweiten Weltkrieg (in $\mathrm{vH}$ )

Tabelle 10: Erwerbsbevölkerung in den südosteuropäischen Ländern insgesamt und in der Landwirtschaft 1965

Tabelle 11: Beschäftigte in den südosteuropäischen Ländern außerhalb des Agrarsektors 1950, 1960 und 1970 (in Mill.)

Tabelle 12: Beschäftigung (ohne Landwirtschaft) in den sijdosteuropäischen Ländern 1965 und 1969

Index $1960=100$

Tabelle 13. Beschäftigte im Bergbau in den südosteuropäischen Ländern 1960-1968 (in 1000)

Tabelle 14: Beschäftigte in der Industrie in den südosteuropäischen Ländern 1960-1969 (in 1000)

Tabelle 15: Beschäftigte in der Bauwirtschaft in den südosteuropäischen Ländern 1960-1969 (in 1000)

Tabelle 16: Gastarbeiter aus Südosteuropa in der Bundesrepublik Deutschland Stand: 30. Sept. 1971

Tabelle 17: Lehrer, Schüler und Studierende in den südosteuropäischen Ländern 1950-1968

Tabelle 18: Studierende in den südosteuropäischen Ländern nach Fachrichtungen 1967-1968

Tabelle 19: Gesundheitswesen in den südosteuropäischen Ländern 1950-1969

Tabelle 20: Buchveröffentlichungen in den südosteuropäischen Ländern 1969

Tabelle 21: Zeitungen, Rundfunkempfänger und Fernsehempfänger in den südosteuropäischen Ländern je 1000 Einwohner 1969 
Seite

E. Wirtschaftswachstum; Nationaleinkommen

Tabelle 22: Wirtschaftswachstum der südosteuropäischen Länder 1950-1970

Tabelle 23: Das Bruttoinlandsprodukt der südosteuropäischen Länder in konstanten Preisen (Indexzahlen 1961-1970;1960 = 100)

Tabelle 24: Nationaleinkommen der südosteuropäischen Länder - Struktur nach Wirtschaftszweigen 1969 (in $\mathrm{vH}$ )

F. Landwirtschaft; Forstwirtschaft; Fischerei

Tabelle 25: Landwirtschaftliche Nutzfläche der südosteuropäischen Länder 1943-1969 (in 1000 ha und vH)

Tabelle 26: Landwirtschaftliche Produktion der südosteuropäischen Länder 1966-1970 (Index: 1952/56 = 100)

Tabelle 27: Getreideernte in den südosteuropäischen Ländern 1948-1970

Tabelle 28: Ernte von Kartoffeln, Zuckerrüben, Tomaten und Weintrauben in den südosteuropäischen Ländern 1948-1970

Tabelle 29: Ernte von Sonnenblumen, Tabak, Baumwolle und Hanf in den südosteuropäischen Ländern $1948-1970$

Tabelle 30: Viehbestand in den südosteuropäischen Ländern $1947 / 48-1969 / 70$ (in 1000)

Tabelle 31: Produktion von Fleisch, Milch, Käse, Honig und Wolle in den südosteuropäischen Ländern 1948-1970 (in $1000 \mathrm{t}$ )

Tabelle 32: Produktion von Häuten und Fellen in den südosteuropäischen Ländern 1948-1969 (in 1000 Stück)

Tabelle 33: Produktion von Eiern in den südosteuropäischen Ländern 1948-1970 (in Mill. Stück)

Tabelle 34: Bestand an landwirtschaftlichen Maschinen in den südosteuropäischen Ländern 1948-1969 (in Stück)

Tabelle 35: Import und Export von Traktoren der südosteuropäischen Länder 1967-1969 
Tabelle 36: Produktion und Verbrauch von Düngemitteln in den südosteuropäischen Ländern 1948-1970 (in $1000 \mathrm{t}$ Handelsgewicht)

Tabelle 37: Import und Export von Düngemitteln der südosteuropäischen Länder 1967-1969 (in 1000 Dollar)

Tabelle 38: Forstwirtschaft in den südosteuropäischen Ländern 1961-1969

Tabelle 39: Fischfang in den südosteuropäischen Ländern 1953-1969 (in $1000 \mathrm{t}$ )

G. Industrieproduktion; Bergbau; Wohnungsbau

Tabelle 40: Industrieproduktion der südosteuropäischen Länder 1955-1971 (Index: $1960=100$ )

Tabelle 41: Industrieproduktion der südosteuropäischen Länder 1948-1971 (Index: $1963=100$ )

Tabelle 42: Produktion von Brennstoffen und Elektroenergie in den südosteuropäischen Ländern 1938-1971

Tabelle 43: Produktion von Erdölderivaten in den südosteuropäischen Ländern 1962, 1965 und 1970 (in $1000 \mathrm{t}$ )

Tabelle 44: Erzbergbau und metallschaffende Industrie der südosteuropäischen Länder 1938-1971 (in 1000 t)

Tabelle 45: Produktion von Schnittholz, Zement und chemischen Erzeugnissen in den südosteuropäischen Ländern 1950-1971 (in $1000 \mathrm{t}$ )

Tabelle 46: Produktion von Textilgarn und Textilgeweben in den südosteu ropäischen Ländern 1950-1971

Tabelle 47: Produktion (P) und Montage (M) von Kraftfahrzeugen in den südosteuropäischen Ländern $1960-1970$

Tabelle 48: Produktion von Rundfunkgeräten und Fernsehgeräten in den südosteuropäischen Ländern $1953-1970$ (in 1000 Stück)

Tabelle 49: Wohnungsbau in den südosteuropäischen Ländern $1965-1970$ 
H. Verkehr; Nachrichtenwesen

Tabelle 50: Das Eisenbahnnetz in den südosteuropäischen

Ländern 1950 und 1970

Tabelle 51: Transportleistung der Eisenbahn in den südosteuropäischen Ländern 1950-1970

Tabelle 52: Seehandelsflotte der südosteuropäischen Länder 1953-1970 (in 1000 BRT)

Tabelle 53: Güterumschlag der Seehäfen in den südosteuropäischen Ländern 1967 und 1968 (in 1000 t)

Tabelle 54: Die Donauflotte der Anliegerstaaten 1968

Tabelle 55: Güterfracht zwischen den Donau-Anliegerstaaten 1968 (in 1000 t)

Tabelle 56: Frachtverkehr der Donauhäfen 1968 (in $1000 \mathrm{t}$ )

Tabelle 57: Kraftfahrzeugbestand in den südosteuropäischen Ländern 1953-1969 (in 1000 Stück)

Tabelle 58: Zivilluft fahrt in den südosteuropäischen Ländern 1953-1970 (Mill. Passagier-km)

Tabelle 59 - Registrierte Rundfunkempfänger und Fernsehempfänger in den südosteuropäischen Ländern 1960 und 1969

Tabelle 60: Telefonanschlüsse in den südosteuropäischen Ländern 1953-1969

I. Außenhandel; Tourismus

Tabelle 61: Import der südosteuropäischen Länder 1938-1970 (in Mill. US-Dollar)

Tabelle 62: Export der südosteuropäischen Länder 1938-1970 (in Mill. US-Dollar)

Tabelle 63 - Import der südosteuropäischen Länder nach

Ländern und Ländergruppen 1969

(in Mill. US-Dollar)

Tabelle 64: Export der südosteuropäischen Länder nach Ländern und Ländergruppen 1969 (in Mill. US-Dollar)

Tabelle 65: Import der südosteuropäischen Länder nach Ländern und Ländergruppen 1969 (in vH) 
Seite

Tabelle 66: Export der südosteuropäischen Länder nach Ländern und Ländergruppen 1969 (in vH)

Tabelle 67: Warenstruktur des Außenhandels der südosteuropäischen Staaten 1970 (in $v \mathrm{H}$ )

Tabelle 68: Import der marktwirtschaftlichen Länder aus den sozialistischen Staaten 1966-1970 (in Mill. US-Dollar und in $\mathrm{vH}$ )

Tabelle 69: Export der marktwirtschaftlichen Länder nach den sozialistischen Staaten 1966-1970

(in Mill. US-Dollar und in $\mathrm{vH}$ )

Tabelle 70: Anteil der sozialistischen Staaten am Außenhandel der marktwirtschaftlichen Länder 1966 und 1970 (in $\mathrm{vH}$ )

Tabelle 71: Warenstruktur des Imports der Bundesrepublik Deutschland aus den südosteuropäischen Staaten 1971 (in Mill. DM und in $\mathrm{vH}$ )

Tabelle 72: Warenstruktur des Exports der Bundesrepublik Deutschland nach den südosteuropäischen Staaten 1971 (in Mill. DM und in $v H$ )

Tabelle 73: Ausländische Touristen und Reisende in den südosteuropäischen Ländern 1960-1969 (in 1000) 


\section{A. Allgemeine Daten}

ALBANIEN : Republika Popullóre e Shqipërisë = RPSh

(Volksrepublik der Schkipetaren)

Währung

Lek ( = 100 Quindarka)

5 Lek = 1 US-Dollar (Apr. 1972)

Staats- und Regierungsform

Kommunistische Volksrepublik. Parlament aus 1 Kammer (Volksversammlung).

Staatsoberhaupt: Vorsitzender des Präsidiums der Volksversammlung, General Haxhi Lleshi (Hadschi Lleschi).

Regierungschef: Vorsitzender des Ministerrats,

General Ltn. Mehmet Shehu (Schehu).

Regierungspartei: Kommunistische Albanische Arbeiterpartei;

I. Sekretär des ZK: Enver Hoxha (Hodscha);

63326 Vollmitglieder (1966).

Bevö1ker.ung: 2170000 (1970)

$98 \%$ Albaner; aromunische, slawische und griechische Minderheiten.

BULGARIEN: Narodna Republika Bălgaria = NRB

(Volksrepublik Bulgarien)

W ährung

Lev ( = 100 Stotinki)

1,07 Leva = 1 US-Dollar; Touristenkurs: 1,85 Leva $=1$ US-Dollar (Apr. 1972)

Staats-und Regierungsform

Volksrepublik. Parlament aus $1 \mathrm{Kammer}$ (Săbranie)

Staatsoberhaupt: Vorsitzender des Staatsrats

Todor Ziwkoff

Regierungschef: Vorsitzender des Ministerrats Todor Ziwkoff

Regierungsparteien: Bulgarische Kommunistische Partei (BKP), 1. Sekretär des ZK: Stanko Todoroff; 637265 Mitglieder (1969)

Bevölkerung: 8490000 (1970)

$93 \%$ Bulgaren; der Rest Türken, Zigeuner, Mazedonier, Aromunen u. a. Minderheiten. 
RUMÄNIEN: Republica Socialistă Rumânia = RSR

(Sozialistische Republik Rumänien)

Währung

Leu (= 100 Bani)

5,53 Leu = 1 US-Dollar; Touristenkurs: 16 Lei $=1$ US-Dollar (Apr. 1972)

Staats - und Regierungsform

Sozialistische Republik Parlament (Marea Adunare Nationala) mit einer Kammer.

Staatsoberhaupt: Staatsrat aus 17 Mitgliedern;

Vorsitzender: Nicolae Ceauşescu.

Regierungschef: Vorsitzender des Ministerrats

Jon Gheorghe Maurer

Regierungspartei: Rumänische Kommunistische Partei (RKP);

2, 1 Mill. Mitglieder (1971)

Bevölkerung: $20250000(1970)$

$87,7 \%$ Rumänen; $8,4 \%$ Madjaren; $2 \%$ Deutsche; außerdem mehr als ein Dutzend kleinere Minderheiten.

UNGARN: Magyar Népköztársaság

(Ungarische Volksrepublik)

Währung

Forint $(=100$ Filler $)$

10,81 Forint $=1$ US-Dollar; Touristenkurs: 27,63 Forint $=1$ US-Dollar (Apr. 1972)

Staats - und Regierungsform

Kommunistische Volksrepublik. Parlament mit

1 Kammer (Országgyülés)

Staatsoberhaupt: Präsidialrat der Nationalversammlung,

Vorsitzender: Pál Losonczi;

Regierungschef: Ministerpräsident Jenö Fock.

Regierungspartei: Ungarische Sozialistische Partei;

584000 Mitglieder (1966).

Erster Sekretär des ZK: János Kádár.

Bevölkerung: 10330000 (1970)

$98 \%$ Madjaren; etwa 200000 Deutsche; 100000 Slowaken;

100000 Juden; 80000 Kroaten; 20000 Rumänen 
JUGOSLAWIEN: SocialistiČeska Federativna Republika Jugoslavija = SFRJ (Soztalistische Foderative Republik Jugoslawien)

Währung

Dinar ( $=100$ Para)

17 Dinar = 1 US-Dollar (Apr. 1972)

Staats - und Regierungs form

Bundesstaatliche Volksrepublik mit Parlament (Savezna Skupstina) aus 5 Räten: Nationalitäten-Rat; Wirtschafts-Rat; Rat für Soziales und Gesundheit; Rat für Erziehung und Kultur; Rat für Gesellschaftspolitische Organisation.

Politische und administrative Gliederung in sechs föderative Republiken (Einwohnerzahl März 1971): Serbien (Srbija; 8, 44 Mill. = 41,2\%) mit den autonomen Republiken Vojvodina (1,95 Mill.) und Kosovo $(1,24$ Mill.); Kroatien (Hrvatska; 4,42 Mill. $=21,6 \%$ ); BosnienHerzegovina (Bosna i Hercegovina; 3,74 Mill. = 18,3\%); Slowenien (Slovenija; $1,73 \mathrm{Mill}$. = 8,4\%); Mazedonien (Makedonija; 1, 65 Mill. $=8 \%$ ) und Montenegro (Crna Gora; 0,53 Mill. = 2,5\%).

Staatspräsidium: Vorsitzender Präsident Marschall Josip Broz-Tito. Vorsitzender des Bundesvollzugsrats (Ministerpräsident) :

Djemal Bijedić

Regierungspartei: Bund der Kommunisten Jugoslawiens (BKJ); 1,05 Mill. Mitglieder (1970)

Bevölkerung: 20530000 (1970)

1971 : 20,8 Mill; (1961: 18,55 Mill.) davon: 40,5\% Serben, 23, $1 \%$ Kroaten; $8,3 \%$ Slowenen; $5,8 \%$ Mazedonier; $5,9 \%$ Muslims; $6,0 \%$ Albaner; $2,9 \%$ Montenegriner; $2,3 \%$ Madjaren, 1,1 \% Turken; der Rest von 2, $1 \%$ Slowaken, Rumänen, Bulgaren, Italiener, Tschechen, A romunen, Zigeuner u. a.

GRIECHENLAND: Hellas; Vasileion Tis Ellados

Währung

Drachme $(=100$ Lepta)

30 Drachmen $=1$ US-Dollar (Apr 1972)

Staats - und Regierungsform

Seit dem Staatsstreich im Mai 1967 ist das Parlament aufgelöst, und die Parteien sind verboten: autoritäres Regime.

Nach der Verfassung Konstitutionelle Monarchie (König Konstantin I) ; seit Dez. 1967 wird der König durch einen Regenten vertreten.

Ab 1972 besteht als eine Art Ersatzparlmment der "Beratende Ausschuß für die Gesetzgebung * 
Regierungschef: Außenminister und Verteidigungsminister Brigadegeneral a. D. Georgios Papadopolus.

Bevölkerung : 8890000 (1970)

Uberwiegend Griechen; außerdem Minderheiten von Bulgaren, Türken, Aromunen u. a.

Außerdem: Mönchsrepublik Athos (Hágion Oros); 336 qkm; 2700 Einwohner; Hauptort: Kariai; 20 Kloster.

TÛREI: Türkiye Cumhuriyeti

(Türkische Republik)

Wàhrung

Türkisches Pfund (= 100 Kurus)

14 turk. Pfund = 1 US-Dollar (Apr. 1972)

Staats- und Regierungsform

Nationale, demokratische und soziale Republik.

Parlament mit 2 Kammern: Volkskammer und Senat.

Staatsoberhaupt: Prăsident General Cevedet Sunay.

Regierungschef: Ministerprăsident Dr. Nihat Erim.

Bevolkerung: $35230000 \quad$ (1970)

$90 \%$ Türken; $7 \%$ Kurden; $1 \%$ Araber

Außerdem Minderheiten von Georgiern, Armeniern,

Tscherkessen, Griechen, Bulgaren u a

ZYPERN: engl.: Cyprus; griech. : Kypriki Demokratia; türk. : Kibris Cumhuriyeti (Zypriotische Republik)

Wà h rung

Zypern-Pfund ( = 1000 Mils)

$0,4167 Z \mathcal{Z}=1$ US-Dollar (Apr. 1972)

Staats- und Regierungsform

Präsidiale Republik; Parlament aus 1 Kammer;

Staatsoberhaupt und Regierungschef: Erzbischof Myriarthos Makarios (Grieche);

Vizepräsident: Dr. Fazil Küçik (Turke)

Bevölkerung: $630000(1970)$

78,8\% Griechen; 17,5\% Tüken; Armenier u.a. 


\section{B. Bevölkerung}

Tabelle 1: Fläche, Bevölkerung und Hauptstädte der südosteuropäischen Länder

\begin{tabular}{|c|c|c|c|c|c|c|c|}
\hline \multirow[b]{2}{*}{ Land } & \multirow[b]{2}{*}{ Jahr } & \multirow{2}{*}{$\begin{array}{c}\text { Fläche } \\
1000 \\
\text { qkm }\end{array}$} & \multicolumn{2}{|c|}{ Bevölkerung } & \multicolumn{3}{|c|}{ Hauptstadt } \\
\hline & & & $\begin{array}{c}1000 \\
\text { Einwohner }\end{array}$ & $\begin{array}{c}\text { Einw } \\
\text { je qkm }\end{array}$ & & Jahr & $\begin{array}{l}1000 \\
\text { Einw. }\end{array}$ \\
\hline Albanien & 1970 & 28,8 & 2170 & 72 & Tirana & 1967 & 169 \\
\hline Bulgarien & 1970 & 110,9 & 8490 & 77 & Sofia & 1970 & 886 \\
\hline Rumänien & 1971 & 237,5 & 20470 & 85 & Bukarest & 1970 & 1480 \\
\hline Ungarn & 1971 & 93,0 & 10360 & 111 & Budapest & 1970 & 1959 \\
\hline Jugoslawien & 1971 & 255,8 & 20550 & 80 & Belgrad & $1971^{a}$ & $742^{a}$ \\
\hline Griechenland & 1971 & 131,9 & 8960 & 67 & A then & 1961 & $628^{b}$ \\
\hline Türkei & 1971 & 780,6 & 36160 & 44 & Ankara ${ }^{c}$ & 1965 & 906 \\
\hline Zypern & 1970 & 9,3 & 630 & 68 & Nikosia & 1968 & 112 \\
\hline
\end{tabular}

Quelle: Rocznik statystyczny 1971 (Warszawa), S. 644, 645. - Wissenschaftlicher Dienst Südosteuropa, München 1971, H. 5, S. 87 . UN, Monthly Bulletin of Statistics, April 1972, S. 1 ff. -

Statističeskij ežegodnik stran-členov SÉV 1971 (Moskva), S. 5 
Tabelle 2: Größere Städte in den südosteuropäischen Ländern (in 1000 Einwohnern)

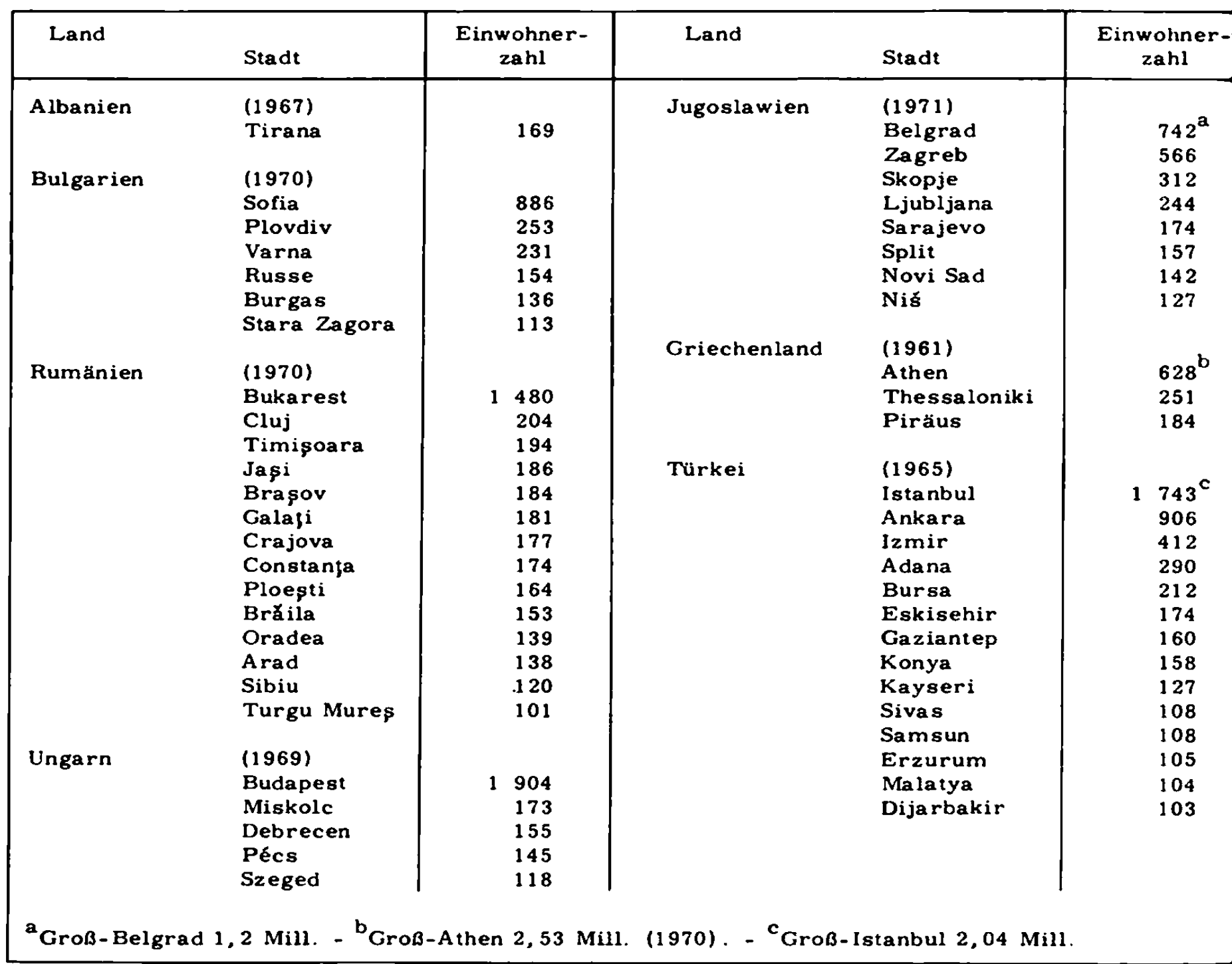

Quelle: UN, Demographic Yearbook 1969, S. $202 \mathrm{ff}$ - Statisticeski ezegodnik stran-clenov SEV 1971 (Moskva), S. $11 \mathrm{ff}$. Jugoslawski Pregled 1971, N. 6. 
Tabelle 3: Bevölkerung der südosteuropäischen Länder nach Altersgruppen 1969

\begin{tabular}{|c|c|c|c|c|c|c|c|c|}
\hline \multirow[b]{2}{*}{ Land } & \multicolumn{4}{|c|}{ in Millionen } & \multicolumn{4}{|c|}{ In $\mathrm{vH}$} \\
\hline & $\begin{array}{c}\text { unter } \\
20 \\
\text { Jahren }\end{array}$ & $\begin{array}{c}20 \text { bis } \\
64 \\
\text { Jahre }\end{array}$ & $\begin{array}{c}\text { Ober } \\
65 \\
\text { Jahre }\end{array}$ & $\begin{array}{l}\text { Insge- } \\
\text { same }\end{array}$ & $\begin{array}{c}\text { unter } \\
20 \\
\text { Jahren }\end{array}$ & $\begin{array}{c}20 \text { bis } \\
64 \\
\text { Jahre }\end{array}$ & $\begin{array}{c}\text { ober } \\
65 \\
\text { Jahre }\end{array}$ & $\begin{array}{c}\ln s g e- \\
\text { samt }\end{array}$ \\
\hline Albanien ${ }^{a}$ & 0.51 & 0,43 & 0,07 & 1.00 & 50.6 & 42,3 & 7.1 & 100.0 \\
\hline Bulgarien & 2.63 & 5,01 & 0.79 & 8,43 & 31.2 & 59,5 & 9,3 & 100,0 \\
\hline Rumanien & 7.00 & 11,31 & 1.69 & 20.01 & 34,9 & 56,7 & 8.4 & 100,0 \\
\hline Ungarn & 3,09 & 6,03 & 1.17 & 10,29 & 30,0 & 58,7 & 11,3 & 100,0 \\
\hline Jugoslawien ${ }^{b}$ & 7,62 & 11.03 & 1,50 & 20.15 & 37.8 & 54.8 & 7.4 & 100.0 \\
\hline Griechenland & 2,92 & 5.04 & 0,87 & 8,83 & 33.0 & 57,1 & 9.9 & 100,0 \\
\hline Turket & 16,06 & 14,04 & 1,29 & 31,39 & 51,1 & 44,8 & 4,1 & 100,0 \\
\hline Zypern & 0.27 & 0.31 & 0.04 & 0,63 & 43,1 & 50,2 & 6.7 & 100,0 \\
\hline Zum Vergleich: & & & & & & & & \\
\hline Schweden & 2,22 & 4,67 & 1,07 & 7,97 & 27.9 & 58.7 & 13.5 & 100.0 \\
\hline BR Deutschland & 18,48 & 33,31 & 6,86 & 58,65 & 31.5 & 56.8 & 11.7 & 100,0 \\
\hline
\end{tabular}

Quelle: UN, Demographic Yearbook 1970, S. $272 \mathrm{ff}$.

Tabelle 4 : Entwicklung der Bevölkerung der südosteuropäischen Länder $1938-1985$

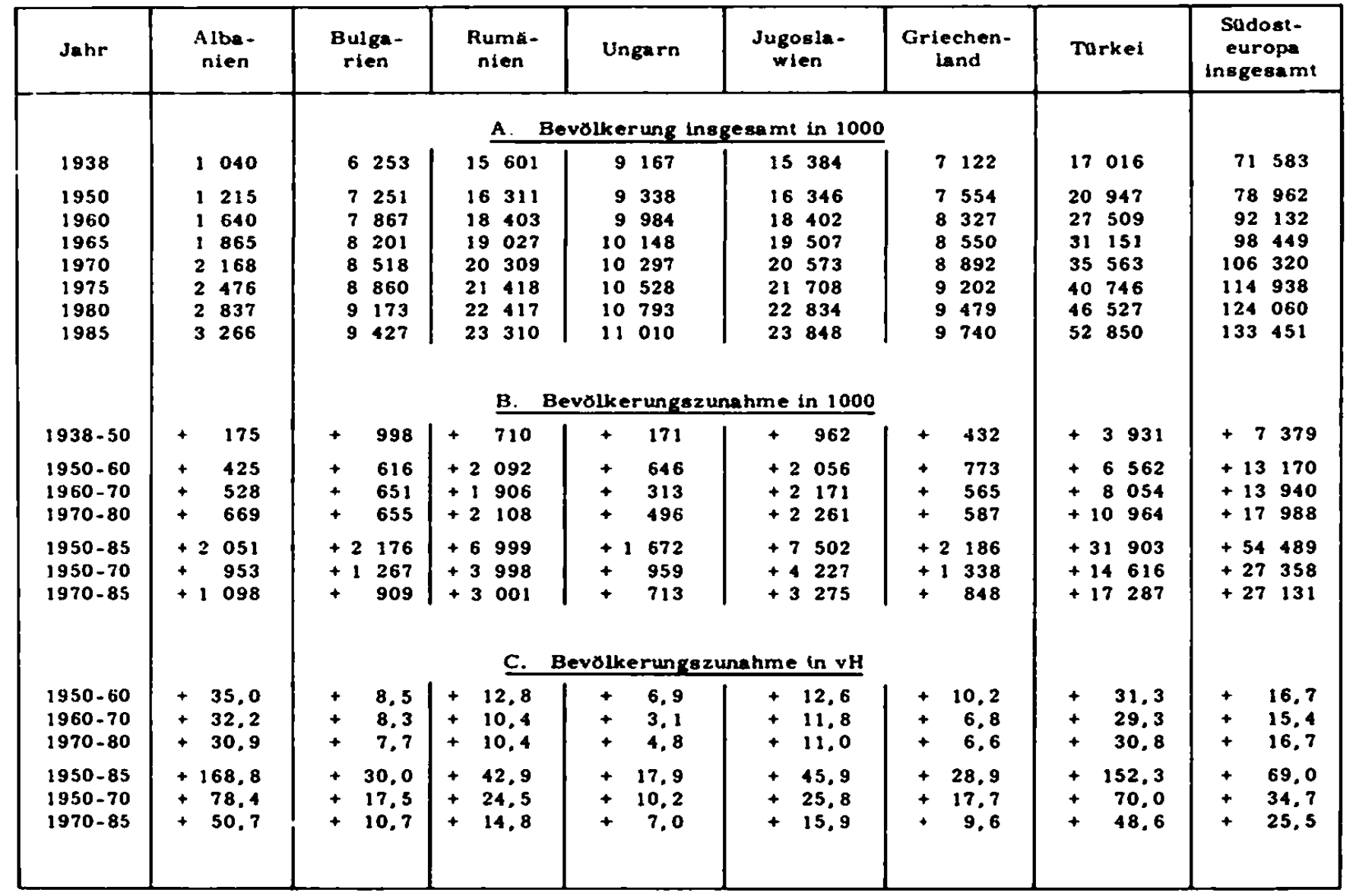

Quelle: UN, Monthly Bulletin of Statistics, November 1971, S. XXVI ff. (Ermittelte und geschätzte Zahlen der UN. Population Division) 
Tabelle 5: Entwicklung der Stadt- und Landbevölkerung in den südosteuropäischen Ländern 1960 - 1985

\begin{tabular}{|c|c|c|c|c|c|c|c|c|}
\hline Jahr & $\begin{array}{l}\text { Alba- } \\
\text { nien }\end{array}$ & $\begin{array}{l}\text { Bulga- } \\
\text { rien }\end{array}$ & $\begin{array}{l}\text { Rumä- } \\
\text { nien }\end{array}$ & Ungarn & $\begin{array}{l}\text { Jugosla- } \\
\text { wien }\end{array}$ & $\begin{array}{l}\text { Grie- } \\
\text { chen- } \\
\text { land }\end{array}$ & Türkei & $\begin{array}{l}\text { Südost- } \\
\text { europa } \\
\text { insgesamt }\end{array}$ \\
\hline \multicolumn{9}{|c|}{ A 1. Stadtbevölkerung insgesamt in 1000} \\
\hline 1960 & 488 & 2967 & 6201 & 4136 & $\begin{array}{ll}5 & 016\end{array}$ & 3568 & 8725 & $31 \quad 101$ \\
\hline 1970 & 813 & 4383 & $\begin{array}{ll}8467\end{array}$ & 4823 & 7574 & 4313 & $\begin{array}{ll}13 & 127\end{array}$ & 43500 \\
\hline 1980 & 1366 & $5 \quad 724$ & 11248 & $\begin{array}{ll}5 & 457\end{array}$ & 10867 & $\begin{array}{ll}5 & 139\end{array}$ & 19743 & 59544 \\
\hline 1985 & 1751 & 6365 & 12695 & 5772 & 12678 & 5556 & 23931 & 68748 \\
\hline 1960 & $\begin{array}{ll}1 & 152\end{array}$ & 4900 & 12202 & $\begin{array}{ll}5 & 848\end{array}$ & 13386 & 4759 & 18784 & $\begin{array}{ll}61 & 031\end{array}$ \\
\hline 1970 & 1355 & 4135 & 11842 & 5474 & 12999 & 4579 & 22436 & 62820 \\
\hline 1980 & 1471 & $\begin{array}{ll}3 & 449\end{array}$ & $11 \quad 169$ & 5336 & 11907 & 4340 & $26 \quad 784$ & 64516 \\
\hline 1985 & 1515 & 3062 & 10615 & 5238 & 11170 & 4184 & 28919 & 64703 \\
\hline \multirow{5}{*}{$\begin{array}{l}1960 \\
1970 \\
1980 \\
1985\end{array}$} & \multicolumn{8}{|c|}{ A 3. Stadtbevölkerung in $\mathrm{vH}$} \\
\hline & 29,8 & 37,7 & 33,7 & 41,4 & 27,3 & 42,8 & 31,7 & 33,8 \\
\hline & 37,5 & 51,5 & 41,7 & 46,8 & 36,8 & 48,5 & 36,9 & 40,9 \\
\hline & 48,1 & 62,4 & 50,2 & 50,6 & 47,6 & 54,2 & 42,4 & 48,0 \\
\hline & 53,6 & 67,5 & 54,5 & 52,4 & 53,2 & 57,0 & 45,3 & 51,5 \\
\hline \multirow{5}{*}{$\begin{array}{l}1960 \\
1970 \\
1980 \\
1985\end{array}$} & \multicolumn{8}{|c|}{ A 4. Landbevölkerung in $\mathbf{v H}$} \\
\hline & 70,2 & 62,3 & 66,3 & 58,6 & 72,7 & 57,2 & 68,3 & 66,2 \\
\hline & 62,5 & 48,5 & 58,3 & 53,2 & 63,2 & 51,5 & 63,1 & 59,1 \\
\hline & 51,9 & 37,6 & 49,8 & 49,4 & 52,4 & 45,8 & 57,6 & 52,0 \\
\hline & 46,4 & 32,5 & 45,5 & 47,6 & 46,8 & 43,0 & 54,7 & 48,5 \\
\hline
\end{tabular}

Quelle: UN, Monthly Bulletin of Statistics, November 1971, S. XXVI ff. (Ermittelte und geschätzte Zahlen der UN. Population Division) 
Tabelle 6: Zunahme (+) bzw. Abnahme (-) der Stadt- und Landbevölkerung der südosteuropäischen Länder 1960 - 1985

\begin{tabular}{|c|c|c|c|c|c|c|c|c|}
\hline Zeitraum & $\begin{array}{l}\text { Alba - } \\
\text { nien }\end{array}$ & $\begin{array}{c}\text { Bulga - } \\
\text { rien }\end{array}$ & $\underset{\text { nien }}{\text { Ruma - }}$ & Ungarn & $\begin{array}{l}\text { Jugosla - } \\
\text { wien }\end{array}$ & $\begin{array}{l}\text { Griechen- } \\
\text { land }\end{array}$ & Torkei & $\begin{array}{l}\text { Sudost- } \\
\text { europa } \\
\text { insgesamt }\end{array}$ \\
\hline & & & 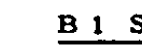 & bevolker & 1000 & & & \\
\hline $\begin{array}{l}1960-70 \\
1970-80 \\
1980-85\end{array}$ & $\begin{array}{r}325 \\
+\quad 553 \\
+\quad 385\end{array}$ & $\begin{array}{r}1416 \\
+1341 \\
+\quad 641\end{array}$ & $\begin{array}{r}+2266 \\
+2781 \\
+1447\end{array}$ & $\begin{array}{r}687 \\
+\quad 634 \\
+\quad 315\end{array}$ & $\begin{array}{l}+2558 \\
+3293 \\
+1811\end{array}$ & $\begin{array}{r}+\quad 745 \\
+\quad 826 \\
+\quad 417\end{array}$ & $\begin{array}{r}+4402 \\
+\quad 6616 \\
+\quad 4188\end{array}$ & $\begin{array}{r}12399 \\
+16044 \\
+\quad 9204\end{array}$ \\
\hline $1960-85$ & +1263 & +3398 & $\begin{array}{r}+6494 \\
\text { B } 2 \\
\end{array}$ & $\begin{array}{l}+1636 \\
\text { dbevolker }\end{array}$ & $\begin{array}{l}+7662 \\
1000 \\
\end{array}$ & +1988 & +15206 & +37647 \\
\hline $\begin{array}{l}1960-70 \\
1970-80 \\
1980-85\end{array}$ & $\begin{array}{r}+\quad 203 \\
+\quad 116 \\
+\quad 44\end{array}$ & $\begin{array}{ll}- & 765 \\
- & 686 \\
- & 387\end{array}$ & $\begin{array}{l}360 \\
-\quad 673 \\
-\quad 554\end{array}$ & $\begin{array}{rr}- & 374 \\
-\quad 138 \\
-\quad 98\end{array}$ & $\begin{array}{l}\quad 387 \\
-\quad 032 \\
-\quad 797\end{array}$ & $\begin{array}{l}180 \\
-\quad 239 \\
-\quad 156\end{array}$ & $\begin{array}{r}3652 \\
+\quad 4348 \\
+\quad 2135\end{array}$ & $\begin{array}{r}1789 \\
+\quad 1696 \\
+\quad 187\end{array}$ \\
\hline $1960-85$ & +363 & -1838 & $\begin{array}{r}-1587 \\
\quad C_{1}\end{array}$ & $\begin{array}{l}-610 \\
\text { dibevolke }\end{array}$ & $\begin{array}{l}-2216 \\
\text { in } \mathrm{vH}\end{array}$ & $-\quad 575$ & +10135 & +3672 \\
\hline $\begin{array}{l}1960-70 \\
1970-80 \\
1980-85\end{array}$ & $\begin{array}{r}66.6 \\
+\quad 68.0 \\
+\quad 28.2\end{array}$ & $\begin{array}{r}47.7 \\
+\quad 30.6 \\
+\quad 11.2\end{array}$ & $\begin{array}{r}36.5 \\
+\quad 32.8 \\
+\quad 12.8\end{array}$ & $\begin{array}{r}16.6 \\
+\quad 13.1 \\
+\quad 5.8\end{array}$ & $\begin{array}{r}+51.0 \\
+\quad 43,5 \\
+\quad 16,7\end{array}$ & $\begin{array}{r}+20.9 \\
+\quad 19.2 \\
+\quad 8.1\end{array}$ & $\begin{array}{l}50.5 \\
+\quad 50.4 \\
+\quad 21.2\end{array}$ & $\begin{array}{r}+\quad 39,9 \\
+\quad 36.9 \\
+\quad 15.5\end{array}$ \\
\hline $1960-85$ & $+258,8$ & $+114,5$ & $\begin{array}{r}+104,7 \\
\mathrm{C} 2\end{array}$ & $\begin{array}{r}+39,6 \\
\text { ndbevolke }\end{array}$ & +152.8 & $+55,7$ & +174.3 & +121.0 \\
\hline $\begin{array}{l}1960-70 \\
1970-80 \\
1980-85\end{array}$ & $\begin{array}{r}17.6 \\
+\quad 8.6 \\
+\quad 3.0\end{array}$ & $\begin{array}{l}-\quad 15,6 \\
-\quad 16.6 \\
-\quad 11.2\end{array}$ & $\begin{array}{l}3.0 \\
-\quad 5.7 \\
-\quad 5.0\end{array}$ & $\begin{array}{l}-\quad 6.4 \\
=\quad 2.5 \\
-\quad 1.9\end{array}$ & $\begin{array}{l}-\quad 2.9 \\
=\quad 7.9 \\
-\quad 6.7\end{array}$ & $\begin{array}{l}3.8 \\
-\quad 5.2 \\
-\quad 3.6\end{array}$ & $\begin{array}{r}+19.4 \\
+\quad 19.4 \\
+\quad 8.2\end{array}$ & $\begin{array}{r}2.9 \\
+\quad 2.7 \\
+\quad 2.9\end{array}$ \\
\hline $1960-85$ & +31.5 & $-\quad 37,5$ & -13.0 & $-\quad 10.4$ & $-\quad 16,6$ & $-\quad 12,1$ & $+\quad 54,0$ & $+\quad 6.0$ \\
\hline
\end{tabular}

Quelle: UN, Monthly Bulletin of Statistics, November 1971, S. XXVI ff. (Ermittelte und geschätzte Zahlen der UN. Population Division) 
Tabelle 7: Zunahmequoten ( + ) bzw. Abnahmequoten (-) der Stadt- und Landbevölkerung in den südosteuropäischen Ländern 1960-1985 (Jahresdurchschnittszahlen in $\mathrm{vH}$ )

\begin{tabular}{|c|c|c|c|c|c|c|}
\hline Land & $\begin{array}{l}\text { Stadt } \\
\text { Land }\end{array}$ & $1960 / 65$ & $1965 / 70$ & $1970 / 75$ & $1975 / 80$ & $1980 / 85$ \\
\hline \multirow[t]{2}{*}{ Albanien } & $\begin{array}{l}\text { Stadt } \\
\text { Land }\end{array}$ & $\begin{array}{r}+4,9 \\
+\quad 2,2 \\
\end{array}$ & $\begin{array}{l}+5,6 \\
+1,1 \\
\end{array}$ & $\begin{array}{r}+5,4 \\
+0,9 \\
\end{array}$ & $\begin{array}{r}+5,2 \\
+0,7 \\
\end{array}$ & $\begin{array}{l}+5,1 \\
+0,6 \\
\end{array}$ \\
\hline & Insges. & \multicolumn{2}{|c|}{$+2,8^{a}$} & $+2,7$ & $+2,7$ & $+2,8$ \\
\hline \multirow[t]{2}{*}{ Bulgarien } & $\begin{array}{l}\text { Stadt } \\
\text { Land }\end{array}$ & $\begin{array}{l}+4,9 \\
-2,0 \\
\end{array}$ & $\begin{array}{r}+3,1 \\
-1,4 \\
\end{array}$ & $\begin{array}{r}+2,9 \\
-1,6 \\
\end{array}$ & $\begin{array}{l}+2,5 \\
-2,0 \\
\end{array}$ & $\begin{array}{l}+2,2 \\
-2,4 \\
\end{array}$ \\
\hline & Insges. & \multicolumn{2}{|c|}{$\div 0,7^{\mathrm{a}}$} & $+0,8$ & $\bullet+0,7$ & $+0,5$ \\
\hline \multirow[t]{2}{*}{ Rumänien } & $\begin{array}{l}\text { Stadt } \\
\text { Land }\end{array}$ & $\begin{array}{l}+2,9 \\
-0,6 \\
\end{array}$ & $\begin{array}{l}+3,4 \\
-0,1 \\
\end{array}$ & $\begin{array}{l}+3,0 \\
-0,4 \\
\end{array}$ & $\begin{array}{l}+2,7 \\
-0,7 \\
\end{array}$ & $\begin{array}{l}+2,5 \\
-\quad 1,0 \\
\end{array}$ \\
\hline & Insges. & \multicolumn{2}{|c|}{$+1,0^{\mathrm{a}}$} & $+1,1$ & $+0,9$ & $+0,8$ \\
\hline \multirow[t]{2}{*}{ Ungarn } & $\begin{array}{l}\text { Stadt } \\
\text { Land }\end{array}$ & $\begin{array}{l}+1,2 \\
-0,3 \\
\end{array}$ & $\begin{array}{r}+2,0 \\
-1,0 \\
\end{array}$ & $\begin{array}{l}+1,2 \\
-0,3 \\
\end{array}$ & $\begin{array}{l}+1,3 \\
-0,2 \\
\end{array}$ & $\begin{array}{l}+1,1 \\
-\quad 0,4 \\
\end{array}$ \\
\hline & insges. & \multicolumn{2}{|c|}{$+0,3^{2}$} & $+0,4$ & $+0,5$ & $+0,4$ \\
\hline \multirow[t]{2}{*}{ Jugoslawien } & $\begin{array}{l}\text { Stadt } \\
\text { Land }\end{array}$ & $\begin{array}{l}+4,4 \\
-0,1 \\
\end{array}$ & $\begin{array}{l}+4,1 \\
-0,5 \\
\end{array}$ & $\begin{array}{r}+3,8 \\
-0,7 \\
\end{array}$ & $\begin{array}{r}+3,8 \\
-\quad 1,0 \\
\end{array}$ & $\begin{array}{r}+3,1 \\
-1,4 \\
\end{array}$ \\
\hline & Insges. & \multicolumn{2}{|c|}{$+1,1^{a}$} & $+1,1$ & $+1,0$ & $+0,9$ \\
\hline \multirow[t]{2}{*}{ Griechenland } & $\begin{array}{l}\text { Stadt } \\
\text { Land }\end{array}$ & $\begin{array}{r}+1,8 \\
-0,5 \\
\end{array}$ & $\begin{array}{r}+2,0 \\
-0,3 \\
\end{array}$ & $\begin{array}{r}+1,9 \\
-0,5 \\
\end{array}$ & $\begin{array}{l}+1,7 \\
-0,6 \\
\end{array}$ & $\begin{array}{l}+1,6 \\
-0,7 \\
\end{array}$ \\
\hline & Insges. & \multicolumn{2}{|c|}{$+0,7^{a}$} & $+0,7$ & $+0,6$ & $+0,5$ \\
\hline \multirow[t]{2}{*}{ Türkei } & $\begin{array}{l}\text { Stadt } \\
\text { Land }\end{array}$ & $\begin{array}{r}+4,1 \\
+1,7 \\
\end{array}$ & $\begin{array}{r}+4.2 \\
+\quad 1,9 \\
\end{array}$ & $\begin{array}{r}+4,2 \\
+\quad 1,9 \\
\end{array}$ & $\begin{array}{r}+4,1 \\
+\quad 1,7 \\
\end{array}$ & $\begin{array}{r}+3,9 \\
+1.6 \\
\end{array}$ \\
\hline & Insges. & \multicolumn{2}{|c|}{$+2,5^{\mathrm{a}}$} & $+2,7$ & $+2,7$ & $+2,5$ \\
\hline
\end{tabular}

Quelle: UN, Monthly Bulletin of Statistics, Nov 1971, S XLII. UN, Demographic Yearbook 1969, S. 120, 121. (Ermittelte und geschätzte Zahlen der UN. Population Division). 
Tabelle 8: Bevölkerungsbewegung in den südosteuropäischen Ländern 1935/39 und 1950-1970 (auf 1000 Einwohner)

\begin{tabular}{|c|c|c|c|c|c|c|}
\hline Land & $\begin{array}{c}\phi \\
1935 / 39\end{array}$ & 1950 & 1960 & 1968 & 1969 & 1970 \\
\hline \multicolumn{7}{|l|}{ Lebendgeborene } \\
\hline$\overline{\text { Albanien }}$ & $34,7^{2}$ & 38,5 & 43,4 & 35,6 & & \\
\hline Bulgarien & 24,1 & 25,2 & 17,8 & 16,9 & 17,0 & 16,3 \\
\hline Rumänien & 30,2 & 26,2 & 19,1 & 26,7 & 23,3 & 21,1 \\
\hline Ungarn & 20,1 & 20,9 & 14,7 & 15,1 & 15,0 & 14,7 \\
\hline Jugoslawien & 27,9 & 30,2 & 23,5 & 18,9 & 18,8 & 17,6 \\
\hline Griechenland & 26,5 & 20,0 & 18,9 & 18,2 & 17,4 & 16,3 \\
\hline Türkei & • & $\cdot$ & • & $43,0^{b}$ & $\cdot$ & $\cdot$ \\
\hline \multicolumn{7}{|l|}{ Sterbefälle } \\
\hline Albanien & $17,8^{a}$ & 14,0 & 10,4 & 8,0 & & $\cdot$ \\
\hline Bulgarien & 13,9 & 10,2 & 8,1 & 8,6 & 9,5 & 9,1 \\
\hline Rumänien & 19,6 & 12,4 & 8,7 & 9,6 & 10,1 & 9,6 \\
\hline Ungarn & 14,3 & 11,4 & 10,2 & 11,2 & 11,3 & 11,7 \\
\hline Jugoslawien & 15,9 & 13,0 & 9,9 & 8,6 & 9,2 & 8,9 \\
\hline Griechenland & 14,5 & 7,1 & 7,3 & 8,3 & 8,1 & 8,3 \\
\hline Türkei & $\cdot$ & $\cdot$ & $\cdot$ & $16,0^{b}$ & $\cdot$ & $\cdot$ \\
\hline \multicolumn{7}{|l|}{ Natürlicher Zuwachs } \\
\hline$\overline{\text { Albanien }}$ & $16,9^{a}$ & 24,5 & 32,9 & 27,6 & $\cdot$ & $\cdot$ \\
\hline Bulgarien & 10,2 & 15,0 & 9,7 & 8,3 & 7,5 & 7,2 \\
\hline Rumänien & 10,6 & 13,8 & 10,4 & 17,1 & 13,2 & 11,5 \\
\hline Ungarn & 5,8 & 9,5 & 4,5 & 3,9 & 3,7 & 3,0 \\
\hline Jugoslawien & 12,0 & 17,2 & 13,6 & 10,3 & 9,6 & 8,7 \\
\hline $\begin{array}{l}\text { Griechenland } \\
\text { Türkei }\end{array}$ & 12,0 & 12,9 & 11,6 & $\begin{array}{c}9,9 \\
27,0 \mathrm{~b}\end{array}$ & 9,3 & 8,0 \\
\hline \multicolumn{7}{|l|}{ Säuglingssterblichkeit } \\
\hline Albanien & $100,8^{a}$ & 121,2 & 83,0 & $86,8^{d}$ & - & \\
\hline Bulgarien & 146,4 & 94,5 & 45,1 & 28,3 & 30,5 & 27,3 \\
\hline Rumänien & $179,0^{\mathbf{a}}$ & 116,7 & 74,6 & 59,5 & 54,9 & 49,4 \\
\hline Ungarn & 133,5 & 85,7 & 47,6 & 35,8 & 35,6 & 35,9 \\
\hline Jugoslawien & 138,8 & 118,4 & 87,7 & 57,9 & 56,3 & . \\
\hline $\begin{array}{l}\text { Griechenland } \\
\text { Türkei }\end{array}$ & . & 35,4 & 40,1 & $\begin{array}{c}34,4 \\
155,0 \mathrm{~b}\end{array}$ & 31,9 & . \\
\hline
\end{tabular}

Quel1e: Rocznik Statystyzcny 1970 (Warszawa), S. 592, 593; 1971, S. 653, 654. - UN, Monthly Bulletin of Statistics, Febr. 1972, S. $6 \mathrm{ff}$. -

Statistisches Bundesamt, Länderkurzberichte TÜRKEI 1969, S. 10.Statistið̌eskij ežegednik stran-členov SÉV 1971 (Moskva) S. 8. 


\section{Beschäftigung}

Tabelle 9: Beschäftıgung in den südosteuropäischen Ländern: Struktur nach Wirtschaftszweigen vor und nach dem Zweiten Weltkrieg (in vH)

\begin{tabular}{|c|c|c|c|c|c|c|}
\hline \multirow[b]{2}{*}{ Land } & \multirow[b]{2}{*}{ Jahr } & \multicolumn{3}{|c|}{$\begin{array}{c}\text { Gewerbliche Wirtschaft } \\
\text { Dienstleistungen }\end{array}$} & \multirow{2}{*}{$\begin{array}{l}\text { Land- } \\
\text { wirt- } \\
\text { schaft, } \\
\text { Forst- } \\
\text { wirt- } \\
\text { schaft }\end{array}$} & \multirow{2}{*}{$\begin{array}{l}\text { Insge- } \\
\text { samt }\end{array}$} \\
\hline & & $\begin{array}{l}\text { Industrie, } \\
\text { Bergbau u. } \\
\text { Bauwirt- } \\
\text { schaft }\end{array}$ & Andere & $\begin{array}{l}\text { Insge- } \\
\text { samt }\end{array}$ & & \\
\hline Albanien $^{2}$ & $\begin{array}{l}1930 \\
1950 \\
1967\end{array}$ & $\begin{array}{r}7,0 \\
15,0\end{array}$ & $\begin{array}{r}8,0 \\
17,9\end{array}$ & $\begin{array}{l}18,0 \\
15,0 \\
33,5\end{array}$ & $\begin{array}{l}82,0 \\
85,0 \\
66,5\end{array}$ & $\begin{array}{l}100,0 \\
100,0 \\
100,0\end{array}$ \\
\hline Bulgarien & $\begin{array}{l}1934 \\
1950 \\
1968 \\
1969 \\
1970\end{array}$ & $\begin{array}{r}8,0 \\
11,4 \\
36,9 \\
37,9 \\
38,8\end{array}$ & $\begin{array}{r}12,0 \\
9,1 \\
23,6 \\
24,5 \\
25,4\end{array}$ & $\begin{array}{l}20,0 \\
20,5 \\
60,4 \\
62,4 \\
64,2\end{array}$ & $\begin{array}{l}80,0 \\
79,5 \\
39,6 \\
37,6 \\
35,8\end{array}$ & $\begin{array}{l}100,0 \\
100,0 \\
100,0 \\
100,0 \\
100,0\end{array}$ \\
\hline Rumänien & $\begin{array}{l}1930 \\
1950 \\
1968 \\
1969 \\
1970\end{array}$ & $\begin{array}{r}7,2 \\
14,2 \\
27,8 \\
29,2 \\
30,8\end{array}$ & $\begin{array}{l}14,6 \\
21,5 \\
19,1 \\
19,6 \\
19,9\end{array}$ & $\begin{array}{l}21,8 \\
25,7 \\
46,9 \\
48,8 \\
50,7\end{array}$ & $\begin{array}{l}78,2 \\
74,3 \\
53,1 \\
51,2 \\
49,3\end{array}$ & $\begin{array}{l}100,0 \\
100,0 \\
100,0 \\
100,0 \\
100,0\end{array}$ \\
\hline Ungarn & $\begin{array}{l}1936 \\
1950 \\
1968 \\
1969 \\
1970\end{array}$ & $\begin{array}{l}29,3 \\
23,3 \\
42,2 \\
43,0 \\
43,7\end{array}$ & $\begin{array}{l}22,5 \\
26,1 \\
29,7 \\
29,9 \\
30,1\end{array}$ & $\begin{array}{l}51,8 \\
49,4 \\
71,9 \\
72,9 \\
73,8\end{array}$ & $\begin{array}{l}48,2 \\
50,6 \\
28,1 \\
27,1 \\
26,2\end{array}$ & $\begin{array}{l}100,0 \\
100,0 \\
100,0 \\
100,0 \\
100,0\end{array}$ \\
\hline Jugoslawien & $\begin{array}{l}1931 \\
1953 \\
1962 \\
1965\end{array}$ & $\begin{array}{c}11,1 \\
11,1 \\
17,5 \\
.\end{array}$ & $\begin{array}{c}10,2 \\
22,1 \\
25,2 \\
\quad .\end{array}$ & $\begin{array}{l}21,3 \\
33,2 \\
42,7 \\
47,0\end{array}$ & $\begin{array}{l}78,7 \\
66,8 \\
57,3 \\
53,0\end{array}$ & $\begin{array}{l}100,0 \\
100,0 \\
100,0 \\
100,0\end{array}$ \\
\hline Griechenland & $\begin{array}{l}1928 \\
1951 \\
1961 \\
1965\end{array}$ & $\begin{array}{c}18,9 \\
19,1\end{array}$ & $\begin{array}{c}32,9 \\
27,0 \\
.\end{array}$ & $\begin{array}{l}46,3 \\
51,8 \\
46,1 \\
48,0\end{array}$ & $\begin{array}{l}53,7 \\
48,2 \\
53,9 \\
52,0\end{array}$ & $\begin{array}{l}100,0 \\
100,0 \\
100,0 \\
100,0\end{array}$ \\
\hline Türkei & $\begin{array}{l}1935 \\
1950 \\
1965\end{array}$ & $\begin{array}{c}8,3 \\
10,3\end{array}$ & $\begin{array}{r}9,9 \\
17,9\end{array}$ & $\begin{array}{l}18,2 \\
14,3 \\
28,2\end{array}$ & $\begin{array}{l}81,8 \\
85,7 \\
71,8\end{array}$ & $\begin{array}{l}100,0 \\
100,0 \\
100,0\end{array}$ \\
\hline
\end{tabular}

Quelle: Rocznik Statystyczny 1969 (Warszawa), S. 621; 1970, S. 596, 597; 1971, S. 657. - Vjetari Statistikor i RPSH 1967-1968 (Tiranë), S.27, 31, 43. - FAO, Production Yearbook 1970, S. 21, 22. Statističeskij ežegodnik stran-と̌lenov SE்V 1971 (Moskva), S. 377, 379 . 
Tabelle 10: Erwerbsbevölkerung in den südosteuropäischen Ländern insgesamt und in der Landwirtschaft 1965

\begin{tabular}{|c|c|c|c|c|c|c|c|c|}
\hline \multirow[b]{3}{*}{ Land } & \multirow{3}{*}{$\begin{array}{l}\text { Gesamt- } \\
\text { bevöl- } \\
\text { kvrung } \\
\text { in } 1000\end{array}$} & \multicolumn{2}{|c|}{$\begin{array}{l}\text { Erwerbsb svolke- } \\
\text { rung insgesamt }\end{array}$} & \multicolumn{5}{|c|}{ Agrarbevölkerung } \\
\hline & & \multirow[b]{2}{*}{ in 1000} & \multirow[b]{2}{*}{$\begin{array}{l}\text { in vH } \\
\text { der } \\
\text { Gesamt- } \\
\text { bevöl- } \\
\text { kerung }\end{array}$} & \multirow[b]{2}{*}{ in 1000} & \multirow[b]{2}{*}{$\begin{array}{l}\text { in vH } \\
\text { der } \\
\text { Gesamt- } \\
\text { bevöl- } \\
\text { kerung }\end{array}$} & \multicolumn{3}{|c|}{ Erwerbsbevölkerung } \\
\hline & & & & & & in 1000 & \begin{tabular}{|l} 
in vH \\
der \\
Agrar- \\
bevöl- \\
kerung
\end{tabular} & $\begin{array}{l}\text { in vH der } \\
\text { Erwerbs- } \\
\text { bevöl- } \\
\text { kerung } \\
\text { insges. }\end{array}$ \\
\hline Albanien & 1865 & 856 & 46 & 1113 & 60 & 499 & 45 & 58 \\
\hline Bulgarien & 8201 & 4435 & 54 & 4675 & 57 & 2615 & 56 & 59 \\
\hline Rumänien & 19027 & 10845 & 57 & 11359 & 60 & 6441 & 57 & 59 \\
\hline Ungarn & 10148 & 4931 & 49 & 2912 & 29 & 1540 & 53 & 31 \\
\hline Jugoslawien & 19507 & 8780 & 45 & $9 \quad 144$ & 47 & 4640 & 51 & 53 \\
\hline Griechenland & 8551 & 3677 & 43 & 4574 & 53 & 1930 & 42 & 52 \\
\hline Türkei & $31 \quad 151$ & 13395 & 43 & 23052 & 74 & 9644 & 42 & 72 \\
\hline
\end{tabular}

Quelle: FAO, Production Yearbook 1970, S. 21, 22.

Tabelle 11 : Beschäftigte in den südosteuropäischen Ländern außerhalb des Agrarsektors 1950, 1960 und 1970 (in Mill.)

\begin{tabular}{|l|c|c|c|c|c|c|c|c|}
\hline \multirow{2}{*}{} & \multicolumn{4}{|c|}{ Beschäftigte insgesamt } & \multicolumn{3}{c|}{ davon im Bergbau, Industrie und } \\
Bauwirtschaft
\end{tabular}

Quellen: Statistiદeskij èžegodnik stran-દlenov SEV 1971 (Moskva), S. 382 ff. - Rocznik Statystyczny 1971 (Warszawa), S. 658. Vjetari Statisticor i RPSH 1967-1968 (Tirane), S. 43. Statistisches Bundesamt Wiesbaden. Länderbericht Türkei, 1969 , S. 14 . 
Tabelle 12: Beschäftigung (ohne Landwirtschaft) in den südosteuropäischen Ländern 1965 und 1969 Index $1960=100$

\begin{tabular}{|l|c|c|c|c|}
\hline \multirow{2}{*}{ Land } & \multicolumn{2}{|c|}{ Beschäftigung insgesamt } & \multicolumn{2}{c|}{ Industriebeschäftigte } \\
\cline { 2 - 5 } Albanien & 1965 & 1969 & 1965 & 1969 \\
Bulgarien & 126,6 & $145,0^{\mathrm{a}}$ & 125,0 & $157,7^{\mathrm{a}}$ \\
Rumänien & 123,9 & 146,6 & 123,3 & 146,7 \\
Ungarn & 131,3 & 157,3 & 133,0 & 157,4 \\
Jugoslawien & 115,4 & 125,3 & 118,2 & 138,6 \\
Griechenland & 125,3 & 130,0 & 128,4 & 129,5 \\
Türkei & 147,1 & 207,0 & 133,3 & 184,4 \\
a $1967 . \quad b 1961=100$. & & & & \\
\hline
\end{tabular}

尺uelle: UN, Statistical Yearbook 1970, S. $102 \mathrm{ff}$.

Tabelle 13: Beschäftigte im Bergbau in den südosteuropäischen Ländern $1960-1968$ (in 1000)

\begin{tabular}{|l|c|c|c|c|c|}
\hline \multicolumn{1}{|c|}{ Land } & 1960 & 1965 & 1966 & 1967 & 1968 \\
\hline Albanien & $\cdot$ &. &. &. &. \\
Bulgarien & 112,7 & 95,2 & 96,7 & 96,6 & 93,9 \\
Rumänien & $54^{\mathrm{a}}$ & 59 & 61 & 61 & 62 \\
Ungarn & 144 & 166 & 163 & 158 & 158 \\
Jugoslawien & 149 & 148 & 143 & 138 & 136 \\
Griechenland & $20,4^{b}$ & 22,8 & 22,9 & 22,3 &. \\
Türkei & 66 & 69 & 73 & 72 &. \\
a $1963 . \quad$ b 1958. & & & & & \\
\hline
\end{tabular}

Quelle: UN Statistical Yearbook 1963, S. $161 \mathrm{ff}$; 1970, S. $185 \mathrm{ff}$. 
Tabelle 14: Beschäftigte in der Industrie in den südosteuropäischen Ländern 1960-1969 (in 1000)

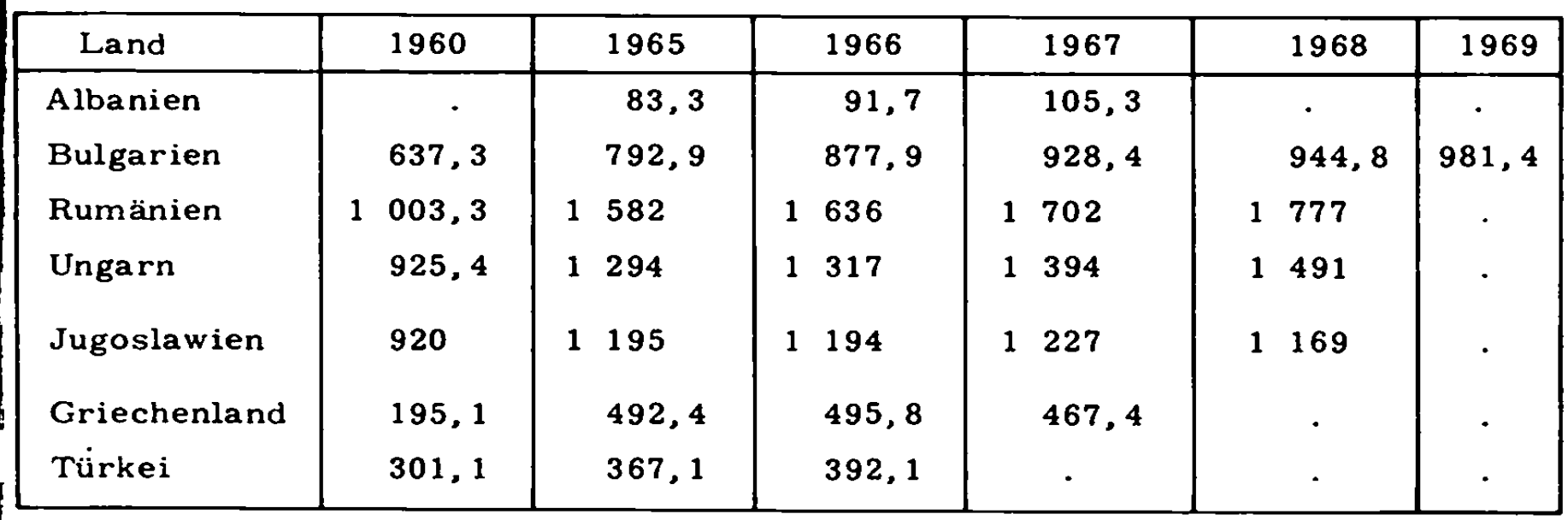

Quelle: UN, Statistical Yearbook 1970, S. 227 ff.; 1963, S. 208 ff.

Tabelle 15: Beschäftigte in der Bauwirtschaft in den südosteuropäischen Ländern 1960-1969 (in 1000)

\begin{tabular}{|l|c|c|c|c|}
\hline \multicolumn{1}{|c|}{ Land } & 1960 & 1965 & 1968 & 1969 \\
\hline Albanien & 30,2 & $33,9^{\mathrm{a}}$ &. &. \\
Bulgarien & 125,4 & 151,5 & 197,7 & 201,2 \\
Rumänien & $433,5^{\mathrm{b}}$ & 472,9 & 597,6 & 611,3 \\
Ungarn & 205,8 & 240,8 & 285,4 & 310,3 \\
Jugoslawien & 316 & 335 & 323 & 339 \\
Griechenland & $57,3^{c}$ &. &. &. \\
Türkei &. & & &. \\
a $1964 . \quad b_{1963 .-c_{1958 .}}$ & & & & \\
\hline
\end{tabular}

Quelle: UN, Statistical Yearbook 1970, S. 326 ff.; 1965, S. 324 ff. 
Tabelle 16: Gastarbeiter aus Südosteuropa in der Bundesrepublik Deutschland Stand: 30 . September 1971

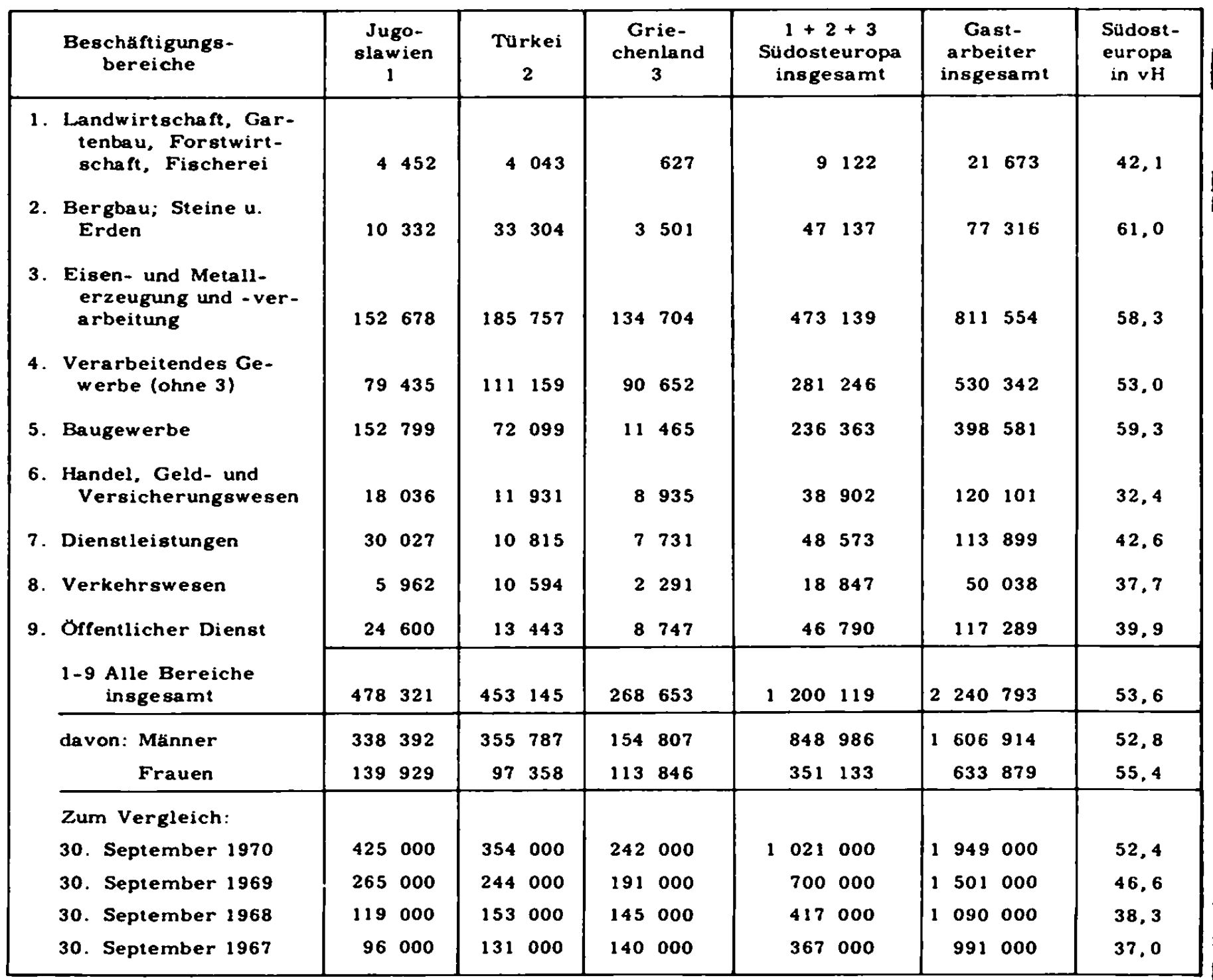

Quelle: Amtliche Nachrichten der Bundesanstalt für Arbeit. Nürnberg, Jg. 19 (29. Dez.1971), Nr. 12, S. 1030 ff. 


\section{Schulwesen, Gesundheit, Kulturelles Leben}

Tabelle 17: Lehrer, Schüler und Studierende in den südosteuropäischen Ländern 1950-1968

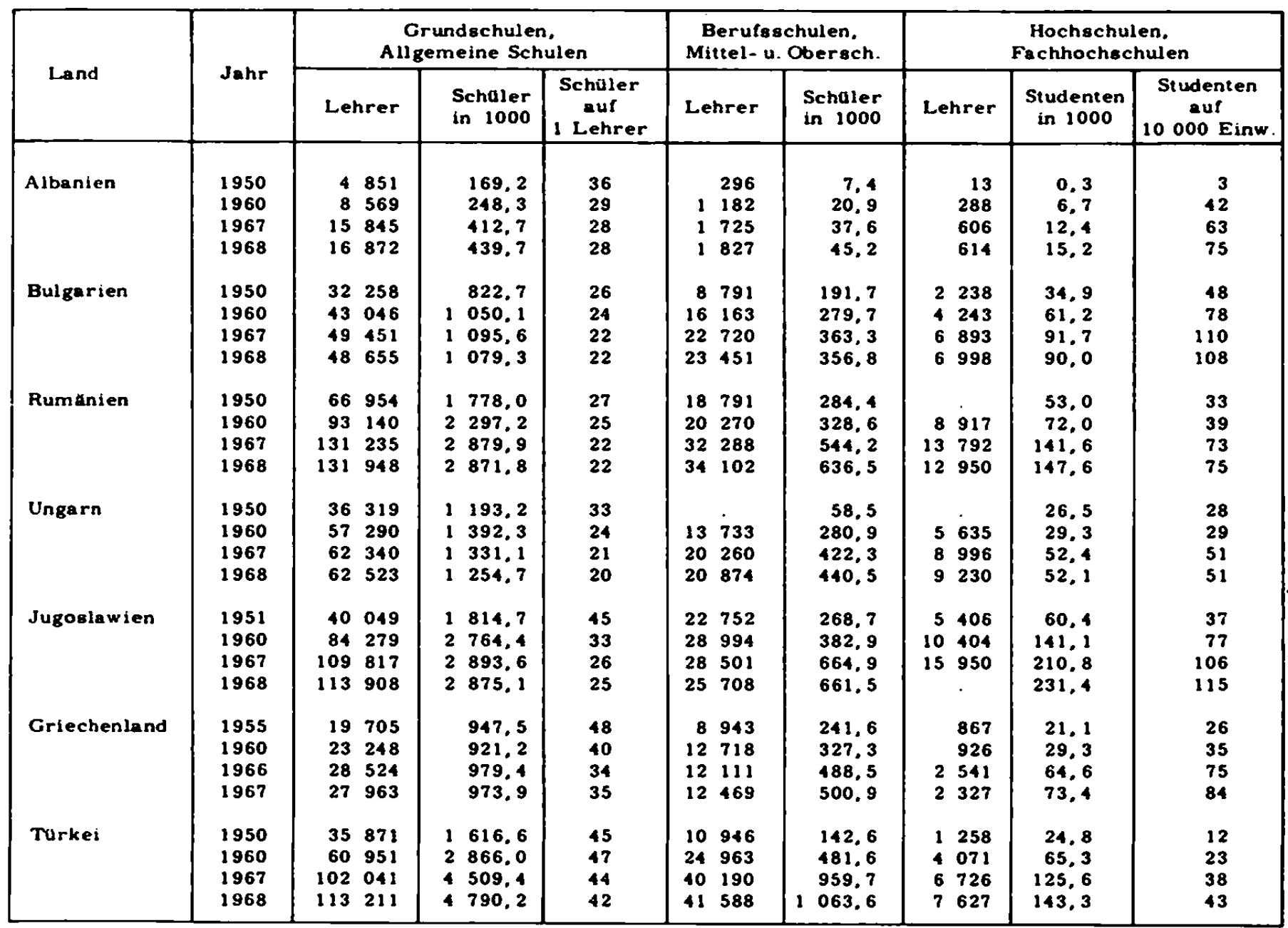

Quelle: UNESCO, Statistical Yearbook 1970, S. $193 \mathrm{ff}$. 
Tabelle 18: Studierende in den südosteuropäischen Ländern nach Fachrichtungen 1967-1968

\begin{tabular}{|c|c|c|c|c|c|c|c|}
\hline Fachrichtungen & $\begin{array}{c}\begin{array}{c}\text { Alba- } \\
\text { nien }\end{array} \\
1967\end{array}$ & $\begin{array}{c}\begin{array}{c}\text { Bulga - } \\
\text { rien }\end{array} \\
1968 \\
\end{array}$ & $\begin{array}{c}\text { Rumä- } \\
\text { nien }\end{array}$ & $\frac{\text { Ungarn }}{1968}$ & $\begin{array}{c}\begin{array}{c}\text { Jugo- } \\
\text { slawien }\end{array} \\
1968\end{array}$ & $\begin{array}{c}\begin{array}{c}\text { Grie- } \\
\text { chenland }\end{array} \\
1967\end{array}$ & $\begin{array}{c}\text { Türkei } \\
1968\end{array}$ \\
\hline $\begin{array}{l}\text { Philosophische } \\
\text { Fakultä́t }\end{array}$ & 1944 & 5952 & 19606 & 3099 & 22818 & 8406 & 11861 \\
\hline $\begin{array}{l}\text { Erziehungswissen- } \\
\text { schaften }\end{array}$ & 2510 & 11400 & 24641 & 6918 & 37474 & 4989 & 8009 \\
\hline Recht & 504 & 1829 & 6141 & 1445 & 28750 & 8582 & 16096 \\
\hline $\begin{array}{l}\text { Wirtschaftswissen- } \\
\text { schaften, Sozialw. }\end{array}$ & 1275 & 13372 & 17275 & 3489 & 42707 & 16135 & 42318 \\
\hline Naturwissenschaften & 1938 & 7483 & $13 \quad 377$ & 4140 & 11438 & 8562 & 10108 \\
\hline $\begin{array}{l}\text { Technische Wissen- } \\
\text { schaften }\end{array}$ & 1259 & $\begin{array}{ll}34 & 059\end{array}$ & 42700 & 17269 & 51935 & 4496 & 32583 \\
\hline Medizin & 1034 & 7614 & 9633 & 7626 & 18566 & 10251 & 16076 \\
\hline Landwirtschaft & 1732 & 5965 & 9657 & 6868 & 12580 & 3901 & 4118 \\
\hline Andere & 239 & 2350 & 4607 & 1207 & 5176 & 8116 & 2110 \\
\hline Insgesamt & 12435 & $90 \quad 024$ & $147 \quad 637$ & $52 \quad 061$ & 231444 & $73 \quad 438$ & $143 \quad 279$ \\
\hline $\mathrm{vH}$ & & & & & & & \\
\hline $\begin{array}{l}\text { Philosophische } \\
\text { Fakultät }\end{array}$ & 15,6 & 6,6 & 13,3 & 6,0 & 9,9 & 11,4 & 8,3 \\
\hline $\begin{array}{l}\text { Erziehungswissen- } \\
\text { schaften }\end{array}$ & 20,2 & 12,7 & 16,7 & 13,3 & 16,2 & 6,8 & 5.6 \\
\hline Recht & 4,1 & 2,0 & 4,2 & 2,8 & 12,4 & 11,7 & 11,2 \\
\hline $\begin{array}{l}\text { Wirtschaftswissen- } \\
\text { schaften, Sozialw. }\end{array}$ & 10,3 & 14,9 & 11.7 & 6.7 & 18,5 & 22,0 & 29,5 \\
\hline Naturwissenschaften & 15,6 & 8,3 & 9,1 & 7.9 & 5,0 & 11,7 & 7,1 \\
\hline $\begin{array}{l}\text { Technische Wissen- } \\
\text { schaften }\end{array}$ & 10,1 & 37,8 & 28,9 & 33,2 & 22,4 & 6,1 & 22,7 \\
\hline Medizin & 8,3 & 8,5 & 6,5 & 14,6 & 8,0 & 14,0 & 11,2 \\
\hline Landwirtschaft & 13,9 & 6,6 & 6,5 & 13,2 & 5,4 & 5,3 & 2,9 \\
\hline Andere & 1,9 & 2,6 & 3,1 & 2,3 & 2,2 & 11,0 & 1,5 \\
\hline Insgesamt & 100,0 & 100,0 & 100,0 & 100,0 & 100,0 & 100,0 & 100,0 \\
\hline
\end{tabular}

Quelle: UNESCO, Statistical Yearbook 1970, S. $372 \mathrm{ff}$. 
Tabelle 19: Gesundheitswesen in den südosteuropäischen Ländern 1950-1969

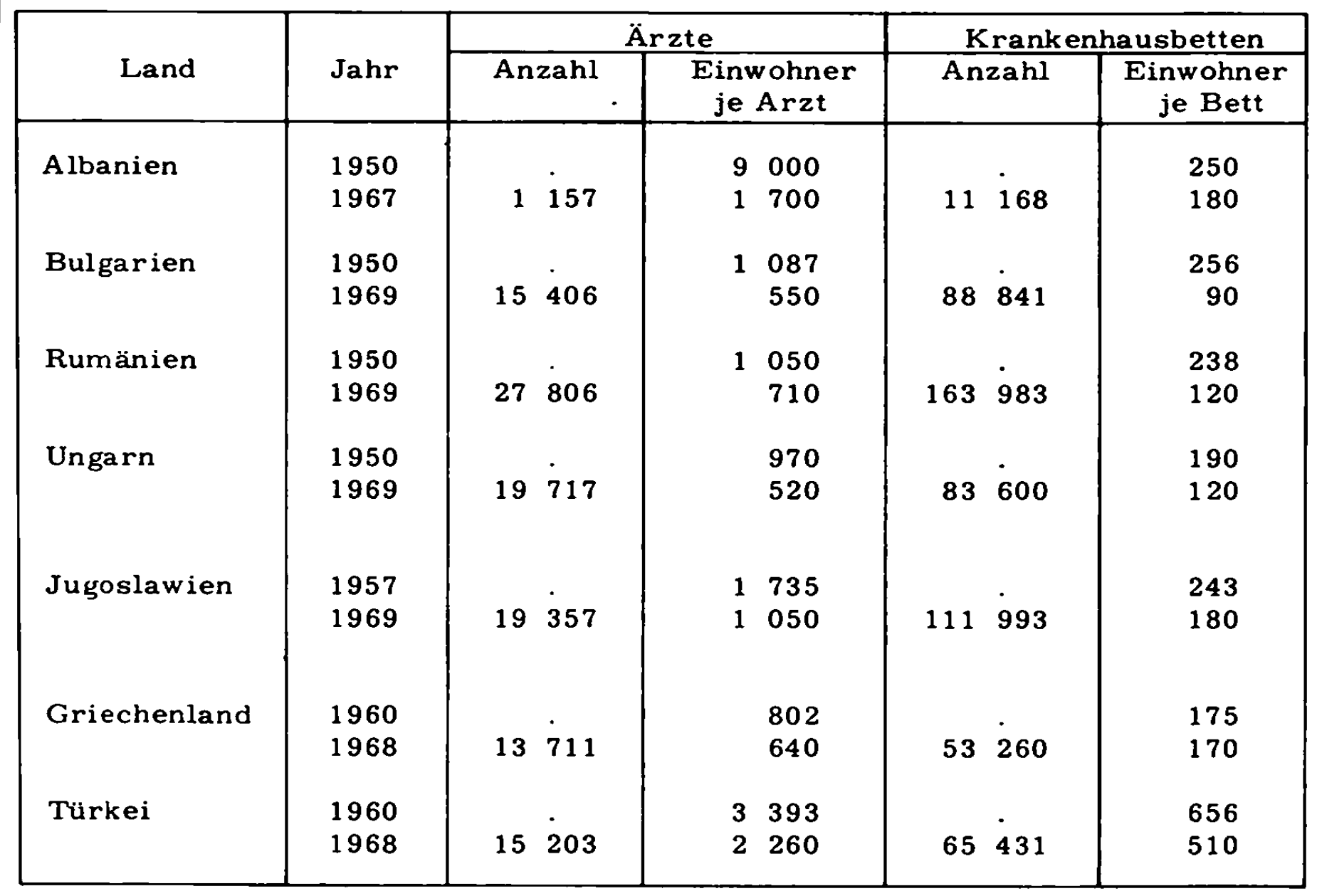

Quelle: UN, Statistical Yearbook 1970, S. 715, 716. - Statistisches Bundesamt, Wiesbaden, Länderkurzberichte. - Statistisches Jahrbuch der DDR 1971, S. 18*. 
Tabelle 20: Buchveröffentlichungen ${ }^{2}$ in den südosteuropäischen Ländern 1969

\begin{tabular}{|c|c|c|c|c|c|c|c|}
\hline \multirow{2}{*}{ Land } & \multirow{2}{*}{ Titel } & \multirow{2}{*}{$\begin{array}{c}\text { Auflage } \\
\text { in } \\
1000\end{array}$} & \multicolumn{2}{|c|}{ Schulbücher } & \multicolumn{3}{|c|}{ Kinderbücher } \\
\hline & & & Titel & $\begin{array}{l}\text { Auflage } \\
\text { in } 1000\end{array}$ & Titel & $\begin{array}{c}\text { Au } \\
\text { in }\end{array}$ & $\begin{array}{l}\text { lage } \\
1000\end{array}$ \\
\hline Bulgarien & 3548 & 36925 & 635 & 13127 & 205 & & 201 \\
\hline Rumänien & 7440 & $78 \quad 217$ & 832 & 21807 & 122 & & 886 \\
\hline Ungarn & 4831 & $\begin{array}{ll}56 & 092\end{array}$ & 967 & 18115 & 64 & 1 & 417 \\
\hline Jugoslawien & 8708 & 63868 & 1785 & 22202 & 637 & 10 & 632 \\
\hline Griechenland & 1822 & . & 143 & . & 59 & & . \\
\hline Türkei & 5669 & . & . & . & . & & . \\
\hline
\end{tabular}

Quelle: UNESCO, Statistical Yearbook 1970, S. $635 \mathrm{ff}$.

Tabelle 21 : Zeitungen, Rundfunkempfänger und Fernsehempfänger in den südosteuropäischen Ländern je 1000 Einwohner 1969

\begin{tabular}{|l|c|c|c|}
\hline \multicolumn{1}{|c|}{ Land } & Zeitungen & $\begin{array}{c}\text { Rundfunk- } \\
\text { empfänger }\end{array}$ & $\begin{array}{c}\text { Fernseh- } \\
\text { empfänger }\end{array}$ \\
\hline Albanien & 51 & $77^{\mathrm{a}}$ & 1,2 \\
Bulgarien & 189 & 269 & 98 \\
Rumänien & 166 & 152 & 64 \\
Ungarn & 212 & 246 & 155 \\
Jugoslawien & 79 & 163 & 76 \\
Griechenland & 85 & $113^{\mathrm{b}}$ & 10 \\
Türkei & 41 & 88 & 0,7 \\
a $1968 . \quad$ b 1965 & & & \\
\hline
\end{tabular}

Quelle: UNESCO, Statistical Yearbook 1970, S. $690 \mathrm{ff}$. 
E. Wirtschaftswachstum, Nationaleinkommen

Tabelle 22: Wirtschaftswachstum der südosteuropäischen Länder 1950-1970

\begin{tabular}{|c|c|c|c|c|c|}
\hline Jahr & Bulgarien & Rumänien & Ungarn & Jugoslawien & Griechenland \\
\hline & \multicolumn{5}{|c|}{$\frac{\text { Jahreszuwachsraten des Nationaleinkommens }}{(\text { Vorjahr }=100)}$} \\
\hline 1951 & 141 & 131 & 116 & 109 & 111 \\
\hline 1952 & 100 & 104 & 99 & 85 & 99 \\
\hline 1953 & 120 & 115 & 113 & 118 & 115 \\
\hline 1954 & 100 & 100 & 96 & 104 & 104 \\
\hline 1955 & 105 & 122 & 109 & 114 & 109 \\
\hline 1956 & 101 & 93 & 89 & 96 & 108 \\
\hline 1957 & 113 & 116 & 123 & 123 & 108 \\
\hline 1958 & 107 & 104 & 106 & 103 & 103 \\
\hline 1959 & 122 & 112 & 107 & 117 & 104 \\
\hline 1960 & 107 & 111 & 109 & 106 & 104 \\
\hline 1961 & 103 & 111 & 106 & 106 & 112 \\
\hline 1962 & 106 & 104 & 105 & 104 & 104 \\
\hline 1963 & 108 & 110 & 106 & 112 & 108 \\
\hline 1964 & 110 & 112 & 105 & 113 & 109 \\
\hline 1965 & 107 & 110 & 101 & 103 & 108 \\
\hline 1966 & 111 & 110 & 108 & 109 & 107 \\
\hline 1967 & 109 & 107 & 109 & 102 & 105 \\
\hline 1968 & 106 & 107 & 105 & 107 & 105 \\
\hline 1969 & 110 & 107 & 108 & 104 & 108 \\
\hline 1970 & 107 & 107 & 105 & 104 & \\
\hline \multicolumn{6}{|c|}{$\frac{\text { Indexzahlen des Nationaleinkommens je Kopf der Bevölkerung }}{(1950=100)}$} \\
\hline 1960 & 260 & 238 & 166 & 175 & 161 \\
\hline 1965 & 343 & 352 & 213 & 231 & 239 \\
\hline 1970 & 506 & 484 & 278 & 287 & $289^{a}$ \\
\hline
\end{tabular}

Quelle: Rocznik statystyczny 1966 (Warszawa), S. 600, 1971, S. 659. 
Tabelle 23: Das Bruttoinlandsprodukt der südosteuropäischen Länder in konstanten Preisen (Indexzahlen 1961-1970; $1960=100$ )

\begin{tabular}{|c|c|c|c|c|c|c|c|}
\hline Jahr & Albanien & $\begin{array}{l}\text { Bulga- } \\
\text { rien }\end{array}$ & Rumänien & Ungarn & $\begin{array}{c}\text { Jugo- } \\
\text { slawien }\end{array}$ & $\begin{array}{c}\text { Griechen- } \\
\text { land }\end{array}$ & Türkei \\
\hline 1960 & 100 & 100 & 100 & 100 & 100 & 100 & \\
\hline 1961 & 107 & 103 & 110 & 106 & 103 & 111 & 100 \\
\hline 1962 & 113 & 109 & 115 & 111 & 109 & 115 & 107 \\
\hline 1963 & 126 & 118 & 126 & 117 & 122 & 124 & 114 \\
\hline 1964 & 133 & 129 & 141 & 123 & 136 & 135 & 120 \\
\hline 1965 & 133 & 138 & 154 & 123 & 138 & 146 & 124 \\
\hline 1966 & 149 & 154 & 169 & 133 & 147 & 157 & 136 \\
\hline 1967 & 166 & 168 & 182 & 144 & 148 & 165 & 147 \\
\hline 1968 & 185 & 178 & 195 & 151 & 154 & 175 & 155 \\
\hline 1969 & . & 196 & 209 & 163 & . & . & 161 \\
\hline 1970 & & 210 & 223 & 170 & . & & \\
\hline
\end{tabular}

Quelle: UN, Monthly Bulletin of Statistics, Juli 1971, S. 196, 197.

Tabelle 24: Nationaleinkommen der südosteuropäischen Länder Struktur nach Wirtschaftszweigen 1969 (in $\mathrm{vH}$ )

\begin{tabular}{|c|c|c|c|c|c|c|}
\hline Land & $\begin{array}{l}\text { Landwirt- } \\
\text { schaft, } \\
\text { Forstwirt- } \\
\text { schaft }\end{array}$ & $\begin{array}{c}\text { Bergbau, } \\
\text { Indu- } \\
\text { strie }\end{array}$ & $\begin{array}{c}\text { Bau- } \\
\text { wirt- } \\
\text { schaft }\end{array}$ & $\begin{array}{l}\text { Trans- } \\
\text { port, } \\
\text { Nach- } \\
\text { richten }\end{array}$ & $\begin{array}{c}\text { Handel, } \\
\text { Dienst- } \\
\text { leistg. } \\
\text { u.a. }\end{array}$ & $\begin{array}{c}\text { Insge- } \\
\text { samt }\end{array}$ \\
\hline Albanien & . & . & . & . & . & \\
\hline Bulgarien & 25,1 & 50,4 & 8,5 & 4,6 & 11,4 & 100,0 \\
\hline Rumänien & $24,4^{\mathrm{a}}$ & 56,6 & 9,5 & 6,0 & 3,5 & 100,0 \\
\hline Ungarn & 20,7 & 42,3 & 11,7 & 6,0 & 19,3 & 100,0 \\
\hline Jugoslawien & 23,1 & 35,6 & 8,3 & 8,4 & 24,6 & 100,0 \\
\hline Griechenland $^{\mathrm{b}}$ & 21,2 & 19,3 & 7,9 & 7,4 & 44,2 & 100,0 \\
\hline Türkei $^{c}$ & 34,5 & 18,7 & 6,7 & 8,2 & 31,9 & 100,0 \\
\hline
\end{tabular}

Quelle: Rocznik Statystyczny 1971 (Warszawa), S. 660 . 


\section{F. Landwirtschaft, Forstwirtschaft, Fischerei}

Tabelle 25: Landwirtschaftliche Nutzfläche der südosteuropäischen Länder 1943 - 1969 (in 1000 ha und $v H$ )

\begin{tabular}{|c|c|c|c|c|c|c|c|c|c|c|c|}
\hline \multirow[b]{2}{*}{ Land } & \multirow[b]{2}{*}{ Jahr } & \multicolumn{6}{|c|}{ in $1000 \mathrm{ha}$} & \multicolumn{4}{|c|}{ in $\mathrm{vH}$} \\
\hline & & $\begin{array}{l}\text { Oher- } \\
\text { ntacte } \\
\text { insges. }\end{array}$ & $\begin{array}{l}\text { Acker- } \\
\text { land } \\
\text { Dauer- } \\
\text { kulturen }\end{array}$ & $\begin{array}{l}\text { Weiden, } \\
\text { Wiesen }\end{array}$ & Wald & Ande & lere & $\begin{array}{l}\text { Acker- } \\
\text { land } \\
\text { Dauer- } \\
\text { kulturen }\end{array}$ & $\begin{array}{l}\text { Weiden, } \\
\text { Wiesen }\end{array}$ & Wald & Andere \\
\hline Albanien & $\begin{array}{l}1943 \\
1967\end{array}$ & $\begin{array}{ll}2 & 875 \\
2 & 875\end{array}$ & $\begin{array}{l}353 \\
556\end{array}$ & $\begin{array}{l}850 \\
688\end{array}$ & $\begin{array}{ll}1 & 130 \\
1 & 242\end{array}$ & & $\begin{array}{l}542 \\
389\end{array}$ & $\begin{array}{l}12,2 \\
19.4\end{array}$ & $\begin{array}{l}29,8 \\
23.9\end{array}$ & $\begin{array}{l}39,3 \\
43,2\end{array}$ & $\begin{array}{l}18,7 \\
13,5\end{array}$ \\
\hline Bulgarien & $\begin{array}{l}1947 \\
1949\end{array}$ & $\begin{array}{ll}11 & 091 \\
11 & 091\end{array}$ & $\begin{array}{l}4286 \\
4555\end{array}$ & . & $\begin{array}{ll}3 & 682 \\
3 & 675\end{array}$ & $\begin{array}{ll}3 & 1 \\
2 & 8\end{array}$ & $\begin{array}{l}123^{a} \\
861^{a}\end{array}$ & $\begin{array}{l}38,7 \\
41,1\end{array}$ & & $\begin{array}{l}33,2 \\
33,1\end{array}$ & $\begin{array}{l}28,1^{a} \\
25,8^{a}\end{array}$ \\
\hline Rumanien & $\begin{array}{l}1947 \\
1949\end{array}$ & $\begin{array}{ll}23 & 750 \\
23 & 750\end{array}$ & $\begin{array}{rr}9 & 300 \\
10 & 544\end{array}$ & $\begin{array}{ll}3 & 400 \\
4 & 424\end{array}$ & $\begin{array}{ll}6 & 326 \\
6 & 316\end{array}$ & $\begin{array}{ll}4 & 7 \\
2 & 4\end{array}$ & $\begin{array}{l}724 \\
466\end{array}$ & $\begin{array}{l}39,2 \\
44,4\end{array}$ & $\begin{array}{l}14.2 \\
18,6\end{array}$ & $\begin{array}{l}26,6 \\
26,6\end{array}$ & $\begin{array}{l}20.0 \\
10.4\end{array}$ \\
\hline Ungern & $\begin{array}{l}1947 \\
1949\end{array}$ & $\begin{array}{ll}9 & 303 \\
9 & 303\end{array}$ & $\begin{array}{ll}5 & 776 \\
5 & 604\end{array}$ & $\begin{array}{ll}1 & 586 \\
1 & 284\end{array}$ & $\begin{array}{ll}1 & 253 \\
1 & 463\end{array}$ & & $\begin{array}{l}688 \\
952\end{array}$ & $\begin{array}{l}62,1 \\
60,3\end{array}$ & $\begin{array}{l}17,0 \\
13,8\end{array}$ & $\begin{array}{l}13,5 \\
15,7\end{array}$ & $\begin{array}{r}7,4 \\
10,2\end{array}$ \\
\hline Jugoslawien & $\begin{array}{l}1954 \\
1969\end{array}$ & $\begin{array}{ll}25 & 580 \\
25 & 580\end{array}$ & $\begin{array}{ll}8 & 077 \\
8 & 237\end{array}$ & $\begin{array}{ll}6 & 456 \\
6 & 403\end{array}$ & $\begin{array}{ll}7 & 895 \\
8 & 812\end{array}$ & $\begin{array}{ll}3 & 1 \\
2 & 1\end{array}$ & $\begin{array}{l}152 \\
128\end{array}$ & $\begin{array}{l}31,9 \\
32,2\end{array}$ & $\begin{array}{l}25,2 \\
25,0\end{array}$ & $\begin{array}{l}30,8 \\
34,5\end{array}$ & $\begin{array}{r}12,1 \\
8,3\end{array}$ \\
\hline Griechenland & $\begin{array}{l}1954 \\
1966\end{array}$ & $\begin{array}{ll}13 & 194 \\
13 & 194\end{array}$ & $\begin{array}{ll}3 & 515 \\
3 & 631\end{array}$ & $\begin{array}{ll}5 & 178 \\
5 & 239\end{array}$ & $\begin{array}{ll}1 & 958 \\
2 & 608\end{array}$ & $\begin{array}{ll}2 & 5 \\
1 & 7\end{array}$ & $\begin{array}{l}543 \\
716\end{array}$ & $\begin{array}{l}26,7 \\
27,5\end{array}$ & $\begin{array}{l}39,3 \\
39,7\end{array}$ & $\begin{array}{l}15,0 \\
19.8\end{array}$ & $\begin{array}{l}19.0 \\
13.0\end{array}$ \\
\hline Turkei & $\begin{array}{l}1954 \\
1969\end{array}$ & $\begin{array}{ll}78 & 058 \\
78 & 058\end{array}$ & $\begin{array}{ll}21 & 333 \\
27 & 743\end{array}$ & $\begin{array}{ll}32 & 484 \\
26 & 135\end{array}$ & $\begin{array}{l}10418 \\
18273\end{array}$ & $\begin{array}{rl}13 & 8 \\
5 & 9\end{array}$ & $\begin{array}{l}823 \\
907\end{array}$ & $\begin{array}{l}27,3 \\
35,5\end{array}$ & $\begin{array}{l}41,6 \\
33,5\end{array}$ & $\begin{array}{l}13,3 \\
23,4\end{array}$ & $\begin{array}{r}17.8 \\
7.6\end{array}$ \\
\hline Zypern & 1968 & 925 & 432 & 93 & 171 & & 229 & 46.7 & 10.0 & 18.5 & 24.8 \\
\hline
\end{tabular}

Quelle: FAO, Production Yearbook 1955, S. 3 ff. -1970, S. 3 ff.

Tabelle 26: Landwirtschaftliche Produktion der südosteuropäischen Länder $1966-1970$ (Index: $1952 / 56=100$ )

\begin{tabular}{|l|c|c|c|c|c|}
\hline \multicolumn{1}{|c|}{ Land } & 1966 & 1967 & 1968 & 1969 & 1970 \\
\hline Albanien & 186 & 192 & 175 & 186 & 193 \\
Bulgarien & 156 & 164 & 157 & 164 & 156 \\
Rumänien & 135 & 140 & 141 & 150 & 141 \\
Ungarn & 182 & 179 & 175 & 197 & 181 \\
Jugoslawien & 171 & 174 & 164 & 173 & 185 \\
Griechenland & 157 & 160 & 167 & 166 & 166 \\
Türkei & 115 & 103 & 93 & 104 & 104 \\
Bulgarien & 114 & 102 & 97 & 103 & 95 \\
Rumänien & 108 & 104 & 100 & 106 & 94 \\
Ungarn & 125 & 98 & 98 & 112 & 91 \\
Jugoslawien & 104 & 102 & 94 & 107 & 106 \\
Griechenland & 111 & 102 & 105 & 98 & 101 \\
Türkei & \multicolumn{2}{|c|}{ Index: Vorjahr } \\
\hline
\end{tabular}

Quelle: FAO, Production Yearbook 1970, S. 30. - Rocznik Statystyczny (Warszawa), 1967, S. 656; 1968, S. 659; 1969, S. 655; 1970, S. $628 ; 1971$, S. 688 . 
Tabelle 27: Getreideernte in den südosteuropäischen Ländern 1948-1970

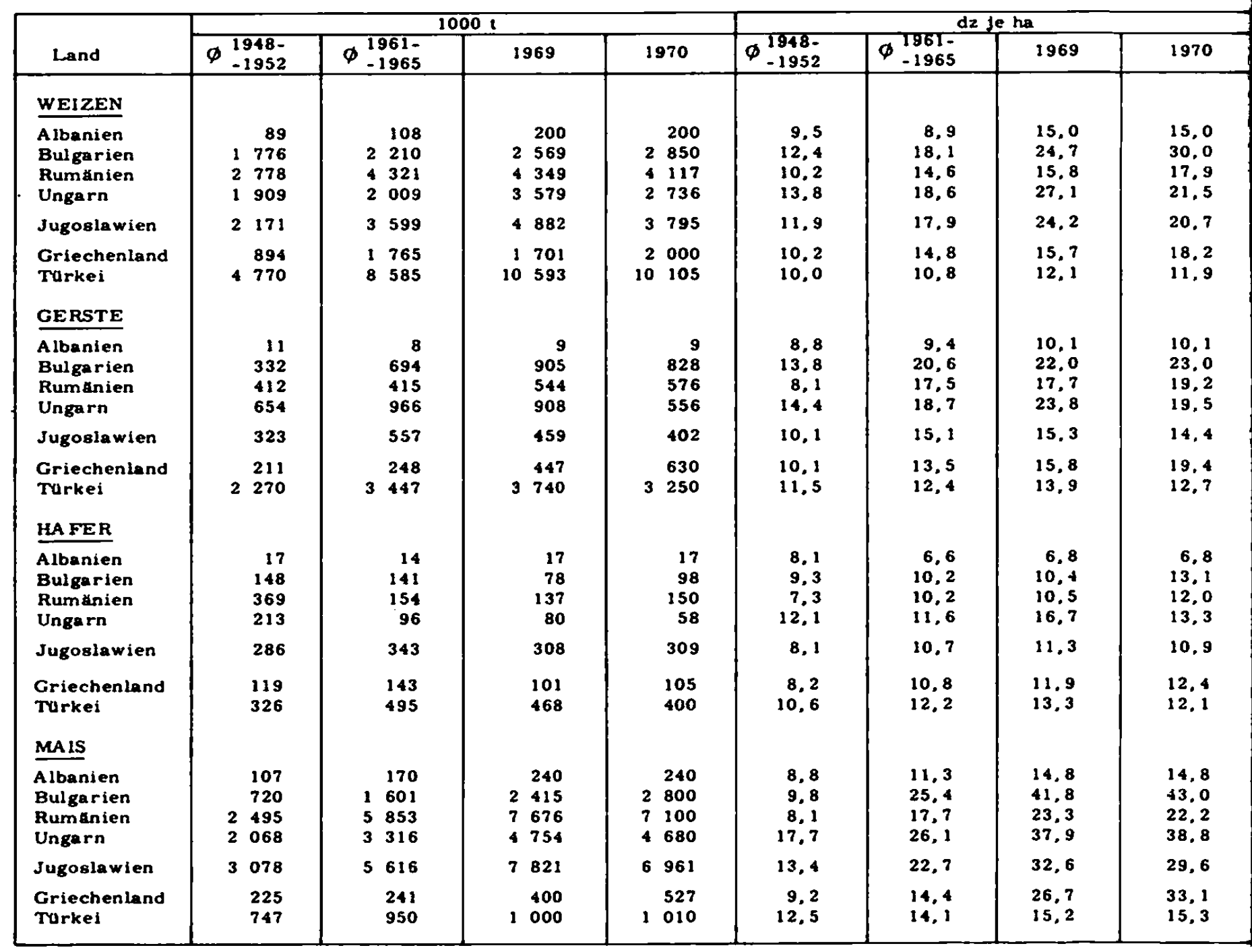

Quelle: FAO, Production Yearbook 1970, S. $37 \mathrm{ff}$. 
Tabelle 28: Ernte von Kartoffeln, Zuckerrüben, Tomaten und Weintrauben in den südosteuropäischen Ländern 1948 - 1970

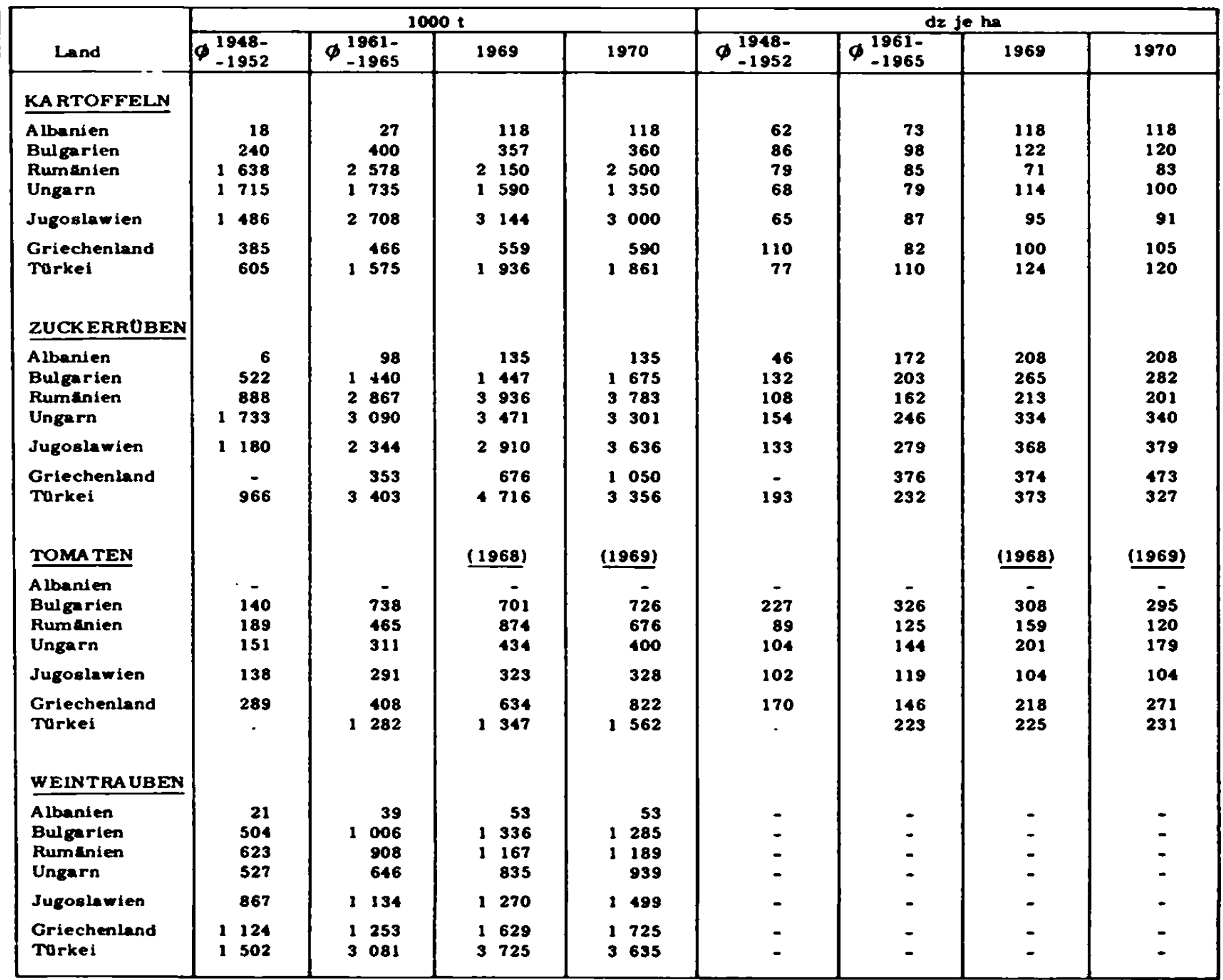

Quelle: FAO, Production Yearbook 1970, S. 94 ff. 
Tabelle 29: Ernte von Sonnenblumen, Tabak, Baumwolle und Hanf in den südosteuropäischen Ländern 1948 - 1970

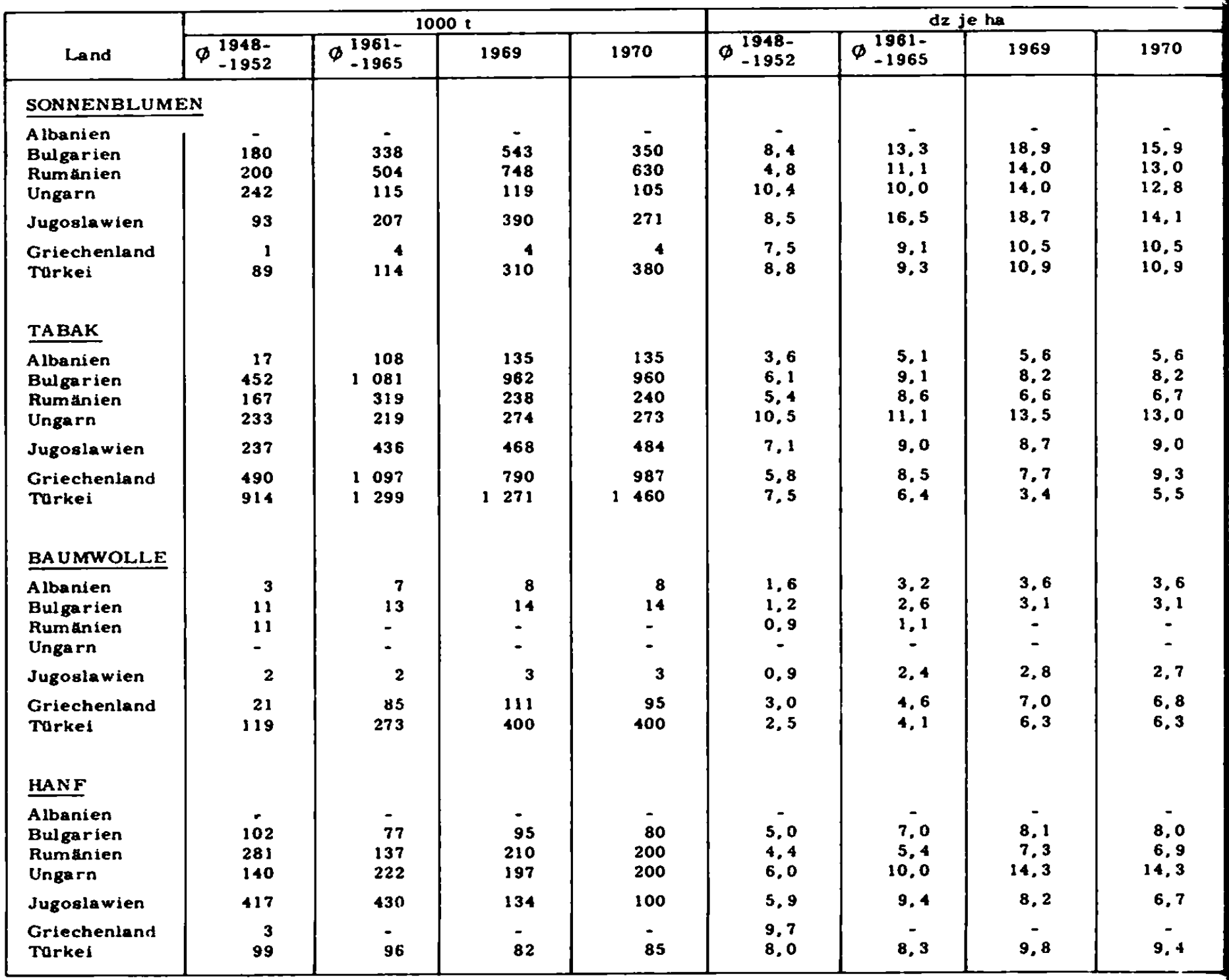

Quelle: FAO, Production Yearbook 1970, S. 253 ff. 
Tabelle $30^{\circ}$ Viehbestand in den südosteuropäischen Ländern $1947 / 48-1969 / 70$ (in 1000 )

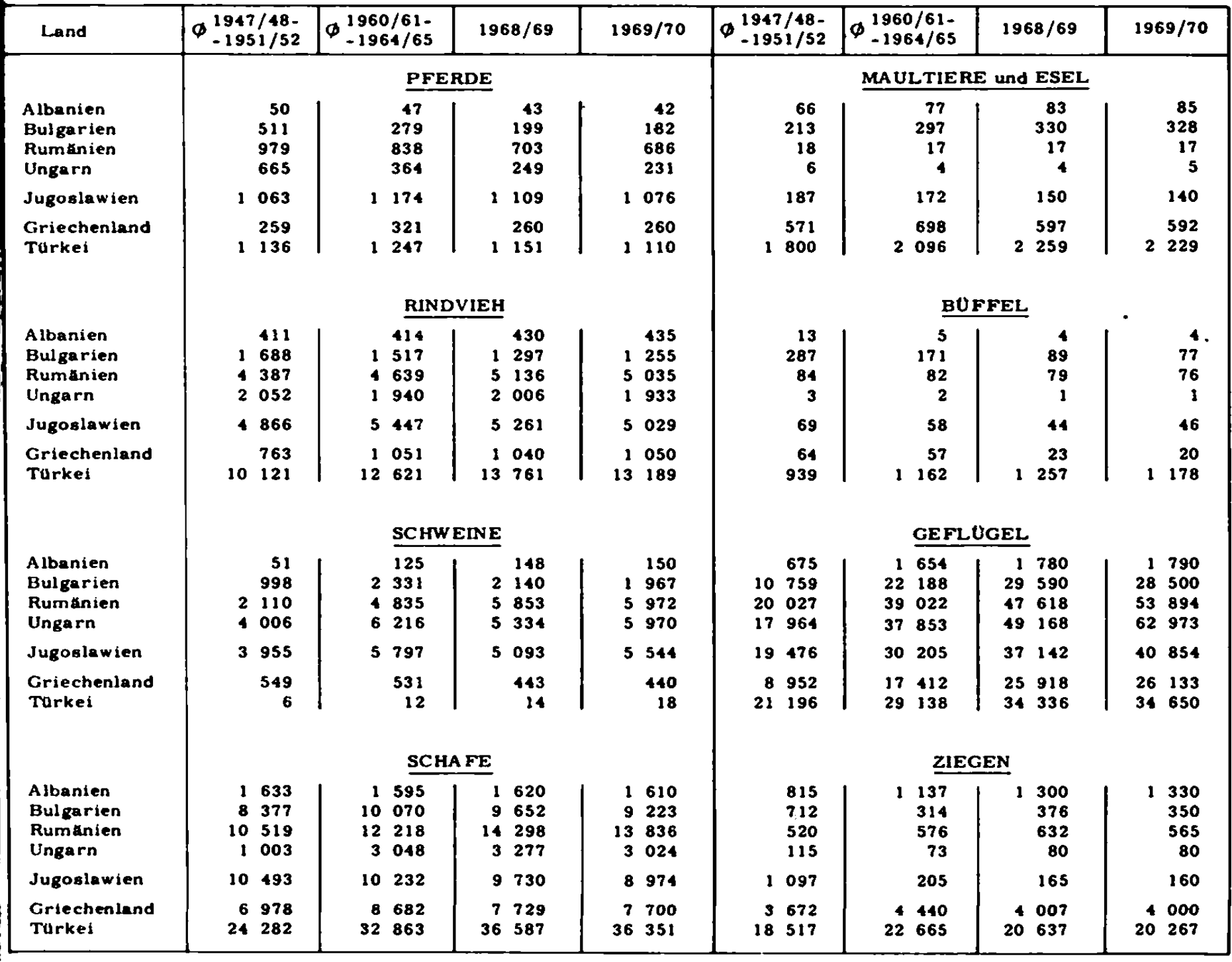

Quelle: FAO, Production Yearbook 1970, S. $306 \mathrm{ff}$. 
Tabelle 31: Produktion von Fleisch, Milch, Käse, Honig und Wolle in den südosteuropäischen Ländern 1948 - 1970 (in 1000 t)

\begin{tabular}{|c|c|c|c|c|c|c|c|c|}
\hline Land & $\phi_{-1952}^{1948-}$ & $\phi_{-1965}^{1961-}$ & 1969 & 1970 & $\phi_{-1952}^{1948-}$ & $\phi_{-1965}^{1961-}$ & 1969 & 1970 \\
\hline & \multicolumn{4}{|c|}{ RIND-, KALB-, BUFFELFLEISCH } & \multicolumn{4}{|c|}{ HA MMEL-, LAMM-, ZIEGEN FLEISCH } \\
\hline $\begin{array}{l}\text { Albanien } \\
\text { Bulgarien } \\
\text { Rumanien } \\
\text { Ungarn }\end{array}$ & $\begin{array}{r}12 \\
39 \\
101 \\
96\end{array}$ & $\begin{array}{r}13 \\
68 \\
151 \\
139\end{array}$ & $\begin{array}{r}15 \\
94 \\
197 \\
198\end{array}$ & $\begin{array}{r}16 \\
100 \\
190 \\
178\end{array}$ & $\begin{array}{r}18 \\
43 \\
14 \\
8\end{array}$ & $\begin{array}{l}26 \\
61 \\
18 \\
13\end{array}$ & $\begin{array}{l}28 \\
87 \\
22 \\
20\end{array}$ & $\begin{array}{l}28 \\
90 \\
20 \\
18\end{array}$ \\
\hline Jugaslawien & 97 & 203 & 275 & 290 & 34 & 49 & 55 & 58 \\
\hline Griechenland & 9 & 42 & 72 & 76 & 38 & 67 & 72 & 72 \\
\hline Turkei & 37 & 97 & 117 & 120 & 52 & 103 & 103 & 105 \\
\hline - & \multicolumn{4}{|c|}{ SCHWEINEFLEISCH } & \multicolumn{4}{|c|}{$\underline{\text { FLEISCH insgesamt }}$} \\
\hline $\begin{array}{l}\text { Albanien } \\
\text { Bulgarien } \\
\text { Rumanien } \\
\text { Ungarn }\end{array}$ & $\begin{array}{r}4 \\
74 \\
28 \\
194\end{array}$ & $\begin{array}{r}4 \\
149 \\
108 \\
294\end{array}$ & $\begin{array}{r}7 \\
167 \\
189 \\
305\end{array}$ & $\begin{array}{r}7 \\
190 \\
170 \\
290\end{array}$ & $\begin{array}{r}35 \\
204 \\
188 \\
409\end{array}$ & $\begin{array}{r}45 \\
384 \\
378 \\
630\end{array}$ & $\begin{array}{r}53 \\
494 \\
528 \\
749\end{array}$ & $\begin{array}{r}51 \\
380 \\
380 \\
486\end{array}$ \\
\hline Jugoslawien & 151 & 295 & 287 & 300 & 351 & 677 & 804 & 648 \\
\hline $\begin{array}{l}\text { Griechenland } \\
\text { Tarkei }\end{array}$ & 19 & $\begin{array}{l}40 \\
-\end{array}$ & $\begin{array}{l}43 \\
-\end{array}$ & $\begin{array}{l}40 \\
-\end{array}$ & $\begin{array}{r}82 \\
107\end{array}$ & $\begin{array}{l}196 \\
225\end{array}$ & $\begin{array}{l}270 \\
251\end{array}$ & $\begin{array}{l}188 \\
225\end{array}$ \\
\hline & \multicolumn{4}{|c|}{ MILCH } & \multicolumn{4}{|c|}{$\underline{\text { KASE }}_{(1968)}$} \\
\hline $\begin{array}{l}\text { Albanien } \\
\text { Bulgarien } \\
\text { Rumanien } \\
\text { Ungarn }\end{array}$ & $\begin{array}{rr} & 63 \\
& 689 \\
2 & 296 \\
1 & 499\end{array}$ & $\begin{array}{ll} & 170 \\
1 & 235 \\
3 & 262 \\
1 & 899\end{array}$ & $\begin{array}{l}193 \\
1582 \\
3 \quad 874 \\
1 \quad 971\end{array}$ & $\begin{array}{ll} & 195 \\
1 & 568 \\
3 & 860 \\
2 & 011\end{array}$ & $\begin{array}{r}1 \\
38 \\
13 \\
5\end{array}$ & $\begin{array}{r}4 \\
105 \\
48 \\
26\end{array}$ & $\begin{array}{r}5 \\
109 \\
59 \\
35\end{array}$ & $\begin{array}{r}5 \\
112 \\
68 \\
39\end{array}$ \\
\hline Jugoslawien & 1716 & 2441 & 2832 & 2825 & 54 & 92 & 102 & 101 \\
\hline $\begin{array}{l}\text { Griechenland } \\
\text { Tarkei }\end{array}$ & $\begin{array}{r}521 \\
3047\end{array}$ & $\begin{array}{ll}1 & 064 \\
4 & 090\end{array}$ & $\begin{array}{ll}1296 \\
4356\end{array}$ & $\begin{array}{l}1300 \\
+425\end{array}$ & $\begin{array}{l}11 \\
44\end{array}$ & $\begin{array}{r}113 \\
80\end{array}$ & $\begin{array}{r}124 \\
90\end{array}$ & $\begin{array}{r}129 \\
92\end{array}$ \\
\hline & \multicolumn{4}{|c|}{ HONIG } & \multicolumn{4}{|c|}{ WOLLE } \\
\hline $\begin{array}{l}\text { A banien } \\
\text { Bulgarien } \\
\text { Rumanien } \\
\text { Ungarn }\end{array}$ & $\begin{array}{r}- \\
1.77 \\
2.34 \\
2.50\end{array}$ & $\begin{array}{l}- \\
2.42 \\
6.03 \\
5.41\end{array}$ & $\begin{array}{c}- \\
7,32 \\
8,60 \\
7,10\end{array}$ & $\begin{array}{c}- \\
6.00 \\
6.00 \\
7.00\end{array}$ & $\begin{array}{r}4,8 \\
22,6 \\
25,6 \\
5,9\end{array}$ & $\begin{array}{r}4,5 \\
37,2 \\
38,4 \\
14,5\end{array}$ & $\begin{array}{r}4,6 \\
42,8 \\
49,3 \\
16,0\end{array}$ & $\begin{array}{r}4,8 \\
43,1 \\
49,6 \\
15,5\end{array}$ \\
\hline Jugoslawien & 4.30 & 3,47 & 5,08 & 5,30 & 24,2 & 20,6 & 20.3 & 18,7 \\
\hline $\begin{array}{l}\text { Griechenland } \\
\text { Tarkei }\end{array}$ & $\begin{array}{l}2,90 \\
5,46\end{array}$ & $\begin{array}{l}6,24 \\
9,36\end{array}$ & $\begin{array}{r}8,57 \\
12,92\end{array}$ & $\begin{array}{r}6.70 \\
12.80\end{array}$ & $\begin{array}{l}12,3 \\
51,3\end{array}$ & $\begin{array}{l}13.2 \\
67.7\end{array}$ & $\begin{array}{l}12.9 \\
72.9\end{array}$ & $\begin{array}{l}12,4 \\
75,2\end{array}$ \\
\hline
\end{tabular}

Quelle: FAO, Production Yearbook 1970, S. 352 ff. 
Tabelle $32 \cdot$ Produktion von Häuten und Fellen in den südosteuropäischen Ländern 1948-1969 (in 1000 Stück)

\begin{tabular}{|c|c|c|c|c|c|c|c|c|}
\hline \multirow{2}{*}{ I, and } & \multicolumn{4}{|c|}{ Büffel, Rinder, Kălber } & \multicolumn{4}{|c|}{ Schafe, Ziegen } \\
\hline & $1948 / 52$ & $1961 / 65$ & 1968 & 1969 & $1948 / 52$ & $1961 / 65$ & 1968 & 1969 \\
\hline Albanien & 90 & 102 & 120 & 120 & 1250 & 1406 & 1500 & 1530 \\
\hline Bulga rien & . & 380 & 405 & 430 & . & 4286 & 4485 & 4600 \\
\hline Rumănien & 1110 & 1430 & 1700 & 1750 & $\cdot$ & - & . & \\
\hline Ungarn & . & 507 & 526 & 517 & . & 501 & 222 & 243 \\
\hline Jugoslawien & . & 1717 & 2274 & 2350 & . & 5496 & 6205 & 6263 \\
\hline Griechenland & 137 & 431 & 500 & 520 & 3140 & $\begin{array}{ll}6 & 197\end{array}$ & 5969 & 6100 \\
\hline Türkei & . & 1484 & 1752 & 2028 & 5067 & 7717 & 8200 & 9000 \\
\hline
\end{tabular}

Quelle: FAO, Production Yearbook 1970, S. 427 ff.

Tabelle 33: Produktion von Eiern in den südosteuropäischen Ländern 1948-1970 (in Mill. Stück)

\begin{tabular}{|l|r|r|r|r|r|}
\hline \multicolumn{1}{|c|}{ Land } & $1948 / 52$ & $1961 / 65$ & 1969 & \multicolumn{1}{c|}{1970} \\
\hline Albanien & 37 & 61 & 63 & 64 \\
Bulgarien & 650 & 1310 & 1472 & 1696 \\
Rumänien & 1102 & 2502 & 3004 & 3 & 100 \\
Ungarn & 936 & 2046 & 2714 & 2800 \\
Jugoslawien & 900 & 1601 & 2476 & 2604 \\
Griechenland & 425 & 1176 & 1765 & 1900 \\
Türkei & 905 & 1366 & 1828 & 1820 \\
\hline
\end{tabular}

Quelle: FAO Production Yearbook 1970, S. 406, 409. 
Tabelle 34: Bestand an landwirtschaftlichen Maschinen in den südosteuropäischen Ländern 1948-1969 (in Stück)

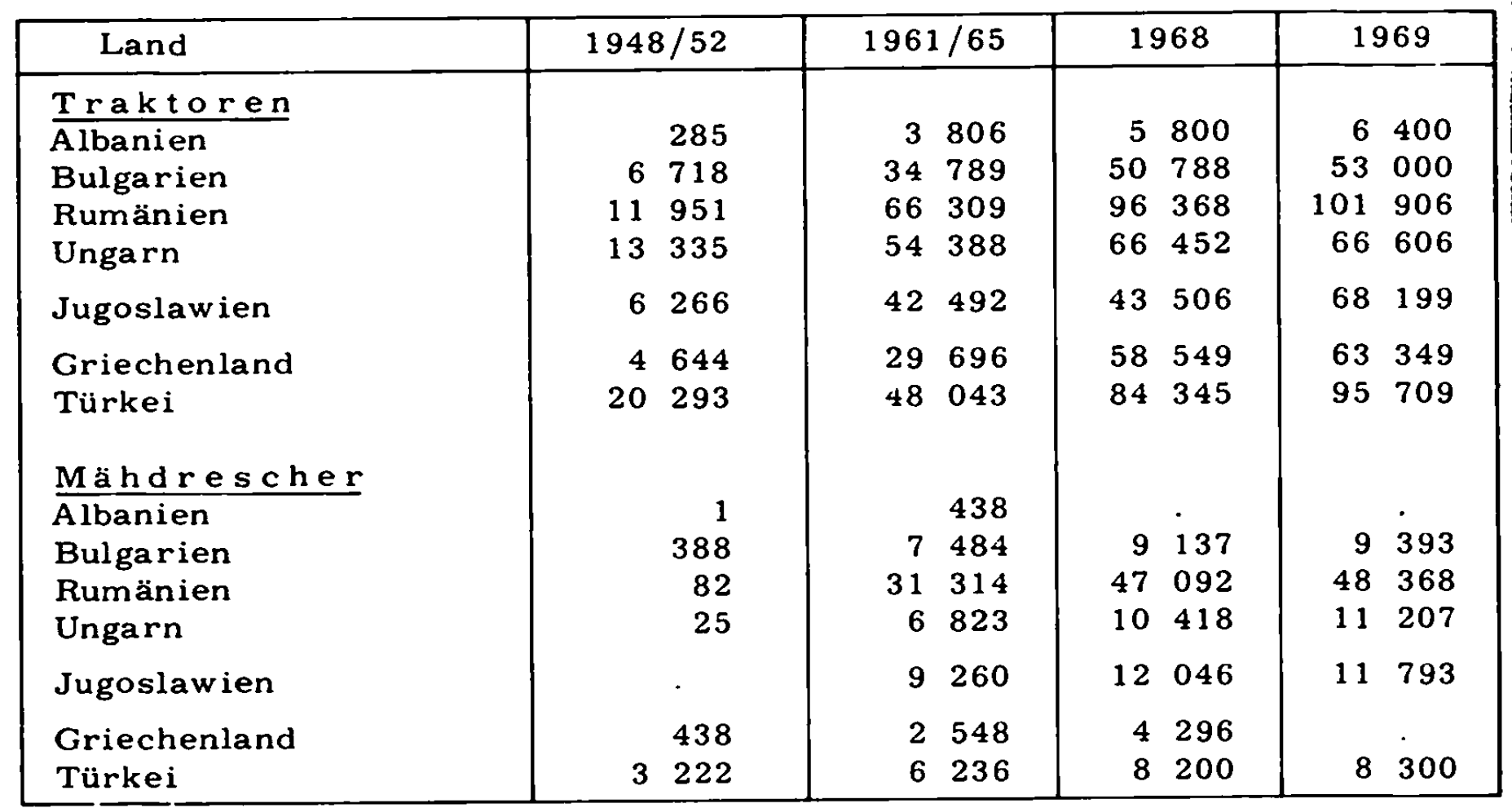

Quelle: FAO, Production Yearbook 1970, S. 480, 490.

Tabelle 35: Import und Export von Traktoren der südosteuropäischen Länder $1967-1969$

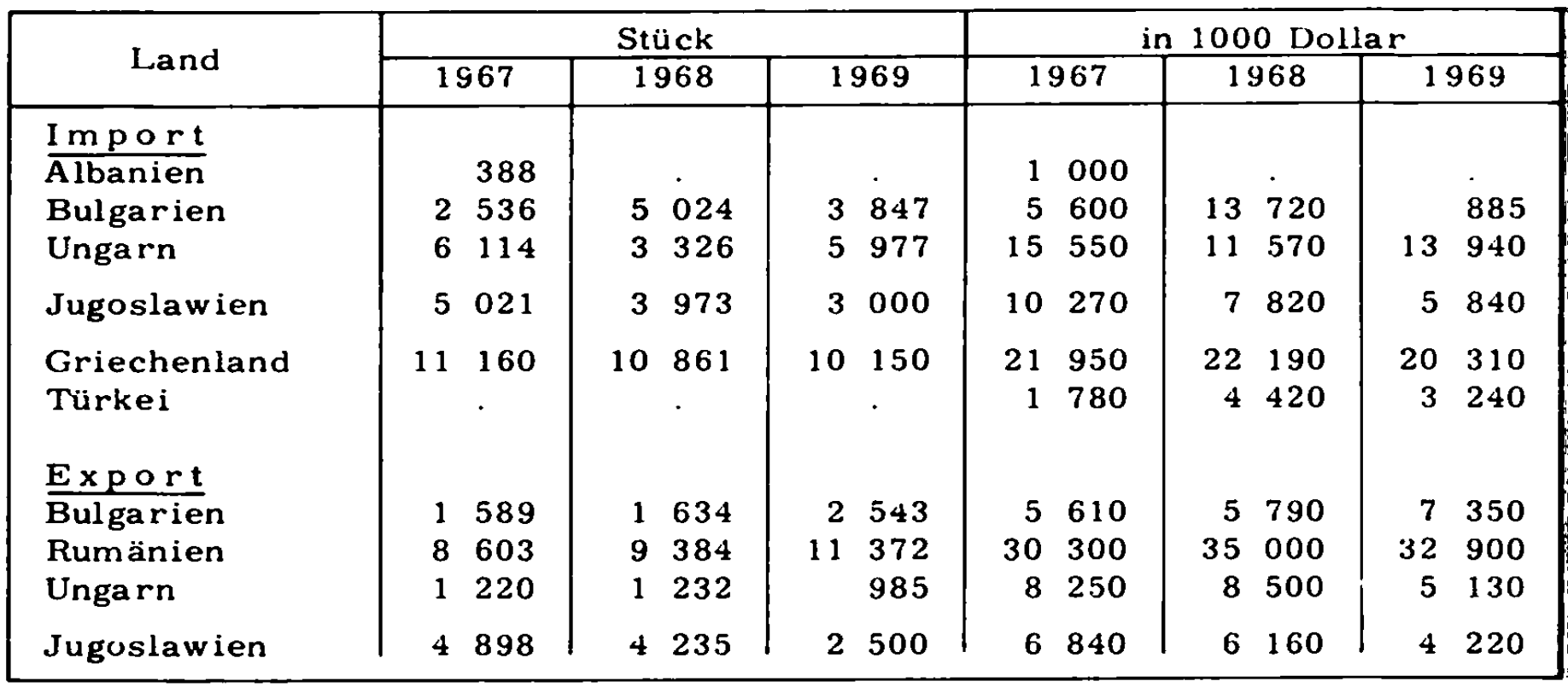

Quelle: FAO, Trade Yearbook 1970, S. 43y, 441. 
Tabelle 36: Produktion und Verbrauch von Düngemitteln in den südosteuropäischen Ländern 1948-1970 (in 1000 t Handelsgewicht)

\begin{tabular}{|c|c|c|c|c|c|c|c|c|}
\hline \multirow[b]{2}{*}{ Lend } & \multicolumn{4}{|c|}{ Stickstoffounger (N) } & \multicolumn{4}{|c|}{ Phosphatdunger $\left(\mathrm{P}_{2} \mathrm{O}_{5}\right)$} \\
\hline & $\begin{array}{l}1948 / 49- \\
-1952 / 53\end{array}$ & $\begin{array}{l}1961 / 62- \\
-1965 / 66\end{array}$ & $1968 / 69$ & $1969 / 70$ & $\begin{array}{r}1948 / 49- \\
-1952 / 53 \\
\end{array}$ & $\begin{array}{l}1961 / 62- \\
-1965 / 66 \\
\end{array}$ & $1968 / 69$ & $1969 / 70$ \\
\hline$\frac{\text { Produktion }}{\text { Albanien }}$ & - & - & 27,0 & 29,0 & - & - & 14,0 & 15,8 \\
\hline Bulgarien & 3.6 & 149.7 & 510,3 & 586,2 & - & 76,0 & 137,6 & 138,8 \\
\hline Rumánien & - & 86.6 & 420.7 & 494.0 & 0.6 & 96,1 & 181.8 & 221.0 \\
\hline Ungarn & 13.0 & 92.0 & 245.1 & 300.1 & 4.0 & 87.0 & 155,9 & 169.7 \\
\hline Jugoslawien & 4.2 & 54,7 & 119,8 & 183.3 & 7.2 & 119.9 & 172,5 & 143.9 \\
\hline Griechenland & - & 22,5 & 126.8 & 146.0 & 20.3 & 60.7 & 134,3 & 121,2 \\
\hline Turkei & 0.7 & 29,5 & 34,5 & 52.2 & 2,6 & 27,3 & 46.5 & 43,5 \\
\hline$\frac{\text { Verbrauch }}{\text { Albanien }}$ & & 2.2 & 19,0 & 25.0 & . & 3,6 & 16,0 & 18,0 \\
\hline Bulgarien & 15,4 & 121,1 & 365,0 & 402,0 & 2,4 & 93,2 & 346,0 & 265,0 \\
\hline Rumanien & 2,6 & 81,8 & 330,0 & 380.0 & 1.6 & 74,6 & 140,5 & 180,0 \\
\hline Ungarn & 11,2 & 142,8 & 304,6 & 347,9 & 18,0 & 99,6 & 176,2 & 182.0 \\
\hline Jugoslawien & 6.0 & 145.6 & 270.3 & 283.5 & 8.4 & 123.0 & 159.4 & 182.7 \\
\hline Griechenland & 23,6 & 112,2 & 282,1 & 190.6 & 19,1 & 88,0 & 116.5 & 114,6 \\
\hline Turkei & 5,4 & 53.7 & 186.6 & 231,1 & 3,6 & 44,5 & 181,7 & 200,6 \\
\hline
\end{tabular}

Quelle: FAO, Production Yearbook 1970, S. $463 \mathrm{ff}$.

Tabelle 37: Import und Export von Düngemitteln der südosteuropäischen Länder 1967-1969 (in 1000 Dollar)

\begin{tabular}{|l|c|c|c|c|c|c|}
\hline \multirow{2}{*}{ Land } & \multicolumn{3}{|c|}{ Import } & \multicolumn{3}{|c|}{ Export } \\
\cline { 2 - 7 } & 1967 & 1968 & 1969 & 1967 & 286 & 1969 \\
\hline Bulgarien & 31100 & 39400 & 18250 & 2300 & 7600 & 1800 \\
Ungarn & 19940 & 29410 & 10000 & 8700 & 3870 & 2000 \\
Jugoslawien & 35920 & 32660 & 22160 & 6730 & 8080 & 3210 \\
Griechenland & 13400 & 8320 & 7340 & 2000 & 3310 & 1530 \\
Turkei & 37090 & 47690 & 52410 & - & - & - \\
\hline
\end{tabular}

Quelle: FAO, Trade Yearbook 1970, S. 446. 
Tabelle 38: Forstwirtschaft in den südosteuropäischen Ländern 1961-1969

\begin{tabular}{|l|c|r|r|r|}
\hline \multirow{2}{*}{ Land } & \multicolumn{2}{|c|}{$\begin{array}{c}\text { Forstfläche } \\
\text { in Nutzung } \\
\text { in } 1000 \text { ha }\end{array}$} & \multicolumn{3}{|c|}{ Holzeinschlag in Mill. cbm } \\
\cline { 3 - 5 } & $1961 / 65$ & 1968 & 1969 \\
\hline Albanien & 1282 &. & $1,5^{2}$ & $\cdot$ \\
Bulgarien & 3169 & 5,7 & 5,1 & 5,2 \\
Rumänien & 5008 & 21,1 & 23,1 & $\cdot$ \\
Ungarn & 1214 & 3,9 & 4,6 & 4,6 \\
Jugoslawien & 6833 & 17,6 & 17,0 & \\
Griechenland & 1992 & 2,8 & 3,3 & 2,6 \\
Türkei & 10516 & 11,0 & 16,2 & 16,5 \\
a 1967 & 5 & & & \\
\hline
\end{tabular}

Quelle: UN, Statistical Yearbook 1970, S. 160, 161

Tabelle 39: Fischfang in den südosteuropäischen Ländern 1953-1969 (in $1000 \mathrm{t}$ )

\begin{tabular}{|l|r|r|c|c|c|}
\hline \multicolumn{1}{|c|}{ Land } & 1953 & 1961 & 1965 & 1968 & 1969 \\
\hline Albanien & $\cdot$ &. &. &. &. \\
Bulgarien & 5,6 & 8,1 & 19,8 & 56,3 &. \\
Rumänien & $\cdot$ & 27,5 & 37,6 & 40,5 &. \\
Ungarn & 4,0 & 19,3 & 24,8 & 29,9 & 27,8 \\
Jugoslawien & 25,7 & 37,3 & 41,9 & 44,9 & 43,8 \\
Griechenland & 46,0 & 110,0 & 82,4 & 92,8 &. \\
Türkei & 102,5 & 82,3 & 135,7 & 135,4 &. \\
\hline
\end{tabular}

@uelle: UN, Statistical Yearbook 1970, S. 164. 
G. Industrieproduktion, Bergbau, Wohnungsbau

Tabelle 40: Industrieproduktion der südosteuropäischen Länder 1955-1971 (Index: $1960=100$ )

\begin{tabular}{|l|c|c|c|c|c|c|c|c|}
\hline \multicolumn{1}{|c|}{ Land } & 1955 & 1965 & 1966 & 1967 & 1968 & 1969 & 1970 & 1971 \\
\hline Albanien & 46 & 139 & 156 & 176 & 209 &. &. &. \\
Bulgarien & 48 & 174 & 195 & 221 & 244 & 267 & 293 & 321 \\
Rumänien & 60 & 191 & 213 & 242 & 270 & 298 & 334 & 375 \\
Ungarn & 70 & 144 & 153 & 167 & 175 & 180 & 193 & 203 \\
Jugoslawien & 54 & 166 & 173 & 172 & 183 & 204 & 222 & 244 \\
Griechenland & 73 & 142 & 163 & 168 & 180 & 200 & 220 & 250 \\
Türkei (1963 100) & $\cdot$ & 144 & 170 & 175 & 192 & 192 &. &. \\
\hline
\end{tabular}

@uelle: Statistisches Jahrbuch der DDR 1971, S. 32*. - Planerfüllungsund andere Berichte der einzelnen Länder. 
Tabelle 41 : Industrieproduktion der südosteuropäischen Länder 1948 - 1971 (Index: $1963=100$ )

\begin{tabular}{|c|c|c|c|c|c|c|c|}
\hline Land & Industrie & 1948 & 1958 & 1968 & 1969 & 1970 & 1971 \\
\hline Albanien & Insgesamt & 14 & 62 & $163^{a}$ & . & - & \\
\hline \multirow[t]{4}{*}{ Bulgarien } & Insgesamt & 12 & 53 & 181 & 199 & 218 & $239^{a}$ \\
\hline & Bergbau & 26 & 69 & 127 & $131^{a}$ & 131 & \\
\hline & Elektrizität & 8 & 43 & 207 & 229 & 259 & \\
\hline & Verarb. Ind. & 11 & 53 & 180 & $196^{\mathrm{a}}$ & 212 & \\
\hline \multirow[t]{4}{*}{ Rumänien } & Insgesamt & 12 & 53 & 182 & 201 & 229 & $255^{a}$ \\
\hline & Bergbau & 20 & 68 & 135 & 142 & 155 & . \\
\hline & Elektrizităt & 9 & 49 & 258 & 298 & 356 & . \\
\hline & Verarb. Ind. & 10 & 52 & 184 & 203 & 230 & . \\
\hline \multirow[t]{4}{*}{ Ungarn } & Insgesamt & 24 & 63 & 132 & 135 & 144 & 151 \\
\hline & Bergbau & 43 & 78 & 107 & 106 & 109 & 110 \\
\hline & Elektrizität & 26 & 68 & 138 & 147 & 158 & 168 \\
\hline & Verarb. Ind. & 22 & 61 & 138 & 141 & 152 & 165 \\
\hline \multirow[t]{4}{*}{ Jugoslawien } & Insgesamt & 25 & 58 & 139 & 154 & 168 & 186 \\
\hline & Bergbau & 33 & 66 & 112 & 119 & 128 & 137 \\
\hline & Elektrizität & 15 & 55 & 152 & 154 & 156 & 156 \\
\hline & Verarb. Ind. & 25 & 57 & 142 & 159 & 174 & 191 \\
\hline \multirow[t]{4}{*}{ Griechenland } & Insgesamt & . & . & 158 & 177 & 195 & 222 \\
\hline & Bergbau & & . & 137 & 158 & 188 & 213 \\
\hline & Elektrizität & 17 & 64 & 224 & 256 & 266 & 317 \\
\hline & Verarb. Ind. & 26 & 77 & 151 & 168 & 152 & 203 \\
\hline \multirow[t]{4}{*}{ Türkei } & Insgesamt & 33 & 81 & 192 & 192 & . & - \\
\hline & Bergbau & 47 & 93 & & & & \\
\hline & Elektrizität & 18 & 60 & 180 & 203 & 224 & 252 \\
\hline & Verarb. Ind. & 28 & 72 & $\cdot$ & . & $\cdot$ & \\
\hline
\end{tabular}

Quellen: UN, Statistical Yearbook 1970, S. $172 \mathrm{ff}$. - Monthly Bulletin of Statistics, April 1972, S. 22 ff. - Planerfüllungsberichte 1971 einiger Länder. 
Tabelle 42: Produktion von Brennstoffen und Elektroenergie in den südosteuropäischen Ländern 1938-1971

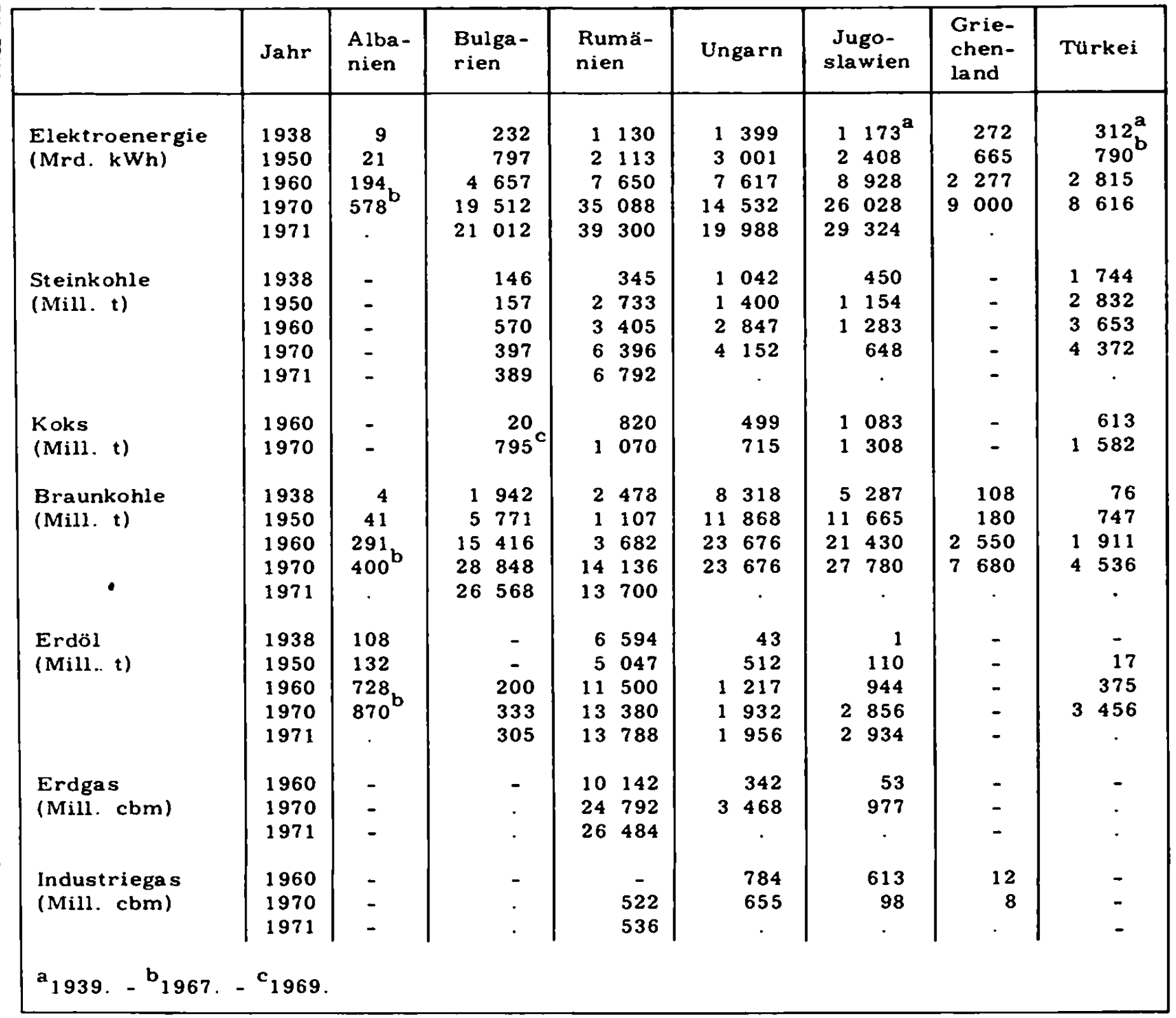

Quelle: Statistisches Bundesamt. Fachstatistiken, Reihe 9, Eisen und Stahl, 2. Vierteljahresheft 1971. - UN, Monthly Bulletin of Statistics, March 1972, S. 34 ff. 
Tabelle 43: Produktion von Erdölderivaten in den südosteuropäischen Ländern 1962, 1965 und 1970 (in 1000 t)

\begin{tabular}{|c|c|c|c|c|c|}
\hline Land & Jahr & Kraftstoffe & Kerosin & Brennstoffe & Rückstände \\
\hline \multirow[t]{3}{*}{ Bulgarien } & 1962 & - & - & 29 & 42 \\
\hline & 1965 & 371 & 74 & 625 & 1097 \\
\hline & 1970 & 1135 & 126 & 1732 & 2777 \\
\hline \multirow[t]{3}{*}{ Rumänien } & 1962 & 2393 & 1234 & 2910 & 3946 \\
\hline & 1965 & 2422 & 965 & 3600 & 3773 \\
\hline & 1970 & 2656 & 969 & 5049 & 4249 \\
\hline \multirow[t]{3}{*}{ Ungarn } & 1962 & 338 & 68 & 923 & 1283 \\
\hline & 1965 & 410 & 38 & 1045 & 1725 \\
\hline & 1970 & 970 & 18 & 1948 & 2288 \\
\hline \multirow[t]{3}{*}{ Jugoslawien } & 1962 & 322 & 92 & 532 & 492 \\
\hline & 1965 & 546 & 97 & 890 & 1148 \\
\hline & 1970 & 1232 & 183 & 2091 & 2509 \\
\hline \multirow[t]{3}{*}{ Griechenland } & 1962 & 213 & 182 & 543 & 765 \\
\hline & 1965 & 240 & 165 & 613 & 687 \\
\hline & 1970 & 582 & 403 & 1668 & 1894 \\
\hline \multirow[t]{3}{*}{ Türkei } & 1962 & 523 & 285 & 616 & 1115 \\
\hline & 1965 & 698 & 489 & 1104 & 1769 \\
\hline & 1970 & 980 & 598 & 1620 & 3278 \\
\hline
\end{tabular}

Que 11e: UN, Monthly Bulletin of Statistics, Juli 1968, S. X ff. April 1972, S. X ff. 
Tabelle 44: Erzbergbau und metallschaffende Industrie der südosteuropäischen Länder 1938-1971 (in $1000 \mathrm{t}$ )

\begin{tabular}{|c|c|c|c|c|c|c|c|c|}
\hline & Jahr & $\begin{array}{l}\text { Alba - } \\
\text { nien }\end{array}$ & $\begin{array}{l}\text { Bulga - } \\
\text { rien }\end{array}$ & $\begin{array}{l}\text { Ruma- } \\
\text { nien }\end{array}$ & Ungarn & $\begin{array}{l}\text { Jugo- } \\
\text { slawien }\end{array}$ & $\begin{array}{l}\text { Grie- } \\
\text { chen- } \\
\text { land }\end{array}$ & Turkei \\
\hline Eisenerz & $\begin{array}{l}1938 \\
1950 \\
1960 \\
1970 \\
1971\end{array}$ & $\begin{array}{c}- \\
255 \\
395^{\mathrm{a}} \\
.\end{array}$ & $\begin{array}{rr} & - \\
& 49 \\
& 415 \\
2412 \\
3000\end{array}$ & $\begin{array}{r}139 \\
395 \\
1460 \\
3204 \\
3468\end{array}$ & $\begin{array}{c}297 \\
368 \\
516 \\
629 \\
.\end{array}$ & $\begin{array}{cc} & 667^{b} \\
& 731 \\
2 & 200 \\
3 & 696 \\
& \end{array}$ & $\begin{array}{r}349 \\
7 \\
300 \\
883 \\
.\end{array}$ & $\begin{array}{r}77 \\
234 \\
397 \\
2928 \\
\end{array}$ \\
\hline Manganerz & $\begin{array}{l}1938 \\
1970\end{array}$ & - & 12,4 & $\begin{array}{l}21,7 \\
29,3\end{array}$ & $\begin{array}{r}8,9 \\
33,8\end{array}$ & 4.0 & 3,6 & $\begin{array}{l}1,1 \\
9,5\end{array}$ \\
\hline Roheisen & $\begin{array}{l}1938 \\
1950 \\
1960 \\
1970 \\
1971\end{array}$ & $\begin{array}{l}- \\
- \\
- \\
-\end{array}$ & $\begin{array}{rr} & - \\
& 3 \\
192 \\
1 & 252 \\
1 & 342\end{array}$ & $\begin{array}{r}133 \\
335 \\
1014 \\
4212 \\
4380\end{array}$ & 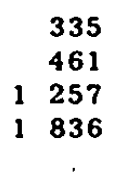 & 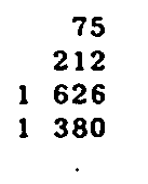 & $\begin{array}{l}- \\
- \\
- \\
-\end{array}$ & $\begin{array}{c}- \\
117 \\
247 \\
1033 \\
\end{array}$ \\
\hline Rohstahl & $\begin{array}{l}1938 \\
1950 \\
1960 \\
1970 \\
1971\end{array}$ & $\begin{array}{l}- \\
- \\
- \\
-\end{array}$ & $\begin{array}{cc} & - \\
& 251 \\
1 & 800 \\
1 & 944\end{array}$ & 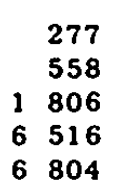 & $\begin{array}{ll} & 648 \\
1 & 048 \\
1 & 886 \\
3 & 110 \\
3 & 110\end{array}$ & $\begin{array}{ll} & 227^{b} \\
& 428 \\
1 & 442 \\
2 & 232 \\
2 & 448\end{array}$ & $\begin{array}{r}20 \\
26 \\
65 \\
450 \\
.\end{array}$ & $\begin{array}{r}- \\
91 \\
280 \\
1312 \\
\\
\end{array}$ \\
\hline Walzstahl & $\begin{array}{l}1938 \\
1950 \\
1960 \\
1969\end{array}$ & $\begin{array}{l}- \\
- \\
-\end{array}$ & $\begin{array}{rr} & - \\
6 \\
193 \\
1208\end{array}$ & $\begin{array}{cc} & - \\
1 & 402 \\
1 & 254 \\
3 & 816\end{array}$ & $\begin{array}{cc} & 495 \\
1 & 187 \\
2 & 020\end{array}$ & $\begin{array}{ll} & 151^{b} \\
& 425^{c} \\
1436^{d} \\
1749\end{array}$ & $\begin{array}{l}- \\
- \\
-\end{array}$ & - \\
\hline Bauxit & $\begin{array}{l}1960 \\
1970 \\
1971\end{array}$ & $\begin{array}{l}- \\
-\end{array}$ & $\begin{array}{l}- \\
-\end{array}$ & $\begin{array}{r}88 \\
200 \\
\end{array}$ & $\begin{array}{ll}1 & 010 \\
2 & 016 \\
2 & 088\end{array}$ & $\begin{array}{ll}1 & 020 \\
2 & 100 \\
1 & 968\end{array}$ & $2 \begin{array}{ll}882 \\
2 \quad 280\end{array}$ & . \\
\hline Aluminium & $\begin{array}{l}1960 \\
1970 \\
1971\end{array}$ & $\begin{array}{l}- \\
-\end{array}$ & - & $\begin{array}{l}- \\
-\end{array}$ & $\begin{array}{l}49,6 \\
66,0 \\
67,0\end{array}$ & $\begin{array}{l}25,1 \\
47,8 \\
46,6\end{array}$ & $\begin{array}{l}- \\
-\end{array}$ & - \\
\hline $\begin{array}{l}\text { Kupfererz } \\
\text { (Metallgehalt) }\end{array}$ & $\begin{array}{l}1960 \\
1970 \\
1971\end{array}$ & $\begin{array}{l}0.9 \\
4.8^{\mathrm{a}} \\
.\end{array}$ & $\begin{array}{l}14,2 \\
33,8\end{array}$ & . & $\begin{array}{r}8,1 \\
11,4\end{array}$ & $\begin{array}{l}33,2 \\
90,8 \\
94,4\end{array}$ & $\begin{array}{l}- \\
- \\
-\end{array}$ & $\begin{array}{l}28,6 \\
22,4\end{array}$ \\
\hline Kupfer & $\begin{array}{l}1960 \\
1970 \\
1971\end{array}$ & $\begin{array}{l}- \\
-\end{array}$ & $\begin{array}{l}35,0 \\
82 \\
.\end{array}$ & - & $\begin{array}{r}8,2 \\
11.2 \\
10.6\end{array}$ & $\begin{array}{r}70,8 \\
179,0 \\
\end{array}$ & $\begin{array}{l}- \\
-\end{array}$ & $\begin{array}{c}37,8 \\
33,1 \\
:\end{array}$ \\
\hline $\begin{array}{l}\text { Bleierz } \\
\text { (Metallgehalt) }\end{array}$ & $\begin{array}{l}1960 \\
1970\end{array}$ & . & $\begin{array}{l}83,8 \\
86,3\end{array}$ & . & . & $\begin{array}{r}91,2 \\
125,3\end{array}$ & $\begin{array}{r}2.8 \\
10,2\end{array}$ & . \\
\hline Blei & $\begin{array}{l}1960 \\
1970 \\
1971\end{array}$ & $\begin{array}{l}- \\
-\end{array}$ & $\begin{array}{c}40.4 \\
98.6 \\
\end{array}$ & - & - & $\begin{array}{l}89,0 \\
97,4 \\
98,1\end{array}$ & - & $\begin{array}{l}- \\
-\end{array}$ \\
\hline $\begin{array}{l}\text { Zinkerz } \\
\text { (Metallgehalt) }\end{array}$ & $\begin{array}{l}1960 \\
1970 \\
1971\end{array}$ & . & $\begin{array}{l}58,7 \\
76,4\end{array}$ & . & . & $\begin{array}{r}56,4 \\
101.0 \\
100,2\end{array}$ & $\dot{.}$ & . \\
\hline Zink & $\begin{array}{l}1960 \\
1970 \\
1971\end{array}$ & . & $\begin{array}{l}16,9 \\
76,0\end{array}$ & & . & $\begin{array}{l}36,0 \\
65,0 \\
53,2\end{array}$ & . & \\
\hline
\end{tabular}

Quelle: Statistisches Bundesamt. Fachstatistiken, Reihe 9, Eisen und Stahl, 2. Vierteljahresheft 1971. - UN, Monthly Bulletin of Statistics, March 1972. - UN, Statistical Yearbook 1969. 
Tabelle 45: Produktion von Schnittholz, Zement und chemischen Erzeugnissen in den südosteuropäischen Ländern 1950-1971 (in 1000 t)

\begin{tabular}{|c|c|c|c|c|c|c|c|c|}
\hline & Jahr & $\begin{array}{l}\text { Alba- } \\
\text { nien }\end{array}$ & $\begin{array}{l}\text { Bulga- } \\
\text { rien }\end{array}$ & $\begin{array}{l}\text { Rumá- } \\
\text { nien }\end{array}$ & Ungarn & $\begin{array}{l}\text { Jugo- } \\
\text { slawien }\end{array}$ & $\begin{array}{l}\text { Grie- } \\
\text { chen- } \\
\text { land }\end{array}$ & Türkei \\
\hline $\begin{array}{l}\text { Schnit tholz } \\
(1000 \mathrm{cbm})\end{array}$ & $\begin{array}{l}1950 \\
1960 \\
1969\end{array}$ & $\begin{array}{c}51 \\
170 \\
200^{a}\end{array}$ & $\begin{array}{ll} & 655 \\
1 & 096 \\
1 & 287\end{array}$ & $\begin{array}{ll}3 & 559 \\
3 & 928 \\
5 & 262\end{array}$ & $\begin{array}{l}174 \\
384 \\
391\end{array}$ & $\begin{array}{ll}2 & 045^{b} \\
2 & 654^{c} \\
3 & 067\end{array}$ & & \\
\hline Zement & $\begin{array}{l}1938 \\
1950 \\
1960 \\
1970 \\
1971\end{array}$ & $\begin{array}{r}9 \\
16 \\
73 \\
220^{a} \\
.\end{array}$ & $\begin{array}{r}194 \\
\quad 602 \\
1 \quad 586 \\
3 \quad 672 \\
3 \quad 876\end{array}$ & $\begin{array}{ll} & 532 \\
1 & 028 \\
3 & 054 \\
8 & 124 \\
8 & 520\end{array}$ & $\begin{array}{rl} & 343 \\
& 797 \\
1 & 571 \\
2 & 772\end{array}$ & $\begin{array}{ll} & 712 \\
1 & 219 \\
2 & 398 \\
4 & 404\end{array}$ & $\begin{array}{r}308 \\
\quad 395 \\
1 \quad 649 \\
4848\end{array}$ & $\begin{array}{r}287 \\
396 \\
2040 \\
6 \quad 360\end{array}$ \\
\hline $\begin{array}{l}\text { Schwefelsăure } \\
\left(100 \% \mathrm{H}_{2} \mathrm{SO}_{4}\right)\end{array}$ & $\begin{array}{l}1950 \\
1960 \\
1970 \\
1971\end{array}$ & $\begin{array}{l}- \\
-\end{array}$ & $\begin{array}{c}- \\
123 \\
502 \\
513\end{array}$ & $\begin{array}{r}52 \\
226 \\
995 \\
1 \quad 048\end{array}$ & $\begin{array}{r}67 \\
178 \\
485\end{array}$ & $\begin{array}{r}39^{d} \\
129 \\
748 \\
807\end{array}$ & $\begin{array}{r}46 \\
135 \\
551\end{array}$ & $\begin{array}{l}20,0^{d} \\
23,9 \\
27,6\end{array}$ \\
\hline $\begin{array}{l}\text { Kalzinierte Soda } \\
\left(100 \% \mathrm{Na}_{2} \mathrm{CO}_{3}\right)\end{array}$ & $\begin{array}{l}1950 \\
1960 \\
1969\end{array}$ & - & $\begin{array}{r}- \\
128 \\
265\end{array}$ & $\begin{array}{r}38 \\
180 \\
595\end{array}$ & - & . & - & $\begin{array}{l}- \\
-\end{array}$ \\
\hline $\begin{array}{l}\text { Kaustische Soda } \\
(100 \% \mathrm{NaOH})\end{array}$ & $\begin{array}{l}1950 \\
1960 \\
1970 \\
1971\end{array}$ & $\begin{array}{l}- \\
- \\
-\end{array}$ & $\begin{array}{r}0 \\
17 \\
46 \\
48\end{array}$ & $\begin{array}{r}15 \\
74 \\
330 \\
340\end{array}$ & $\begin{array}{r}6 \\
10 \\
63 \\
.\end{array}$ & $\begin{array}{l}20^{\mathrm{d}} \\
36 \\
90 \\
\end{array}$ & $\begin{array}{l}- \\
- \\
-\end{array}$ & $v_{4}$ \\
\hline $\begin{array}{l}\text { Plastik- und } \\
\text { Kunststoffmasse }\end{array}$ & $\begin{array}{l}1960 \\
1970 \\
1971\end{array}$ & - & . & $\begin{array}{l}206 \\
250\end{array}$ & $\begin{array}{l}10 \\
55 \\
.\end{array}$ & $\begin{array}{r}9 \\
97\end{array}$ & - & $\begin{array}{l}- \\
-\end{array}$ \\
\hline
\end{tabular}

Quelle: UN, Monthly Bulletin of Statistics, March 1972. - UN, Statistical Yearbook 1969. - Statistisches Jahrbuch der DDR 1971, S. 6*, 7*. 
Tabele 46: Produktion von Textilgarn und Textilgeweben in den südosteuropäischen Ländern 1950-1971

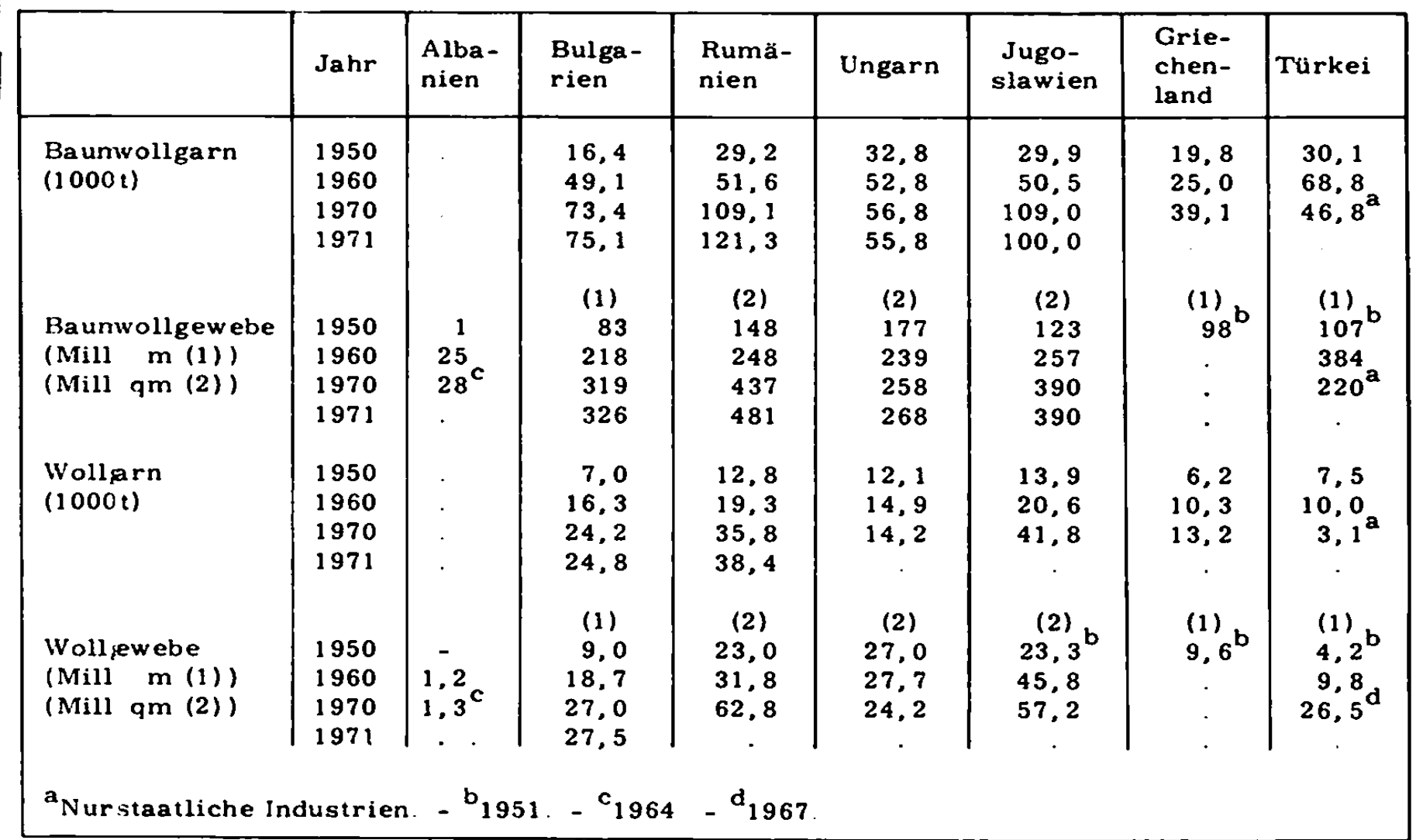

Que le: UN, Monthly Bulletin of Statistics, March 1972. - UN, Statistical Yearbook 1958, 1969. - Statistisches Jahrbuch der DDR 1971. 
Tabelle 47: Produktion (P) und Montage (M) von Kraftfahrzeugen in den südosteuropäischen Ländern (PKW = Personenkraftwagen; LKW = Lastkraftwagen; Obu = Omnibusse) $1960-1970$

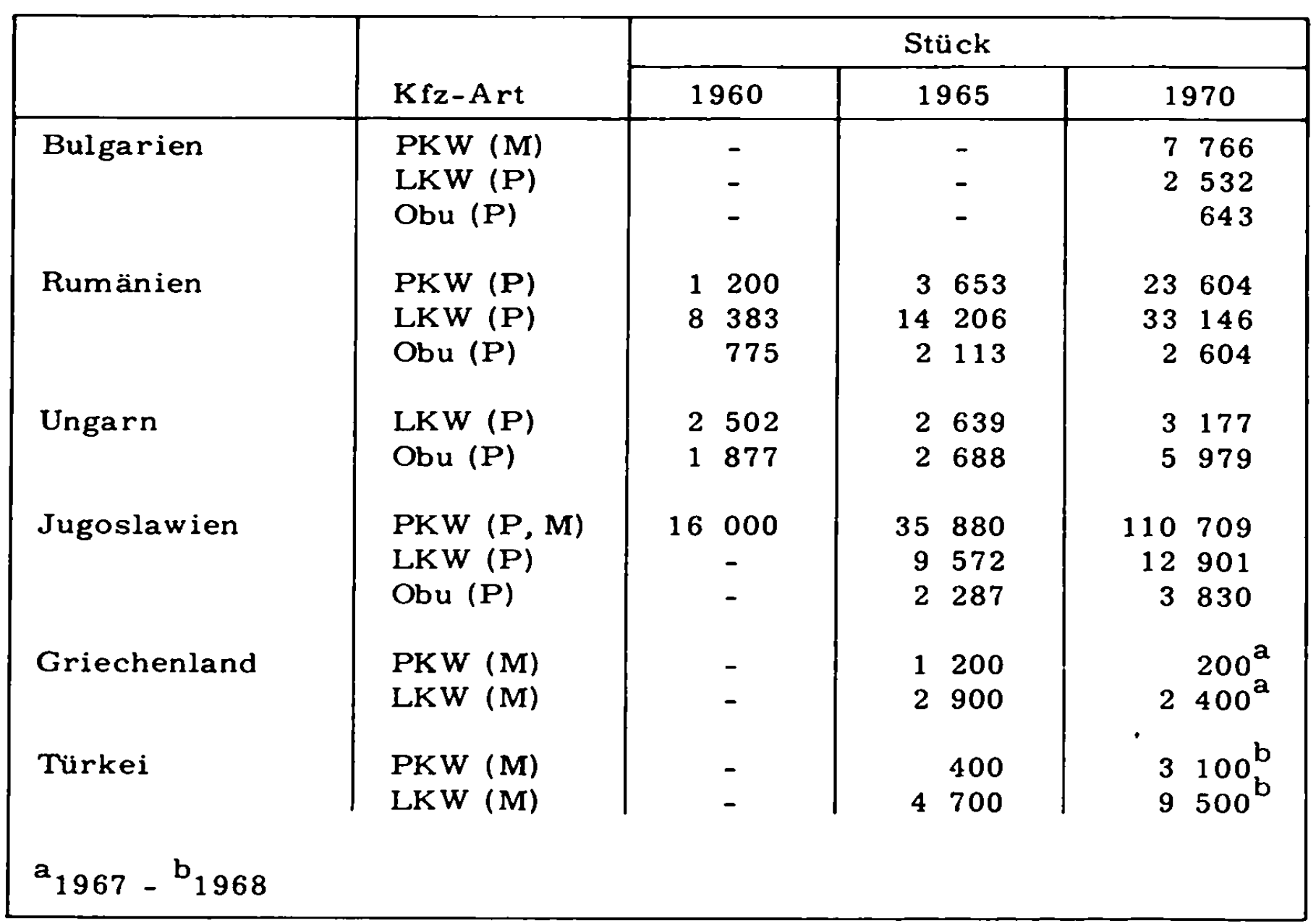

Quelle:U.N. Statistical Yearbook 1970, S. 320 ff.; - 1965, S. 318 ff. StatistiCeskij eżegodnik stran-členov SÉV 1971 (Moskva), S. 88,89 . 
Tabelle 48: Produktion von Rundfunkgeräten und Fernsehgeräten in den südosteuropäischen Ländern 1953-1970 (in 1000 Stück)

\begin{tabular}{|c|c|c|c|c|c|c|}
\hline Land & 1953 & 1960 & 1965 & 1968 & 1969 & 1970 \\
\hline \multicolumn{7}{|c|}{ Rundfunkempfänger } \\
\hline Bulgarien & 22 & 157 & 130 & 139 & 160 & 145 \\
\hline Rumänien & 23 & 167 & 323 & 388 & 428 & 455 \\
\hline Ungarn & 158 & 212 & 228 & 253 & 234 & 206 \\
\hline Jugoslawien & 38 & 244 & 504 & 227 & 282 & 277 \\
\hline Türkei & . & . & 257 & 258 & 253 & - \\
\hline \multicolumn{7}{|c|}{ Fernsehempfänger } \\
\hline Bulgarien & - & $5^{a}$ & 74 & 153 & 174 & 193 \\
\hline Rumänien & - & $15^{\mathrm{a}}$ & 101 & 161 & 221 & 280 \\
\hline Ungarn & - & 139 & 267 & 339 & 345 & 364 \\
\hline Jugoslawien & - & 14 & 254 & 286 & 334 & 320 \\
\hline
\end{tabular}

Quelle: UN, Statistical Yearbook 1970, S. 317.

Statistið̌eskij ežegednik stran-členov SÉV 1971 (Moskva), S. 92, 93.

Tabelle 49: Wohnungsbau in den südosteuropäischen Ländern 1965-1970

\begin{tabular}{|l|r|r|r|r|r|r|}
\hline \multirow{2}{*}{ Land } & \multicolumn{3}{|c|}{$\begin{array}{c}\text { Neubauwohnungen } \\
\text { in 1000 }\end{array}$} & \multicolumn{3}{c|}{$\begin{array}{c}\text { Neubauwohnungen } \\
\text { auf 1000 Einwohner }\end{array}$} \\
\cline { 2 - 7 } & 1965 & 1969 & 1970 & 1965 & 1969 & 1970 \\
\hline Albanien & 5,6 & $9,2^{\mathrm{a}}$ &. & 3,0 & $4,6^{\mathrm{a}}$ &. \\
Bulgarien & 45,2 & 47,1 & 45,7 & 5,5 & 5,6 & 5,4 \\
Rumänien & 121,0 & 143,6 & 163,0 & 6,0 & 7,2 & 8,0 \\
Ungarn & 54,6 & 61,8 & 80,0 & 5,4 & 6,0 & 7,7 \\
Jugoslawien & 122,0 & 120,1 & 115,0 & 6,6 & 5,9 & 5,6 \\
Griechenland & 79,4 & 130,5 & 114,7 & 9,3 & 14,8 & 12,9 \\
Türkei & 80,5 & 132,1 & 154,9 & 2,6 & 3,9 & 4,4 \\
a 1967 & & & & &
\end{tabular}

Quelle: UN, Statistical Yearbook 1970, S. $341 \mathrm{ff}$. - UN, Monthly Bulletin of Statistics, Jan. 1972, S. 92, 96. - Rocznik Statystyczny 1971 (Warszawa), S. 724 . - Statističeskij eżegodnik stran-členov SÉV 1971 (Moskva), S. 178. 


\section{H. Verkehr, Nachrichtenwesen}

Tabelle 50: Das Eisenbahnnetz in den südosteuropäischen Ländern 1950 und 1970

\begin{tabular}{|c|c|c|c|c|c|}
\hline \multirow[b]{2}{*}{ Land } & \multicolumn{3}{|c|}{ Strecken in $\mathbf{k m}$} & \multicolumn{2}{|c|}{$\begin{array}{c}\mathrm{km} \text { auf } 1000 \mathrm{qkm} \\
\text { Territorium }\end{array}$} \\
\hline & 1950 & 1970 & $\begin{array}{l}\text { davon } \\
\text { Elektri- } \\
\text { fizierg. }\end{array}$ & 1950 & 1970 \\
\hline Albanien & $167^{\mathrm{a}}$ & $205^{b}$ & - & $5,8^{a}$ & $7,1^{b}$ \\
\hline Bulgarien & 3967 & 4196 & 811 & 35,8 & 37,8 \\
\hline Rumänien & 10853 & 11012 & 494 & 45,7 & 46,4 \\
\hline Ungarn & 10101 & 9168 & 935 & 109 & 99 \\
\hline Jugoslawien & $11652^{a}$ & $10 \quad 289$ & 558 & 45,6 & 40,2 \\
\hline Griechenland & $2605^{a}$ & $2571^{c}$ & - & 19,7 & 19,5 \\
\hline Türkei & $7804^{d}$ & $8008^{b}$ & - & 10,0 & 10,3 \\
\hline
\end{tabular}

Quelle: Statisticeskij ežegodnik stran-ělenov SĖV 1971 (Moskva), S. $278 \mathrm{ff}$. - Svetăt v cifri. Sofia 1970, S. $150 \mathrm{ff}$. - Statistið̌eski godišnjak Jugoslavije 1971, S. 189. - Statistisches Bundesamt, Wiesbaden, Länderberichte Griechenland 1970, S. 19. - Statistisches Bundesamt, Wiesbaden, Länderberichte Türkei 1969, S. 19 . 
Tabelle 51: Transportleistung der Eisenbahn in den südosteuropäischen Ländern 1950-1970

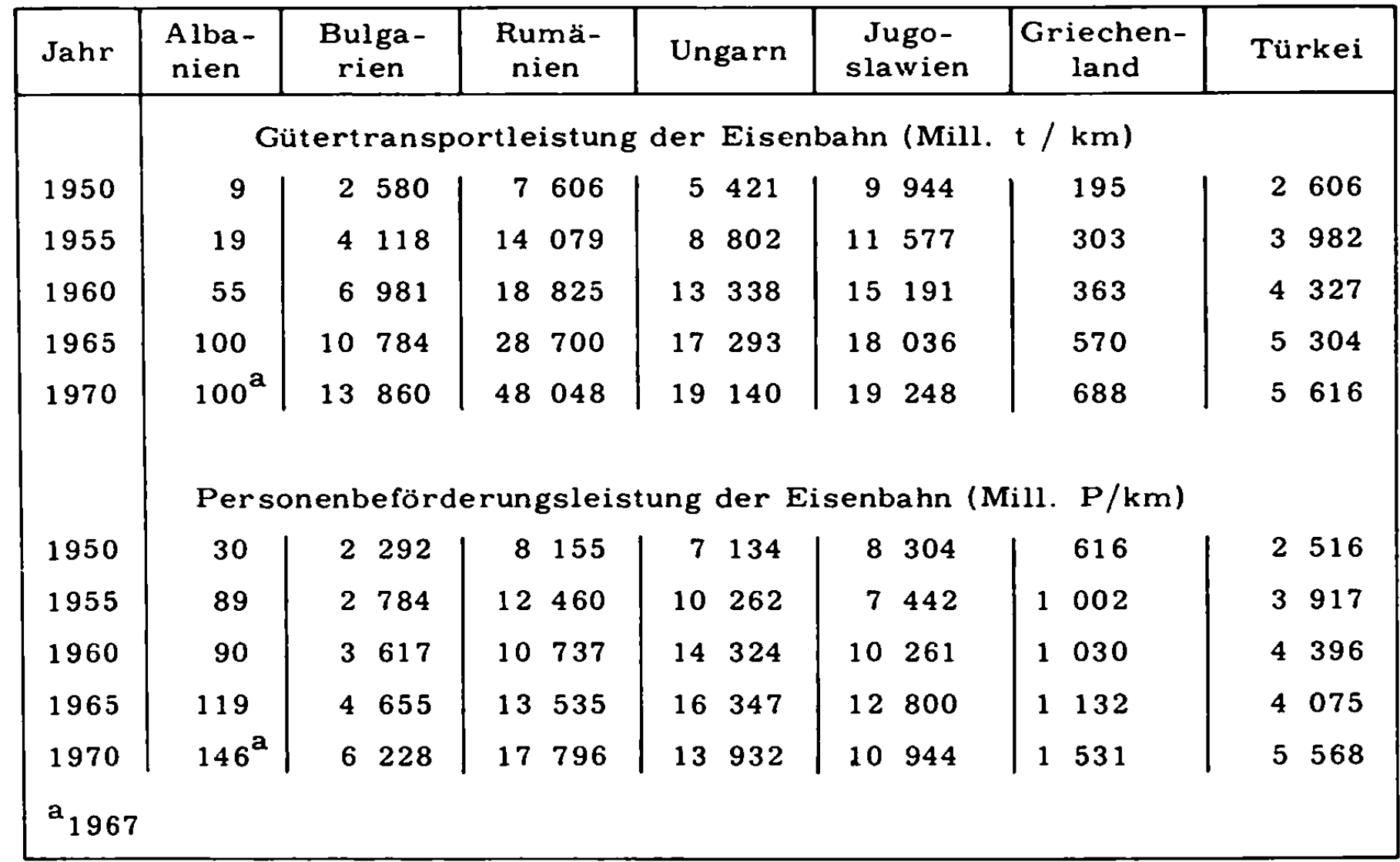

Quelle: UN, Monthly Bulletin of Statistics, Okt. 1971, S. 138 ff. - Statistisches Jahrbuch der DDR 1971, S. 15* und 80*, 81*. 
Tabelle 52: Seehandelsflotte der südosteuropäischen Länder 1953-1970 (in $1000 \mathrm{BRT}$ )

\begin{tabular}{|c|c|c|c|c|c|c|c|c|c|}
\hline \multirow{2}{*}{ Land } & \multicolumn{4}{|c|}{ Gesamttonnage } & \multicolumn{5}{|c|}{ davon Tanker } \\
\hline & 1953 & 1965 & & 1970 & 1953 & & 1965 & & 1970 \\
\hline Bulgarien & - & 237 & & 686 & - & & 55 & & 163 \\
\hline Rumänien & . & 108 & & 341 & - & & 25 & & 69 \\
\hline Jugoslawien & 246 & 991 & 1 & 516 & - & & 75 & & 255 \\
\hline Griechenland & 1222 & $7 \quad 137$ & 10 & 952 & 121 & 1 & 706 & 3 & 872 \\
\hline Türkei & 478 & 672 & & 697 & . & & 114 & & 170 \\
\hline
\end{tabular}

Quelle: UN, Statistical Yearbook 1970, S. 429.

Tabelle 53: Güterumschlag der Seehäfen in den südosteuropäischen Ländern 1967 und 1968 (in $1000 \mathrm{t}$ )

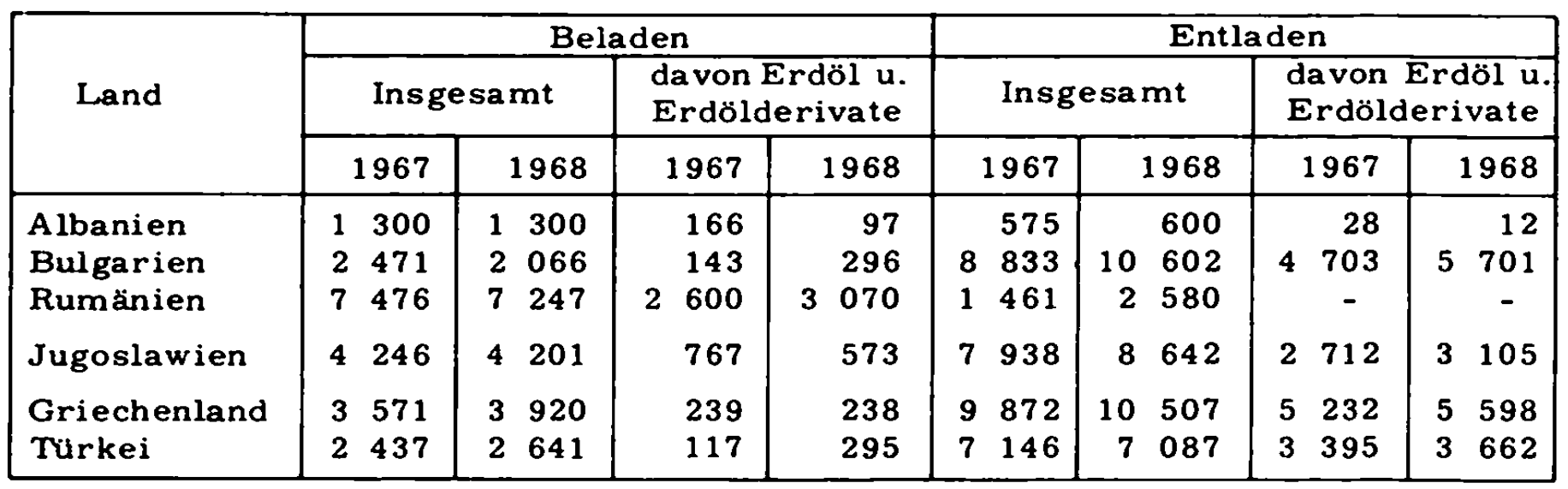

Quelle: UN, Statistical Yearbook 1970, S. $448 \mathrm{ff}$.

Tabelle 54: Die Donauflotte der Anliegerstaaten 1968

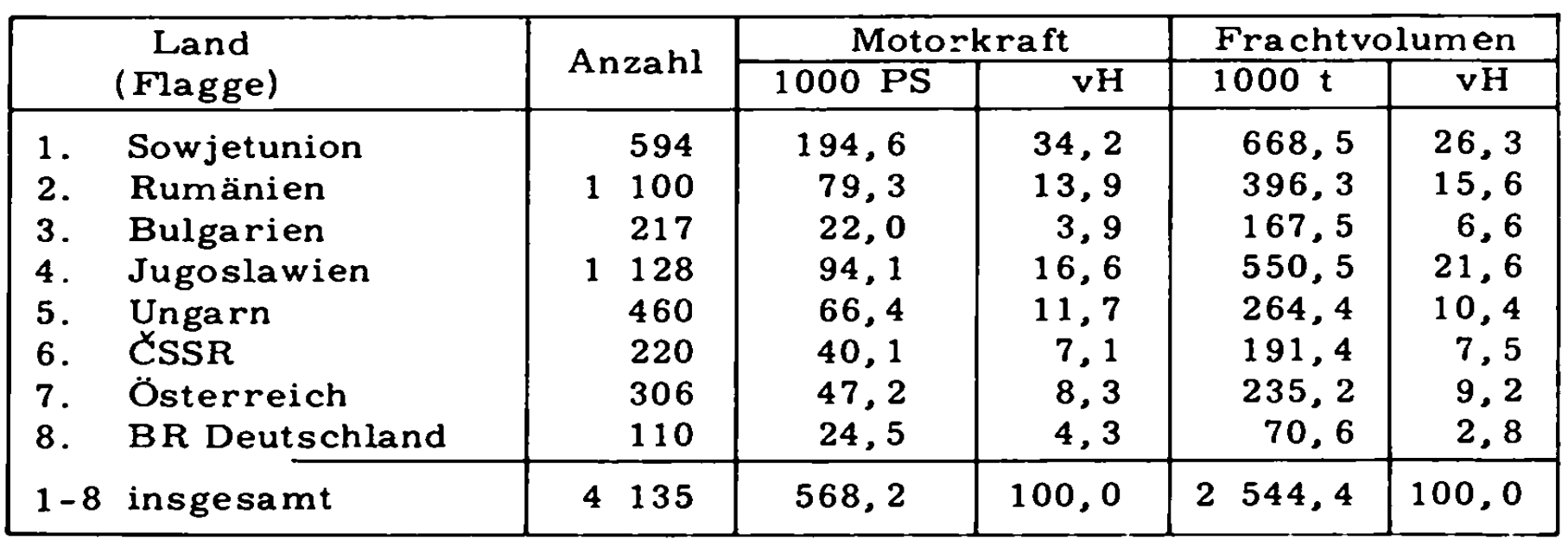

Quelle: Annuaire statistique de la Commission de Danube pour 1968, Budapest 1969 , S. 18 . 
Tabelle 55: Güterfracht zwischen den Donau-Anliegerstaaten 1968 (in 1000 t)

\begin{tabular}{|c|c|c|c|c|c|c|c|c|c|c|}
\hline $\mathrm{C}_{\text {von }}^{\text {nach }}$ & $\begin{array}{l}1 \\
\text { Sowjet- } \\
\text { union }\end{array}$ & \begin{tabular}{l}
\multicolumn{1}{c}{2} \\
Rumä- \\
nien
\end{tabular} & $\begin{array}{l}\text { 3 } \\
\text { Bulga- } \\
\text { rien }\end{array}$ & $\begin{array}{c}4 \\
\text { Jugo- } \\
\text { slawien }\end{array}$ & $\begin{array}{c}5 \\
\text { Ungarn }\end{array}$ & $\begin{array}{c}6 \\
\text { ČssR }\end{array}$ & \begin{tabular}{l}
\multicolumn{1}{c}{7} \\
Oster- \\
reich
\end{tabular} & $\begin{array}{c}8 \\
\text { BRD }\end{array}$ & $\begin{array}{c}9 \\
\text { Andere }\end{array}$ & \begin{tabular}{l}
\multicolumn{1}{c}{$1-9$} \\
Insge- \\
samt \\
\end{tabular} \\
\hline 1. Sowjetunion & - & 9,0 & 2907,1 & 1495,0 & 887,4 & 527,0 & 1748,0 & 28,6 & 531,8 & 8133,9 \\
\hline 2. Rumänien & - & - & 334,4 & 334,0 & 70,9 & 461,0 & 254,0 & 113,5 & 1773,0 & 3340,8 \\
\hline 3. Bulgarien & 554,0 & 4,0 & - & 27,0 & 4,6 & 39,0 & 250,0 & 41,1 & 8,4 & 928,1 \\
\hline 4. Jugoslawien & 173,4 & 85,0 & 320,2 & - & 55,7 & 75,0 & 454,0 & 382,6 & - & 1545,9 \\
\hline 5. Ungarn & 117,5 & 18,0 & 51,8 & 30,0 & - & - & 611,0 & 299,5 & 5,4 & 1133,2 \\
\hline 6. $\operatorname{CSSR}$ & 95,2 & 112,0 & 174,9 & 51,0 & 84,9 & - & 623,0 & 40,8 & - & 1181,8 \\
\hline 7. Österreich & 152,9 & 67,0 & 41,0 & 111,0 & 169,4 & - & - & 716,0 & - & 1257,3 \\
\hline 8. BR Deutschland & 0,2 & 9,0 & 16,5 & 63,0 & 48,7 & - & 1358,0 & - & - & 1495,4 \\
\hline 9. Andere & 384,1 & 990,0 & 42,0 & - & 8,8 & - & - & - & - & 1424,9 \\
\hline $1-9$ Insgesamt & 1477,3 & 1294,0 & 3887,9 & 2111,0 & 1330,4 & 1102,0 & 5298,0 & 1622,1 & 2318,6 & 20441,3 \\
\hline
\end{tabular}

Quelle: Annuaire statistique de la Commission du Danube pour 1968, Budapest 1969, S. 63. 
Tabelle 56: Frachtverkehr der Donauhäfen $1968^{\mathrm{a}}$ (in 1000 t)

\begin{tabular}{|c|c|c|c|c|c|c|}
\hline Hafen & & eladen & & tladen & Insgesamt & $\mathbf{v H}$ \\
\hline Kilia & & 294,5 & & 269,9 & 564,4 & 0,9 \\
\hline Isman̂l & 2 & 662,0 & 2 & 779,7 & 5441,7 & 8,5 \\
\hline Réni & 5 & 453,9 & 2 & 855,3 & 8309,2 & 13,0 \\
\hline Galaţi & 1 & 132,0 & 1 & 359,0 & 2491,0 & 3,9 \\
\hline Brăila & & 773,0 & 1 & 318,0 & 2091,0 & 3,3 \\
\hline Hîr ̧̧ova & & 592,0 & & 141,0 & 733,0 & 1,1 \\
\hline Călăraşi & & 484,0 & & 408,0 & 892,0 & 1,4 \\
\hline Silistra & & 42,3 & & 581,0 & 623,3 & 1,0 \\
\hline Giurgiu & & 849,0 & & 669,0 & 1518,0 & 2,4 \\
\hline Roussé & & 177,2 & 2 & 653,2 & 2830,4 & 4,4 \\
\hline Svistov & & 90,0 & 1 & 562,0 & 1652,0 & 2,6 \\
\hline Somovit & & 202,8 & & 656,4 & 859,2 & 1,3 \\
\hline Lom & & 368,6 & 1 & 462,6 & 1831,2 & 2,9 \\
\hline Prahovo & & 492,0 & & 498,0 & 990,0 & 1,6 \\
\hline Beograd & & 108,0 & 4 & 170,0 & 4278,0 & 6,7 \\
\hline Novi Sad & & 96,0 & & 739,0 & 835,0 & 1,3 \\
\hline Vukovar & & 186,0 & & 378,0 & 564,0 & 0,9 \\
\hline Mohács & & 753,1 & & 893,1 & 1646,2 & 2,6 \\
\hline Dunaujváros & & 67,4 & 2 & 158,1 & 2225,5 & 3,5 \\
\hline Budapest & & 760,2 & 3 & 540,6 & 4300,8 & 6,7 \\
\hline Almás fủzitö & & 660,4 & & 687,7 & 1348,1 & 2,1 \\
\hline Komárno & & 269,0 & 2 & 510,0 & 2779,0 & 4,4 \\
\hline Bratislava & 1 & 128,0 & & 329,0 & 1457,0 & 2,3 \\
\hline Wien & & 415,0 & 2 & 582,0 & 2997,0 & 4,7 \\
\hline $\operatorname{Linz}$ & 1 & 460,0 & 3 & 039,0 & 4499,0 & 7,0 \\
\hline Regensburg & 1 & 571,1 & 2 & 084,4 & 3655,5 & 5,7 \\
\hline Andere & & 601,5 & 1 & 855,0 & 2456,5 & 3,8 \\
\hline Insgesamt & 21 & 689,0 & 42 & 179,0 & 63868,0 & 100,0 \\
\hline
\end{tabular}

Quelle: Annuaire statistique de la Commission du Danube pour 1968, Budapest 1969 , S. 78 . 
Tabelle 57: Kraftfahrzeugbestand in den südosteuropäischen Ländern 1953-1969 (in 1000 Stück)

\begin{tabular}{|l|c|c|c|c|c|c|}
\hline \multirow{2}{*}{ Land } & \multicolumn{3}{|c|}{ P k w } & \multicolumn{3}{c|}{ L w } \\
\cline { 2 - 7 } Rumänien & 1953 & 1963 & 1969 & 1953 & 1963 & 1969 \\
Ungarn &. &. &. &. & 27,9 & 43,9 \\
Jugoslawien & 10,2 & 112,5 & 562,5 & 21,4 & 49,2 & 108,6 \\
Griechenland & 15,1 & 67,6 & 194,9 & 24,2 & 57,1 & 107,0 \\
Türkei & 27,7 & 72,0 & 137,0 & 33,5 & 100,0 & 157,5 \\
\hline
\end{tabular}

Quelle: UN, Statistical Yearbook 1970, S. 426, 427.

Tabelle 58: Zivilluftfahrt in den südosteuropäischen Ländern 1953-1970 (Mill. Passagier-km)

\begin{tabular}{|l|c|c|c|c|}
\hline \multicolumn{1}{|c|}{ Land } & 1953 & 1963 & 1969 & 1970 \\
\hline Bulgarien & 24,9 & 102,2 & 294,6 &. \\
Rumänien & $\cdot$ & 142,3 & 331,6 & 354,0 \\
Ungarn & 19,5 & 100,5 & 290,4 &. \\
Jugoslawien & 27,8 & 190,1 & 606,0 & 774,0 \\
Griechenland & 43,7 & 401,3 & 1717,5 & 226,4 \\
Türkei & 66,3 & 137,7 & 494,1 & 639,6 \\
\hline
\end{tabular}

Quelle: UN, Statistical Yearbook 1970, S. 458 ff. - UN, Monthly Bulletin of Statistics, Dec. 1971 , S. $140 \mathrm{ff}$. 
Tabelle 59: Registrierte Rundfunkempfänger und Fernsehempfänger in den südosteuropäischen Ländern 1960 und 1969

\begin{tabular}{|c|c|c|c|c|}
\hline \multirow{2}{*}{ Land } & \multicolumn{2}{|c|}{ Bestand in 1000} & \multicolumn{2}{|c|}{$\begin{array}{c}\text { Stück je } \\
1000 \text { Einwohner }\end{array}$} \\
\hline & 1960 & 1969 & 1960 & 1969 \\
\hline$\frac{\text { Rundfunkempfänger }}{\text { Albanien }}$ & 54 & 160 & 33 & 77 \\
\hline Bulgarien & 1431 & 2271 & 182 & 269 \\
\hline Rumänien & 2008 & 3050 & 109 & 152 \\
\hline Ungarn & 2224 & 2531 & 222 & 246 \\
\hline Jugoslawien & 1562 & 3320 & 84 & 163 \\
\hline Griechenland & 713 & . & 85 & . \\
\hline Türkei & 1352 & $\begin{array}{ll}3 & 030\end{array}$ & 49 & 88 \\
\hline$\frac{\text { Fernsehemplänger }}{\text { Albanien }}$ & - & 2,5 & - & 1,2 \\
\hline Bulgarien & 5 & 829 & 0,6 & 98 \\
\hline Rumänien & 55 & 1288 & 3 & 64 \\
\hline Ungarn & 104 & 1596 & 10 & 155 \\
\hline Jugoslawien & 25 & 1546 & 1,4 & 76 \\
\hline Griechenland & - & 86 & - & 10 \\
\hline Turkei & 1 & 25 & 0,04 & 0,7 \\
\hline
\end{tabular}

Quelle: UN, Statistical Yearbook 1970, S. 804, 805.

Tabelle 60: Telefonanschlüsse in den südosteuropäischen Ländern 1953-1969

\begin{tabular}{|l|r|r|r|r|r|r|}
\hline \multirow{2}{*}{ Land } & \multicolumn{3}{|c|}{ in 1000} & \multicolumn{3}{c|}{$\begin{array}{c}\text { Anschlüsse auf } \\
\end{array}$} \\
\cline { 2 - 7 } & 1953 & 1965 & 1969 & 1953 & 1965 & 1969 \\
\hline Bulgarien & 100 & 279 & 414 & 14 & 34 & 41 \\
Rumänien & 124 & 473 & 606 & 8 & 25 & 30 \\
Ungarn & 159 & 566 & 778 & 17 & 56 & 76 \\
Jugoslawien & 127 & 415 & 623 & 8 & 20 & 30 \\
Griechenland & 104 & 508 & 881 & 13 & 59 & 100 \\
Türkei & 97 & 351 & 514 & 4 & 11 & 15 \\
\hline
\end{tabular}

Quelle: UN, Statistical Yearbook 1970, S. 501, 502. 


\section{Außenhandel, Tourismus}

Tabelle 61: Import der südosteuropäischen Länder 1938-1970 (in Mill. US-Dollar)

\begin{tabular}{|c|c|c|c|c|c|c|c|}
\hline Jahr & Albanien & Bulgarien & Rumänien & Ungarn & $\begin{array}{l}\text { Jugo- } \\
\text { slawien }\end{array}$ & $\begin{array}{c}\text { Griechen- } \\
\text { land }\end{array}$ & Türkei \\
\hline 1938 & 7 & 60 & 137 & 123 & 115 & 132 & 119 \\
\hline 1950 & . & 135 & 243 & 316 & 231 & 428 & $\begin{array}{l}286 \\
532\end{array}$ \\
\hline $\begin{array}{l}1953 \\
1954\end{array}$ & . & $\begin{array}{l}200 \\
196\end{array}$ & $\begin{array}{l}385 \\
338\end{array}$ & $\begin{array}{l}488 \\
532\end{array}$ & $\begin{array}{l}395 \\
339\end{array}$ & $\begin{array}{l}296 \\
330\end{array}$ & $\begin{array}{l}533 \\
478\end{array}$ \\
\hline 1955 & 43 & 250 & 384 & 554 & 441 & 382 & 498 \\
\hline 1956 & 39 & 251 & 352 & 481 & 474 & 464 & 407 \\
\hline 1957 & 53 & 332 & 415 & 683 & 661 & 524 & 397 \\
\hline 1958 & 79 & 367 & 482 & 631 & 685 & 565 & 315 \\
\hline 1959 & 85 & 580 & 502 & 793 & 687 & 567 & 470 \\
\hline 1960 & 81 & 633 & 648 & 976 & 826 & 702 & 468 \\
\hline 1961 & 72 & 666 & 815 & 1026 & 910 & 714 & 510 \\
\hline 1962 & 65 & 785 & 942 & 1149 & 888 & 701 & 622 \\
\hline 1963 & 71 & 933 & 1022 & 1306 & 1057 & 804 & 691 \\
\hline 1964 & 98 & 1062 & 1168 & 1495 & 1323 & 885 & 542 \\
\hline 1965 & 100 & 1178 & $\begin{array}{ll}1077\end{array}$ & 1521 & 1288 & $1 \quad 134$ & 577 \\
\hline 1966 & 103 & 1478 & 1213 & 1566 & 1577 & 1215 & 725 \\
\hline 1967 & 123 & 1572 & 1546 & 1776 & 1707 & 1186 & 691 \\
\hline 1968 & 123 & 1782 & 1609 & 1803 & 1794 & 1390 & 770 \\
\hline 1969 & 138 & 1749 & 1741 & 1928 & 2133 & 1598 & 756 \\
\hline 1970 & 150 & 1816 & 1960 & 2505 & 2876 & 1959 & 888 \\
\hline \multicolumn{8}{|c|}{$\begin{array}{l}\text { Index: } \\
1960=100\end{array}$} \\
\hline 1961 & 89 & 105 & 126 & 105 & 110 & 102 & 109 \\
\hline 1962 & 80 & 124 & 145 & 118 & 108 & 100 & 133 \\
\hline 1963 & 88 & 147 & 158 & 134 & 128 & 115 & 148 \\
\hline 1964 & 121 & 168 & 180 & 153 & 160 & 126 & 116 \\
\hline 1965 & 123 & 186 & 166 & 156 & 156 & 162 & 123 \\
\hline 1966 & 127 & 233 & 187 & 160 & 191 & 174 & 155 \\
\hline 1967 & 152 & 248 & 239 & 182 & 207 & 169 & 148 \\
\hline 1968 & 152 & 282 & 248 & 185 & 218 & 199 & 165 \\
\hline 1969 & 170 & 276 & 269 & 198 & 258 & 227 & 161 \\
\hline 1970 & 185 & 289 & 302 & 257 & 348 & 279 & 189 \\
\hline
\end{tabular}

Quel1e: UN, Statistical Yearbook 1970, S. 404; 1963, S. 350,352 . UN, Monthly Bulletin of Statistics, Dez. 1971, S. 112, 114. Statistisches Jahrbuch für die Bundesrepublik Deutschland 1971, S. 78* - Rocznik Statystyczny 1971 (Warszawa). S. 719.UN/ECE, Economic Bulletin for Europe, Vol. 23 (1972), No. 2, S. 23 . 
Tabelle 62: Export der südosteuropäischen Länder 1938-1970 (in Mill. US-Dollar)

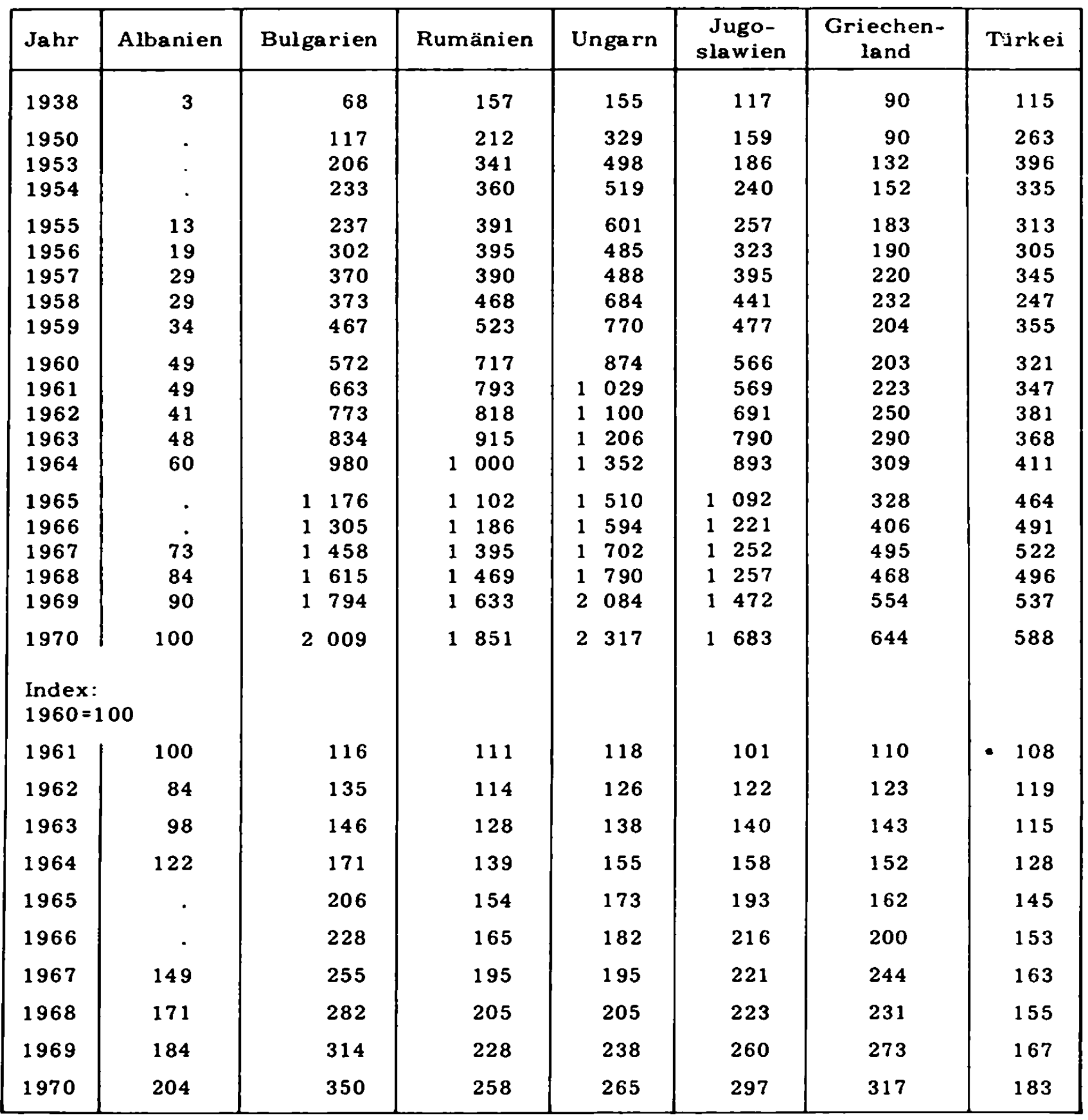

Quelle: UN, Statistical Yearbook 1970, S. 405; 1963, S. 351, 353. UN, Monthly Bulletin of Statistics, Dez. 1971, S. 113,115. Statistisches Jahrbuch für die Bundesrepublik Deutschland 1971 , S. 79*. - Rocznik Statystyczny 1971 (Warszawa), S. 720. UN/ECE, Economic Bulletin for Europe, Vol. 23 (1972), No. 2, S. 22. 
Tabelle 63. Import der südosteuropäischen Länder nach Ländern und Ländergruppen 1969 (in Mill US-Dollar)

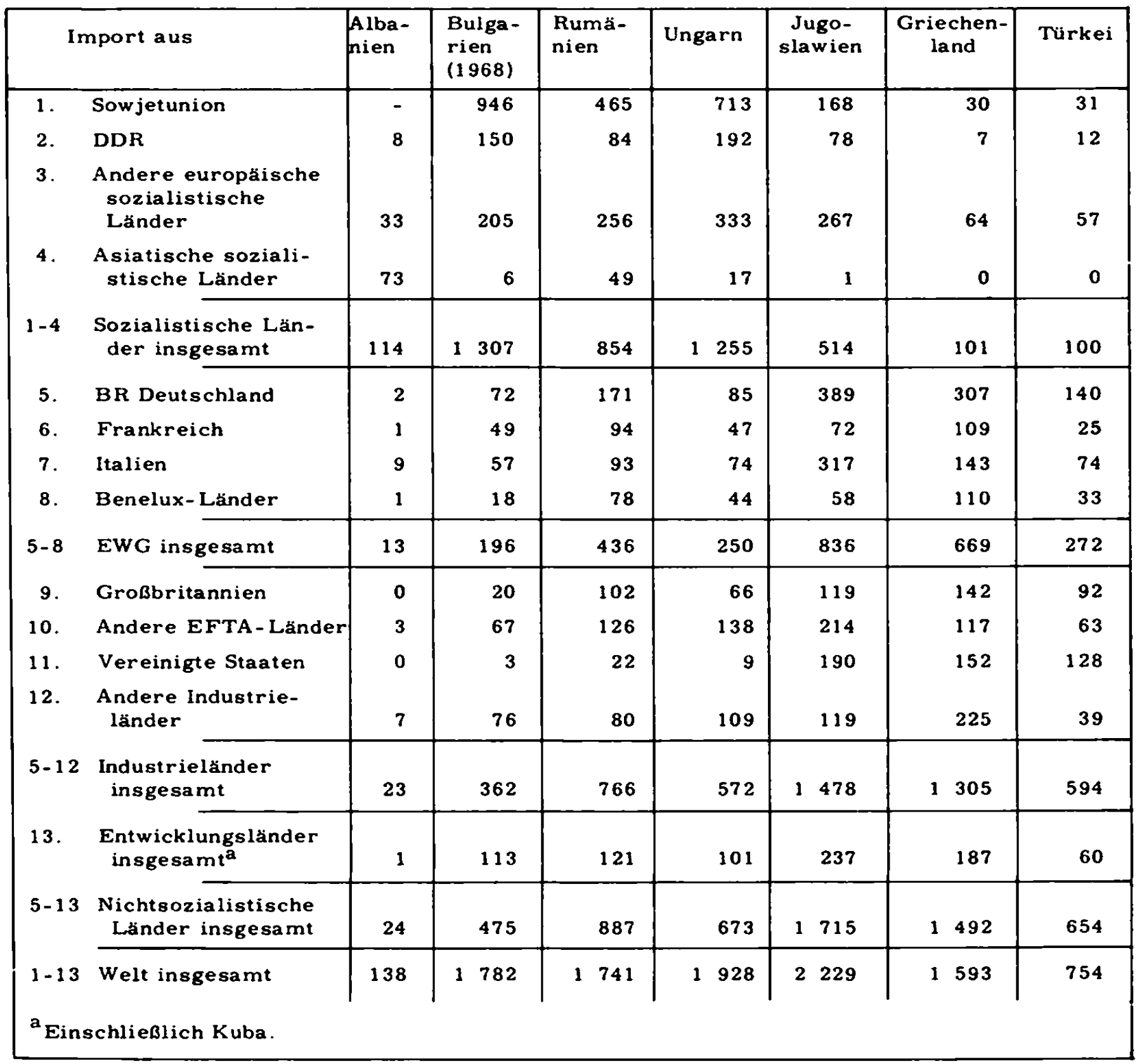

Quelle: Statistisches Jahrbuch für die Bundesrepublik Deutschland 1971. S 78*. - IMF, Direction of Trade. A Supplement to International Financial Statistics, März 1970. 
Tabelle 64 : Export der südosteuropäischen Länder nach Ländern und Ländergruppen 1969 (in Mill. US-Dollar)

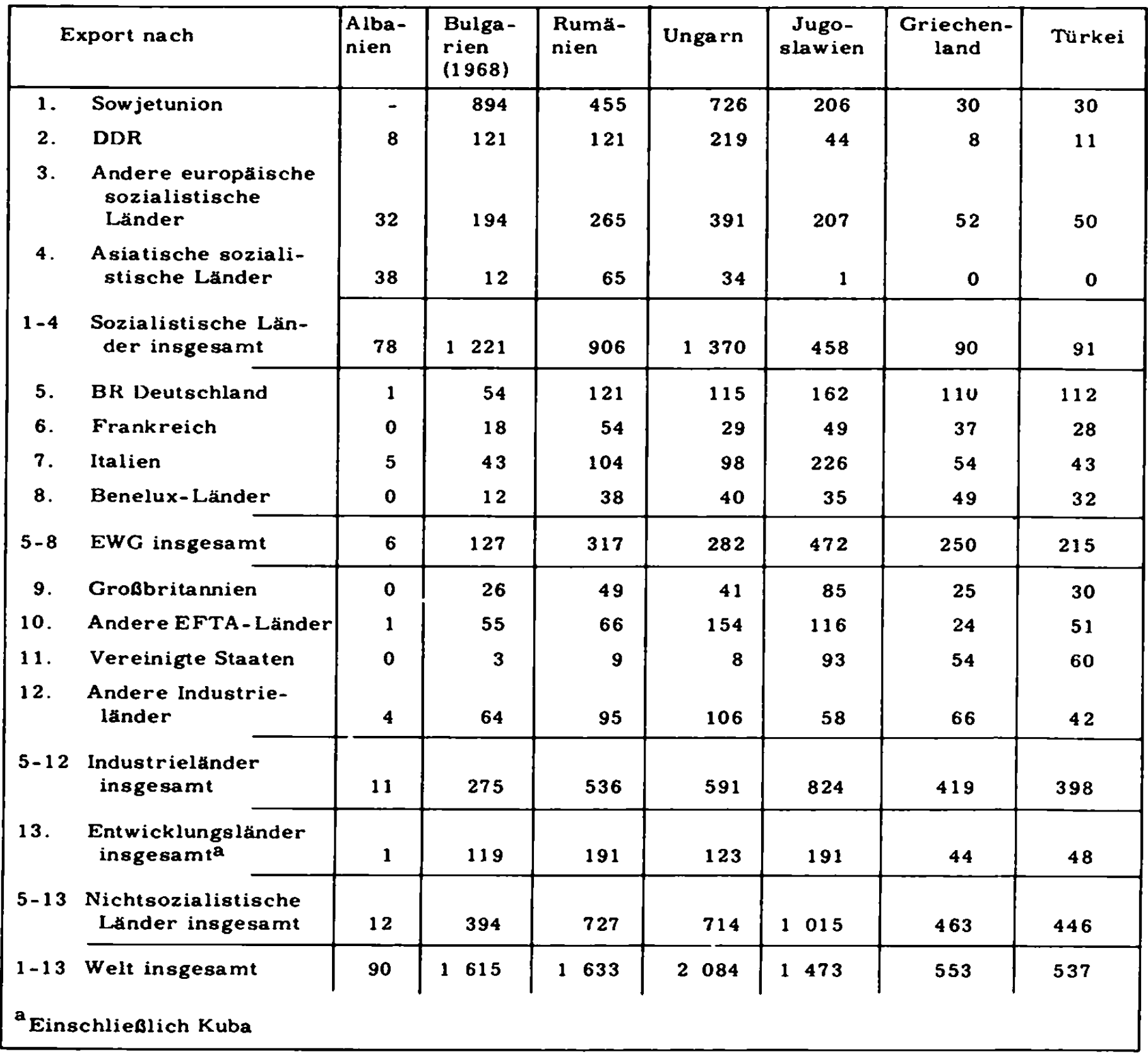

Quelle: Statistisches Jahrbuch für die Bundesrepublik Deutschland 1971 , S. 79*. - IMF, Direction of Trade. A Supplement to International Financial Statistics, März 1970. 
Tabelle 65 Import der südosteuropäischen Länder nach Ländern und Ländergruppen 1969 (in $\mathrm{vH}$ )

\begin{tabular}{|c|c|c|c|c|c|c|c|c|}
\hline \multicolumn{2}{|c|}{ Import aus } & $\begin{array}{l}\text { Alba- } \\
\text { nien }\end{array}$ & $\begin{array}{l}\text { Bulga- } \\
\text { rien }\end{array}$ & $\begin{array}{l}\text { Rumä- } \\
\text { nien }\end{array}$ & Ungarn & $\begin{array}{l}\text { Jugo- } \\
\text { slawien }\end{array}$ & $\begin{array}{l}\text { Griechen- } \\
\text { land }\end{array}$ & Türkei \\
\hline 1. & Sow jetunion & - & 53,1 & 26,7 & 37,0 & 7,5 & 1,9 & 4,1 \\
\hline 2. & DDR & 5,8 & 8,4 & 4,8 & 9,9 & 3,5 & 0,4 & 1,6 \\
\hline 3. & $\begin{array}{l}\text { Andere europäische } \\
\text { sozialistische } \\
\text { Länder }\end{array}$ & 23,9 & 11,5 & 14,7 & 17,3 & 12,0 & 4,0 & 7,6 \\
\hline 4. & $\begin{array}{l}\text { Asiatische soziali- } \\
\text { stische Länder }\end{array}$ & 52,9 & 0,3 & 2,8 & 0,9 & 0,1 & 0,0 & 0,0 \\
\hline $1-4$ & $\begin{array}{l}\text { Sozialistische Län- } \\
\text { der insgesamt }\end{array}$ & 82,6 & 73,3 & 49,0 & 65,1 & 23,1 & 6,3 & 13,3 \\
\hline 5. & BR Deutschland & 1,5 & 4,0 & 9,8 & 4,4 & 17,5 & 19,3 & 18,6 \\
\hline 6. & Frankreich & 0,7 & 2,8 & 5,4 & 2,4 & 3,2 & 6,8 & 3,3 \\
\hline 7. & Italien & 6,5 & 3,2 & 5,3 & 3,9 & 14,2 & 9,0 & 9,8 \\
\hline 8. & Benelux-Länder & 0,7 & 1,0 & 4,5 & 2,3 & 2,6 & 6,9 & 4,4 \\
\hline $5-8$ & EWG insgesamt & 9,4 & 11,0 & 25,0 & 13,0 & 37,5 & 42,0 & 36,1 \\
\hline 9. & Großbritannien & 0,0 & 1,1 & 5,9 & 3,4 & 5,3 & 8,9 & 12,2 \\
\hline 10 & Andere EFTA - Länder & 2,2 & 3,7 & 7,2 & 7,2 & 9,6 & 7,4 & 8,3 \\
\hline 11. & Vereinigte Staaten & 0,0 & 0,2 & 1,3 & 0,5 & 8,6 & 9,5 & 17,0 \\
\hline 12. & $\begin{array}{l}\text { Andere Industrie- } \\
\text { länder }\end{array}$ & 5,1 & 4,3 & 4,6 & 5,6 & 5,3 & 14,1 & 5,2 \\
\hline $5-12$ & $\begin{array}{l}\text { Industrieländer } \\
\text { insgesamt }\end{array}$ & 16,7 & 20,3 & 44,0 & 29,7 & 66,3 & 81,9 & 78,8 \\
\hline 13. & $\begin{array}{l}\text { Entwicklungsländer } \\
\text { insgesamt }\end{array}$ & 0,7 & 6,4 & 7,0 & 5,2 & 10,6 & 11,8 & 7,9 \\
\hline $5-13$ & $\begin{array}{l}\text { Nicht sozialistische } \\
\text { Länder insgesamt }\end{array}$ & 17,4 & 26,7 & 51,0 & 34,9 & 76,9 & 93,7 & 86,7 \\
\hline $1-13$ & Welt insgesamt & 100,0 & 100,0 & 100,0 & 100,0 & 100,0 & 100,0 & 100,0 \\
\hline
\end{tabular}

Quelle: Statistisches Jahrbuch für die Bundesrepublik Deutschland 1971 , S. 78*. - IMF, Direction of Trade. A Supplement to International Financial Statistics, März 1970. 
Tabelle 66: Export der südosteuropäischen Länder nach Ländern und Ländergruppen 1969 (in $\mathrm{vH}$ )

\begin{tabular}{|c|c|c|c|c|c|c|c|c|}
\hline \multicolumn{2}{|r|}{ Export nach } & \multirow{3}{*}{\begin{tabular}{|c|}
$\begin{array}{l}\text { Alba- } \\
\text { nien }\end{array}$ \\
- \\
8,9
\end{tabular}} & \multirow{2}{*}{$\begin{array}{l}\begin{array}{l}\text { Bulga - } \\
\text { rien } \\
(1968)\end{array} \\
55,4\end{array}$} & \multirow{2}{*}{$\begin{array}{c}\begin{array}{l}\text { Rumä- } \\
\text { nien }\end{array} \\
27,9\end{array}$} & \multirow{2}{*}{$\begin{array}{r}\text { Ungarn } \\
34,8\end{array}$} & \multirow{2}{*}{$\begin{array}{c}\begin{array}{c}\text { Jugo- } \\
\text { slawien }\end{array} \\
14,0\end{array}$} & \multirow{2}{*}{$\begin{array}{c}\begin{array}{c}\text { Griechen- } \\
\text { land }\end{array} \\
5,4\end{array}$} & \multirow{2}{*}{$\begin{array}{r}\text { Türkei } \\
5,6\end{array}$} \\
\hline 1. & Sowjetunion & & & & & & & \\
\hline 2. & DDR & & 7,5 & 7,4 & 10,5 & 3,0 & 1,5 & 2,0 \\
\hline 3. & $\begin{array}{l}\text { Andere europäische } \\
\text { sozialistische } \\
\text { Länder }\end{array}$ & 35,6 & 12,0 & 16,2 & 18,8 & 14,0 & 9,4 & 9,3 \\
\hline 4. & $\begin{array}{l}\text { Asiatische soziali- } \\
\text { stische Lander }\end{array}$ & 42,2 & 0,7 & 4,0 & 1,6 & 0,1 & 0,0 & 0.0 \\
\hline $1-4$ & $\begin{array}{l}\text { Sozialistische Lan- } \\
\text { der insgesamt }\end{array}$ & 86,7 & 75,6 & 55,5 & 65,7 & 31,1 & 16,3 & 16,9 \\
\hline 5. & BR Deutschland & 1,1 & 3,4 & 7,4 & 5,5 & 11,0 & 19,9 & 20,8 \\
\hline 6. & Frankreich & 0,0 & 1,1 & 3,3 & 1,4 & 3,3 & 6,7 & 5,2 \\
\hline 7. & Italien & 5,6 & 2,7 & 6,4 & 4,7 & 15,3 & 9,8 & 8,0 \\
\hline 8. & Benelux-Länder & 0,0 & 0,7 & 2,3 & 1,9 & 2,4 & 8,8 & 6,0 \\
\hline $5-8$ & EWG insgesamt & 6.7 & 7,9 & 19,4 & 13,5 & 32,0 & 45,2 & 40,0 \\
\hline 9. & Großbritannien & 0,0 & 1,6 & 3,0 & 2,0 & 5,8 & 4,5 & 5,6 \\
\hline 10. & Andere EFTA-Lander & 1,1 & 3,4 & 4,0 & 7,4 & 7,9 & 4,4 & 9,5 \\
\hline 11. & Vereinigte Staaten & 0,0 & 0,2 & 0,6 & 0,4 & 6,3 & 9,8 & 11,2 \\
\hline 12. & $\begin{array}{l}\text { Andere Industrie- } \\
\text { lander }\end{array}$ & 4.4 & 3,9 & 5,8 & 5,1 & 3,9 & 11.9 & 7.8 \\
\hline $5-12$ & $\begin{array}{l}\text { Industrieländer } \\
\text { insgesamt }\end{array}$ & 12,2 & 17,0 & 32,8 & 28,4 & 55,9 & 75,8 & 74,1 \\
\hline 13. & $\begin{array}{l}\text { Entwicklungsländer } \\
\text { insgesamt }\end{array}$ & 1,1 & 7,4 & 11,7 & 5,9 & 13,0 & 7,9 & 9,0 \\
\hline $5-13$ & $\begin{array}{l}\text { Nichtsozialistische } \\
\text { Lánder insgesamt }\end{array}$ & 13,3 & 24,4 & 44.5 & 34,3 & 68,9 & 83,7 & 83,1 \\
\hline $\begin{array}{l}1-13 \\
{ }^{a} \text { Eins }\end{array}$ & $\begin{array}{l}\text { Welt insgesamt } \\
\text { schließlich Kuba. }\end{array}$ & 100,0 & 100,0 & 100,0 & 100,0 & 100.0 & 100,0 & 100,0 \\
\hline
\end{tabular}

Quelle: Statistisches Jahrbuch für die Bundesrepublik Deutschland 1971 , S. 79* - IMF, Direction of Trade. A Supplement to International Financial Statistics, März 1970. 
Tabelle 67: Warenstruktur des Außenhandels der südosteuropäischen Staaten 1970 (in $v H$ )

\begin{tabular}{|c|c|c|c|c|c|}
\hline Land & $\begin{array}{l}\text { Maschinen, } \\
\text { Ausrústun- } \\
\text { gen }\end{array}$ & $\begin{array}{c}\text { Andere } \\
\text { Industrie- } \\
\text { erzeugnisse }\end{array}$ & $\begin{array}{c}\text { Brennstoffe, } \\
\text { mineral. } \\
\text { Rohstoffe, } \\
\text { Metalle }\end{array}$ & $\begin{array}{l}\text { Landw. Roh- } \\
\text { stoffe, Nah- } \\
\text { rungsmittel }\end{array}$ & $\begin{array}{c}\text { Insge- } \\
\text { samt }\end{array}$ \\
\hline \multicolumn{6}{|l|}{ Import } \\
\hline Bulgarien & 40,6 & 14,2 & 29,1 & 16,1 & 100,0 \\
\hline Rumänien & 39,6 & 13,7 & 31,1 & 15,6 & 100,0 \\
\hline Ungarn & 31,0 & 21,4 & 23,2 & 24,4 & 100,0 \\
\hline Jugoslawien ${ }^{a}$ & 33,9 & 41,6 & 17.6 & 6.9 & 100,0 \\
\hline Griechenland $^{2}$ & 29,8 & 26,2 & 30,6 & 13,4 & 100,0 \\
\hline Türkei $^{\mathbf{a}}$ & 40.3 & 42,6 & 14,2 & 2,9 & 100,0 \\
\hline \multicolumn{6}{|l|}{ Export } \\
\hline Bulgarien & 29,1 & 19,3 & 8,2 & 43,4 & 100,0 \\
\hline Rumänien & 22,6 & 27,7 & 22,9 & 26,8 & 100,0 \\
\hline Ungarn & 32.4 & 26.0 & 14,9 & 26.7 & 100,0 \\
\hline Jugoslawien ${ }^{a}$ & 20,4 & 49,2 & 10.8 & 19,6 & 100,0 \\
\hline Griechenland $^{\mathbf{a}}$ & $2,6^{b}$ & 15,9 & 24,3 & 57,2 & 100,0 \\
\hline Türkei ${ }^{\mathbf{a}}$ & 0.0 & 7,3 & 35,5 & 57,2 & 100,0 \\
\hline
\end{tabular}

Que 11 e:Rocznik Statystyczny 1971 (Warszawa), S. 721, 722. Statističeskij eźegodnik stran-Clenov SÉV 1971 (Moskva), S. 344. - OECD, Economic Surveys. Greece. Paris 1971, S. 18 . 
Tabelle 68: Import der marktwirtschaftlichen Länder aus den sozialistischen Staaten $^{\mathrm{a}}$ 1966-1970 (in Mill. US-Dollar und in $\mathrm{vH}$ )

\begin{tabular}{|c|c|c|c|c|c|c|c|}
\hline Land & 1966 & 1967 & 1968 & 1969 & 1970 & \multicolumn{2}{|c|}{ in $\mathrm{VH}$} \\
\hline $\begin{array}{l}\text { 1. BR Deutechlend' } \\
\text { 2. Grobbritannien } \\
\text { 3. Italien } \\
\text { 4. Frankreich } \\
\text { 5. Niederlande } \\
\text { 6. Belg. - Luxemburg } \\
\text { 7. Danemark } \\
\text { 8. Norwegen } \\
\text { 9. Irland }\end{array}$ & $\begin{array}{r}788,2 \\
783,8 \\
576,9 \\
415,6 \\
187,0 \\
157,3 \\
133,7 \\
78,6 \\
18,8\end{array}$ & $\begin{array}{r}754,7 \\
793.9 \\
748,8 \\
426.4 \\
193,3 \\
153,3 \\
130,8 \\
88,9 \\
28,4\end{array}$ & $\begin{array}{r}854,7 \\
827,1 \\
711,3 \\
442,9 \\
211,0 \\
168,1 \\
127,6 \\
83,5 \\
28,0\end{array}$ & $\begin{array}{r}1022,5 \\
901,7 \\
786.2 \\
554,9 \\
252,6 \\
173,1 \\
140,4 \\
78,0 \\
27,4\end{array}$ & $\begin{array}{r}203,6 \\
969,6 \\
904,8 \\
551,4 \\
253,2 \\
193,4 \\
158,3 \\
90,0 \\
33,1\end{array}$ & $\begin{array}{l}9,7 \\
9,6 \\
7.1 \\
5,1 \\
2,3 \\
1,9 \\
1,6 \\
1,0 \\
0,2\end{array}$ & $\begin{array}{r}11.7 \\
9,4 \\
8.8 \\
5,4 \\
2,5 \\
1,9 \\
1.5 \\
0.9 \\
0,3\end{array}$ \\
\hline 1-9 EWG-LAnder insg. & 3139,9 & 3318,5 & 3454,2 & 3936,8 & 4357.4 & 38,5 & 42,4 \\
\hline $\begin{array}{l}\text { 10. Jugoslawien } \\
\text { 11. Schweden } \\
\text { 12. Oeterreich } \\
\text { 13. Finnland } \\
\text { 14. Schweiz } \\
\text { 15. Turkei } \\
\text { 16. Spanien } \\
\text { 17. Griechenland } \\
\text { 18. Island } \\
\text { 19. Portugel } \\
\text { 20. Malta }\end{array}$ & $\begin{array}{r}508,6 \\
223,7 \\
232,6 \\
343,1 \\
115,9 \\
84,4 \\
88,7 \\
101,3 \\
18,0 \\
13,5 \\
5,7\end{array}$ & $\begin{array}{r}462,9 \\
225,6 \\
217,8 \\
342,2 \\
112,8 \\
91,2 \\
1100,8 \\
91,8 \\
18,8 \\
11,6 \\
7,1\end{array}$ & $\begin{array}{r}512,5 \\
255,6 \\
251,9 \\
337,3 \\
110,0 \\
98,9 \\
111,2 \\
113,0 \\
16,4 \\
14,6 \\
6,0\end{array}$ & $\begin{array}{r}513,6 \\
296,8 \\
282,5 \\
339,5 \\
125,9 \\
99,9 \\
117,3 \\
101,3 \\
15,4 \\
17,2 \\
6,5\end{array}$ & $\begin{array}{r}594,4 \\
354,2 \\
345,7 \\
431,6 \\
155,2 \\
115,1 \\
103,1 \\
101,5 \\
17,0 \\
9,3 \\
7,4\end{array}$ & $\begin{array}{l}6,2 \\
2,7 \\
2,9 \\
1,2 \\
1,4 \\
1.0 \\
1.1 \\
1.3 \\
0,2 \\
0,2 \\
0,1\end{array}$ & $\begin{array}{l}5,8 \\
3,4 \\
3,3 \\
4,2 \\
1,5 \\
1,1 \\
1,0 \\
1.0 \\
0,2 \\
0,1 \\
0,1\end{array}$ \\
\hline $\begin{array}{l}\text { 10-20 And. europsische } \\
\text { Lander }\end{array}$ & 1735.5 & 1682.6 & $18: 7.4$ & 1915,9 & 2234.5 & 21,3 & 21.7 \\
\hline $\begin{array}{l}\text { 1-20 Europ. Lander } \\
\text { insgesamt }\end{array}$ & 4875.4 & 5001,0 & 5281,6 & 5852,6 & 6591,7 & 59,8 & 64,1 \\
\hline $\begin{array}{l}\text { 21. Japan } \\
\text { 22. Vereinigte Stanten } \\
\text { 23. Kanada } \\
\text { 24. Australien u. a. C }\end{array}$ & $\begin{array}{r}710,4 \\
200,4 \\
81,9 \\
54,7\end{array}$ & $\begin{array}{r}894,7 \\
197,6 \\
111,9 \\
57,6\end{array}$ & $\begin{array}{r}870,7 \\
220,8 \\
107,2 \\
66,9\end{array}$ & $\begin{array}{r}916,2 \\
217,6 \\
112,9 \\
70,6\end{array}$ & $\begin{array}{r}998,0 \\
248,9 \\
101,5 \\
80,8\end{array}$ & $\begin{array}{l}8.7 \\
2.4 \\
1.0 \\
0.7\end{array}$ & $\begin{array}{l}9.7 \\
2.4 \\
1.0 \\
0.8\end{array}$ \\
\hline $\begin{array}{l}\text { 21-24 And. entwickelte } \\
\text { Linder insg. }\end{array}$ & 1047,4 & 1261,8 & 1265,6 & 1317,3 & 1429,2 & 12,8 & 13,9 \\
\hline $\begin{array}{l}\text { 25. Indien } \\
\text { 26. Agypten } \\
\text { 27. Pakistan } \\
\text { 28. Irak } \\
\text { 29. Syrien } \\
\text { 30. Iran } \\
\text { 31. Bracilien } \\
\text { 32. Hongkong } \\
\text { 33. And. Entwicklungslander }\end{array}$ & $\begin{array}{r}280,7 \\
287,0 \\
76,2 \\
91,4 \\
85,9 \\
70,8 \\
73,1 \\
497,4 \\
769,4\end{array}$ & $\begin{array}{r}259,2 \\
331.4 \\
92,9 \\
79,4 \\
86,6 \\
80,5 \\
79,6 \\
405,6 \\
789,2\end{array}$ & $\begin{array}{r}303,8 \\
262,3 \\
112,4 \\
85,4 \\
106,9 \\
106,3 \\
93,5 \\
114,5 \\
711,7\end{array}$ & $\begin{array}{r}418,0 \\
195,3 \\
117,1 \\
102,4 \\
113,0 \\
109,9 \\
73,2 \\
460,8 \\
741,4\end{array}$ & $\begin{array}{r}311,3 \\
146,8 \\
112,1 \\
133,0 \\
121,4 \\
117,0 \\
52,8 \\
487,7 \\
783,2\end{array}$ & $\begin{array}{l}3,4 \\
3,5 \\
0,9 \\
1,1 \\
1,1 \\
0,9 \\
0.9 \\
6,1 \\
9,4\end{array}$ & $\begin{array}{l}3,0 \\
1,4 \\
1,2 \\
1,3 \\
1.2 \\
1,2 \\
0,5 \\
4,7 \\
7,6\end{array}$ \\
\hline $\begin{array}{l}\text { 25-33 Entw. - Lander } \\
\text { insgesamt }\end{array}$ & 2231.9 & 2204,4 & 2196,8 & 2331,1 & 2265.3 & 27.4 & 22,0 \\
\hline $\begin{array}{l}\text { 1-33 Marktwirtachaftliche } \\
\text { Lander insg. }\end{array}$ & $8 \quad 154,8$ & 8647,3 & 8744,1 & 9501,2 & 10286,3 & 100,0 & 100,0 \\
\hline
\end{tabular}

Albanien, Bulgarien, DDR, Polen, Rumanien, Tachechoslowakei, Ungarn, UdSSR; VR China, Mongolische VR, Nordkorea. Nordvietnam; Kuba. - bohne den Innerdeutschen Handel. - CNeuseeland, Sudafrikanische Union.

Quelle: IMF, Direction of Trade, Annual 1966-70, S. 85. 
Tabelle 69: Export der marktwirtschaftlichen Länder nach den sozialistischen Staaten $^{2}$ 1966-1970 (in Mill. US-Dollar und in $\mathrm{vH}$ )

\begin{tabular}{|c|c|c|c|c|c|c|c|c|}
\hline \multirow{2}{*}{ Land } & \multirow{2}{*}{1966} & \multirow{2}{*}{1967} & \multirow{2}{*}{1968} & \multirow{2}{*}{1969} & \multirow{2}{*}{\multicolumn{2}{|c|}{1970}} & \multicolumn{2}{|c|}{$\ln \mathrm{vH}$} \\
\hline & & & & & & & 1966 & 1970 \\
\hline $\begin{array}{l}\text { 1. BR Deutschland } \\
\text { 2. Grobbritannien } \\
\text { 3. Italien } \\
\text { 4. Frankreich } \\
\text { 5. Niederlande } \\
\text { 6. Belg. - Luxemburg } \\
\text { 7. Danemark } \\
\text { 8. Norwegen } \\
\text { 9. Irland }\end{array}$ & $\begin{array}{r}832,9 \\
537,5 \\
429,7 \\
503,4 \\
143,9 \\
139,5 \\
94,6 \\
54,0 \\
1,5\end{array}$ & $\begin{array}{r}1 \quad 104,5 \\
612,6 \\
549,9 \\
594,9 \\
204,6 \\
184,6 \\
107,6 \\
56,9 \\
1,4\end{array}$ & $\begin{array}{r}138,0 \\
648,3 \\
637,9 \\
705,8 \\
215,3 \\
167,4 \\
93,2 \\
61,4 \\
3,0\end{array}$ & $\begin{array}{r}325.4 \\
717,3 \\
775.9 \\
658,9 \\
254.9 \\
168,5 \\
107,6 \\
64.7 \\
4.7\end{array}$ & 1 & $\begin{array}{r}501,2 \\
777,2 \\
826,3 \\
792,5 \\
247,8 \\
198,7 \\
121,0 \\
75,2 \\
7,9\end{array}$ & $\begin{array}{l}10,9 \\
7,1 \\
5,6 \\
6.6 \\
1,9 \\
1.8 \\
1,3 \\
0,7 \\
0,0\end{array}$ & $\begin{array}{r}14.0 \\
7.2 \\
7.7 \\
7.4 \\
2.3 \\
1.8 \\
1.1 \\
0.7 \\
0.1\end{array}$ \\
\hline 1-9 EWG-Lander insg. & 2737,0 & 3417,0 & 3670,3 & 4077.9 & 4 & 547,8 & 35,9 & 42,3 \\
\hline $\begin{array}{l}\text { 10. Jugoslawien } \\
\text { 11. Schweden } \\
\text { 12. Osterreich } \\
\text { 13. Finnland } \\
\text { 14. Schweiz } \\
\text { 15. Turkei } \\
\text { 16. Spanien } \\
\text { 17. Griechenland } \\
\text { 18. Island } \\
\text { 19. Portugal } \\
\text { 20. Malta }\end{array}$ & $\begin{array}{r}455,5 \\
192,0 \\
264,0 \\
285,7 \\
135,1 \\
74,5 \\
135,9 \\
98,4 \\
16,7 \\
7,2 \\
0,2\end{array}$ & $\begin{array}{r}459.8 \\
237,3 \\
307.2 \\
332,2 \\
147,0 \\
87.8 \\
99,9 \\
89.5 \\
18,0 \\
7.8 \\
0,3\end{array}$ & $\begin{array}{r}141,1 \\
248,5 \\
304,8 \\
316,0 \\
162,2 \\
91,0 \\
92,4 \\
71,6 \\
12,4 \\
6,4 \\
.\end{array}$ & $\begin{array}{r}457,3 \\
301.9 \\
331,9 \\
353,9 \\
199.0 \\
90,7 \\
100.3 \\
90.1 \\
12,3 \\
7.1 \\
0,2\end{array}$ & & $\begin{array}{r}547,6 \\
366,6 \\
380,7 \\
375,0 \\
245,0 \\
84.7 \\
104,7 \\
106,5 \\
15,4 \\
7.8 \\
0.4\end{array}$ & $\begin{array}{l}6,0 \\
2,5 \\
3,4 \\
3,7 \\
1,8 \\
1,0 \\
1,8 \\
1.3 \\
0,2 \\
0,1 \\
0.0\end{array}$ & $\begin{array}{l}5.1 \\
3.4 \\
3.5 \\
3.5 \\
2.3 \\
0.8 \\
1.0 \\
1.0 \\
0.1 \\
0.1 \\
0.0\end{array}$ \\
\hline $\begin{array}{l}\text { 10-20 And. europaische } \\
\text { Lander }\end{array}$ & 1665,2 & 1786,8 & 1746,4 & 1944.7 & 2 & 234.4 & 21,8 & 20,8 \\
\hline $\begin{array}{l}\text { 1-20 Europ. Lander } \\
\text { insgesamt }\end{array}$ & 4402,2 & 5203,8 & 5416.7 & 6022,6 & 6 & 782,2 & 57.7 & 63,1 \\
\hline $\begin{array}{l}\text { 21 Japan } \\
\text { 22. Vereinigte Staaten } \\
\text { 23. Kanada } \\
24 \text {. Australien u. a. }{ }^{c}\end{array}$ & $\begin{array}{l}607,2 \\
198,1 \\
593,7 \\
183,5\end{array}$ & $\begin{array}{l}532,7 \\
195,2 \\
291.3 \\
285,8\end{array}$ & $\begin{array}{l}584,4 \\
215,0 \\
320,0 \\
196,8\end{array}$ & $\begin{array}{l}774,5 \\
249,3 \\
179,5 \\
225,2\end{array}$ & 1 & $\begin{array}{l}084.4 \\
353.3 \\
329.5 \\
276.9\end{array}$ & $\begin{array}{l}8.0 \\
2.6 \\
7,8 \\
2.4\end{array}$ & $\begin{array}{r}10,1 \\
3,3 \\
3.0 \\
2.6\end{array}$ \\
\hline $\begin{array}{l}\text { 21-24 And. entwickelte } \\
\text { Lander insg. }\end{array}$ & 1582,5 & 1305,0 & 1316.2 & 1428,5 & $\mathbf{2}$ & 044,1 & 20.8 & 19,0 \\
\hline $\begin{array}{l}\text { 25. Indien } \\
\text { 26 Agypten } \\
\text { 27. Pakistan } \\
\text { 28. Irak } \\
\text { 29. Syrien } \\
\text { 30. Iran } \\
\text { 31. Brasilien } \\
\text { 32. Hongkong } \\
\text { 33. And. Entwicklungslander }\end{array}$ & $\begin{array}{r}296.2 \\
321.9 \\
77,4 \\
11.3 \\
60.8 \\
38.4 \\
107.0 \\
12.8 \\
712.4\end{array}$ & $\begin{array}{r}291,6 \\
283,6 \\
84,5 \\
10,0 \\
47,2 \\
56,4 \\
97.0 \\
9,0 \\
521,5\end{array}$ & $\begin{array}{r}319,6 \\
301,9 \\
59,3 \\
11,4 \\
40,4 \\
60,6 \\
122,6 \\
8,0 \\
554,7\end{array}$ & $\begin{array}{r}350,6 \\
391,5 \\
99,7 \\
17,4 \\
73,5 \\
129,0 \\
8,2 \\
522,6\end{array}$ & & $\begin{array}{r}410,5 \\
485,5 \\
126,6 \\
21,4 \\
106,6 \\
135,8 \\
13,3 \\
627,8\end{array}$ & $\begin{array}{l}3,9 \\
4.2 \\
1.0 \\
0.1 \\
0.8 \\
0.5 \\
1.5 \\
0.2 \\
9.3\end{array}$ & $\begin{array}{l}3.8 \\
4.5 \\
1.2 \\
0.2 \\
1.0 \\
1,3 \\
0.1 \\
5.8\end{array}$ \\
\hline $\begin{array}{l}\text { 25-33 Entw. - Lander } \\
\text { insgesamt }\end{array}$ & 1638,2 & 1400,8 & 1478,5 & 1592,5 & 1 & 927.5 & 21.5 & 17.9 \\
\hline $\begin{array}{l}\text { 1.33 Marktwirtschafliche } \\
\text { lander insg. }\end{array}$ & 7622,9 & 7909.6 & 8211,4 & 9043.5 & 10 & 753.9 & 100.0 & 100.0 \\
\hline
\end{tabular}

Quelle: IMF, Direction of Trade, Annual 1966-70, S. 85. 
Tabelle 70: Anteil der sozialistischen Staaten ${ }^{2}$ am Außenhandel der marktwirtschaftlichen Länder 1966 und 1970 (in vH)

\begin{tabular}{|c|c|c|c|c|}
\hline \multirow{2}{*}{ Land } & \multicolumn{2}{|c|}{ Import } & \multicolumn{2}{|c|}{ Export } \\
\hline & 1966 & 1970 & 1966 & 1970 \\
\hline \multirow[t]{2}{*}{$\begin{array}{l}\text { 1. Bundesrepublik Deutschland } \\
\text { 2. Großbritannien } \\
\text { 3. Italien } \\
\text { 4. Frankreich } \\
\text { 5. Niederlande } \\
\text { 6. Belgien-Luxemburg } \\
\text { 7. Dänemark } \\
\text { 8. Norwegen } \\
\text { 9. Irland } \\
\text { 1-9 EWG-Länder insgesamt }\end{array}$} & $\begin{array}{l}4,3 \\
4,7 \\
6,7 \\
3,5 \\
2,3 \\
2,2 \\
4,5 \\
3,3 \\
1,8\end{array}$ & $\begin{array}{l}4,0 \\
4,5 \\
6,1 \\
2,9 \\
1,9 \\
1,7 \\
3,6 \\
2,4 \\
2,1\end{array}$ & $\begin{array}{l}4,1 \\
3,7 \\
5,3 \\
4,6 \\
2,1 \\
2,0 \\
3,9 \\
3,5 \\
0,2\end{array}$ & $\begin{array}{l}4,4 \\
4,0 \\
6,3 \\
4,4 \\
2,1 \\
1,7 \\
3,6 \\
3,1 \\
0,8\end{array}$ \\
\hline & 4,1 & 3,6 & 3,8 & 4,0 \\
\hline $\begin{array}{l}\text { 10. Jugoslawien } \\
\text { 11. Schweden } \\
\text { 12. Österreich } \\
\text { 13. Finnland } \\
\text { 14. Schweiz } \\
\text { 15. Türkei } \\
\text { 16. Spanien } \\
\text { 17. Griechenland } \\
\text { 18. Island } \\
\text { 19. Portugal } \\
\text { 20. Malta }\end{array}$ & $\begin{array}{r}32,3 \\
4,9 \\
10,0 \\
19,9 \\
2,9 \\
11,7 \\
2,5 \\
8,3 \\
11,3 \\
1,3 \\
5,2\end{array}$ & $\begin{array}{r}20,7 \\
5,1 \\
9,7 \\
16,4 \\
2,4 \\
12,9 \\
2,2 \\
5,2 \\
10,8 \\
0,6 \\
4,3\end{array}$ & $\begin{array}{r}37,3 \\
4,5 \\
15,7 \\
19,0 \\
4,1 \\
15,2 \\
10,8 \\
24,2 \\
11,9 \\
1,1 \\
0,7\end{array}$ & $\begin{array}{r}32,5 \\
5,4 \\
13,3 \\
16,3 \\
4,8 \\
14,4 \\
4,4 \\
16,5 \\
10,5 \\
0,8 \\
1,0\end{array}$ \\
\hline 10-20 Andere europäische Länder & 8,3 & 7,3 & 11,1 & 9,5 \\
\hline 1-20 Europäische Länder insges. & 5,0 & 4,3 & 5,1 & 4,9 \\
\hline \multirow{2}{*}{$\begin{array}{l}\text { 21. Japan } \\
\text { 22. Vereinigte Staaten } \\
\text { 23. Kanada } \\
\text { 24. Australien u. a. } \\
21-24 \text { Andere entwickelte Länder insg. }\end{array}$} & $\begin{array}{l}7,5 \\
0,7 \\
0,8 \\
0,8\end{array}$ & $\begin{array}{l}5,3 \\
0,6 \\
0,7 \\
0,8\end{array}$ & $\begin{array}{l}6,2 \\
0,7 \\
6,2 \\
3,1\end{array}$ & $\begin{array}{l}5,6 \\
0,8 \\
2,0 \\
3,4\end{array}$ \\
\hline & 1,9 & 1,6 & 2,8 & 2,4 \\
\hline $\begin{array}{l}\text { 25. Indien } \\
\text { 26. Ägypten } \\
\text { 27. Pakistan } \\
\text { 28. Irak } \\
\text { 29. Syrien } \\
\text { 30. Iran } \\
\text { 31. Brasilien } \\
\text { 32. Hongkong } \\
\text { 33. Andere Entwicklungsländer }\end{array}$ & $\begin{array}{r}11,8 \\
26,8 \\
9,5 \\
18,6 \\
29,2 \\
7,6 \\
4,9 \\
0,8 \\
2,7\end{array}$ & $\begin{array}{r}21,5 \\
15,1 \\
11,9 \\
26,1 \\
31,2 \\
6,7 \\
1,9 \\
0,5 \\
1,9\end{array}$ & $\begin{array}{r}15,9 \\
53,1 \\
11,6 \\
1,2 \\
35,8 \\
2,9 \\
6,1 \\
34,2 \\
2,5\end{array}$ & $\begin{array}{r}13,9 \\
49,0 \\
13,8 \\
1,9 \\
36,0\end{array}$ \\
\hline 25-33 Entwicklungsländer insges. & 5,9 & 4,1 & 4,5 & 3,6 \\
\hline $\begin{array}{l}\text { 1-33 Marktwirtschaftliche Länder } \\
\text { insgesamt } \\
\text { a } \\
\text { Albanien, Bulgarien, DDR, Polen, Rumär } \\
\text { deutschen Handel. - }{ }^{C} \text { Neuseeland, Sudafrik } \\
\text { deutschen Hongolische VRordkorea, }\end{array}$ & etne & $\begin{array}{l}\text { slowa } \\
\text { ba }\end{array}$ & 4,3 & $\begin{array}{l}3,9 \\
\text { dSSR; } \\
\text { er- }\end{array}$ \\
\hline
\end{tabular}

Quelle: IMF, Direction of Trade, Annual 1966-70, S. 3; errechnet nach S. 85 . 
Tabelle 71: Warenstruktur des Imports der Bundesrepublik Deutschland aus den südosteuropäischen Staaten 1971 (in Mill. DM und vH)

\begin{tabular}{|c|c|c|c|c|c|c|c|}
\hline & $\begin{array}{l}\text { Alba- } \\
\text { nien }\end{array}$ & $\begin{array}{l}\text { Bulga- } \\
\text { rien }\end{array}$ & $\begin{array}{l}\text { Rumä- } \\
\text { nien }\end{array}$ & Ungarn & $\begin{array}{l}\text { Jugo- } \\
\text { slawien }\end{array}$ & $\begin{array}{l}\text { Griechen - } \\
\text { land }\end{array}$ & Türkei \\
\hline $\begin{array}{l}\text { in Mill. DM } \\
\text { Ernährungswirtschaft } \\
\text { - Nahrungsmittel tieri- } \\
\text { schen Ursprungs } \\
\text { - Nahrungsmit tel pflanz- } \\
\text { lichen Ursprungs } \\
\text { - Genußmittel }\end{array}$ & $\begin{array}{l}0.7 \\
0.2 \\
0.5 \\
0.0\end{array}$ & $\begin{array}{r}110,7 \\
14,3 \\
74,1 \\
22,4\end{array}$ & $\begin{array}{r}171,1 \\
34,4 \\
133,2 \\
3.5\end{array}$ & $\begin{array}{r}185.4 \\
100,3 \\
76.0 \\
9.1\end{array}$ & $\begin{array}{r}110,8 \\
18.7 \\
63,4 \\
28,7\end{array}$ & $\begin{array}{r}312,4 \\
1,5 \\
173,5 \\
137,3\end{array}$ & $\begin{array}{r}255,6 \\
8,6 \\
179,3 \\
67,7\end{array}$ \\
\hline $\begin{array}{l}\text { Gewerbliche Wirtschaft } \\
\text { - Rohstoffe } \\
\text { - Halbwaren } \\
\text { - Fertigwaren } \\
\text { - Vorerzeugnisse } \\
\text { - Enderzeugnisse }\end{array}$ & $\begin{array}{l}3,2 \\
2,7 \\
0,2 \\
0,3 \\
0,0 \\
0.3\end{array}$ & $\begin{array}{r}110,3 \\
5,2 \\
20,2 \\
85,0 \\
13,7 \\
71,3\end{array}$ & $\begin{array}{r}569,9 \\
25,2 \\
216,2 \\
328,6 \\
121,3 \\
207,3\end{array}$ & $\begin{array}{r}322,5 \\
24,6 \\
58,8 \\
239,1 \\
60,6 \\
178,5\end{array}$ & $\begin{array}{r}988,1 \\
63,3 \\
165,3 \\
759,5 \\
119,4 \\
640.1\end{array}$ & $\begin{array}{r}364,2 \\
68,0 \\
60,6 \\
235,6 \\
86,9 \\
148,7\end{array}$ & $\begin{array}{r}220,6 \\
144,4 \\
36,0 \\
40,2 \\
12,1 \\
28,1\end{array}$ \\
\hline Ruckwaren & 0,0 & 5,3 & 6.1 & 12,4 & 39,3 & 8,2 & 5,3 \\
\hline Import 1970 insgesamt & 3,9 & 226,3 & 747,1 & 520,3 & 1138,2 & 684.8 & 481,5 \\
\hline $\begin{array}{l}\text { Zum Vergleich: } \\
\text { Import } 1937 \text { Deutsches } \\
\text { Reich insges. Mill. RM } \\
\text { davon. } \\
\text { Fertigwaren Mill. RM }\end{array}$ & $\begin{array}{l}0,14 \\
0,00 \\
\end{array}$ & $\begin{array}{r}71,8 \\
2,5 \\
\end{array}$ & $\begin{array}{r}179,5 \\
0.6 \\
\end{array}$ & $\begin{array}{r}114,0 \\
11,4 \\
\end{array}$ & $\begin{array}{r}132,2 \\
0,4 \\
\end{array}$ & $\begin{array}{r}76,4 \\
1,4 \\
\end{array}$ & $\begin{array}{r}97,8 \\
2,0 \\
\end{array}$ \\
\hline in $\vee \mathrm{H}$ & & & & & & & \\
\hline $\begin{array}{l}\text { Ernährungswirtschaft } \\
\text { - Nahrungsmittel tieri- } \\
\text { schen Ursprungs } \\
\text { - Nahrungsmittel pflanz- } \\
\text { lichen Ursprungs } \\
\text { - Genußmittel }\end{array}$ & $\begin{array}{r}16.6 \\
4.2 \\
12.2 \\
0.2\end{array}$ & $\begin{array}{r}48,9 \\
6,3 \\
32,7 \\
9,9\end{array}$ & $\begin{array}{r}22.9 \\
4.6 \\
17.8 \\
0.5\end{array}$ & $\begin{array}{r}35,6 \\
19,3 \\
14,6 \\
1.7\end{array}$ & $\begin{array}{l}9.7 \\
1.6 \\
5.6 \\
2.5\end{array}$ & $\begin{array}{r}45,6 \\
0,2 \\
25,3 \\
20,1\end{array}$ & $\begin{array}{r}53,1 \\
1,8 \\
37,2 \\
14,1\end{array}$ \\
\hline $\begin{array}{l}\text { Gewerbliche Wirtschaft } \\
\text { - Rohstoffe } \\
\text { - Halbwaren } \\
\text { - Fertigwaren } \\
\text { - Vorerzeugnisse } \\
\text { - Enderzeugnisse }\end{array}$ & $\begin{array}{r}83,3 \\
69,4 \\
5,2 \\
8,7 \\
0,7 \\
8,0\end{array}$ & $\begin{array}{r}48,8 \\
2,3 \\
8,9 \\
37,6 \\
6.1 \\
31,5\end{array}$ & $\begin{array}{r}76.3 \\
3.4 \\
28.9 \\
44.0 \\
16.2 \\
27.8\end{array}$ & $\begin{array}{r}62,0 \\
4,7 \\
11,3 \\
46,0 \\
11,7 \\
34,3\end{array}$ & $\begin{array}{r}86.8 \\
5.6 \\
14.5 \\
66.7 \\
10.5 \\
56.2\end{array}$ & $\begin{array}{r}53,2 \\
9,9 \\
8,9 \\
34,4 \\
12,7 \\
21,7\end{array}$ & $\begin{array}{r}45,8 \\
30,0 \\
7,5 \\
8,3 \\
2,5 \\
5,8\end{array}$ \\
\hline Ruckwaren & 0.1 & 2,3 & 0.8 & 2,4 & 3,5 & 1.2 & 1.1 \\
\hline Import 1970 insgesamt & 100.0 & 100.0 & 100.0 & 100.0 & 100.0 & 100,0 & 100,0 \\
\hline
\end{tabular}

Quelle: Statistisches Bundesamt Wiesbaden, Außenhandel, Reihe 3: Spezialhandel nach Länderri und Warengruppen, 4. Vierteljahr und Jahr 1971, S. 20. 
Tabelle 72: Warenstruktur des Exports der Bundesrepublik Deutschland nach den südosteuropäischen Staaten 1971 (in Mill. DM und vH)

\begin{tabular}{|c|c|c|c|c|c|c|c|}
\hline & $\begin{array}{l}\text { Alba- } \\
\text { nien }\end{array}$ & $\begin{array}{l}\text { Bulga- } \\
\text { rien }\end{array}$ & $\begin{array}{l}\text { Rumä- } \\
\text { nien }\end{array}$ & Ungarn & $\begin{array}{l}\text { Jugo- } \\
\text { slawien }\end{array}$ & $\begin{array}{l}\text { Griechen- } \\
\text { land }\end{array}$ & Türkei \\
\hline $\begin{array}{l}\text { in Mill. DM } \\
\text { Ernährungswirtschaft }\end{array}$ & 2,0 & 1,3 & 14,8 & 60,2 & 44,6 & 19,5 & 17,4 \\
\hline $\begin{array}{l}\text { Gewerbliche Wirtschaft } \\
\text { - Rohstoffe } \\
\text { - Halbwaren } \\
\text { - Fertigwaren } \\
\text { - Vorerzeugnisse } \\
\text { - Enderzeugnisse }\end{array}$ & $\begin{array}{l}9,7 \\
0,1 \\
3,0 \\
6,6 \\
3,2 \\
3,4\end{array}$ & $\begin{array}{r}253,7 \\
1,9 \\
13,5 \\
238,2 \\
93,9 \\
144,3\end{array}$ & $\begin{array}{r}659,7 \\
6,9 \\
59,8 \\
592,9 \\
226,7 \\
366,2\end{array}$ & $\begin{array}{r}645,4 \\
14,1 \\
51,4 \\
579,9 \\
186,6 \\
393,3\end{array}$ & $\begin{array}{r}2474,2 \\
28,0 \\
139,3 \\
2306,9 \\
639,1 \\
1667,8\end{array}$ & $\begin{array}{r}1617,7 \\
39,5 \\
55,6 \\
1522,5 \\
269,6 \\
1252,9\end{array}$ & $\begin{array}{r}760,9 \\
16,2 \\
71,2 \\
673,5 \\
113,7 \\
559,8\end{array}$ \\
\hline Rückwaren & - & 1,4 & 4,2 & 3,9 & 8,4 & 2,5 & 1,0 \\
\hline Export 1970 insgesamt & 11,7 & 256,4 & 678,7 & 709,5 & 2527,2 & 1639,7 & 779,3 \\
\hline $\begin{array}{l}\text { Zum Vergleich: } \\
\text { Export } 1937 \text { Deutsches } \\
\text { Reich insg. Mill. RM } \\
\text { davon. } \\
\text { Fertigwaren in Mill. RM }\end{array}$ & $\begin{array}{l}0,65 \\
0,62\end{array}$ & $\begin{array}{l}68,2 \\
63,3\end{array}$ & $\begin{array}{r}129,5 \\
107,5\end{array}$ & $\begin{array}{r}110,5 \\
87,5\end{array}$ & $\begin{array}{r}134,4 \\
114,3\end{array}$ & $\begin{array}{r}113,1 \\
96,8\end{array}$ & $\begin{array}{r}111,1 \\
99,7\end{array}$ \\
\hline $\begin{array}{l}\text { in } \vee H \\
\text { Ernährungswirtschaft }\end{array}$ & 17,2 & 0,5 & 2,2 & 8,5 & 1.8 & 1,2 & 2,2 \\
\hline $\begin{array}{l}\text { Gewerbliche Wirtschaft } \\
\text { - Rohstoffe } \\
\text { - Halbwaren } \\
\text { - Fertigwaren } \\
\text { - Vorerzeugnisse } \\
\text { - Enderzeugnisse }\end{array}$ & $\begin{array}{r}82,8 \\
0,8 \\
25,7 \\
56,3 \\
27.0 \\
29,3\end{array}$ & $\begin{array}{r}98,9 \\
0,7 \\
5,3 \\
92,9 \\
36,6 \\
56,9\end{array}$ & $\begin{array}{r}97,2 \\
1,0 \\
8,8 \\
87,4 \\
33,4 \\
54,0\end{array}$ & $\begin{array}{r}91,0 \\
2,0 \\
7,3 \\
81,7 \\
26,3 \\
55,4\end{array}$ & $\begin{array}{r}97,9 \\
1,1 \\
5,5 \\
91,3 \\
25,3 \\
66,0\end{array}$ & $\begin{array}{r}98,6 \\
2,4 \\
3,4 \\
92,8 \\
16,4 \\
76,4\end{array}$ & $\begin{array}{r}97,7 \\
2,1 \\
9,2 \\
86,4 \\
14,6 \\
71,8\end{array}$ \\
\hline Rückwaren & - & 0,6 & 0,6 & 0,5 & 0,3 & 0,2 & 0,1 \\
\hline Export 1970 insgesamt & 100,0 & 100,0 & 100,0 & 100,0 & 100,0 & 100,0 & 100,0 \\
\hline $\begin{array}{l}\text { Zum Vergleich } \\
\text { Export } 1937 \text { Deutsches } \\
\text { Reich } \\
\text { davon: } \\
\text { Fertigwaren in vH }\end{array}$ & 95.4 & 92,8 & 82,9 & 79,2 & 85.0 & 85,6 & 89,7 \\
\hline
\end{tabular}

Q uelle: Statistisches Bundesamt Wiesbaden, Außenhandel. Reihe 3 . Spezialhandel nach Ländern und Warengruppen, 4. Vierteljahr und Jahr 1970, S. 21. 
Tabelle 73: Ausländische Touristen und Reisende in den südosteuropäischen Ländern 1960-1969 (in 1000)

\begin{tabular}{|l|r|r|r|r|}
\hline \multicolumn{1}{|c|}{ Land } & \multicolumn{1}{|c|}{1960} & \multicolumn{1}{|c|}{1965} & \multicolumn{1}{c|}{1968} & \multicolumn{1}{c|}{1969} \\
\hline Bulgarien & 200,6 & 1083,9 & 1783,1 & 2131,3 \\
Rumänien & 102,6 & 287,8 & 1450,9 & 1839,0 \\
Ungarn & 244,3 & 1318,9 & 4307,2 & 6069,1 \\
Jugoslawien & 873,1 & 2657,7 & 3887,4 & 4746,3 \\
Griechenland & 546,0 & 847,0 & 879,5 & 139,4 \\
Türkei & 94,1 & 355,2 & 330,3 & 373,3 \\
\hline
\end{tabular}

Quelle: UN, Statistical Yearbook 1970, S. 471, 472; 1969, S. 437, 438. 



\section{Anhang:}

\section{Veröffentlichungen der Südosteuropa-Gesellschaft}

Im Namen der Südosteuropa-Gesellschaft herausgegeben von

Wilhelm Gülich $+(1957-1960)$

Rudolf Vogel (1960 - 1965)

Walter Althammer (ab 1966)

Bestellungen über den Buchhandel

und bei Dr. Dr. Rudolf Trofenik, Verlag

8 München 13, Elisabethstr. 18

SÜDOSTEUROPA-STUDIEN und MITTEILUNGEN der SüdosteuropaGesellschaft auch direkt bei Südosteuropa-Gesellschaft e. V. 8 München 22, Widenmayerstr. 49 
- The

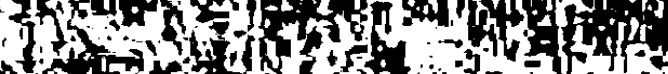

H. $=3$.

(5)

4.

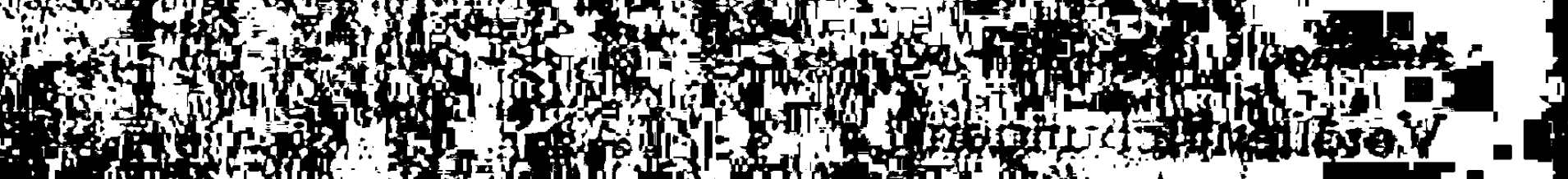

Hof

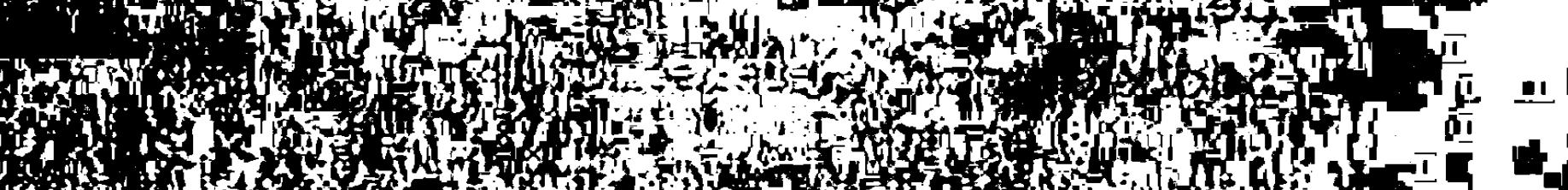

fyon

15

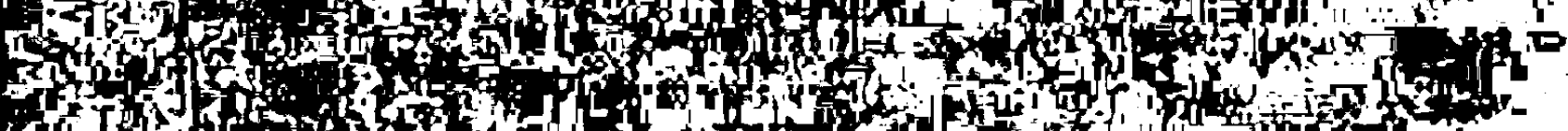

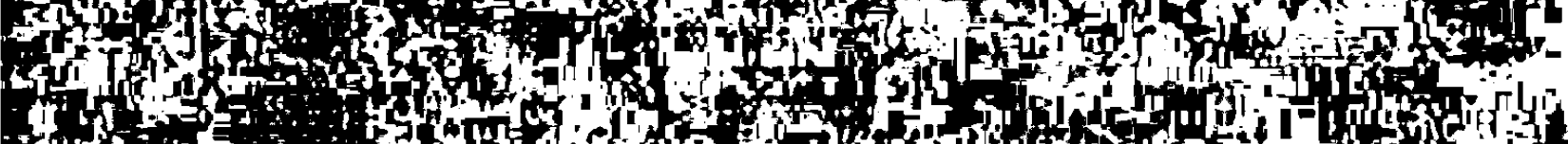

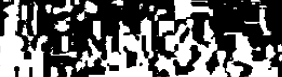

int

Exp 10 .

fis

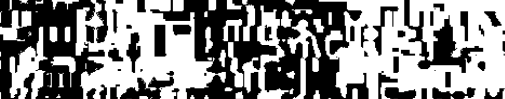

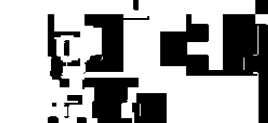

2.

15

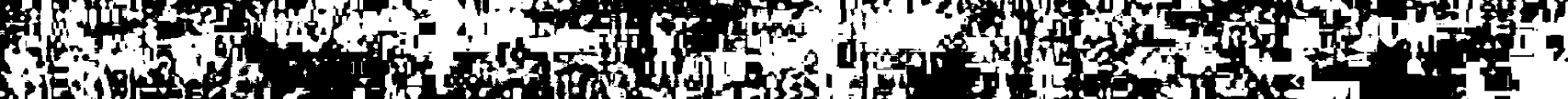

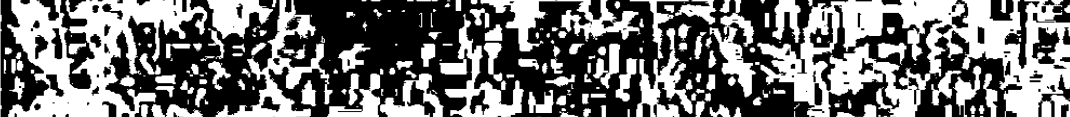

1.

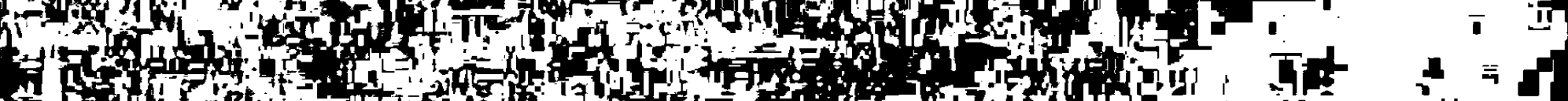

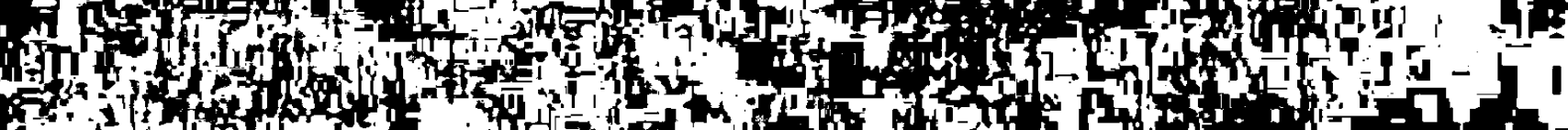

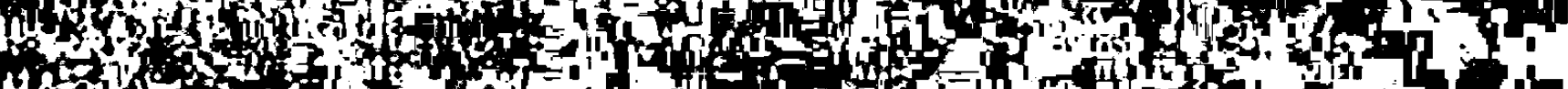

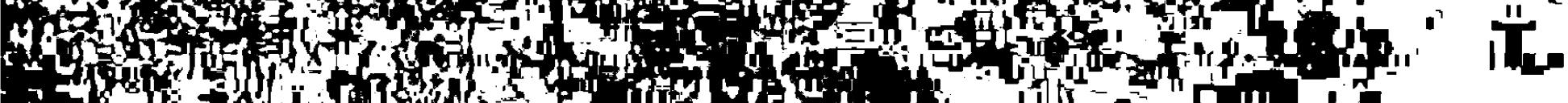

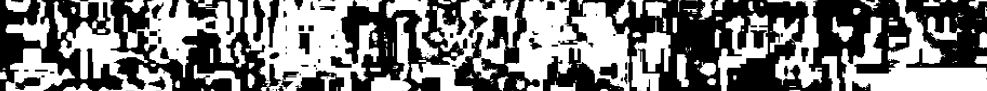

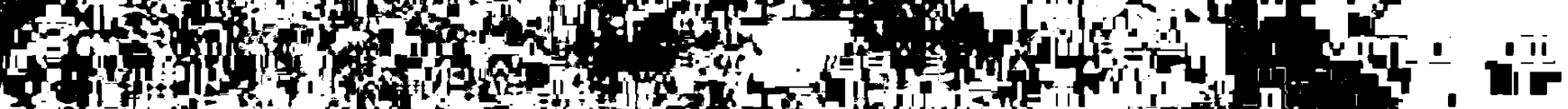

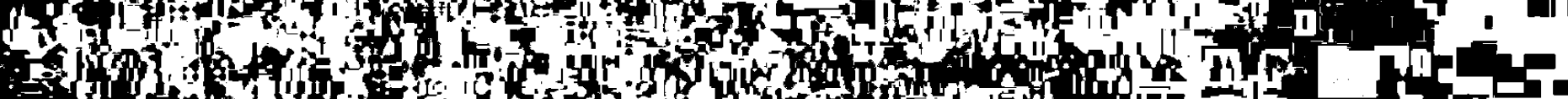

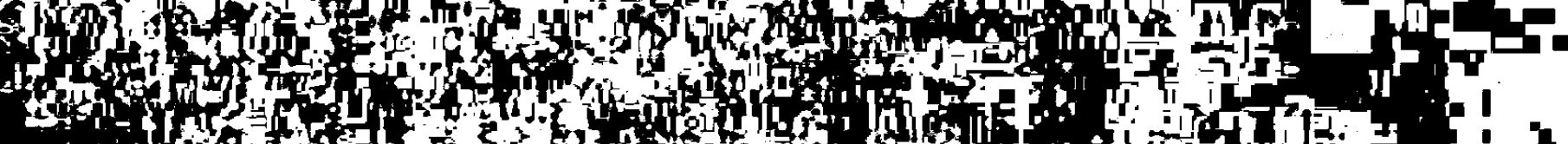

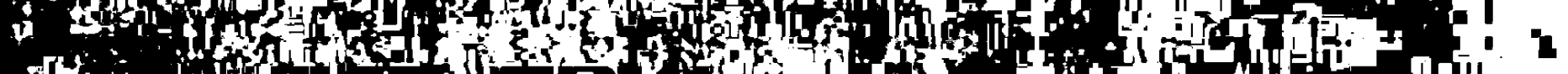

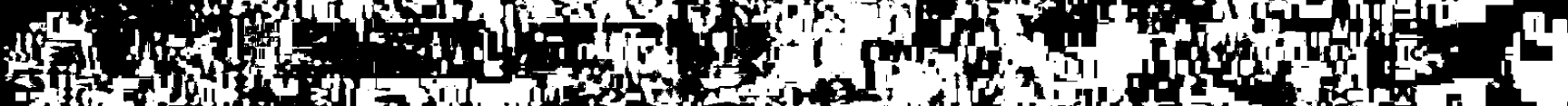
(14)

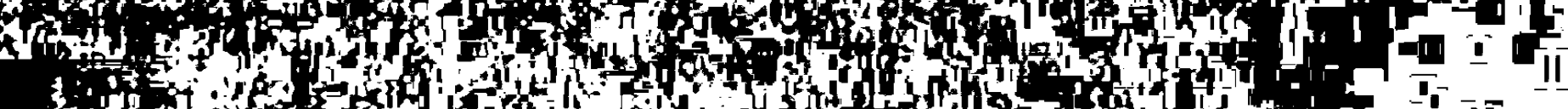

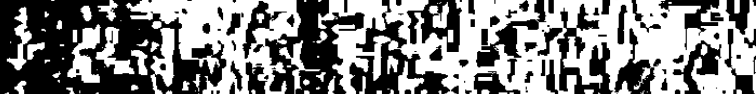

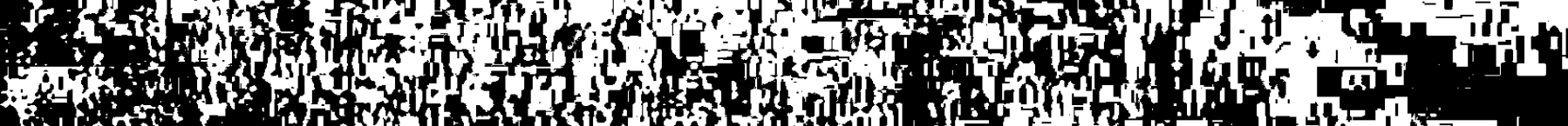
she

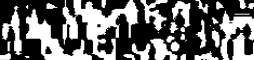

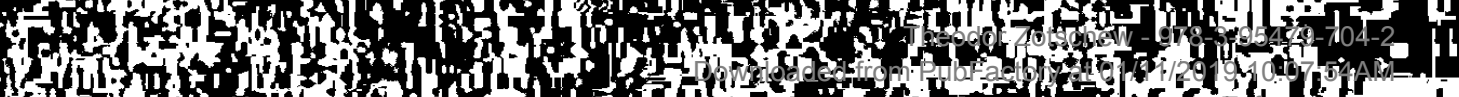




\title{
Reihe: SUDOSTEUROPA - JAHRBUCH
}

\section{SUDOSTEUROPA - JAHRBUCH - Band 1}

\author{
SÜDOSTEUROPA ZWISCHEN OST UND WEST \\ München 1957. 224 Seiten, Leinen DM 15.80
}

Wilhelm Güli ch, Eröffnungsansprache: Südosteuropa zwischen Ost und West Hermann Gross, Die deutsch-südosteuropäischen Wirtschaftsbeziehungen

Diskussion: Thalheim, Kiderlen, Zotschew, Förster, Gross

Fritz Valjavec, Die Eigenart Südosteuropas in Geschichte und Kultur

Diskussion: Gülich, Dölger, Schmaus, Gross, Wierer, Arntz

Franz Dölger, Geistiges Leben im heutigen Griechenland

Muhlis Ete, Die Türkei im Rahmen der Europawirtschaft

Hans Wilbrandt, Die südosteuropäische Landwirtschaft im Rahmen der

Weltwirtschaft - Diskussion: Gross

Theodor Zots chew, Die Industrialisierung Südosteuropas

Diskussion: Vogel, Gross, Ete, Thalheim, Förster, Glück, Kügler, Zotschew

Radivoje Davidović, Die Industrialisierung Jugoslawiens

Dusan Lopandić, Die Agrarpolitik Jugoslawiens

Diskussion: Gülich, Wilbrandt, Gross, Lopandić

Demetrius Kalitsunakis, Probleme des Seehandels und der Seeschiffahrt

Griechenlands

Register - Biographische Angaben

\section{SUDOSTEUROPA - JAHRBUCH - Band 2}

IDEOLOGISCHE, KULTURELLE UND WIRTSCHAFTLICHE W A N D U NGEN IN SUDOSTEUROPA

München 1958. 199 Seiten, Leinen DM 15.80

Wilhelm Güli ch, Wirklichkeit und Ideologie in Südosteuropa

Milovan Gavazzi, Die Kulturzonen Südosteuropas

Diskussion: Skrehunetz-Hillebrand, Valjavec, Schier, Mergl, Kissling,

Lambertz, v. Uzorinac-Kohary, Delivanis

Fritz Valjavec, Österreich und Rußland auf dem Balkan im 19. Jahrhundert

Diskussion: Hertz, Gülich, Czell, Hauptmann

Karl Förster, Die Donau als Schiffahrts- und Handelsweg

Diskussion: Kiesewetter, Pribić, Valjavec, Schmid 
Bruno Kiesewetter, Die Wandlungen der Handelspolitik in den Ostblockstaaten

Karl C. Thalheim, Die Rolle der südosteuropäischen Länder in der Wirtschaftsintegration des Ostblocks

Theodor Zotschew, Die Wirtschaftsbeziehungen der südosteuropäischen Länder zu den überseeischen Entwicklungsländern

Dimitrios Delivanis, Die deutsch-griechischen Handelsbeziehungen Diskussion: Gross, Schramm-v. Thadden

Vladimir Murko, Probleme der jugoslawischen Finanzwirtschaft unter Berücksichtigung der ausländischen Kapitalzufuhr

Diskussion: Gross, Kiesewetter, Delivanis

Register - Biographische Angaben

\title{
SUDOSTEUROPA - JAHRBUCH - Band 3
}

\author{
WIRTSCHAFTLICHE ENTWICKLUNG UND VOLKLICHE \\ EIGENSTÄNDIGKEIT IN SÜDOSTEUROPA \\ München 1959. 245 Seiten, Leinen DM 15.80
}

Wilhelm Gülich, Wirtschaftliche Entwicklung und volkliche Eigenständigkeit in Südosteuropa

Heinrich Gleissner, Begrüßungsansprache

Alfred Weikert, Begrüßungsansprache

Fritz Valjavec, Kulturpolitische Probleme Südosteuropas seit 1945

Heinrich Felix Schmid, Funktion und Organisation der orthodoxen Kirchen in Südosteuropa

Karl Kurt Klein, Deutsche Kultur und Kirche in Südosteuropa

Hermann Gross, Neuere Tendenzen in der Agrar- und Industrialisierungspolitik Ostmittel- und Südosteuropas

Theodor Zotschew, Der "Rat für Gegenseitige Wirtschaftshilfe (Comecon)" als Instrument für die wirtschaftliche Integration und weltwirtschaftliche Expansion der Ostblockländer

Kurt Wessely, Verkehrsstruktur und Verkehrspolitik der Donauländer Hugo $\mathrm{Hantsch}$, Die einheitlichen Kulturkräfte im übernationalen Staat Alois Schmaus, Die geistige Kultur der Südslawen

Heinrich Zillich, Das vergangene Südosteuropa. Eine Plauderei

Schrifttumsnachweise - Register - Biographische Angaben 


\section{SUDDOSTEUROPA - JAHRBUCH - Band 4}

DER GEGENW ARTIGE STAND DER WIRTSCHAFTLICHEN UND KULTURELLEN BEZIEHUNGEN ZU SUDOSTEUROPA München 1960. 191 Seiten, Leinen DM 15.80

Staatssekretär Dr. West $\mathbf{r}$ i $\mathbf{c k}$ zur Tagung der Südosteuropa-Gesellschaft am 25. März 1960

Hermann Gross, Die Außenhandelsverflechtung der Südoststaaten

Demetrios A. Delis, Außenhandel und wirtschaftspolitische Verflechtung Griechenlands

Ursula von Köppen, Die aktuellen Probleme des Donauverkehrs Mahmut Se yda, Die Probleme der türkischen Handelsbilanz

Ernst Lederer, Kreditprobleme im Verkehr mit dem Südosten

Leonard Stitz-Ulrici, Probleme im Investitionsgüter-Export nach dem Südosten

Europäische Integration und der Südosthandel

Diskussion des Vortrags Gross: Zotschew, Wessely, Sirc, Lederer

Finanzierungs- und Kreditprobleme und Importförderung als Maßnahme zur Erhaltung und Erweiterung der südosteuropäischen Märkte

Diskussion des Vortrags Stitz-Ulrici: Kühn, Reithinger, Lederer

Die deutsch-südosteuropäischen Clearingschulden

Diskussion des Vortrags Lederer: Gross, Wessely, Lederer

Der Flottenbestand auf der Donau, die Kapazitätsgrenze und ihre Ausdehnung durch Schubschiffahrt

Diskussion des Vortrags von Köppen: Wessely, Grimm, Köppen

Josef $M$ at 1 , Die kulturellen Beziehungen $z w i s c h e n$ dem deutschsprachigen Mitteleuropa und dem Südosten in der Gegenwart

Emanuel Turczynski, Die deutsch-rumänischen Kulturbeziehungen

Franz Hieronymus Riedl, Deutsch-ungarische kulturelle Verbindungen

Diskussion des Vortrags $M$ at 1 : Gross

Diskussion des Vortrags Turczynski: Maurer, Grimm, Gross

Schrifttumsnachweise - Register - Biographische Angaben

\section{SÚDOSTEUROPA - JAHRBUCH - Band 5}

DIE DONAU IN IHRER GESCHICHTLICHEN, WIRTSCHAFTLICHEN UND KULTURELLEN BEDEUTUNG München 1961. 180 Seiten, Leinen DM 15.80

Johannes Karayannopulos, Die Donau als Faktor der politischen und kulturellen Geschichte des Balkans in byzantinischer Zeit (325-1453) 
Franz Babinger, Die Donau als Schicksalsstrom des Osmanenreiches Diskussion: Gross, Benedikt, Kissling

Alfred $H$ offmann, Die Donau und Österreich

Diskussion: Benedikt

Mathias Bernath, Anfänge der Nationbildung an der unteren Donau Diskussion: Matl, Benedikt, Babinger, Popinceanu, Konstantinović, Turczynski

Charles Jelavich, Die Habsburger Monarchie und die nationale Frage der Südslawen

Diskussion: Berger, Bauer, Matl

Franz Ronneberger, Die bindende und lösende Bedeutung der Donau im Zusammenleben der Donauvölker

Lujo Ton čić - Sorinj, Die Geschichte der Internationalisierung der Donau Diskussion: Gross, Kossmann

Karl Förster, Die Zukunft der Donau unter besonderer Berücksichtigung ihres hydroenergetischen Potentials und ihrer Verbindung mit dem mitteleuropảischen Wasserstraßennetz

Diskussion: Gross, Zotschew, Krajčević, Pisecky

Paul Feuchter, Die Bedeutung der bayerischen Landeshäfen für den West-Ost - Verkehr

Vinzenz Kotzina, Die Donau und Österreich in europäischer Sicht Diskussion der Vorträge Feuchter und Kotzina: Vogel, Gross, Meier, Förster, Vogel

Hans $W \ddot{u} h r$, Städtebau und Gotik im Donauraum Diskussion: Matl, v. Bogyay, Andritsch

Schrifttumsnachweise - Register - Biographische Angaben

\section{SUDOSTEUROPA - JAHRBUCH - Band 6}

DIE VOLKSKULTUR DER SUDOSTEUROPÄISCHEN VOLLER München 1962. 216 Seiten, Leinen DM 18.-

Hermann Proebst, Deutsch-südosteuropäische Berührung

Zoran Konstantínović, Die Volkspoesie des europäischen Südostens. Begriff und Deutung

Leopold Kretzenbacher. Die Volksdichtung im deutsch-slawischen Grenzraum Südosteuropas

Cvetana Romanska, Die Haiducken in der bulgarischen Volksdichtung

Eleutherios N. Platis, Die neugriechische Volksdichtung

Bruno Schier, Räume und Schichten der slowakischen Volkskultur

Richard Wolf ram, Der Volkstanz als kulturelle Ausdrucksform der südosteuropäischen Völker 
Robert Schwanke, Volksmusik und Volkslied in Albanien. Neue Forschungen und Ergebnisse

Gültekin Oransay, Von der Türcken dölpischer Music. Die Musik des türkischen Bauern und die abendländische Kunstmusik

Vedat Nedim Tör, Die Türkei als Neuland für die Erforschung der Volkstänze Emanuel Turczynski, Elemente der rumänischen Volkskunst

Hristo Vakarelski, Charakteristische Merkmale der bäuerlichen Volkskultur in Bulgarien

Heinrich Felix Schmid, Dalmatien, das Land romanisch-slawischer Kultursymbiose. Eröffnungsworte zur Sonderausstellung "Alte Volkskunst aus Dalmatien"

Adolf $\mathrm{M}$ a is, Sonderausstellung "Alte Volkskunst aus Dalmatien - Sammlung Natalie Bruck-Auffenberg"

Josef Matl, Zukunftspläne der Südostarbeit

Verzeichnis der Abbildungen - Register - Biographische Angaben

Anhang: Statistische Ubersichten, bearbeitet von Theodor $Z$ ot s chew

\title{
SÜDOSTEUROPA - JAHRBUCH - Band 7
}

\author{
DEUTSCH - SÜ DOSTEUROP ÄISCHE \\ WIRTSCHAFTSPROBLEME \\ München 1966. 138 Seiten, Leinen DM 32. -
}

Staatssekretär Rolf Lahr, Zur Begrüßung

Hermann Gross, Wirtschaftssysteme und Wirtschaftspolitik der südosteuropäischen Staaten

Franz Nem schak, Österreichs Wirtschaft zwischen West- und Südosteuropa

Rudolf Vogel, Das Türkeikonsortium als Beispiel der Finanzierung von Entwicklungsvorhaben

Ziya Müezzinoglu, Die Ein- und Ausfuhrnotwendigkeiten der Türkei

Ioannis S. Pesmazoglu, Wirtschaftsbeziehungen Griechenlands mit dem Ausland. Vergleiche und Probleme

Ernst Lederer. Die Wirtschaftsbeziehungen der Bundesrepublik Deutschland mit Griechenland, der Türkei und Jugoslawien

Vesseline Todorov, Veränderungen in der Wirtschaftsstruktur Bulgariens und ihre Einwirkung auf die Bedürfnisse der Ein- und Ausfuhr

Susanne Havas, Die Außenhandelsbeziehungen Ungarns mit den westeuropäischen Industriestaaten

Mircea Nastase, Die Entwicklungsmöglichkeiten des rumänischen Außenhandels

Otto Wolff von Amerongen, Der bulgarische, ungarische und rumänische Markt in deutscher Sicht.

Biographische Angaben

Anhang: Statistische Übersichten, bearbeitet von Theodor $Z$ ot s chew 


\title{
SUDOSTEUROPA - JAHRBUCH - Band 8
}

\author{
DIE STADT IN SUDOSTEUROPA \\ Struktur und Geschichte \\ München 1968. 183 Seiten, Leinen DM 38. - \\ In Memoriam Dr. Theodor v. Uzorinac-Kohary
}

Balduin Saria, Die antike Stadt in Südosteuropa

Velizar Velkov, Die antike und die mittelalterliche Stadt im Ostbalkan (im Licht der neuesten Forschungen)

Hans-Wilhelm Hausig, Die byzantinische Stadt

Kaus-Detlev Grothusen, Das mittelalterliche Städtewesen Südosteuropas im Einflußbereich der italienischen und mitteleuropäisch-deutschen Rechtsstädte

Hans-Joachim Kissling, Die türkische Stadt auf dem Balkan

Avdo Suceska, Die Rechtsstellung der Bevölkerung in den Städten Bosniens und der Herzegowina unter den Osmanen (1463-1878)

Josef Mat l, Die kulturelle Strahlungsfunktion der Stadt in Südosteuropa

László Sziklay, Das Zusammenleben und Zusammenwirken mehrerer südosteuropäischer Kulturen in Ofen-Pest zu Beginn des 19. Jahrhunderts

Virginia Paskaleva. Die bulgarische Stadt im XVIII. und XIX. Jahrhundert (bis zum russisch-türkischen Krieg 1877-1878)

Ion I ona scu, Die Entwicklung der Stadt Bukarest im XVIII. und XIX. Jahrhundert

Toša Tišma, Die Städte Jugoslawiens in der Industrialisierungsperiode unter den Bedingungen administrativer Wirtschaftsverwaltung

Register

\section{SÚDOSTEUROPA - JAHRBUCH - Band 9}

WIRTSCHAFTS- UND GESELLSCHAFTSGESCHICHTE SUUDOSTEUROPAS IM 19. UND 20. JAHRHUNDERT München 1969. 217 Seiten, Leinen DM 52.-

Hans-Joachim Kissling. Die wirtschaftliche und soziale Entwicklung Südosteuropas im Osmanischen Reiche

Klaus-Detlev Grothusen, Die wirtschaftliche und soziale Entwicklung Südosteuropas im Bereich Österreich-Ungarns

Hermann Gross, Die Industrialisierungspolitik der südosteuropäischen Staaten bis zum Zweiten Weltkrieg 
Franz R on neberger, Wandlungen der Agrargesellschaft der südosteuropäischen Staaten

Emanuel Turczynski, Die städtische Gesellschaft in den Staaten des Donauraumes

Josef Mat l, Entwicklung der städtischen Gesellschaft auf dem Balkan

Krisztina Fink, Spezielle Aspekte der Wirtschafts- und Sozialentwicklung seit der Jahrhundertwende in Ungarn

Josif Anghe l, Die Wirtschaftsentwicklung Rumäniens in der Zwischen- und Nachkriegszeit unter besonderer Berücksichtigung der Evolution des

"Koeffizienten des Kapitals" der Verbrauchsgüterindustrie

Theodor D. Zotschew, Spezielle Aspekte der Wirtschafts- und Sozialentwicklung seit der Jahrhundertwende in Bulgarien

Stefan Heretik und Josef Faltus, Die Haupttendenzen der Wirtschafts- und Sozialentwicklung der Slowakei seit der Jahrhundertwende

Basil Voyatzis, Spezielle Aspekte der Wirtschafts- und Sozialentwicklung in Griechenland seit der Jahrhundertwende

Robert Schwanke, Wirtschafts- und Sozialentwicklung Albaniens vor und nach dem Jahre 1912

Register 


\title{
Reihe: SÜDOSTEUROPA - SCHRIFTEN SUDOSTEUROPA - SCHRIFTEN - Band 1
}

\author{
VÖLKER UND KULTUREN SÜDOSTEUROPAS \\ Kulturhistorische Beiträge \\ München 1959. 284 Seiten, broschiert DM 22. -
}

Wilhelm $G$ ülich, Zur Einführung

Balduin Saria, Die antiken Grundlagen der südosteuropäischen Kulturen

Balduin Saria, Die Christianisierung des Donauraumes

Karl Kurt Klein, Germanen in Südosteuropa

Franz Dölger, Byzanz und Südosteuropa

Josef $M$ at 1 , Die Slawen auf dem Balkan

Thomas v. Bogyay, Die Reiternomaden im Donauraum des Frühmittelalters Josef Mat l, Hirtentum und Stammesverfassung als Kulturfaktor

Anton $\mathrm{M}$ ichel, Die Kaisermacht in der Ostkirche

Franz Dölger, Der byzantinische Anteil an der Kultur des Balkans

Günter Reichenkron, Das Ostromanische

Alexander $V$. Soloviev, Bogomilentum und Bogomilengräber in den südslawischen Ländern

Franz B a binger, Der Islam in Südosteuropa

Franz Babinger, Die Osmanen auf dem Balkan

Josef Matl, Die Europäisierung des Südostens

Friedrich Hertz, Die Nationalitäten im alten Österreich

Georgi Schischkoff, Zur Psychologie der bulgarischen Wiedergeburt im 19. Jahrhundert

Anhang: Wichtigstes Schriftum zu den behandelten Themen

Register

\section{SUDOSTEUROPA - SCHRIFTEN - Band 2}

WIRTSCHAFT UND GESELLSCHAFT SUDOSTEUROPAS
München 1961.600 Seiten, Ganzleinen DM 48. -

Gedenkschrift für Wilhelm Gülich

Johann Wilhelm Mannhardt, Wilhelm Gülich als Wissenschaftler und Politiker

Hermann Gross, Wirtschaftspolitik und weltwirtschaftliche Verflechtung Südosteuropas

Bruno Kiesewetter. Die Wirtschaftsbeziehungen der Südosteuropastaaten zur Bundesrepublik Deutschland und zur sogenannten DDR 
Hans Wilbrandt und Hans $R$ uthenberg. Der Südosten in der Welternährungswirtschaft

Kurt wessely, Grundlagen der Verkehrsbeziehungen Deutschlands und Österreichs zu Südosteuropa

Karl Förster, Der Binnenschiffsverkehr der Südoststaaten

Bruno Kna 11, Die östlichen und westlichen Planungsmethoden für Entwicklungspläne

Franz R on neberger. Staatsverfassungstendenzen der Südoststaaten seit 1945. Ein Beitrag zu Sozial- und Verfassungsstruktur von Entwicklungsländern

Wilfried Krallert, Die Verstädterung in Südosteuropa und ihre sozialen und wirtschaftlichen Auswirkungen

Josef Matl, Der Panslawismus als politische Idee in Südosteuropa im 19. und 20. Jahrhundert

Emanuel Turczynski, München und Südosteuropa

Franz Hieronymus Riedl, Bestand und Lage des Deutschtums in Südosteuropa. Blick über vier Jahrzehnte

Otto Liess, Ungarns Sozialpolitik seit 1945

Rudolf $\mathrm{Tr}$ ofenik, Über die rechtliche Stellung der Religionsgemeinschaften in Jugoslawien und dessen Kirchenpolitik

Vladimir Pertot, Die langfristigen Tendenzen in der regionalen Orientierung des Außenhandels Jugoslawiens

Dimitrios Delivanis, Die Probleme der Zahlungsbilanz und die außenwirtschaftliche Integration Griechenlands

Schrifttumsverzeichnisse - Register - Biographische Angaben

\title{
SUDOSTEUROPA - SCHRIFTEN - Band 3
}

AUFSÄTZE UND ABHANDLUNGEN ZUR GESCHICHTE SÜDOSTEUROPAS UND DER LEVANTE I

\author{
von Franz Babinger
}

München 1962. 474 Seiten, Ganzleinen DM 56. -

Vorwort von H. J. Kissling - A. Schmaus

Franz Babinger: Schriftenverzeichnis (1910-1961)

In halt: Der Islam in Kleinasien - Quelques problèmes d'études islamiques dans le sud-est-européen - Das Bektaschi-Kloster Demir Baba - Ein Freibrief Mehmeds 11., des Eroberers, für das Kloster Hagia Sophia zu Saloniki, Eigentum der Sultanin Mara (1459) - Firište-Oghlu - Ein Besitzstreit um Sulu Manastir unter Mehmed II. (1473) - Die Örtlichkeit der Siebenschläferlegende in muslimischer Schau - Byzantinisch-osmanische Grenzstudien - Von Amurath zu Amurath - Mehmeds II., der Eroberers, Mutter - Mehmeds II., des Eroberers, Geburtstag - Mehmed Il., der Eroberer, und Italien - Die Gründung von Elbasan - La date de la prise de Trébizonde par les Turcs (1461) - Sultan 
Mehmed II. und ein heiliger Rock - Mehmeds II. Heirat mit Sitt-Chatun (1449) Le vicende veneziane nella lotta contro i Turchi durante il secolo XV - Zwe: diplomatische $Z w$ ischenspiele im deutsch-osmanischen Staatsverkehr unter Bajezid II. (1497 und 1504) - Kaiser Maximilians I. "Geheime Praktiken" mit den Osmanen (1510/11) - "Bajezid Osman" (Calixtus Ottomanus), ein Vorläufer und Gegenspieler Dschem-Sultans - Zur Lebensgeschichte des Calixtus Ottomanus - Dawud-Celebi, ein osmanischer Thronwerber des 15 . Jahrhunderts - Witwensitz und Sterbeplatz der Sultanin Mara - Eine Verfügung des Paläologen Cháss Murâd-Pała - Beiträge zur Geschichte des Geschlechtes der Malqoč-Oghlus - Beiträge zur Geschichte von Qarly-Eli vornehmlich aus osmanischen Quellen - Marino Sanutos Tagebücher als Quelle zur Geschichte der Safawijja - Die osmanischen Statthalter von Damaskus - Zwei türkische Schutzbriefe für Georg II. Rákóczi, Fürsten von Siebenbürgen, aus dem Jahre 1649 - Abbildungen

\title{
SUDOSTEUROPA - SCHRIFTEN - Band 4
}

\author{
WIRTSCHAFTSWISSENSCHAFTLICHE \\ SUDOSTEUROPA - FORSCHUNG \\ Grundlagen und Erkenntnisse \\ Ausgewählt und redigiert von Theodor $Z$ ot $s \mathrm{ch}$ ew \\ München 1963. 362 Seiten, Ganzleinen DM 36. -
}

Hermann Gross zum 60. Geburtstag

Rudolf Voge 1, Hermann Gross - Forschung, Lehre, Leben

Franz Ronneberger. Wandlungen im Verständnis Südosteuropas. Betrachtungen über Gegenstand und Aufgabe der Südosteuropaforschung in Abhängigkeit von politischen und sozialen Konstellationen

Theodor Zotschew, Wirtschaftliche Entwicklung und gegenseitige Handelsbeziehungen der südosteuropäischen Staaten

Boris Meis ner, Die Auseinandersetzung zwischen dem Sowjet- und dem Reformkommunismus

Georg W. Strobel, Balkanpakt und Ostpolitik

Friedbert Glü ck, Der Mitteleuropäische Wirtschaftstag. Beispiel organischer Entwicklungsarbeit

Bruno Kna 11, Die Beurteilung und Bewertung von Entwicklungsplänen und ihre Erfolgsmessung

Jens $M$ e ie $r$. Industrieforschung in einzel- und gesamtwirtschaftlicher Sicht

Jens Hacker, Kiel - eines der ostwissenschaftlichen Zentren in der Bundesrepublik. Der Ausbau der Osteuropa-Forschung und-Lehre in Kiel

Gertrud Savels ber $g$. Anleitung zu wirtschaftswissenschaftlichen Arbeiten

Gerhard Teich, Bibliographie der Bibliographien Südosteuropas. Ein Beitrag zur Bibliographie über den Gesamtraum Südosteuropa sowie über Albanien, Griechenland und die Türkei 
Eva Pohlhausen, Die gesellschaftlichen Organisationen Polens und ihre Veröffentlichungen. Grundlagen für die wirtschafts- und sozialwissenschaftliche Erforschung Polens

Kat a log wirtschafts- und sozialwissenschaftlicher Zeitschriften und anderer Periodika aus den mittelost- und südosteuropäischen Ländern. Zusammengestellt von Eva Pohlhausen und Gerhard Te i ch

Das Schrift tum von Hermann Gross, Zusammengestellt von Hanna GülichBielenberg

Register - Biographische Angaben

\title{
SÜDOSTEUROPA - SCHRIFTEN - Band 5
}

\author{
Mirko Rupel
}

PRIMUS TRUBER

Leben und Werk des slowenischen Reformators

Deutsche Übersetzung und Bearbeitung von Balduin Saria

München 1965. 312 Seiten, Ganzleinen DM 56. -

Die Anfänge - Auf dem Gipfel - Dem Abend zu - Trubers Werke

Literatur - Register - Abbildungen

\section{SÜDOSTEUROPA - SCHRIFTEN - Band 6}

DIE KULTUR SUDOSTEUROPAS, IHRE GESCHICHTE UND I HRE AUSDRUCKSFORMEN

Herausgegeben und redigiert von: Günter $R$ eichenkron, Alois $S c h m$ a $S$ München 1965. 337 Seiten, Ganzleinen DM 58. -

Octavian Buhociu, Survivances mythiques indo-européennes et relations épiques byzantines dans un chant populaire roumain

Martin Camaj, Zur Entwicklung der Nasalvokale der slavischen Lehnwörter im Albanischen

Emil Condurachi, Relation entre les Grecs et la population autochtone du Bas-Danube, à la lumière des dernières découvertes archéologiques

Ernst Gamillscheg, Zur rumänischen Frühgeschichte

Milovan Gavazzi, Das Los der Großfamilie auf dem Balkan

Otto Haas, Das Phrygische und die Sprachen der Balkanländer

Johannes $H u b s c h m i d$, Substrate in den Balkansprachen

Hasan Kaleshi, Türkische Angaben über den Kanun des Leka Dukadjini

Hans-Joachim Kissling, Uber die Anfänge des Bektaschitums in Albanien

Ernesto Koliqi, Considerazioni sui "Canti Eroici" del popolo albanese

Zoran Konstantinović, Neueste jugoslawische Beiträge zur Erforschung der deutsch-südslawischen Kulturbeziehungen 
Demetrios Loukatos, L'invitation aux noces: sujet d'étude comparative chez les peuples balkaniques

Josef Matl. Sprache und Dichtung als Schicksalsspiegel der südosteuropäischen Völker (in balkanologischer Sicht)

Milivoje Pavlović, Les substrats de l'Illyricum

Emil Petrovici, Traits balkaniques communs dans les systèmes phonétiques du roumain et de l'albanais (La voyelle du Type a)

Václav Polák, Die Beziehungen des Albanischen zu den europäischen Substratsprachen mit Rücksicht auf die balkanische Situation

Mircea Popescu, Dieci balade romene con rispondenze balkaniche

Ivan Pudić, Alt(ost) germanische Ortsnamen in den Balkansprachen

Günter Reichenkron, Vorrömische Elemente im Rumänischen

Rupprecht Alexander Rohr, Zum Albanischen in Acquaformosa (Kalabrien)

Johann Schröpfer, Slavisches in Mykene und Umgebung. Griechischslavische Namen-, Wort- und Mythenentlehnung

Stavro Skendi, The Emergence of the Modern Balkan Literary Languages a Comparative Approach

Walther Wün s ch, Über alte Musiktraditionen am Balkan

Biographische Angaben - Tafeln

\section{SUDOSTEUROPA - SCHRIFTEN - Band 7}

VOLKSMUSIK SUDOSTEUROPA Beiträge zur Volkskunde und Musikwissenschaft Herausgegeben und redigiert von $W$. Wü $\mathrm{s} c \mathrm{~h}$ München 1966. 167 Seiten, Ganzleinen DM 32.-

Rudolf Vogel zum 60. Geburtstag

Erich Mar ckhl, Ansprache anläßlich der Eröffnung der Tagung

Walther Wüns ch, Über die Aufgaben der Musikwissenschaft in der Epenforschung

Alois S chmaus, Probleme und Aufgaben der balkanischen Epenforschung Vinko Žganec, Utber das Redigieren der Volksliedersammlungen

Milovan Gavazzi, Die Namen der altslavischen Musikinstrumente

Leopold Kretzenbacher, Südosteuropäische Primitivinstrumente vom

"Rummelpott"- Typ in vergleichend-musikvolkskundlicher Forschung

Guido Waldmann, Mehrstimmiges Singen im slawischen Bauernlied

Richard W olf ram. Altformen im Tanz der Volker des pannonischen und Karpatenraums

Karl Michael Kom ma, Das böhmische Musikantentum

Solon $\mathrm{M}$ ichaelides, The Neohellenic Folk-Music

Friedrich Körner, Bericht über den Verlauf der Tagung 


\title{
SÚDOSTEUROPA - SCHRIFTEN - Band 8
}

\author{
A UFS ÄTE UND ABHANDLUNGEN ZUR GESCHICHTE \\ SÜDOSTEUROPAS UND DER LEVANTE II \\ von Franz Babinger \\ München 1966. 318 Seiten, Ganzleinen DM 56. -
}

Vorwort von H. J. Kissling - A. Schmaus

Inhalt: Die Chronik des Quaramâni Mehmed-Pascha, eine neuerschlossene osmanische Geschichtsquelle - 'Ấyq-Pašas Gharłb-Nâme - Eine altosmanische anonyme Chronik in hebrăischer Umschrift - Qara Mustafâ-Paschas Esseger Sendschreiben an den Markgrafen Herman von Baden - ein marokkanisches Staatsschreiben an den Freistaat Ragusa vom Jahre 1194/1780 - Ein türkischer Stiftungsbrief des Merkesî vom Jahre 1029/1620 - Ewlijâ Tschelebi's Reisewege in Albanien - Kávalla (Anatolien) - Seyyid Nûh and his Turkish Sailing Handbook Moschee und Grabmal des 'Osmân-Schah zu Trikkala. Ein Werk des Baumeisters Sinân - Die großherrliche Tughra - Zur Frage der osmanischen Goldprägungen im 15. Jahrhundert unter Murâd II. und Mehmed II. - Contraffaziono ottomane dello zecchino veneziano nel XV secolo - Papierhandel und Papierbereitung in der Levante - Appunti sulle cartiere e sull' importazione di carta nell' impero ottomano spezialmente da Venecia - Die türkischen Quellen Dimitrie Kantemir's - Eine lateinische Totenklage auf Mehmed II. - Ein Auslandsbrief des Kaisers Johannes VIII. vom Jahre 1447 - An Italian Map of the Balkans, Presumably Owned by Mehmed II. , the Conqueror (1452-53). - Eine Balkankarte aus dem Ende des XIV. Jahrhunderts - Ein venedischer Lageplan der Feste Rûmeli Hisâry - Südosteuropäische Handelsmünzen am Ausgang des Mittelalters - Das Rätsel um die Goldbeute von Byzanz (1453) - Eine neuentdeckte ungarische Kerbinschrift aus Konstantinopel vom Jahre 1515 - Ein schriftgeschichtliches Rätsel? - Die älteste türkische Urkunde des deutschosmanischen Staatsverkehrs - Ja' qûb-Pascha, ein Leibarzt Mehmed's II. Der Quellenwert der Berichte über den Entsatz von Belgrad am 21./22. Juli 1456. Abbildungen.

\section{SUDOSTEUROPA - SCHRIFTEN - Band 9}

\author{
DIE ÖSTERREICH-UNGARISCHE MONARCHIE \\ ALS WIRTSCHAFTSGEMEINSCHAFT \\ Ein historischer Beitrag $z u$ aktuellen Integrationsproblemen \\ von Krisztina Maria Fink \\ München 1968. 88 Seiten, Ganzleinen DM 38. -
}

Kap. 1: Das Werden der Wirtschaftsgemeinschaft von den Anfängen bis 1867

Kap. 2: Allgemeine Beurteilung der durch den Ausgleich von 1867 bestätigten Wirtschaftseinheit

Kap. 3: Das Zoll- und Handelsbündnis im besonderen, sein Inhalt, sein Werdegang und seine Ergebnisse

Tabellen - Abbildungen - Karten 


\section{Reihe: SUDOSTEUROPA - STUDIEN}

Heft 1: Franz Ronneberger, Vorschläge zur Einordnung der SüdosteuropaForschung in die Aufbaupläne der deutschen Hochschulen München 1962. 30 Seiten, broschiert DM 4.-

Heft 2: Die Donau. Ein Verzeichnis des in der Bibliothek des Instituts für Weltwirtschaft an der Universität Kiel vorhandenen einschlägigen Schriftums - Zusammengestellt von Max Gamst und Gerhard Teich München 1960. 69 Seiten, broschiert DM 8. -

Heft 3: Stefan Varga, Wesen und Funktionen des Geldes im Sozialismus München 1962. 38 Seiten, broschiert DM 6.-

Heft 4: Gert $Z$ iegler, Griechenland in der EWG München 1962. 110 Seiten, broschiert DM 10.-

Heft 5: Muhlis Ete, Probleme der Assoziierung der Türkei mit der EWG München 1963. 106 Seiten, broschiert DM 10. -

Heft 6: Karl Förster, Die Bedeutung der Rheinregion für den Donauraum und des Donauraums für die Rheinregion

München 1964. 28 Seiten, broschiert DM 6.-

Heft 7: Cornel I $r$ imie, Das Hirtenwesen der Rumänen. Forschung in der Mârginimea Sibiului bei Hermannstadt/Sibiu München 1965. 60 Seiten, 31 Abb., broschiert DM 12.-

Heft 8: Beiträge zum Bank- und Devisenrecht in Südosteuropa. Vorträge gehalten auf der Tagung der Südosteuropa-Gesellschaft zu München vom 7. - 10. Nov. 1962

München 1965. 160 Seiten, broschiert DM 28. -

Heft 9: Constantin Daicoviciu, Die Herkunft des rumänischen Volkes im Lichte der neuesten Forschungen und Ausgrabungen München 1967. 21 Seiten, broschiert DM 6. -

Heft 10: Franz Ron neberger, Südosteuropa in den internationalen politischen Beziehungen der Gegenwart

München 1968, 89 Seiten, broschiert DM 14.-

Heft 11: Dieter $M$ e i e r, Leitung, Besteuerung und Finanzierung der jugoslawischen Industrieunternehmungen im Vergleich mit deutschen Aktiengesellschaften

München 1968, 116 Seiten, broschiert DM 18.-

Heft 12: Rudolf Bićanić, Jugoslawiens Stellung in der Weltwirtschaft und das Auslandskapital in Jugoslawien

München 1968. 30 Seiten, broschiert DM 8. -

Heft 13: Claus-Dieter Rohleder, Die Osthandelspolitik der EWG-Mitgliedstaaten, Großbritanniens und der USA gegenüber den Staatshandelsländern Südosteuropas

München 1969. 137 Seiten, broschiert DM 20. -

Heft 14: Die Donau als Verkehrsweg Südosteuropas und die Großschiffahrtsstraße Rhein-Main-Donau. Vorträge gehalten vom 19. - 21. Mai in Augsburg auf der internationalen verkehrswissenschaftlichen Tagung der Südosteuropa-Gesellschaft

München 1969. 126 Seiten, broschiert DM 20. - 
Heft 15: Die Europäische Wirtschaftsgemeinschaft und der Handel mit Südosteuropa. Die Folgen der EWG-Kompetenzerweiterung für den Südosthandel. Vorträge gehalten am 4. Juni 1970 in Frankfurt/M. auf der Kuratoriumssitzung der Südosteuropa-Gesellschaft München 1970. 34 Seiten, broschiert DM 12.-

Heft 16: Theodor D. Zotschew, Der Außenhandel als Faktor des wirtschaftlichen Wachstums der sozialistischen Staaten Südosteuropas München 1971. 30 Seiten, broschiert 8. -

Heft 17: Der Tourismus und seine Perspektiven für Südosteuropa. Vorträge auf der internationalen Fremdenverkehrstagung in München vom 7 . -10. Dezember 1970, zusammengestellt von Karl $R$ uppert und Jörg $M$ ei e r München 1971. 185 Seiten, broschiert DM 24.-

Heft 18: Hans-Joachim Pernack, Probleme der wirtschaftlichen Entwicklung Albaniens. Untersuchung des ökonomischen und sozial-ökonomischen Wandlungsprozesses von $1912 / 13$ bis in die Gegenwart München 1972. 197 Seiten, broschiert DM 20. -

Heft 19: Symposion des Wissenschaftlichen Beirates der Südosteuropa-Gesellschaft am 25./26. Juni 1971 in München. Ergebnisse und Pläne der Südosteuropa-Forschung in der Bundesrepublik Deutschland und Österreich.

Redaktion Klaus-Detlev Grothusen München 1972. 194 Seiten, broschiert DM 20. -

Heft 20: Theodor D. Zotschew, Strukturwandel in Wirtschaft und Gesellschaft Südosteuropas. Eine sozial-ökonomische und statistische Analyse anläßlich des 20 jährigen Bestehens der SüdosteuropaGesellschaft München i972. 132 Seiten, broschiert DM 20.-

\section{MITTEILUNGEN DER SÜDOSTEUROPA - GESELLSCHAFT \\ Vierteljahreszeitschrift}

Wissenswertes aus und über Südosteuropa

Berichterstattung über Gang und Ergebnis der deutschen und internationalen Südosteuropa-Forschung

Südost europa - Veranstaltungen

Südost europa-Personalien

Südosteuropa-Buchbesprechungen

Jährlich etwa 250 Seiten, Jahresabonnement: DM 18. -

Redaktion: Alfred Hönig, Vizepräsident der Südosteuropa-Gesellschaft 


\title{
VON DER AGRAR-ZUR INDUSTRIEGESELLSCHAFT Sozialer Wandel auf dem Lande in Südosteuropa
}

\author{
Herausgegeben von Franz Ronneberger und Gerhard Te i ch \\ in Zusammenarbeit mit der Südosteuropa-Gesellschaft, München \\ Verlag Hoppenstedt \& Co. , Darmstadt. 1968/70. 472 Seiten u. Tabellen, DM 85. - \\ I. Franz Ronneberger \\ (Nürnberg) \\ II. Josef $\mathrm{M}$ a $\mathrm{t} \mathrm{l}$ \\ (Graz) \\ III. Hermann Gros s \\ (München) \\ IV. Todor D. Zots chew \\ (Kiel) \\ V. Otto R. Lie B \\ (Wien) \\ VI. Josef Schram m \\ (Mainz) \\ VII. Trojan Herse ni \\ (Bukarest) \\ VIII. Ingrid Sobot t ke \\ (Nürnberg) \\ IX. Darinka Kostic $†$ \\ (Novisad) \\ X. Laszlo A. Vaskovics \\ (Graz) \\ XI. Helmut Klocke \\ (München) \\ XII. András $\mathrm{H}$ e g e düs \\ (Budapest) \\ XIII. N. N. Constantinescu \\ und Henri H. Stah 1 \\ (Bukarest) \\ XIV. Dimo Vladov \\ (Sofia) \\ XV. Dinko Tošev \\ (Sofia) \\ Südosteuropa auf dem Weg zur Industrie- \\ gesellschaft, 1970, $36 \mathrm{~S}$. \\ Bauer und Grundherr in der Geschichte \\ der Balkanvölker, 1968, 27 S. \\ Elemente der Agrarstruktur und Ten- \\ denzen der Agrarpolitik in Südosteuropa, \\ $1970,36 \mathrm{~S}$. \\ Wechselbeziehungen von Sozialstruktur und \\ Außenhandel in den südosteuropäischen \\ Ländern, 1969, $34 \mathrm{~S}$. \\ Agrarideologie in Südosteuropa, \\ $1970,17 \mathrm{~S}$. \\ Sozio-ökonomische Struktur der deutschen \\ Bauern in Südosteuropa bis 1945, 1969, \\ $38 \mathrm{~S}$. \\ Soziologie des Hirtenwesंens in Südost- \\ europa, 1971, $35 \mathrm{~S}$. \\ Formen sozialistischer Agrarwirtschaft \\ am Beispiel Jugoslawiens 1971, $35 \mathrm{~S}$. \\ Die Neukolonisten in der Wojwodina, \\ $1970,31 \mathrm{~S}$. \\ Familie und Bevölkerungsbewegung im \\ sozialen Wandel Ungarns, 1969, $26 \mathrm{~S}$. \\ Die Städte Ungarns im Wandel von der \\ agrarischen zur industriellen Gesellschaft, \\ 1969, $22 \mathrm{~S}$. \\ Nivellierung und Differenzierung im unga- \\ rischen Dorfe, 1968, $18 \mathrm{~S}$. \\ Der Wandel der gesellschaftlichen Struktur \\ in Rumänien seit 1945 , \\ $1968,19 \mathrm{~S}$. \\ Der wirtschaftliche und soziale Struktur- \\ wandel im bulgarischen Dorf nach 1945 , \\ $1968,21 \mathrm{~S}$. \\ Die sozialen Auswirkungen der Industriali- \\ sierung auf das Landvolk in Bulgarien, \\ $1968,20 \mathrm{~S}$.
}


XVI. Gerhard Teich (Kiel)

XVII. Basil Voyatzis (Saloniki)

XVIII. Vamik Taysi (Izmir)

XIX. Zdenek Stastny (Bratislava)

XX. Gertrud Krallert (München)

XXI. Gerhard Te i ch (Kiel)

XXII.
Das albanische Dorf, 1969, 34 S.

Das griechische Dorf, 1968, 25 S.

Die sozialen Auswirkungen der türkischen Agrarpolitik, 1972, $32 \mathrm{~S}$.

Berufsrollen in einer slowakischen landwirtschaftlichen Produktionsgenossenschaft, $1969,10 \mathrm{~S}$.

Stalinistische Grundlagen zur Agrarsoziologie Südosteuropas, 1972, Tabellen

Schriftum zur Agrarsoziologie Südost europas, 1972, $40 \mathrm{~S}$.

Register, 1972, $16 \mathrm{~S}$.

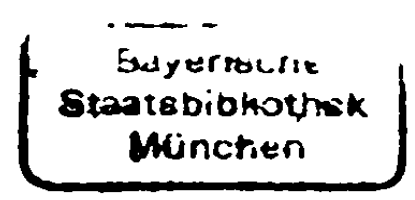

